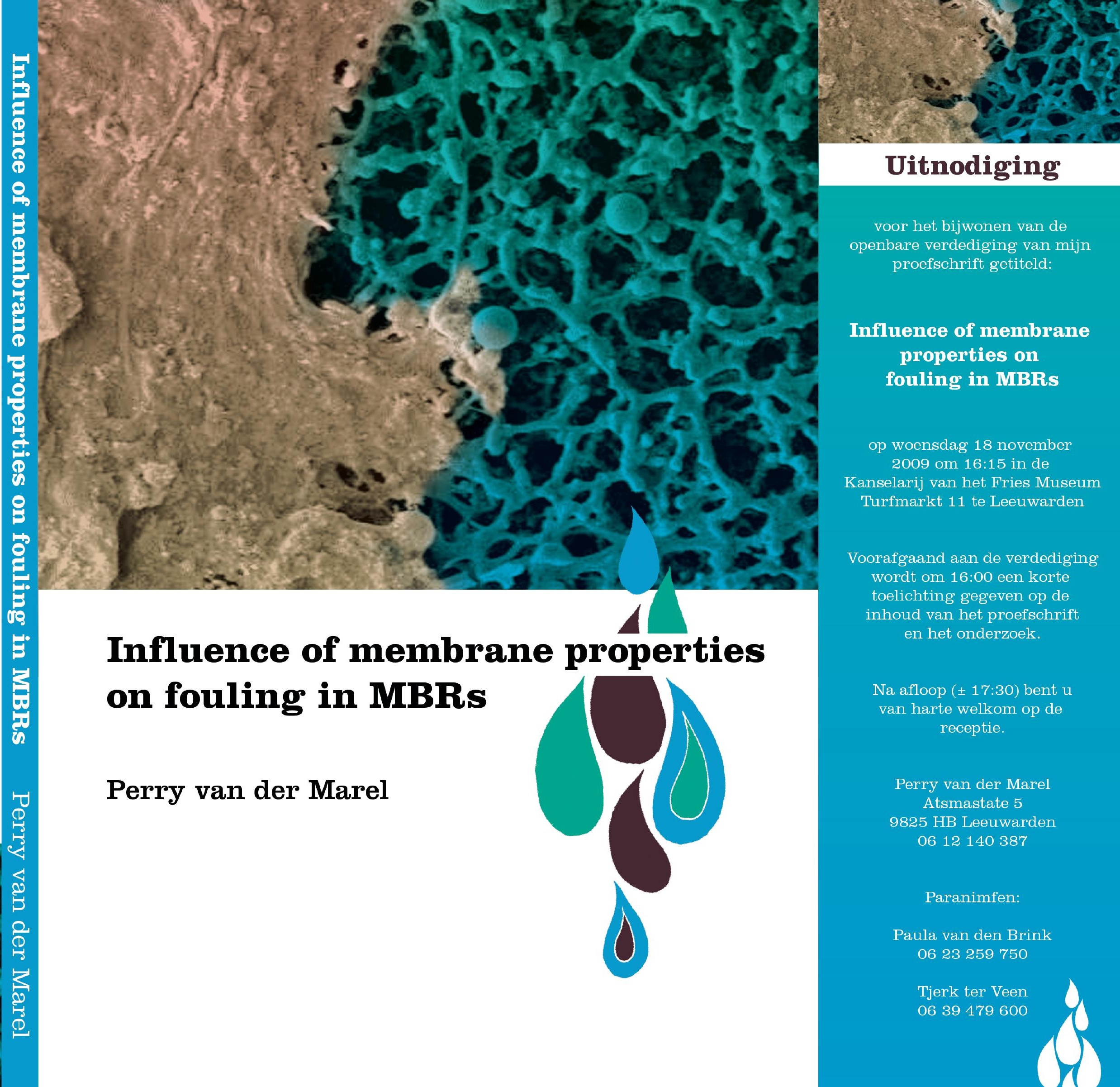




\title{
INFLUENCE OF MEMBRANE PROPERTIES ON FOULING IN MBRs
}

\author{
Perry van der Marel
}


The research described in this thesis was carried out at Wetsus, Centre of Excellence for Sustainable Water Technology, Leeuwarden, The Netherlands under supervision of the Membrane Technology Group, University of Twente, Enschede, The Netherlands.

Perry van der Marel

Influence of membrane properties on fouling in MBRs

Ph.D. Thesis, University of Twente, The Netherlands

ISBN: 978-90-365-2926-6

CC P. van der Marel, 2009

All rights reserved

Cover design by MAKI

Printed by PrintPartners Ipskamp B.V., Enschede, The Netherlands 


\title{
INFLUENCE OF MEMBRANE PROPERTIES ON FOULING IN MBRs
}

\author{
PROEFSCHRIFT
}

\author{
ter verkrijging van \\ de graad van doctor aan de Universiteit Twente, \\ op gezag van de rector magnificus, \\ prof.dr. H. Brinksma, \\ volgens besluit van het College voor Promoties \\ in het openbaar te verdedigen \\ op woensdag 18 november 2009 om 16.00 uur
}

door

\section{Perry van der Marel}

geboren op 21 augustus 1981

te Delft 
Dit proefschrift is goedgekeurd door de promotor:

Prof.dr.ir. W.G.J. van der Meer

en de assistent promotor:

Dr.ir. A.J.B. Kemperman 
Voor Sam 



\section{Table of Contents}

\section{Influence of membrane properties on fouling in MBRs}

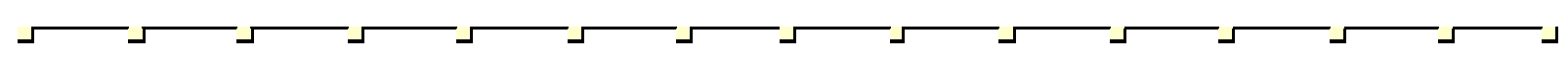

Chapter $1 \quad$ Membrane fouling in membrane bioreactors 1

$1.1 \quad$ Wastewater treatment in conventional activated sludge systems 3

$1.2 \quad$ Membrane bioreactors 4

$\begin{array}{lll}1.3 & \text { MBR configuration } & 6\end{array}$

$\begin{array}{lll}1.4 & \text { Membrane fouling } & 7\end{array}$

$\begin{array}{lll}\text { 1.4.1 Membranes properties } & 7\end{array}$

$\begin{array}{lll}\text { 1.4.2 } & \text { Feed properties and operational conditions } & 9\end{array}$

$\begin{array}{lll}1.4 .3 & \text { Fouling mechanisms in MBRs } & 10\end{array}$

1.4.4 Reversible and irreversible fouling 11

$\begin{array}{lll}1.5 & \text { Critical flux } & 12\end{array}$

$\begin{array}{lll}1.6 & \text { Outline } & 14\end{array}$

$\begin{array}{lll}1.7 & \text { Used symbols and abbreviations } & 15\end{array}$

$\begin{array}{lll}1.8 & \text { References } & 15\end{array}$

Chapter 2 An improved flux-step method to determine the critical flux and the critical flux for irreversibility in a membrane bioreactor $\quad 19$

$2.1 \quad$ Introduction 21

$2.2 \quad$ Material and methods $\quad 22$

$\begin{array}{lll}2.2 .1 & 22\end{array}$

2.2.2 Experimental set-up 23

$\begin{array}{lll}2.2 .3 & \text { Experimental procedure } & 24\end{array}$

$2.3 \quad$ Results 26

2.3.1 Comparison of the common and improved flux-step method 26

2.3.2 Fouling development during consecutive filtration runs with the IFSM 29

$\begin{array}{lll}2.4 & \text { Discussion } & 30\end{array}$

$2.5 \quad$ Conclusions $\quad 32$

$2.6 \quad$ Acknowledgements 32

2.7 Used symbols and abbreviations 33

$2.8 \quad$ References 33 
Chapter 3 Influence of membrane properties on membrane fouling in submerged membrane bioreactors $\quad 35$

$\begin{array}{lll}3.1 & 37\end{array}$

$3.2 \quad$ Material and methods 38

3.2.1 Membranes 38

3.2.2 Experimental set-up 38

$\begin{array}{lll}3.2 .3 & \text { Experimental procedure } & 39\end{array}$

3.2.4 Membrane cleaning 40

3.2.5 Chemical oxygen demand 40

$3.3 \quad$ Results 40

3.3.1 Membrane characterization 40

3.3.2 Critical flux $\left(\mathrm{J}_{\mathrm{C}}\right)$ and critical flux for irreversibility $\left(\mathrm{J}_{\mathrm{Ci}}\right) \quad 42$

3.3.3 Irreversible fouling during consecutive filtration runs 44

$\begin{array}{lll}3.3 .4 & \text { Long-term experiments } & 47\end{array}$

3.4 Discussion 50

3.5 Conclusions 53

3.6 Acknowledgements 53

3.7 Used symbols and abbreviations 53

$\begin{array}{lll}3.8 & \text { References } & 54\end{array}$

Chapter 4 Influence of membrane properties on membrane fouling in three different activated sludge mixtures $\quad 57$

4.1 Introduction 59

$4.2 \quad$ Material and Methods 59

4.2.1 Activated sludge mixtures and membranes 59

$\begin{array}{lll}4.2 .2 & \text { Experimental set-up } & 61\end{array}$

$\begin{array}{lll}\text { 4.2.3 Experimental procedure } & 62\end{array}$

$4.3 \quad$ Results and discussion 64

4.3.1 Fouling trends in three activated sludge mixtures 64

4.3.2 Consecutive IFSMs using MBR-V activated sludge 66

4.3.3 Long-term filtration at a fixed flux with MBR-V sludge 68

4.3.4 Fouling behavior in different activated sludges 69

$\begin{array}{lll}4.4 & \text { Conclusions } & 70\end{array}$

$\begin{array}{lll}4.5 & \text { Acknowledgements } & 70\end{array}$

$\begin{array}{lll}4.6 & \text { Used symbols and abbreviations } & 71\end{array}$

$\begin{array}{ll}\text { Appendix I: Particle size distributions (PSD) } & 72\end{array}$

Appendix II: Images of fouled membranes $\quad 73$

$\begin{array}{lll}4.7 & \text { References } & 74\end{array}$

Chapter 5 Backwashing versus relaxation of flat-sheet membranes in a membrane bioreactor $\quad 75$

$\begin{array}{lll}5.1 & \text { Introduction } & 77\end{array}$

$5.2 \quad$ Material and Methods $\quad 78$

$\begin{array}{lll}\text { 5.2.1 Membranes } & 78\end{array}$ 
$\begin{array}{lll}\text { 5.2.2 } & \text { Experimental set-up } & 79\end{array}$

$\begin{array}{lll}\text { 5.2.3 Experimental procedure } & 80\end{array}$

5.2.4 Chemical cleaning and forward flush 81

$5.3 \quad$ Results 82

5.3.1 The effect of relaxation and backwashing on membrane fouling 82

5.3.2 The effect of chemically enhanced backwash on membrane fouling 83

5.3.3 Comparison of filtration characteristics 85

5.4 Discussion 86

$\begin{array}{lll}5.5 & \text { Conclusions } & 87\end{array}$

$5.6 \quad$ Used symbols and abbreviations 88

$\begin{array}{lll}5.7 & \text { References } & 88\end{array}$

Chapter $6 \quad$ Reducing fouling in membrane bioreactors by using corrugated membranes $\quad 91$

6.1 Introduction 93

6.2 Corrugated membranes, a short review 95

6.3 Materials and methods 95

6.3.1 Smooth and corrugated membranes 95

$\begin{array}{lll}\text { 6.3.2 } & \text { Experimental set-up } & 97\end{array}$

$\begin{array}{lll}\text { 6.3.3 Experimental procedure } & 98\end{array}$

$\begin{array}{lll}6.4 & \text { Results and discussion } & 98\end{array}$

6.4.1 Corrugate form, membrane pore size, and surface porosity 98

$\begin{array}{lll}6.4 .2 & 100\end{array}$

$\begin{array}{ll}\text { 6.4.3 Critical flux measurements } & 101\end{array}$

$\begin{array}{ll}\text { 6.4.4 Long-term experiments } & 101\end{array}$

6.4.5 Optimization of corrugated membranes for MBR 104

$\begin{array}{lll}6.5 & \text { Conclusions } & 105\end{array}$

6.6 Used symbols and abbreviations 105

$\begin{array}{lll}6.7 & \text { References } & 106\end{array}$

$\begin{array}{lll}\text { Chapter } 7 & \text { Conclusions \& Outlook } & 109\end{array}$

7.1 Improved flux-step method 111

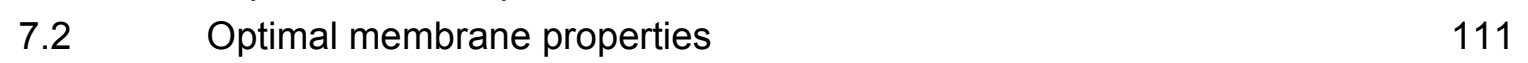

7.3 Fouling reversibility by relaxation and (chemical) backwashing 113

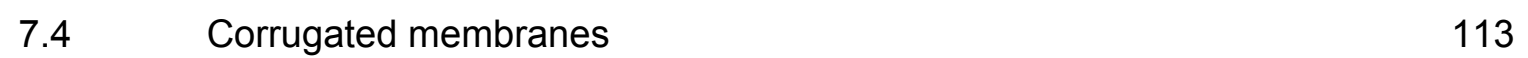

$\begin{array}{lll}7.5 & \text { Mobile filtration unit } & 114\end{array}$

$\begin{array}{lll}7.6 & \text { References } & 115\end{array}$

$\begin{array}{ll}\text { Summary } & 117\end{array}$

$\begin{array}{ll}\text { Samenvatting } & 123\end{array}$

$\begin{array}{ll}\text { Curriculum Vitae } & 128\end{array}$

List of publications $\quad 129$

$\begin{array}{ll}\text { Dankwoord } & 130\end{array}$ 



\section{Chapter 1}

Membrane fouling in membrane bioreactors

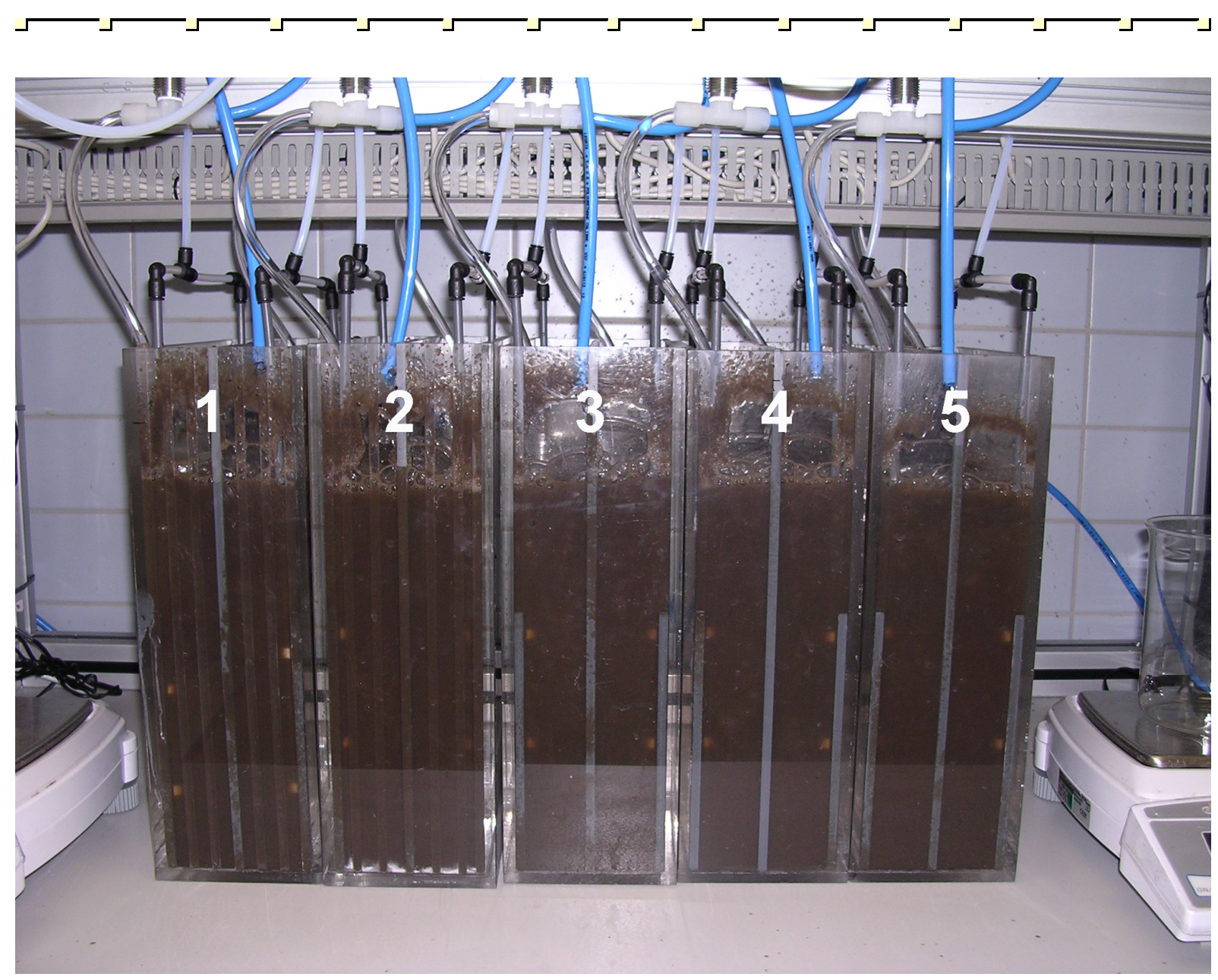




\section{Abstract}

In this Chapter a general overview of municipal wastewater treatment using membrane bioreactors (MBR) is given. The MBR offers a smaller foot print and better effluent quality compared to conventional activated sludge systems. Operational costs of MBRs however, are higher due to measures necessary to reduce membrane fouling. Membrane fouling is a complex process affected by three key parameters: membrane properties, feed properties, and operational conditions. The process of membrane fouling comprises four fouling mechanisms which can occur individually, simultaneously, or which mutually interact. It can be either reversible or irreversible depending on the applied cleaning method. Investigation of the fouling process can be performed by analysis of the filtration resistance to determine whether fouling is reversible or irreversible, and by measuring the critical flux. The topic of this $\mathrm{PhD}$-thesis is to elucidate optimal membrane properties with reduced fouling characteristics, i.e. that have the largest critical flux and also suffer the least from irreversible fouling. Optimal membrane properties with respect to fouling reduction will decrease operational costs, and will make MBR cost competitive with conventional wastewater treatment systems. They will result in larger applicable fluxes, which allows for a reduction of the installed membrane surface. This not only decreases operational cost for filtration, but also minimizes the use of air scouring necessary to limit fouling.

This Chapter describes in detail the fouling mechanisms and how the three key parameters are involved. An outline of the work presented in this thesis is given in the last section of this Chapter.

P. van der Marel, A. Zwijnenburg, A.J.B. Kemperman, M. Wessling, H. Temmink, and W.G.J. van der Meer. 


\subsection{Wastewater treatment in conventional activated sludge systems}

In wastewater treatment plants (WWTPs) municipal and industrial wastewater are treated both mechanically and biologically. For biological treatment nearly all WWTPs apply the activated sludge process in which settleable sludge flocs are formed containing the micro-organisms [1]. In conventional activated sludge (CAS) systems the sludge is separated from the treated water by secondary clarification (settling) to maintain the sludge in the system. Settling is performed in clarifiers which usually are round basins with a relatively large surface area compared to the bioreactor. The sludge-water mixture enters in the center and slowly flows to the border enabling sufficient time for the sludge flocs to settle. The effluent that runs over should be free of sludge flocs, which limits the sludge concentration also called the mixed liquor suspended solids (MLSS) concentration - in the bioreactor at typical values of 4-6 $\mathrm{g} \mathrm{L}^{-1}$.

Besides the clarifiers, CAS systems comprise at least primary treatment by for example grit removal, sieving and sedimentation, and secondary treatment in a bioreactor with anaerobic, anoxic, and aerobic zones to stimulate the appropriate microbial processes for removal of organics, nitrogen and phosphorus. This process schematically is shown in Figure 1.1. The aerobic part is intensively aerated to enable the conversion of biodegradable material and ammonia by the micro-organisms. Anaerobic and anoxic zones are installed to remove nutrients such as nitrate that originates from oxidation of ammonium, and to remove phosphorus. Because the microbial biomass increases while consuming the waste material, a net production of biomass takes place that needs to be removed from the system.

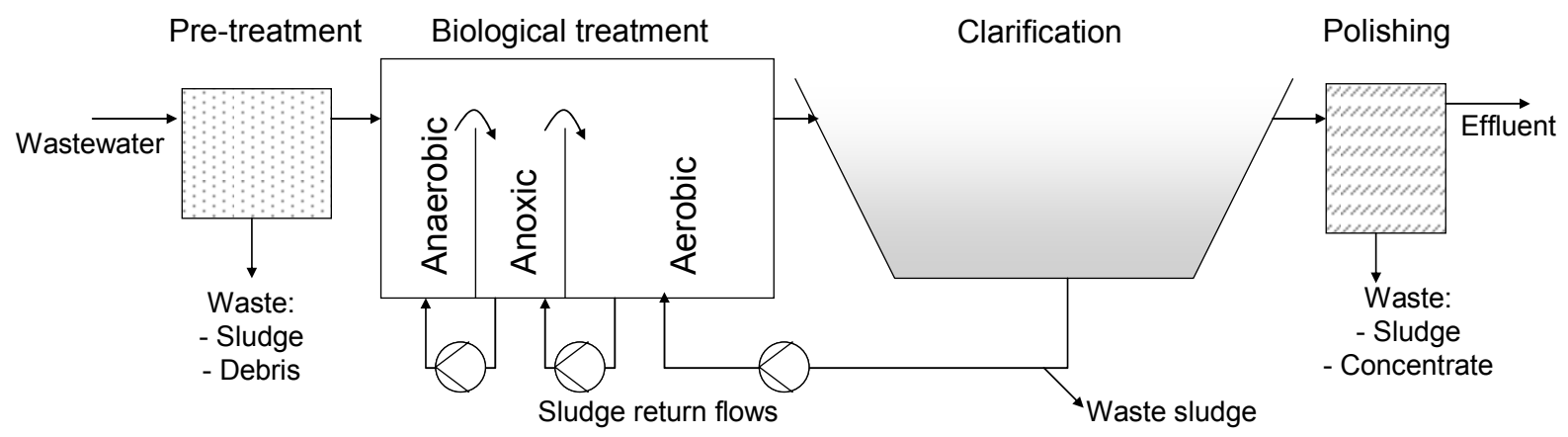

Figure 1.1 Conventional activated sludge system (CAS) with effluent polishing.

Nowadays CAS systems may be equipped with additional polishing steps of the effluent to reach the more stringent treatment levels for nutrients and soluble organic material set by the European Water Framework Directive for discharging effluent on surface waters [2]. Furthermore, the removal of micro-pollutants from the wastewater - such as medicine residues and endocrine disruptors - becomes important, because these substances were 
recently assessed to have a negative impact on the environment [3], and may cause problems for potable water production [4]. Tertiary treatment of the effluent (polishing) can be applied for example by disinfecting the effluent by chlorination, or by filtering the effluent using sand filters or membranes for advanced particle and pathogen removal. Such actions offer possibilities to reuse effluent as process water in industry, or can even upgrade the effluent to a source for potable water production. The polishing step determines the reuse possibilities. In case membranes are applied for polishing, the use of microfiltration with a pore size ranging from 0.1 to $1 \mu \mathrm{m}$ allows for discharging the water on surface waters, whereas ultrafiltration $(0.01-0.1 \mu \mathrm{m})$ probably allows for the reuse of the water as process water. For potable water production a pore size smaller than $0.01 \mu \mathrm{m}$ should be considered by using nanofiltration and reversed osmosis membranes.

\subsection{Membrane bioreactors}

In contrast to CAS systems with additional polishing steps, a membrane bioreactor (MBR) applies direct membrane filtration of the mixed-liquor in the bioreactor to separate the treated water (permeate) from the sludge. No space consuming secondary clarifiers are required anymore, and a complete retention of activated sludge by the membrane enables a much larger MLSS concentration in the bioreactor (in practice $10-20 \mathrm{~g} \mathrm{~L}^{-1}$ ). The larger MLSS concentration facilitates a smaller bioreactor which, together with the absence of clarifiers, results in a smaller footprint of the WWTP. This smaller footprint especially can be of importance in populated areas. A much larger MLSS concentration is not preferred, since this increases viscosity of the activated sludge. A higher viscosity lowers the rate of uprising air-bubbles which reduces scouring, with the net result a higher fouling rate of the membranes [5]. Furthermore, a higher viscosity also lowers the efficiency of mass transfer of oxygen to the biomass, and therefore decreases the dissolved oxygen concentration in the aerobic bioreactor [6]. The lower availability of oxygen may negatively affect biological treatment.

Compared to CAS systems without a polishing step, the barrier function of the membrane in an MBR facilitates a better permeate quality with respect to (non-settable) suspended solids (and with it associated heavy metals, nitrogen, and phosphorus), pathogens and depending on the membrane pore size - soluble organic material. Furthermore, in an MBR the hydraulic retention time (HRT) has a lower impact on biological performance as the sludge always is maintained in the bioreactor. Summarized, due to the membrane present the permeate of an MBR has a higher reuse potential compared to effluent of CAS systems, which can be of value for industries and in areas suffering from water scarcity [7-9]. 
The high quality permeate in MBR is produced at a higher cost compared to CAS systems with additional effluent polishing. The Foundation of Applied Research for Water Management in the Netherlands ('Stichting Toegepast Onderzoek Waterbeheer', STOWA) compared MBR with a CAS system that was extended with a post sand filtration step [10]. The investment costs approximately were the same (in agreement to what Adham et al. [9] estimated), while the operational costs of the MBR system was 10 to $20 \%$ higher, depending on the treatment capacity. This implies MBRs are only useful in situations where a high quality product is necessary (for example in the case of water reuse), or when a small foot print is required. Operational cost for an MBR should be decreased for it to become cost competitive with CAS systems, and to become a more standard wastewater treatment technology.

The higher operational costs of an MBR are primarily caused by its higher energy use, being approximately $30 \%$ higher compared to CAS systems with a post sand filtration step [11]. Energy is required for aerating the biomass, which is of a lower efficiency in MBR compared to CAS systems due to the higher MLSS concentration [12]. Furthermore, an MBR requires additional energy for permeate production, and for aerating the membranes in the case of submerged systems or cross-flow in the case of side-stream systems (see Section 1.3). For the full scale MBR in Varsseveld (the Netherlands) for instance, the energy use for aerating the membranes to limit fouling contributes to $38 \%$ of the total energy requirement of the MBR, whereas $14 \%$ is used for membrane filtration and $23 \%$ for aerating the biomass [12]. Finally, energy is required for periodic cleaning of fouled membranes (see Section 1.4). Fouling is a serious drawback of MBR systems [13, 14] which reduces membrane performance, decreases MBR robustness, and increases operational costs due to frequent membrane cleaning and membrane aeration. Despite its fouling issues and the higher operating cost, according to a technical market research report the global MBR market was valued at an estimated $\$ 217$ million in 2006 and is expected to approach \$363 million in 2010 [15]. Apparently, the advantages of MBRs with a smaller footprint and better permeate quality seems to be more important than the higher energy consumption.

The energy consumption of MBRs should decrease to make MBRs cost competitive with CAS systems. The energy consumption can be decreased by preventing membrane fouling as much as possible. This reduces the aeration necessity of the membranes and increases the filtration flux. A larger flux decreases the required membrane surface area installed, which also lowers the energy consumption for filtration. Additionally, the energy consumption can be reduced by optimizing the operating procedures (for instance filtration time, intermittent aeration, and appropriate cleaning measures) and by further developing optimal membranes with respect to fouling reduction [11]. The research described in this thesis is aimed at the reduction of fouling in MBR (and with it the energy consumption) by searching for optimal membrane properties (Chapter 2 - 4), optimal cleaning procedures (Chapter 5), and a new membrane configuration (Chapter 6). 


\subsection{MBR configuration}

MBRs are designed either in side-stream or in submerged configuration. In side-stream systems cross-flow circulation of sludge through primarily tubular membrane modules placed outside the bioreactor takes place (Figure 1.2). Most side-stream systems are based on pumped flow through horizontally mounted modules, but more recent systems apply vertically mounted membranes which are operated with liquid pumping combined with airlift at a much lower cross-flow rate [16]. The cross-flow velocity of sludge by liquid pumping with or without airlift exerts high shear on the membrane surface which limits fouling. In submerged configuration the membranes are immersed in the bioreactor itself using either flat-sheet or hollow fiber membranes (Figure 1.2). Shear to minimize fouling is exerted by coarse bubble aeration along the membrane surface which scours off foulants. For comparison, Table 1.1 shows some general values of operational properties of side-stream and submerged MBR operation [16].

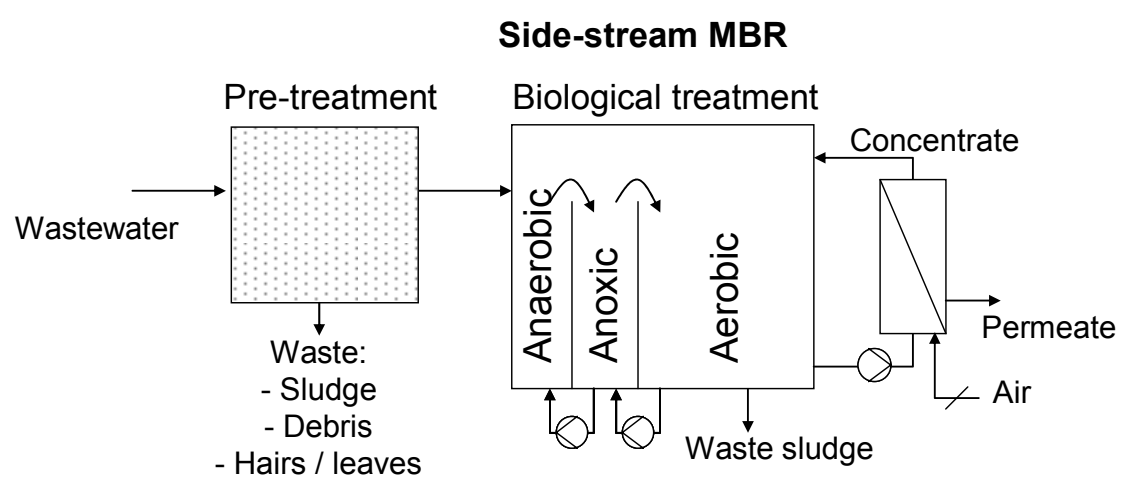

Submerged MBR

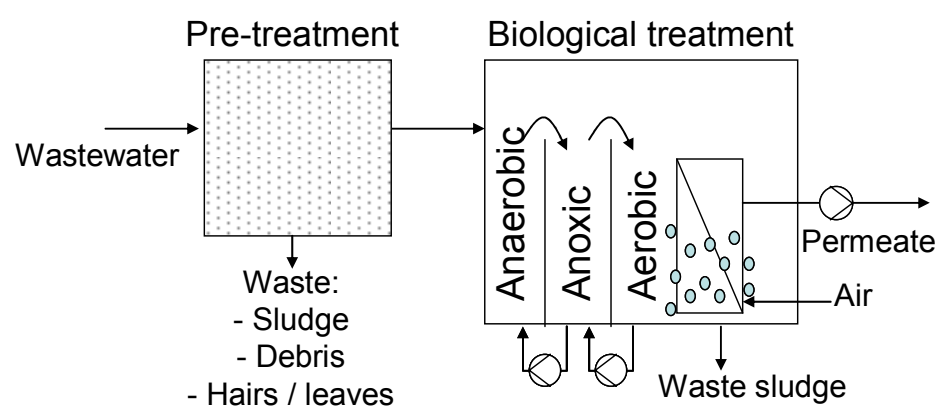

Figure 1.2 Schemes of a side-stream MBR configuration and a submerged MBR configuration. 
Table 1.1 Operational parameters of three MBR configurations.

\begin{tabular}{lccc}
\hline Property & Side-stream & Airlift & Submerged \\
\hline Filtration type & Inside-out & Inside-out & Outside-in \\
TMP $($ bar $)$ & $1-5$ & $0.05-0.3$ & $0.2-0.5$ \\
Flux $\left(\mathrm{L} \mathrm{m}^{-2} \mathrm{~h}^{-1}\right)$ & $80-200$ & $30-60$ & $10-40$ \\
Energy use $\left(\mathrm{kWh} \mathrm{m}^{-3}\right)$ & $1.5-4$ & $0.5-0.7$ & $0.2-0.5$ \\
Cross-flow velocity $\left(\mathrm{m} \mathrm{s}^{-1}\right)$ & $0.5-5$ & $0.3-0.5$ liquid $+0.3-0.5$ air & $0.1-1$ \\
Fouling potential & Low & Low & High \\
Membrane surface/bioreactor volume & Low & Low & High \\
\hline
\end{tabular}

Submerged membranes generally show a larger fouling potential compared to side-stream membranes. This is due to the lower shear rate caused by the uprising air bubbles in the sludge in submerged systems compared to cross-flow of sludge with or without airlift in sidestream systems. In addition, the permeate flux in submerged systems is about a factor two lower than in side-stream systems, increasing the required membrane surface area for filtration. Furthermore, cleaning or replacing submerged membranes is more difficult compared to side-stream membrane units that can be uncoupled easily from the biological reactor. Despite these disadvantages most municipal MBRs nowadays are submerged systems. In Europe for instance, $99 \%$ of the installed membrane surface area is represented by submerged MBRs, of which $75 \%$ are applied for treatment of municipal wastewater [17]. The main reason for the preference of submerged MBR in municipal wastewater treatment is the lower energy consumption involved due to the absence of a cross-flow [18], but is also due to lower membrane costs and the easier operating principle. In the case of industrial MBR applications - where the energy consumption is less an issue - the market more significantly is occupied by the side-stream configuration.

This thesis is focused on submerged MBRs treating municipal wastewater. The commercial market for submerged MBRs almost entirely is dominated by Kubota (flat-sheet membranes) and GE Zenon (hollow fiber membranes). There is an ongoing debate on which of these systems offers the best design. Flat-sheet systems generally run at higher net fluxes and their operation is simpler compared to hollow fiber systems [16, 19]. Hollow fiber membranes on the other hand easily can be backwashed to remove fouling (see Section 1.4.4).

\subsection{Membrane fouling}

\subsubsection{Membranes properties}

Membrane fouling is the accumulation of material on the membrane surface or within the membrane pores [20], which causes loss of membrane performance as revealed by an increase in TMP or by a decrease in permeate flux. The research in this thesis focuses on 
the role of the membrane properties on membrane fouling in MBRs, with the aim to identify which membrane properties are important for reducing membrane fouling. Optimal membrane properties with respect to fouling reduction will decrease operational costs. Moreover, optimal membrane properties will increase the applicable permeate flux, which considerably lowers the investment costs since less membrane surface area is required. The reduction in both operational and investment costs will make MBR cost competitive or even a cheaper solution compared to CAS systems with additional effluent polishing.

The effect of properties like membrane material, pore size, surface porosity, pore morphology, hydrophobicity, and membrane charge on fouling should be investigated systematically under similar conditions. Previous work on the effect of membrane properties on fouling however, focused on one membrane property only, while at the same time the other membrane properties also were not kept identical [21, 22]. This makes an interpretation with respect to the optimum membrane properties extremely difficult, if not impossible [5], and may have contributed to inconclusive results that are given in literature. For instance, the membrane material and its surface characteristics hydrophobicity and charge influence the interaction of feed substances with the membrane. Metsamuuronen et al. [22] compared a hydrophobic polysulphone membrane with a hydrophilic regenerated cellulose acetate membrane, and concluded that a hydrophobic membrane inhibited more fouling. Yamato et al. [23] reported that a polyethylene membrane suffers more from fouling than a polyvinylidenefluoride membrane. In these two investigations however, for instance also the membrane pore size and the pore morphology of the different membrane materials were not identical. The difference in fouling behavior therefore could not only be attributed to hydrophobicity or the membrane material, respectively.

Probably the most important membrane property is the membrane pore size which in MBRs varies between 0.04 and $0.4 \mu \mathrm{m}$ [5]. It determines the retention of feed-substances, and thus which foulants might enter and pass the membrane matrix or might deposit on the membrane surface. Results on the influence of the membrane pore size on fouling so far are contradictory, because an increase in membrane pore size is reported to have no influence on fouling, to decrease fouling, or to increase fouling [24-26]. The membrane surface porosity also is different for membranes with different pore sizes, and therefore both factors should be considered. An increase in surface porosity decreases fouling, since at identical fluxes the velocity of material towards each pore is lower when porosity is higher [27]. Generally a larger pore would have a higher fouling propensity as more material is able to enter the membrane matrix [16]. This effect however, also is influenced by the pore morphology (symmetric or asymmetric structure), which determines the amount of fouling that becomes trapped in the membrane matrix.

Since a variety of different flat-sheet membrane materials with different properties are easily available (Chapter 3), flat-sheet submerged MBRs were selected for the research work described in this thesis instead of hollow fiber membranes. Investigation of the influence of membrane properties on fouling requires a well designed experimental procedure in order to 
be able to discriminate between the influences of each individual membrane property. A suitable method is the critical flux concept, which is described in Section 1.5 and in Chapter 2 of this thesis.

\subsubsection{Feed properties and operational conditions}

Fouling is a complex process not only influenced by the membrane configuration and membrane properties, but also by two other key parameters: feed properties and operational conditions $[28,29]$. The influence of these two key parameters also should be considered in identifying optimal membrane properties. Table 1.2 summarizes the main factors involved in the fouling process for each of these three key parameters.

Table 1.2 Parameters influencing membrane fouling.

\begin{tabular}{ccc}
\hline Membrane properties & Feed properties & Operational conditions \\
\hline Membrane material & Particle size distribution & Flux \\
Roughness & EPS & Membrane configuration \\
Hydrophobicity and charge & MLSS concentration & Shear \\
Pore size and surface porosity & Wastewater composition and fluctuation & Cleaning procedure \\
Pore morphology & Temperature and viscosity & SRT and HRT \\
\hline
\end{tabular}

The potential membrane foulants can be present in the influent, or originate from the activated sludge (particulate material) and bacterial metabolism (extracellular polymeric substances, EPS). This suggests that fouling in different MBR systems will be difficult to compare as they treat wastewater with different compositions and at different process conditions. The high levels of MLSS in an MBR together with varying levels of colloidal and soluble material that are influenced by wastewater composition and its fluctuation, temperature, salinity, and redox conditions - and also by operational conditions such as shear, HRT, and solid retention time (SRT) - makes it difficult to prevent or control membrane fouling. Furthermore, the foulants can contribute to fouling via different mechanisms (see Section 1.4.3), while their fouling potential is strongly linked to their concentration [29]. Given the above, the suitability of the developed measurement method described in this thesis and the potential optimal membrane properties therefore should be verified using different sludges. For this reason, in this thesis experiments with three types of activated sludge mixtures are carried out, as described in Chapter 4.

The membrane operational conditions in full scale MBRs are chosen such that fouling is minimized. For example, a relatively low permeate flux is applied to minimize convection of foulants to the membrane surface. Shear continuously is exerted on the membrane surface to scour off foulants. Periodic physical cleaning is employed to remove reversible fouling, or chemical cleaning is applied to restore from irreversible fouling (see also Section 1.4.4). Each of these actions however increases the operational cost, which should be decreased to 
make MBR more cost competitive with CAS systems. The effect of different cleaning methods is investigated in Chapter 5 , whereas a method to reduce fouling without applying more air scouring is described in Chapter 6.

\subsubsection{Fouling mechanisms in MBRs}

Concentration polarization, adsorption, pore blocking, and layer formation are the four processes that contribute to reversible and irreversible fouling phenomena observed during filtration in MBR as an increase in resistance [30]. These four processes are influenced by the three key parameters membrane properties, feed properties, and operational conditions. By investigating reversible and irreversible fouling using the improved flux-step method described in Chapter 2 for determination of the critical flux, optimal membrane properties are identified.

Concentration polarization is the development of a concentration gradient across the boundary layer near the membrane surface [31], possibly increasing the filtration resistance. For pressure driven membrane processes like microfiltration and ultrafiltration, concentration polarization implies a mass accumulation near the surface due to rejection of solutes. Concentration polarization plays an important role in the process of membrane fouling. It is however not a fouling mechanism, since it does not cause direct fouling on or in the membrane [20]. It may however e.g. raise the concentration of foulants to such levels that gel or cake layer formation occurs.

Adsorption, pore blocking, and layer formation are the important fouling mechanisms in MBRs. These fouling mechanisms may take place simultaneously with a strong interaction. Determining which fouling mechanism is dominant therefore often is difficult. The biomass in an MBR contains a diversity of solutes (like EPS) that individually can adsorb on the membrane surface, as well as in the pore depending on membrane and solute properties. A monolayer of adsorbed material can be formed in the pore structure. After that, several layers can be physically attached to the first monolayer which finally can narrow and close the membrane pores. Unlike pore narrowing, pore blocking can occur by particles having dimensions in the range of the pore diameter. Obviously, the membrane pore size is of importance in this process, as well as the pore morphology: if a particle is able to enter a pore it can either pass the membrane or become stuck somewhere in the tortuous path in the membrane matrix.

Fouling by layer formation on the membrane surface happens by a cake layer or a gel layer. A cake layer is formed by rejected and accumulated individual particles at the feed side of the membrane. A gel layer is a highly swollen three dimensional and possibly cross-linked network structure of macromolecules on the membrane surface [20,31]. When for instance EPS substances approach each other at high concentrations this may lead to entanglements, gradually forming a gel covering the membrane surface [16]. Distinction 
between cake and gel layers is difficult since EPS can deposit in the cake layer, whereas individual particles can also be trapped in gel layers.

\subsubsection{Reversible and irreversible fouling}

To determine the optimal membrane properties and also to select appropriate actions to tackle membrane fouling (type of cleaning and duration, adjusting the flux or shear) it is important to know whether the fouling is reversible or irreversible. A common method to elucidate fouling reversibility is by analysis of the hydraulic filtration resistance, which is calculated by Darcy's law (Equation 1.1):

Hydraulic filtration resistance: $\quad R=\frac{T M P}{\eta J}$

in which $R$ is the total hydraulic resistance $\left(\mathrm{m}^{-1}\right)$, TMP is the trans membrane pressure $(\mathrm{Pa})$, $\eta$ is the dynamic viscosity of the permeate $\left(\mathrm{Pa} \mathrm{s}^{-1}\right)$, and $J$ is the flux $\left(\mathrm{m}^{3} \mathrm{~m}^{-2} \mathrm{~s}^{-1}\right)$. The dynamic viscosity of permeate is influenced by temperature, and therefore in this thesis $\eta$ always is corrected for temperature using equation 1.2 [32].

Temperature correction of dynamic viscosity: $\quad \eta=0.497 \times(T+42.5)^{-1.5}$

where $\mathrm{T}$ is the temperature (in ${ }^{\circ} \mathrm{C}$ ) of the activated sludge mixture or permeate.

The total hydraulic resistance is composed of three individual resistances, i.e. the membrane resistance, the resistance associated with reversible fouling, and the resistance associated with irreversible fouling (Equation 1.3).

Reversible and irreversible fouling: $\quad R=R_{\mathrm{m}}+R_{\text {reversible }}+R_{\text {irreversible }}$

The membrane resistance $\left(R_{\mathrm{m}}\right)$ depends on membrane pore size (distribution), pore morphology, surface porosity, and membrane thickness. The membrane resistance usually is determined by a clean water filtration test. It is an intrinsic membrane property that does not change during filtration.

The resistances attributed to reversible and irreversible fouling can be determined empirically by applying physical and chemical cleaning steps once filtration has stopped. In this way the filtration resistance finally is restored to the clean membrane resistance in case all fouling is removable. The resistance that is restored by physical cleaning is associated with the reversible fouling ( $R_{\text {reversible) }}$. Physical cleaning can be applied by relaxation (ceasing filtration 
while maintaining scouring) or by backwashing (reversing the permeate flow). With relaxation the driving force towards the membrane is stopped. This procedure allows the removal of foulants from the membrane surface because of the applied shear [33-35]. Additionally, accumulated matter at or in the membrane can diffuse away from the surface back to the bulk due to their concentration gradient. Backwashing lifts the fouling layer, making it easier to remove it by air scouring. The most important advantage of backwashing above relaxation however, would be the removal of material deposited inside the membrane matrix. In Chapter 5 of this thesis this potential advantage is investigated for flat-sheet membranes.

Fouling that cannot be removed by relaxation or backwashing is called irreversible fouling. The irreversible fouling has to be removed by more rigorous cleaning, i.e. by using chemicals or by a more intensive physical cleaning compared to backwashing and relaxation (e.g. by a forward flush). The resistance that is restored by the more rigorous cleaning is associated with the irreversible fouling $\left(R_{\text {irreversible }}\right)$. Such definition seems a misnomer, since practically the fouling is 'reversible' by the more rigorous cleaning. Chemical cleaning most often is performed by soaking the membranes in a solution of permeate containing sodiumhypochlorite in the case of organic fouling or citric acid in the case of inorganic fouling [16, 36]. Fouling that is still present when the above cleaning methods are applied, results in an incomplete recovery of the clean membrane resistance and is called irrecoverable fouling

\subsection{Critical flux}

For microfiltration processes the critical flux is defined as the flux on start-up below which a decline of flux or increase of TMP with time does not occur, and above which fouling is observed [37]. The value of the critical flux depends on the key fouling parameters mentioned in Table 1.2. In literature therefore different critical flux values are reported, varying from less than $10 \mathrm{~L} \mathrm{~m}^{-2} \mathrm{~h}^{-1}$ [38] to more than $50 \mathrm{~L} \mathrm{~m}^{-2} \mathrm{~h}^{-1}$ [24]. The dependency of the critical flux on the key fouling parameters can be used to elucidate their influence on fouling, a procedure becoming increasingly popular for submerged MBRs [39]. By changing each key parameter independently in short-term experiments of a few hours [24, 40-42], their impact on fouling can be measured as a variation in the critical flux.

The critical flux concept will be used in this study to determine optimal low fouling membrane properties. Methods described in literature to determine critical flux in MBR are (1) the first flux where particles deposit on the membrane elucidated by direct observation through the membrane (DOTM) [43, 44], (2) calculating mass-balances of particles going in and out of a cross-flow system where the critical flux is reached once the particle concentration in the outgoing stream decreases [25], and (3) flux-step methods where the critical flux is reached once the TMP during an applied flux starts to increase [38]. DOTM is the only adequate tool to real-time measure particle deposition in a reactor. Major drawbacks of this tool however, are the necessity of transparent membranes and the use of relatively large particles at low 
concentrations. For the mass-balance approach the accuracy is twice as low compared to experimental verification by flux-TMP experiments [45]. Therefore the critical flux in an MBR usually is measured using flux-step methods [24, 46]. The flux-step method was standardized by Le Clech et al. [38] and is termed common method throughout this thesis (Figure 1.3). A step-wise increase in flux is performed (in Figure 1.3 by $2 \mathrm{~L} \mathrm{~m}^{-2} \mathrm{~h}^{-1}$ ) and each flux is applied for a fixed time $(0.25 \mathrm{~h}$ in Figure 1.3$)$. The highest flux-step at which the TMP remains constant in time is the critical flux $\left(2 \mathrm{~L} \mathrm{~m}^{-2} \mathrm{~h}^{-1}\right.$ in Figure 1.3). The critical flux can also be measured using fixed pressure-steps where the TMP is step-wise increased while the stability of the flux is monitored. This leads to a critical TMP below which the flux remains constant. However, in submerged MBRs most often flux-step methods are used, since the control of flux is easier than the control of TMP $[42,45]$.

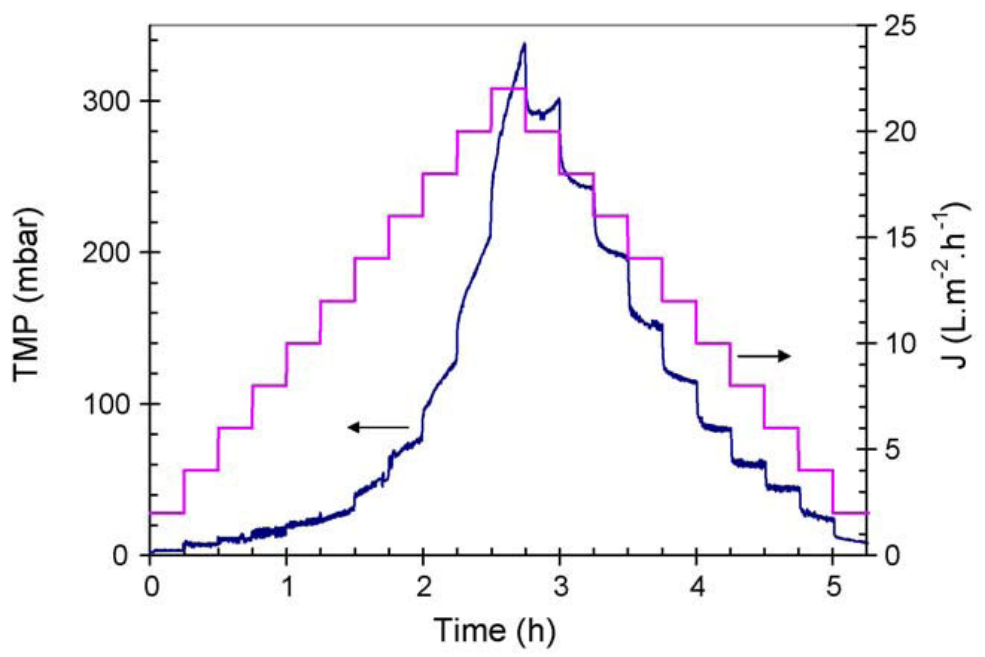

Figure 1.3 Common flux-step method, from [38].

A disadvantage of current flux-step methods is that they cannot distinguish whether fouling is reversible or irreversible. This distinction is required to determine the optimal membrane properties, since a membrane that suffers from much reversible fouling for instance can be operated without any problems compared to a membrane suffering from minor irreversible fouling. In this thesis therefore an improved flux-step method is described that not only determines the critical flux, but also is able to measure the critical flux for irreversibility. The critical flux for irreversibility is the flux where fouling becomes irreversible, i.e. can not be removed anymore using relaxation only. Using this distinction, a membrane with optimal properties for minimal fouling will need to reveal:

- A high critical flux, which shows a low fouling tendency and indicates a small physical cleaning frequency;

- A much higher critical flux for irreversibility, which shows that fouling is primarily reversible reducing the need for chemical cleaning, and shows the applicability of large fluxes (supra-critical fluxes) in case periodic physical cleaning is applied. 


\subsection{Outline}

This thesis describes the work performed on fouling in submerged MBRs with the main focus on elucidating optimal membrane properties in order to reduce fouling problems as much as possible.

Chapter 2 introduces the improved flux-step method (IFSM): a new experimental protocol which is able to compare the influence of many different membrane properties on fouling, fouling reversibility, and critical flux. The method is experimentally compared with the common flux-step method (Figure 1.3). The method measures the critical flux as well as the critical flux for irreversibility.

Chapter 3 describes the use of the IFSM for five different polymeric membrane materials with varying membrane properties. The objective is to identify which membrane properties are important for reducing membrane fouling in order to find the optimal membrane properties that suffer from the least membrane fouling. The operational conditions for each membrane type are kept constant, and one type of activated sludge was used to maintain approximately equal feed properties.

In Chapter 4 the IFSM is applied for the same membranes as in Chapter 3, but now in two other activated sludge mixtures. The objective is to determine whether the different feed properties influence the optimal membrane properties.

Chapter 5 investigates the two physical cleaning strategies applied in submerged MBRs, i.e. relaxation and backwashing. Flat-sheet polymeric membranes and also a ceramic flat-sheet membrane is investigated. Additionally, chemical cleaning by chemically enhanced backwashing is investigated.

Chapter 6 describes a pioneering study to reduce membrane fouling by using corrugated flat-sheet membranes. Chapter 3 showed that gel layer formation was the dominant fouling mechanism. With corrugated membranes it is aimed to extend the time before gel layer formation occurs.

The main conclusions of the work in this thesis are given in Chapter 7 , together with the outlook for each addressed fouling topic. The outlook reveals directions in order to optimize MBR performance. 


\subsection{Used symbols and abbreviations}

\begin{tabular}{llc} 
Symbol & & Unit \\
\hline CAS & Conventional activated sludge system & \\
DOTM & Direct observation through the membrane & \\
EPS & Extracellular polymeric substances & $\mathrm{h}$ \\
HRT & Hydraulic retention time & $\mathrm{L} \mathrm{m}^{-2} \mathrm{~h}^{-1}$ \\
$J$ & Permeate flux & \\
MBR & Membrane bioreactor & $\mathrm{g} \mathrm{L}^{-1}$ \\
MLSS & Mixed liquor suspended solids & $\mathrm{m}^{-1}$ \\
$R$ & Total hydraulic filtration resistance & $\mathrm{m}^{-1}$ \\
$R_{\text {irreversible }}$ & Resistance attributed to irreversible fouling & $\mathrm{m}^{-1}$ \\
$R_{\mathrm{m}}$ & Membrane resistance & $\mathrm{m}^{-1}$ \\
$R_{\text {reversible }}$ & Resistance attributed to reversible fouling & $\mathrm{h}$ \\
SRT & Solid retention time & $\mathrm{Pa}^{-1}$ \\
TMP & Transmembrane pressure & \\
WWTP & Wastewater treatment plant & $\mathrm{Pa} \mathrm{s}^{-}$ \\
$\eta$ & Permeate viscosity &
\end{tabular}

\subsection{References}

1. Metcalf\&Eddy, Wastewater engineering: treatment and reuse. 4th international ed. 2003, New York: McGraw-Hill.

2. Hoppe, H., M. Weilandt, and H. Orth, A combined water management approach based on river water quality standards. Journal of Environmental Informatics, 2004. 3: p. 67-76.

3. Brooks, B., Fish on Prozac - How depressing. in Reuters, 2003.

4. Townsend, M., Stay calm - Prozac in your drinking water. In the Observer, 2004.

5. Le-Clech, P., V. Chen, and T.A.G. Fane, Fouling in membrane bioreactors used in wastewater treatment. Journal of Membrane Science, 2006. 284: p. 17-53.

6. Germain, E., T. Stephenson, and P. Pearce, Biomass characteristics and membrane aeration: Toward a better understanding of membrane fouling in submerged membrane bioreactors (MBRs). Biotechnology and Bioengineering, 2005. 90: p. 316.

7. Gander, M.A., B. Jefferson, and S.J. Judd, Membrane bioreactors for use in small wastewater treatment plants: membrane materials and effluent quality. Water Science and Technology, 2000. 41: p. 205-211.

8. Jefferson, B., et al., Membrane bioreactors and their role in wastewater reuse. Water Science and Technology, 2000. 41: p. 197-204.

9. Adham, S., et al., Feasibility of the membrane bioreactor process for water reclamation. Water Science and Technology, 2001. 43: p. 203-209. 
10. STOWA, Vergelijkend onderzoek MBR en zandfiltratie. STOWA 2004-28. Utrecht, 2004.

11. van Bentem, A., and $\mathrm{H}$. van der Roest, $M B R$ energiezuiniger in de toekomst. Afvalwaterwetenschap, 2007, jaargang 6, nr. 2, pp. 105-114.

12. Pearce, G., Introduction to membranes: An introduction to membrane bioreactors. Filtration \& Separation, 2008. 45: p. 32-35.

13. Rosenberger, S., et al., Performance of a bioreactor with submerged membranes for aerobic treatment of municipal waste water. Water Research, 2002. 36: p. 413-420.

14. Wen, X.B., Q. Huang, X., Study on fouling characteristics of axial hollow fibers crossflow microfiltration under different flux operations. In: Proceedings of the Water Environment-Membrane Technology Conference, Seoul, Korea. 2004.

15. Atkinson, S., Research studies predict strong growth for MBR markets. Membrane Technology, 2006. 2: p. 8.

16. Judd, S.J., The MBR Book: Principles and Applications of Membrane Bioreactors in Water and Wastewater Treatment. 1st ed. 2006, Oxford: Elsevier.

17. Lesjean, B., and E.H. Huisjes, Survey of European MBR market, trends and perspectives. in: Proceedings of the $4^{\text {th }}$ IWA International Membrane Technologies Conference, Harrogate, 2007.

18. Stephenson, T., Judd, S., Jefferson, B., and Brindle, K., Membrane bioreactors for wastewater treatment. 2000, London: IWA Publishing.

19. Le-Clech, P., B. Jefferson, and S.J. Judd, A comparison of submerged and sidestream tubular membrane bioreactor configurations. Desalination, 2005. 173: p. 113-122.

20. Koros, W.J., Ma Y. H., and Shimidzu T., Terminology for membranes and membrane processes. Journal of Membrane Science, 1996. 120: p. 149-159.

21. Wu, Z., et al., Effects of various factors on critical flux in submerged membrane bioreactors for municipal wastewater treatment. Separation and Purification Technology, 2008. 62: p. 56-63.

22. Metsamuuronen, S., J. Howell, and M. Nystrom, Critical flux in ultrafiltration of myoglobin and baker's yeast. Journal of Membrane Science, 2002. 196: p. 13-25.

23. Yamato, N., et al., Difference in membrane fouling in membrane bioreactors (MBRs) caused by membrane polymer materials. Journal of Membrane Science, 2006. 280: p. 911-919.

24. Madaeni, S.S., A.G. Fane, and D.E. Wiley, Factors influencing critical flux in membrane filtration of activated sludge. Journal of Chemical Technology and Biotechnology, 1999. 74: p. 539-543.

25. Kwon, D.Y., et al., Experimental determination of critical flux in cross-flow microfiltration. Separation and Purification Technology, 2000. 19: p. 169-181.

26. Chen, V., Performance of partially permeable microfiltration membranes under low fouling conditions. Journal of Membrane Science, 1998. 147: p. 265-278.

27. Kuiper, S., et al., Determination of particle-release conditions in microfiltration: a simple single-particle model tested on a model membrane. Journal of Membrane Science, 2000. 180: p. 15-28.

28. Lesjean, B., et al., Correlation between membrane fouling and soluble/colloidal organic substances in membrane bioreactors for municipal wastewater treatment. Water Science and Technology, 2005. 51: p. 1-8. 
29. Chang, I.S., et al., Membrane fouling in membrane bioreactors for wastewater treatment. Journal of Environmental Engineering, 2002. 128: p. 1018-1029.

30. Mulder, M., Basic principles of membrane technology. 2nd ed. 2003, Dordrecht: Kluwer Academic Publishers.

31. Koops, G.H., Nomenclature and symbols in membrane science and technology. 1995, European Society of Membrane Science and Technology, the Netherlands.

32. Roorda, J.H. and J. van der Graaf, New parameter for monitoring fouling during ultrafiltration of WWTP effluent. Water Science and Technology, 2001. 43: p. 241248.

33. Hong, S.P., et al., Fouling control in activated sludge submerged hollow fiber membrane bioreactors. Desalination, 2002. 143: p. 219-228.

34. Chua, H.C., T.C. Arno, and J.A. Howell, Controlling fouling in membrane bioreactors operated with a variable throughput. Desalination, 2002. 149: p. 225-229.

35. Ng, C.A., et al., Strategies to improve the sustainable operation of membrane bioreactors. in: Proceedings of International Desalination Association Conference, Singapore. 2005.

36. Pall Corporation, 2009, Membrane chemical cleaning: From art to science. Available: http://www.pall.com/pdf/mtcpaper.pdf, accessed Jan. 13, 2009.

37. Field, R.W., et al., Critical flux concept for microfiltration fouling. Journal of Membrane Science, 1995. 100: p. 259-272.

38. Le Clech, P., et al., Critical flux determination by the flux-step method in a submerged membrane bioreactor. Journal of Membrane Science, 2003. 227: p. 81-93.

39. Jefferson, B., et al., Methods for understanding organic fouling in MBRs. Water Science and Technology, 2004. 49: p. 237-244.

40. Vera, L., et al., Cross-flow microfiltration of biologically treated wastewater. Desalination, 1997. 114: p. 65-75.

41. Defrance, L. and M.Y. Jaffrin, Reversibility of fouling formed in activated sludge filtration. Journal of Membrane Science, 1999. 157: p. 73-84.

42. Defrance, L. and M.Y. Jaffrin, Comparison between filtrations at fixed transmembrane pressure and fixed permeate flux: application to a membrane bioreactor used for wastewater treatment. Journal of Membrane Science, 1999. 152: p. 203-210.

43. $\mathrm{Li}, \mathrm{H}$., et al., Direct observation of particle deposition on the membrane surface during crossflow microfiltration. Journal of Membrane Science, 1998. 149: p. 83-97.

44. Fane, A.G., P. Beatson, and H. Li, Membrane fouling and its control in environmental applications. Water Science and Technology, 2000. 41: p. 303-308

45. Bacchin, P., P. Aimar, and R.W. Field, Critical and sustainable fluxes: Theory, experiments and applications. Journal of Membrane Science, 2006. 281: p. 42-69.

46. Andreottola, G. and G. Guglielmi. Critical flux determination in two MBRs for municipal wastewater treatment. in: Proceedings of the IMSTEC, Sydney, Australia. 2003. 



\section{Chapter 2}

An improved flux-step method to determine the critical flux and the critical flux for irreversibility in a membrane bioreactor

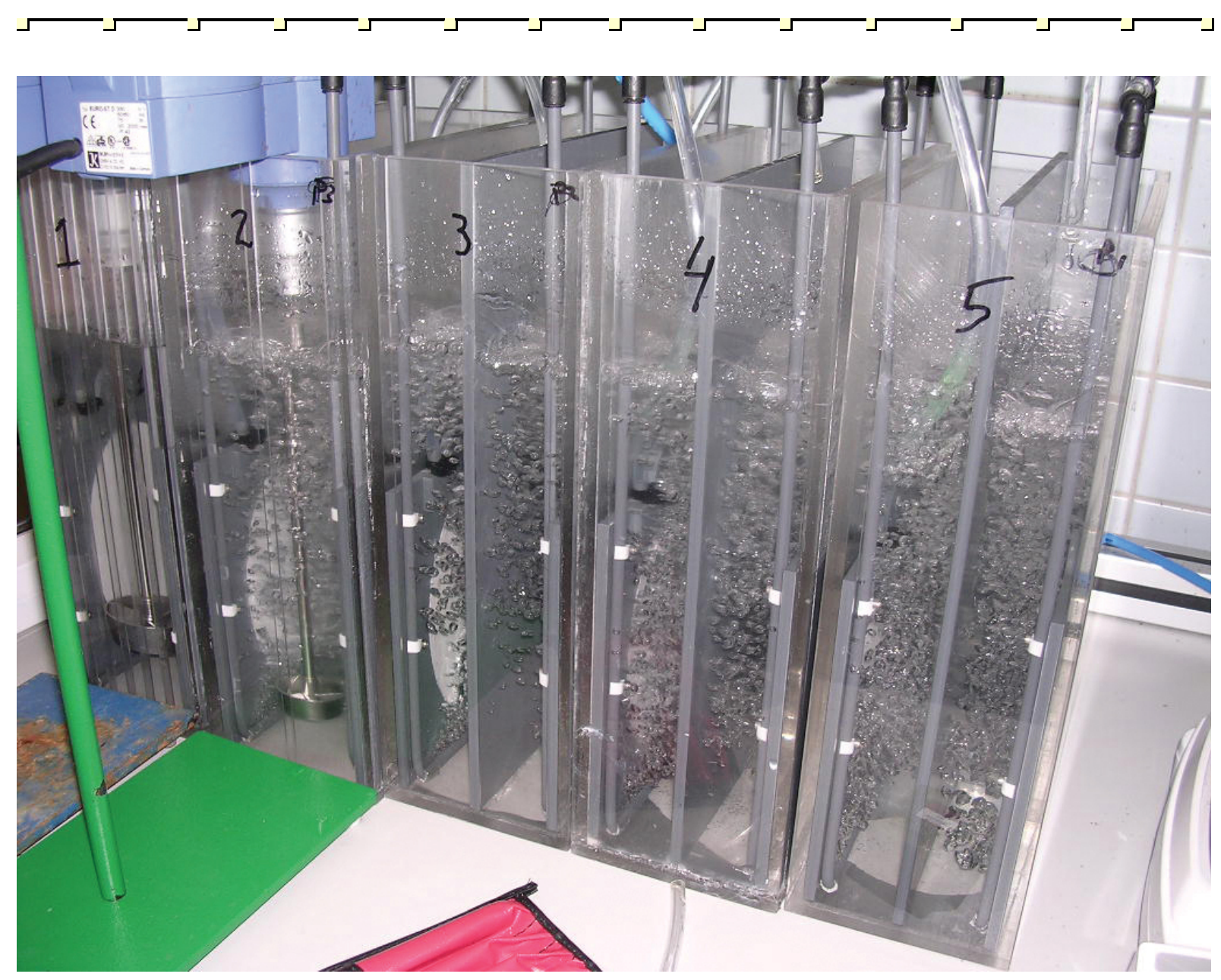




\section{Abstract}

An improved flux-step method is presented incorporating cleaning steps by relaxation to determine the critical flux and the critical flux for irreversibility. Experiments are performed with activated sludge fed with real municipal wastewater. The improved flux-step method is compared with a common flux-step method often used in literature. The critical flux for a polyvinylidenefluoride flat-sheet membrane with a pore size of $0.1 \mu \mathrm{m}$ is $56 \pm 2 \mathrm{~L} \mathrm{~m}^{-2} \mathrm{~h}^{-1}$ according to the common flux-step method and $52 \pm 3 \mathrm{~L} \mathrm{~m}^{-2} \mathrm{~h}^{-1}$ according to the improved flux-step method. The marginal difference is explained by the application of larger flux-steps in the improved flux-step method. By applying intermediate relaxation the fouling appears to be almost completely reversible, indicating that cake layer formation is the dominant fouling mechanism. The cake layer remains removable up to a flux of $100 \mathrm{~L} \mathrm{~m}^{-2} \mathrm{~h}^{-1}$. The critical flux for irreversibility is therefore larger than $100 \mathrm{~L} \mathrm{~m}^{-2} \mathrm{~h}^{-1}$.

The influence of fouling history is reduced by intermediate relaxation. As a result, the total fouling rate is much lower with the improved flux-step method compared to the common flux-step method, showing almost no fouling rate hysteresis in the improved method.

A low amount of irreversible fouling is measured due to the adsorption of macromolecules, pore blocking, and/or gel formation. Applying the improved method ten times consecutively shows the influence of irreversible fouling on the long term. The critical flux decreases by $4 \mathrm{~L} \mathrm{~m}^{-2} \mathrm{~h}^{-1}$ as a consequence of irreversible fouling during the ten runs representing a long filtration run of $150 \mathrm{~h}$ at a net flux of $19 \mathrm{~L} \mathrm{~m}^{-2} \mathrm{~h}^{-1}$.

This Chapter has been published as: van der Marel, P., Zwijnenburg, A., Kemperman, A.J.B., Wessling, M., Temmink, H., van der Meer, W.G.J. An improved flux-step method to determine the critical flux and the critical flux for irreversibility in a membrane bioreactor. Journal of Membrane Science, 2009. 332: p. 24-29. 


\subsection{Introduction}

A membrane bioreactor (MBR) has potential benefits compared to conventional wastewater treatment systems such as a smaller footprint, and a better effluent quality [1, 2]. Despite these advantages, membrane fouling prohibits the application of this technology in practice, in particular for municipal wastewater treatment. Membrane fouling can be managed by operating the system below the so-called critical flux $\left(J_{C}\right) . J_{C}$ is a quantitative parameter for the filterability of different membranes and/or different activated sludge mixtures. $J_{C}$ is generally regarded as the flux above which cake or gel formation by particles or colloids [3] occurs, i.e. convection of these materials towards the membrane by the permeate drag flow exceeds the back transport velocity of material from the membrane induced by shear and Brownian diffusion. $J_{C}$ usually is measured by flux- or pressure-step methods. Flux-stepping is preferred as the control of the flux is easier. Moreover, at fixed flux a constant flow of foulants towards the membrane is established [4]. A practical method based on a threshold fouling rate $\left(>10 \mathrm{~Pa} \mathrm{~min}{ }^{-1}\right)$ or permeability change $\left(K / K_{0}<0.9\right)$ was introduced by Le Clech et al. [5]. A threshold is used because a flux below which fouling is completely absent does not exist for activated sludge mixtures. The method applies successive flux-steps of constant height up to a maximum and back (see Figure 1.3 in Chapter 1 of this thesis). Each flux is applied for the same duration and reveals a constant transmembrane pressure (TMP) for fluxes below $J_{C}$. An ever-increasing fouling rate above $J_{C}$ occurs, because more material will deposit at larger fluxes. Also fouling history will affect the fouling rate above $J_{C}$, since the fouling occurring at the previous steps is not removed.

The critical flux for irreversibility $\left(J_{\mathrm{C}}\right)$ is determined by irreversible fouling only, and is defined as the flux where fouling cannot be removed by intermediate physical cleaning techniques like relaxation (stopping permeation) and backwashing (reversing the permeate flow) [6]. Several fouling mechanisms can be elucidated by $J_{\mathrm{C} i}$. Firstly, the flux where a cake layer becomes too cohesive; for instance by compression caused by reaching a large TMP. Secondly, the flux where adsorption or pore blocking becomes noticeable caused by the increase in concentration polarization. Thirdly, the flux where the so-called gel concentration [7] is reached forming a hydrolyzed irreversible gel structure due to adhesion of the substances to the membrane. Clearly, the reversibility of these phenomena depends on the applied cleaning technique. For example, pore blocking will be removable via backwashing but not by relaxation. The nature of the cleaning method should therefore always be part of the definition of $J_{\mathrm{C}}$. Espinasse et al. [8] discriminated between reversible fouling and irreversible fouling in a pressure-step method able to define both $J_{C}$ and $J_{\mathrm{Ci}}$ for constant pressure systems. Several studies have applied different forms of flux-stepping in order to observe fouling reversibility [4, 9-12], but no standardized flux-step method incorporating intermediate physical cleaning is available. These studies show that the fouling formed at fluxes above $J_{C}$ becomes more cohesive at higher TMP resulting in irreversible fouling, while 
it was reversible at lower TMP. From that perspective a flux larger than $J_{C}$ can only be applied as long as the fouling remains removable, i.e. the flux is below $J_{\mathrm{C} i}$.

$J_{C}$ is either equal or lower than $J_{C \text { i. }}$. $J_{C}$ is smaller than $J_{C i}$ in case fouling is reversible at $J_{C}$. Such behavior indicates cake layer formation at $J_{C}$ and for instance cake layer compression at much larger flux. $J_{C}$ is equal to $J_{C i}$ in case all fouling is irreversible. In that situation for instance gel layer formation might be the responsible fouling mechanism, which is assumed to be less reversible than a cake layer [13].

In this Chapter an improved flux-step method is proposed allowing the measurement of both $J_{\mathrm{C}}$ and $J_{\mathrm{Ci}}$ via relaxation in one single experiment. Experimental comparison with the flux-step method from Le Clech et al. (termed common method throughout this Chapter) is performed in terms of the obtained $J_{C}$, the fouling rates above $J_{C}$, fouling reversibility, and fouling rate hysteresis. The practical application of the method is shown for one membrane material and membrane pore size, and one type of activated sludge mixture. The improved flux-step method however, can be used to investigate the filterability of different membrane properties (see Chapter 3) and different activated sludge mixtures (see Chapter 4).

\subsection{Material and methods}

\subsubsection{Membranes}

Two flat-sheet polyvinylidenedifluoride (PVDF) membranes were made by phase inversion. The membrane morphology and pore size were investigated with a scanning electron microscope. The membranes were microporous and the nominal pore size was $0.1 \mu \mathrm{m}$ as estimated from SEM images via an image processing tool (ImageJ, NIH). The membrane resistance was measured in activated sludge - at very low fluxes - and equaled $6.0 \pm 0.5 \times 10^{10} \mathrm{~m}^{-1}\left(K_{0}: 5950 \pm 400 \mathrm{~L} \mathrm{~m}^{-2} \mathrm{~h}^{-1}\right.$ bar $\left.^{-1}\right)$.

A PVC plate was used as support frame for the membranes (Figure 2.1). The plate contained a milled space with a diameter of $0.142 \mathrm{~m}$ and a depth of $0.005 \mathrm{~m}$. The outer part of the circular membranes was glued in this space resulting in an effective membrane surface area of $0.014 \mathrm{~m}^{2}$. An aerator was placed beneath each membrane producing an air flow rate of $0.4 \mathrm{~m}^{3} \mathrm{~h}^{-1}$ per membrane at approximately $0.25 \mathrm{~m} \mathrm{~s}^{-1}$ superficial velocity across the membrane surface. 


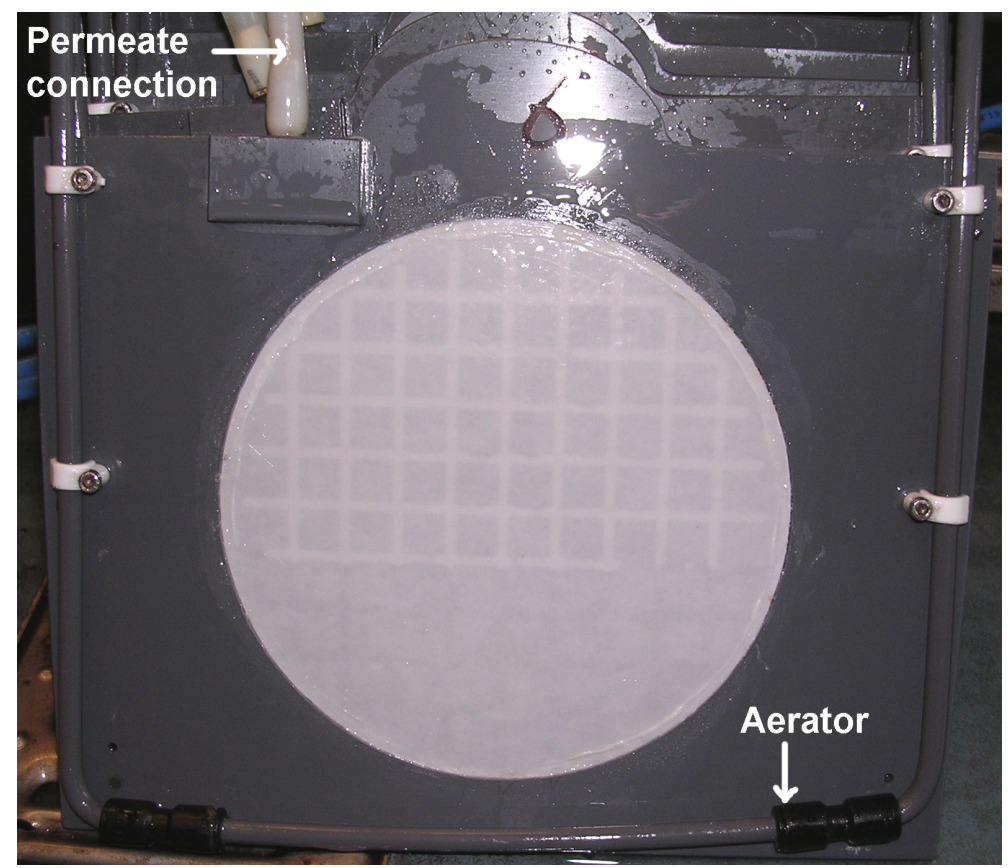

Figure 2.1 Plate and frame module for flat-sheet polymeric membranes.

\subsubsection{Experimental set-up}

Two flat-sheet membranes were placed vertically in a perspex reactor (Figure 2.2). Two peristaltic pumps extracted permeate from the activated sludge by suction. The underpressure was measured with pressure sensors (Endress and Hauser, Cerabar M). A PC with Labview (National Instruments) controlled the peristaltic pumps by automatically setting the flux according to the desired flux-step protocol. The permeate flow was measured at each flux-step to determine the flux. The temperature was measured with a temperature sensor submerged in the activated sludge mixture.

Activated sludge recirculation from an MBR pilot fed with municipal wastewater was applied [14]. The volume and hydraulic retention time (HRT) in the filtration reactor were controlled at $5 \mathrm{~L}$ and $1 \mathrm{~h}$, respectively. The MBR pilot (total volume $85 \mathrm{~L}$ ) was equipped with a nitrification and de-nitrification compartment, and a membrane tank equipped with flat-sheet PVDF membranes $\left(0.5 \mathrm{~m}^{2}, 0.1 \mu \mathrm{m}\right)$. The MBR operated at an average activated sludge concentration of $10 \mathrm{~g} \mathrm{~L}^{-1}$, an overall HRT of $10 \mathrm{~h}$, and a sludge retention time (SRT) of $25 \mathrm{~d}$. 


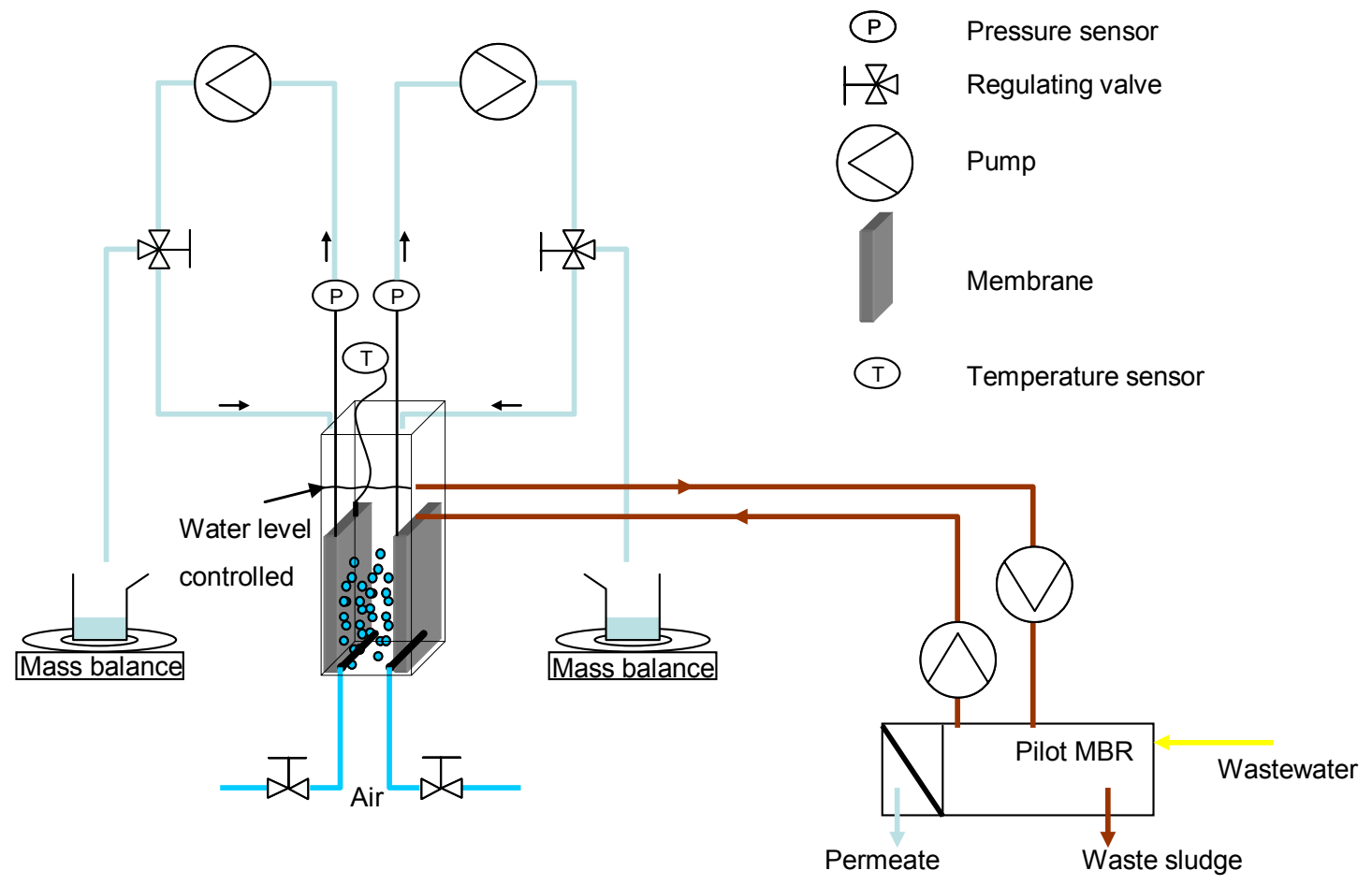

Figure 2.2 Experimental filtration set-up.

\subsubsection{Experimental procedure}

The improved flux-step method applies successive fluxes $\left(J_{H}\right)$ up to a maximum flux and back (Figure 2.3A) analogous to the common flux-step method shown in figure 1.3 in Chapter 1. Fouling occurs at flux F4 (no stable TMP) revealing that $J_{C}$ is situated between flux F3 and F4.

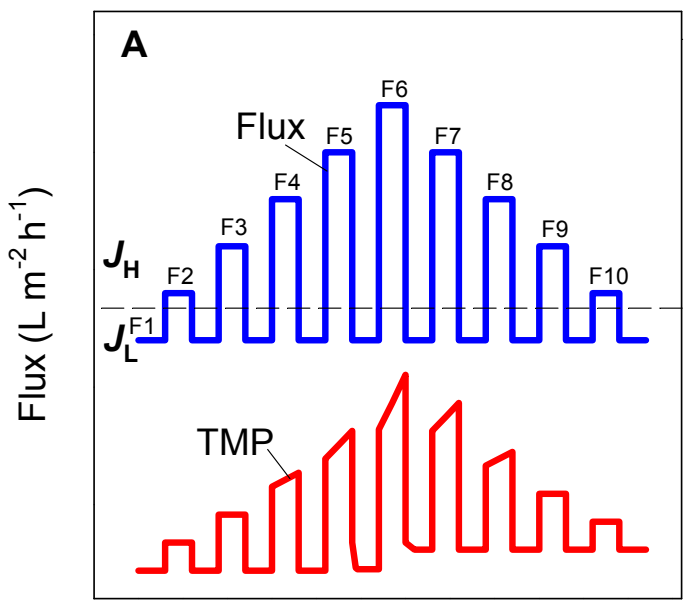

Time $(\mathrm{h})$

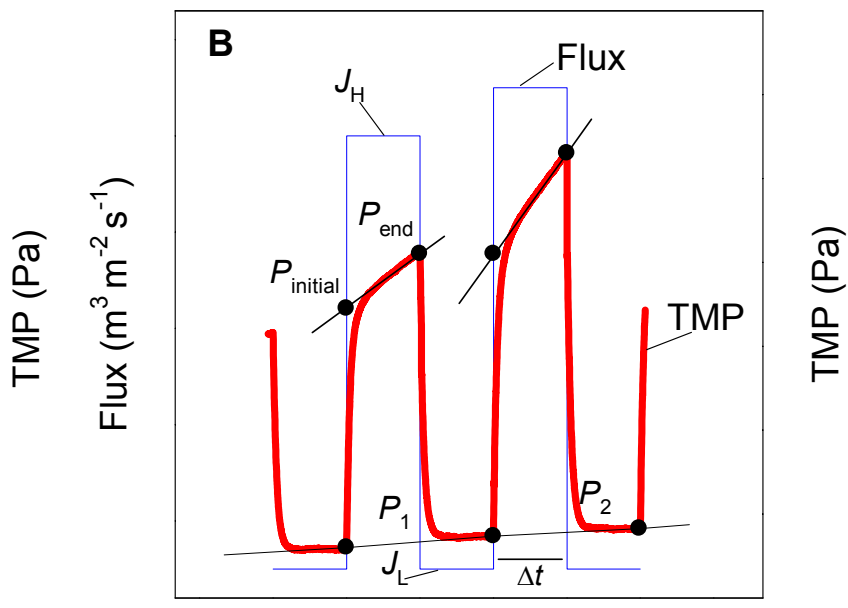

Time (h)

Figure 2.3 Example of a flux-TMP profile of the improved flux-step method (A) and a schematic representation of the improved flux-step protocol (B). 
An intermediate decrease in flux to a low reference flux $\left(J_{\mathrm{L}}\right)$ is applied after each $J_{H}$ in both the ascending and the descending phase. The flux-stepping in the improved flux-step method is therefore different from the common flux-step method. No fouling occurs at $J_{L}$, and filtration at this low flux is considered as a form of relaxation as shown in other studies $[4,11$, 15]. For real relaxation filtration should be ceased $\left(0 \mathrm{~L} \mathrm{~m}^{-2} \mathrm{~h}^{-1}\right)$. However, a flux larger than 0 $\mathrm{L} \mathrm{m}^{-2} \mathrm{~h}^{-1}$ must be applied in order to measure a value for TMP before and after a $J_{H}$. At the low flux the convective flow towards the membrane is reduced and due to air scouring the reversible fouling is removed. In Figure 2.3A no increase in TMP at $J_{L}$ occurs up till flux F6 implying that the fouling at fluxes F4 and F5 is reversible. Fouling becomes irreversible at flux F6 as the TMP at $J_{L}$ after flux F6 increased.

Figure 2.3B illustrates the flux-TMP profile in more detail for determination of $J_{C}$ and $J_{C \text { i }}$. The total fouling rate $\left(F_{\text {total }}\right)$ - including both reversible and irreversible fouling - was calculated by the change in TMP with time (dTMP/dt) at each $J_{H}$ (Equation 2.1). The same procedure was applied in the common flux-step method. The TMP values at $J_{\mathrm{L}}$ before and after $J_{\mathrm{H}}\left(P_{1}\right.$ and $P_{2}$, respectively) were used to calculate the irreversible fouling rate $\left(F_{\text {irr }}\right)$ by using Equation 2.2 .

Total fouling rate, $\quad F_{\text {total }}=\frac{\mathrm{d} R_{\text {total }}}{\mathrm{d} t}=\frac{P_{\text {end }}-P_{\text {initial }}}{\eta J_{\mathrm{H}}} \frac{1}{\Delta t}$

Irreversible fouling rate, $\quad F_{\text {irr }}=\frac{\mathrm{d} R \text { irreversible }}{\mathrm{d} t}=\frac{P_{2}-P_{1}}{\eta J_{\mathrm{L}}} \frac{1}{\Delta t}$

where $R$ is the hydraulic resistance $\left(\mathrm{m}^{-1}\right), P$ is the pressure $(\mathrm{Pa}), J$ is the flux $\left(\mathrm{m}^{3} \mathrm{~m}^{-2} \mathrm{~s}^{-1}\right)$, $\eta$ is the viscosity of the permeate which always was corrected for temperature (Pa.s), and $t$ is the flux-step duration (s).

An arbitrary minimum increase in the TMP of $10 \mathrm{~Pa} \mathrm{~min}^{-1}$ was used to determine $J_{C}$ in both flux-step methods. A critical fouling rate $\left(F_{\text {crit }}\right)$ was calculated for each flux by using this minimum increase in TMP in Equation 2.1. The critical fouling rate is an asymptote to zero with increasing flux, since a fixed TMP change with time was divided by an increasing flux. $J_{C}$ is reached once $F_{\text {total }}$ becomes equal to $F_{\text {crit. }} J_{C i}$ is reached once $F_{\text {irr }}$ becomes equal to $F_{\text {crit. }}$ As mentioned in the introduction $J_{C}$ is either equal or lower than $J_{\mathrm{Ci}}$. It is important to realize that $J_{\mathrm{Ci}}$ is distinguished on TMP differences of $150 \mathrm{~Pa}$ between low reference fluxes in the IFSM, and its value therefore is susceptible to experimental error. As a safe boundary, $J_{\mathrm{Ci}}$ was considered to be approximately equal to $J_{C}$ when their difference was less than $20 \%$.

Both the step-height and the step-length of $J_{H}$ influence the fouling behavior [5]. They were arbitrarily chosen at $5 \mathrm{~L} \mathrm{~m}^{-2} \mathrm{~h}^{-1}$ and $0.25 \mathrm{~h}$, respectively. The maximum flux for both flux-step methods was set at $100 \mathrm{~L} \mathrm{~m}^{-2} \mathrm{~h}^{-1}$, which was roughly four times larger than the flux used in 
practice for MBR. The size of the applicable $J_{L}$ is limited as no fouling must occur at this flux. The step-duration of $J_{L}$ is also limited as the TMP should be stabilized before $P_{2}$ is measured. Especially at very high TMP it may take several minutes before a stable TMP is reached. For these reasons $J_{L}$ was set at $5 \mathrm{~L} \mathrm{~m}^{-2} \mathrm{~h}^{-1}$ and the step-duration was set at $0.25 \mathrm{~h}$ in this study.

\subsection{Results}

\subsubsection{Comparison of the common and improved flux-step method}

The two flux-step methods run parallel by using one PVDF membrane in each flux-step method. By doing so, both methods were examined with identical activated sludge mixtures. Figure 2.4 shows the flux-TMP profile of the common (A) and improved (B) flux-step method. Note the difference in scale. The improved method lasted twice as long as the common method due to the intermediate low flux operation. For both methods initially the TMP only increased proportionally with the increase in flux. A slope change in TMP versus time occurred in both methods indicating the initiation of membrane fouling.
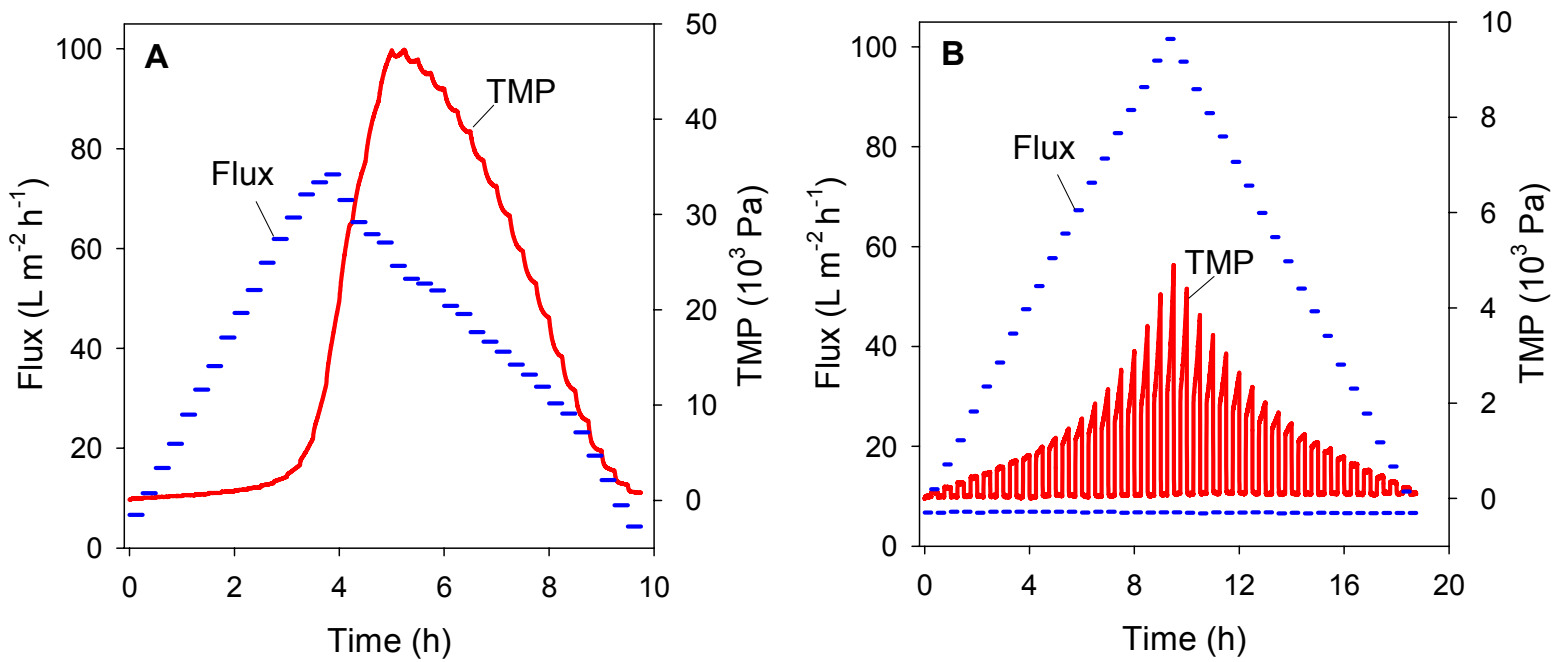

Figure 2.4 Flux-TMP profile of the common flux-step method $(\mathrm{A})$ and the improved flux-step method (B) up to a flux of $100 \mathrm{~L} \mathrm{~m}^{-2} \mathrm{~h}^{-1}$.

The slope increased very sharp in the common method caused by an increasing deposition rate and fouling history. A very high TMP was reached when a flux of $80 \mathrm{~L} \mathrm{~m}^{-2} \mathrm{~h}^{-1}$ was approached. Due to experimental limitations the peristaltic pump was unable to extract the requested amount of permeate through the membranes at these large TMPs. When the TMP 
decreased in the descending phase the requested amount of permeate could be extracted. The TMP appeared to rise initially further in the descending phase although the flux was lowered. Fouling became removable after roughly $5 \mathrm{~h}$ indicated by the decrease in TMP during the flux-steps in the descending phase.

The form of the flux-TMP curve was much different for the improved flux-step method attributed to the application of the intermediate low reference flux. The maximum flux of 100 $L \mathrm{~m}^{-2} \mathrm{~h}^{-1}$ could be reached. The slope of TMP versus time increased with increasing flux, but large TMP values were not obtained caused by the intermediate removal of fouling. The influence of fouling history was reduced also visible by the similarity of the TMP development in the descending phase compared to the ascending phase. A very small increase in TMP at $J_{L}$ was also visible. Finally, a small absolute TMP difference was observed between identical fluxes in the ascending and descending phase.

Figure 2.5 shows $F_{\text {total }}$ for the common flux-step method $(\mathrm{A})$ and $F_{\text {total }}$ and $F_{\text {irr }}$ for the improved flux-step method (B). $F_{\text {crit }}$ is indicated in both figures. In the ascending phase $(>)$ in $(A), F_{\text {total }}$ was negligible below a flux of $40 \mathrm{~L} \mathrm{~m}^{-2} \mathrm{~h}^{-1}$. $F_{\text {total }}$ gradually increased above this flux and crossed $F_{\text {crit }}$ at a flux of $57 \mathrm{~L} \mathrm{~m}^{-2} \mathrm{~h}^{-1}$ being $J_{\mathrm{C}}$. A sharp increase in $F_{\text {total }}$ was observed above $J_{C}$. The influence of fouling history can be observed by comparing the fouling rates at identical fluxes in the ascending phase to that in the descending phase. $F_{\text {total }}$ was initially larger at identical fluxes in the descending phase $(<)$ revealing significant hysteresis and a large influence of fouling history. By decreasing the flux further, a negative fouling rate was observed as the removal of fouling became larger than its supply. The negative fouling rate hampered accurate analysis of fouling rate hysteresis.
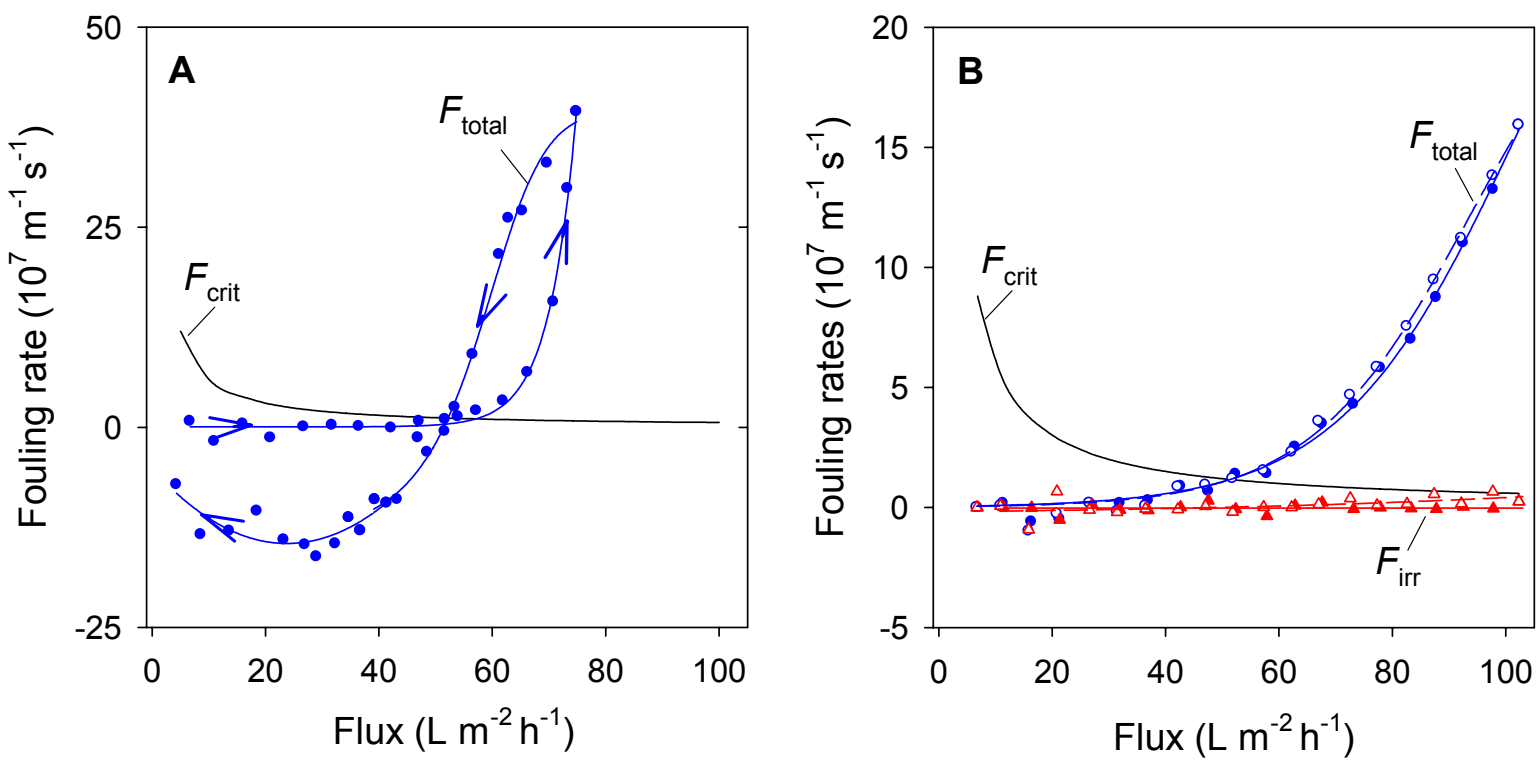

Figure 2.5 The total fouling rate of the common flux-step method $(A)$ and the total fouling rate and irreversible fouling rate of the improved flux-step method (B) both with the arbitrary critical fouling rate. 
The total amount of irreversible fouling after a complete flux-step run can be quantified by the TMP difference between the first and the last flux-step. The fouling rate remained negative up to and including the last flux-step. The total amount of irreversible fouling therefore could not accurately be defined, but based on the first and last TMP data at $5 \mathrm{~L} \mathrm{~m}^{-2} \mathrm{~h}^{-1}$, an increase in resistance of $60 \times 10^{10} \mathrm{~m}^{-1}$ was calculated. This amounts to ten times the clean membrane resistance. Most likely, the large TMP (maximum $47 \times 10^{3} \mathrm{~Pa}$ ) at the highest fluxes resulted in a more cohesive fouling which could not be removed completely when the flux was decreased to the starting flux.

In Figure 2.5B fouling rates in the descending phase have open symbols and are connected by a dashed line for clarity. $J_{C}$ was $51 \mathrm{~L} \mathrm{~m}^{-2} \mathrm{~h}^{-1} . F_{\text {total }}$ at fluxes above $J_{C}$ was much lower than in (A). Apparently, the intermediate relaxation removed the reversible fouling, reduced fouling history, and thereby decreased $F_{\text {total }}$ compared to the common flux-step method. The much lower effect of fouling history was also demonstrated by comparing the total fouling rate at identical fluxes in the ascending phase and the descending phase. These two fouling rates almost completely overlapped each other revealing a very small hysteresis.

$F_{\text {irr }}$ was very low and did not cross $F_{\text {crit }}$ up to the maximum flux of $100 \mathrm{~L} \mathrm{~m}^{-2} \mathrm{~h}^{-1}$. $J_{\mathrm{Ci}}$ was therefore larger than $100 \mathrm{~L} \mathrm{~m}^{-2} \mathrm{~h}^{-1}$ under the applied relaxation conditions. However, irreversible fouling did occur. The total amount of irreversible fouling after a complete fluxstep run was $1.7 \times 10^{10} \mathrm{~m}^{-1}$. This much lower amount of irreversible fouling compared to the amount of irreversible fouling in the common flux-step method was attributed to the intermediate removal of fouling. The very small amount of irreversible fouling may be caused by the adsorption of macro molecules [16, 17], pore blocking, and/or gel formation. These mechanisms cannot be removed by relaxation. The small hysteresis visible in the total fouling rate may have been caused by the irreversible fouling.

The two flux-step methods were repeated four times. The membranes were switched in the second experiment to exclude the influence of possible differences in membrane properties and aeration conditions. Both the first as well as the second experiment were repeated to check the reproducibility. The four experiments did not show much variation in the results, showing that the membranes were comparable and the results were reproducible. The average $J_{C}$ based on the four experiments for the common flux-step method equaled $56 \pm 2 \mathrm{~L} \mathrm{~m}^{-2} \mathrm{~h}^{-1}$. The average total amount of irreversible fouling during the four runs for the common flux-step method was $59 \pm 3 \times 10^{10} \mathrm{~m}^{-1}$. The average $J_{\mathrm{C}}$ for the improved flux-step method was $52 \pm 3 \mathrm{~L} \mathrm{~m}^{-2} \mathrm{~h}^{-1}$. The average total amount of irreversible fouling for the improved flux-step method $\left(1.9 \pm 0.5 \times 10^{10} \mathrm{~m}^{-1}\right)$ remained always lower than for the common flux-step method. In all four experiments $J_{\mathrm{Ci}}$ was larger than the maximum flux of $100 \mathrm{~L} \mathrm{~m}^{-2} \mathrm{~h}^{-1}$ showing that the fouling was mainly reversible. The maximum flux should be increased for a more accurate measurement of $J_{\mathrm{Ci}}$. 


\subsubsection{Fouling development during consecutive filtration runs with the improved flux-step method}

$J_{C}$ measured in one run by a flux-step method does not always comply with the behaviour of the filterability on the long term. Often fouling occurs far below $J_{C}[3,17,18]$ which was explained by solute-membrane interaction causing irreversible fouling via the adsorption of macromolecules [16]. Wu et al. [19] applied filtration below $J_{C}$ for 13 days, and a periodic measurement of $J_{C}$ during this period showed a decrease of $J_{C}$. Variation of $J_{C}$ due to irreversible fouling during consecutive flux-step runs might be an indication for the stability of $J_{C}$ value on the long term. The improved flux-step method therefore was performed ten times after each other. The influence of irreversible fouling on both $J_{C}$ and $J_{\mathrm{Ci}}$ was determined in the ascending phase. The descending phase of the flux-step method therefore was not necessary. The maximum flux, flux-step duration, and flux-step height were similar as in Section 2.3.1. In between two consecutive runs, no filtration was applied for $5 \mathrm{~h}$ while air scouring was maintained. The entire experiment lasted for $150 \mathrm{~h}$, resembling a long filtration run at a net flux of $19 \mathrm{~L} \mathrm{~m}^{-2} \mathrm{~h}^{-1}$ (all fluxes summed including relaxation and the down-time divided by the total filtration time). The results of each run are shown in Figure 2.6.

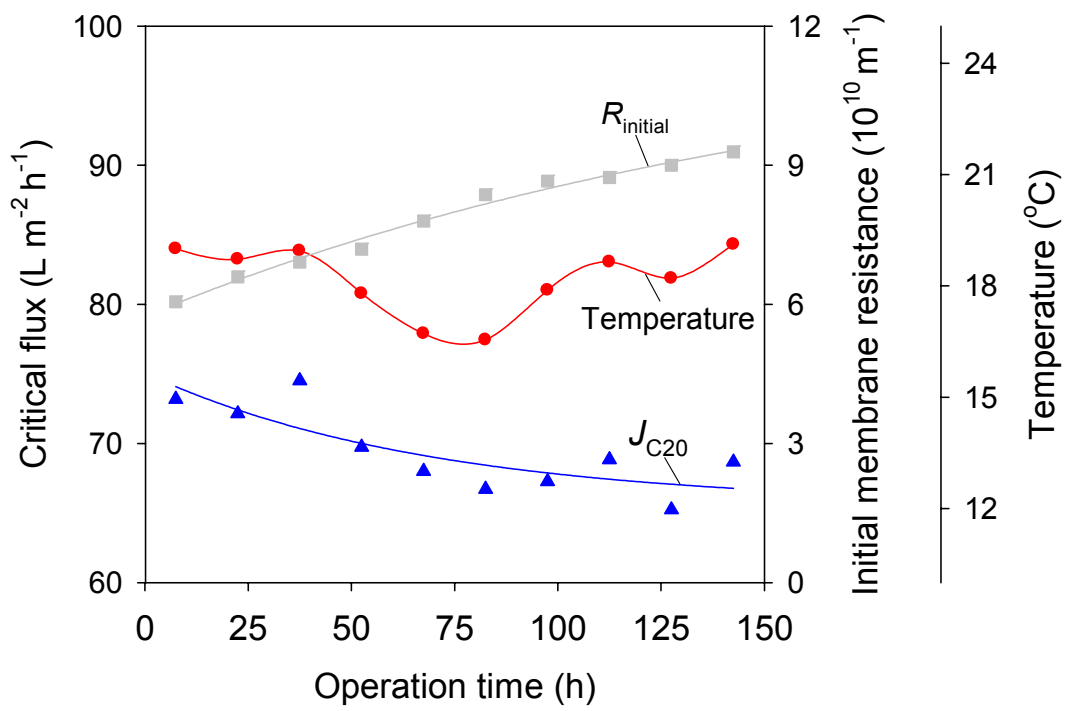

Figure 2.6 The average temperature, the critical flux corrected for temperature $\left(J_{C 20}\right)$, and the initial filtration resistance of ten consecutive runs of the improved flux-step method.

The initial resistance $\left(R_{\text {initial }}\right)$ was measured at the first six flux-steps of each run in activated sludge. In this flux region there is still a linear relationship between the applied flux and obtained pressure (no fouling), resulting in the same value for the resistance at each fluxstep. A small increase in initial resistance was visible after each separate run caused by irreversible fouling. The increase in initial resistance slowed down with increasing operation 
time or run number revealing a non-linear relation. This indicated that increasingly less irreversible fouling was built up during successive filtration runs. $F_{\text {irr }}$ however, did not cross $F_{\text {crit }}$ in all ten runs and $J_{\mathrm{Ci}}$ always was larger than $100 \mathrm{~L} \mathrm{~m}^{-2} \mathrm{~h}^{-1}$.

$F_{\text {total }}$ (Equation 2.1) is inversely proportional to the permeate viscosity; for that reason the permeate viscosity has been corrected for temperature differences. Despite this correction, $J_{C}$ was significantly lower at a lower temperature $\left(10 \mathrm{~L} \mathrm{~m}^{-2} \mathrm{~h}^{-1}\right.$ when the temperature was $2.5{ }^{\circ} \mathrm{C}$ lower). Several reasons explaining a lower $J_{C}$ at a lower temperature have been suggested [20,21]. The viscosity of the sludge increases at a lower temperature reducing the shear stress created by the air bubbles. Secondly, the diffusion of material away from the membrane decreases at a lower temperature since Brownian diffusion decreases linearly with decreasing temperature. Both mechanisms slow down the back transport of material from the membrane, and this result in a lower $J_{C}$. Fan et al. [21] corrected $J_{C}$ itself for a change in temperature using the empirical relation (Equation 2.3):

Temperature corrected critical flux, $\quad J_{\mathrm{c}}=J_{\mathrm{c} 20} \times 1.025^{(T-20)}$

where $J_{\mathrm{C} 20}$ is the corrected critical flux for a temperature of $20{ }^{\circ} \mathrm{C}\left(\mathrm{L} \mathrm{m}^{-2} \mathrm{~h}^{-1}\right)$, and $T$ is the temperature of the activated sludge mixture $\left({ }^{\circ} \mathrm{C}\right)$. The critical flux shown in Figure 2.6 has been corrected according to this relation. By doing so, the influence of temperature was ruled out as far as possible.

Clearly, $J_{\mathrm{C} 20}$ decreased with increasing run number. The only difference of a run with respect to its previous one is the fouling history, caused by irreversible fouling. Although the amount of irreversible fouling is very low, $J_{\mathrm{C} 20}$ decreased from 73 to $69 \mathrm{~L} \mathrm{~m}^{-2} \mathrm{~h}^{-1}$ during the ten consecutive runs. It was assumed that the irreversible fouling by pore blocking, adsorption, and/or irreversible gel formation reduced the open, accessible surface area of the membrane. As a consequence, the local flow towards the open area - i.e. the local flux [18] increased with each run. An increase in local flux increased $F_{\text {total }}$ and thereby decreased $J_{\mathrm{C} 20}$ with increasing run number. Wu et al. [19] also showed a decreasing critical flux as a consequence of fouling history, though they reported a linear correlation. In this study $J_{\mathrm{C} 20}$ and the initial resistance revealed an opposite development.

\subsection{Discussion}

The experiments described in the previous sections focused on the comparison of a common flux-step method with an improved flux-step method including relaxation steps, using activated sludge of an MBR fed with municipal wastewater. $J_{C}$ determined with the improved 
flux-step method was marginally lower than $J_{C}$ determined with the common flux-step method (52 and $56 \mathrm{~L} \mathrm{~m}^{-2} \mathrm{~h}^{-1}$, respectively). At higher fluxes, increasing the flux from $J_{\mathrm{L}}$ to $J_{\mathrm{H}}$ (e.g. from 5 to $50 \mathrm{~L} \mathrm{~m}^{-2} \mathrm{~h}^{-1}$ ) causes the fouling to be imbalanced more than during the more gradual increase in flux with steps of only $5 \mathrm{~L} \mathrm{~m}^{-2} \mathrm{~h}^{-1}$ in the common method. The latter method allows for a more ordered concentration polarization at fluxes below $J_{C}[5,11,19]$. The net result is the small variation in $J_{C}$ between the common and improved flux-step method, which becomes more apparent in case $J_{C}$ is larger. Despite the marginally lower $J_{C}$, a much lower total fouling rate was found above $J_{C}$ with the improved flux-step method. This was explained by the removal of reversible fouling during the intermediate relaxation at a low reference flux of $5 \mathrm{~L} \mathrm{~m}^{-2} \mathrm{~h}^{-1}$, which was not the case in the common flux-step method. In addition, almost no hysteresis was found between the fouling rates at equal fluxes in the ascending and the descending phase of the improved flux-step method. Finally, a much lower total amount of irreversible fouling was measured in the improved flux-step method compared to the common flux-step method. The improved flux-step method therefore is very suitable for the examination of fouling rates at fluxes above $J_{C}$, and to determine the reversible character of fouling. The often used common flux-step method is less suited for such fouling characterization.

$J_{\mathrm{Ci}}$ was always found to be larger than the maximum applied flux of $100 \mathrm{~L} \mathrm{~m}^{-2} \mathrm{~h}^{-1}$. The large difference ( $>50 \mathrm{~L} \mathrm{~m}^{-2} \mathrm{~h}^{-1}$ ) between $J_{\mathrm{C}}$ and $J_{\mathrm{Ci}}$ indicated that fouling was pre-dominantly reversible during the relaxation at a low reference flux. This indicated that cake formation was the dominant fouling mechanism.

$J_{C}$ measured with the improved flux-step method was higher in the experiment described in Section 2.3.2 compared to that in Section 2.3.1 (72 and $52 \mathrm{~L} \mathrm{~m}^{-2} \mathrm{~h}^{-1}$, respectively). In the time period between the two experiments the SRT of the MBR pilot was increased from 25 to 50 days. The longer SRT increased the filterability of the activated sludge which was also observed by Fan et al. [21] who attributed it to a decrease in colloidal substances (between 0.01-1 $\mu \mathrm{m}$ ).

When intermittent relaxation was applied, the results from this study show that a flux somewhere between $J_{C}$ and a flux of $100 \mathrm{~L} \mathrm{~m}^{-2} \mathrm{~h}^{-1}$ can be applied for long-term filtration with a PVDF membrane. The net flux obtained in this way is larger than now being applied in practice for flat-sheet submerged membrane bioreactors. The ten consecutive runs of the improved flux-step method did show a gradual increase in irreversible fouling. This fouling however, resulted only in a drop of $4 \mathrm{~L} \mathrm{~m}^{-2} \mathrm{~h}^{-1}$ in $J_{C}$ after $150 \mathrm{~h}$ of filtration at a net flux of $20 \mathrm{~L} \mathrm{~m}^{-2} \mathrm{~h}^{-1}$. The fouling almost completely remained reversible. The small decrease in $J_{C}$ and the low amount of irreversible fouling showed that a flux far above $J_{C}$ up to $100 \mathrm{~L} \mathrm{~m}^{-2} \mathrm{~h}^{-1}$ was applicable when intermittent relaxation at a low reference flux was used. Optimization practices may elucidate a shorter relaxation time than $0.25 \mathrm{~h}$. 


\subsection{Conclusions}

Both the common flux-step method as well as the new improved flux-step method that was proposed in this study can be used to determine the critical flux. A marginally lower critical flux was measured with the improved flux-step method.

In contrast with the common flux-step method, both reversible and irreversible fouling can be determined with the improved flux-step method. Based on an arbitrary critical fouling rate of $10 \mathrm{~Pa} \mathrm{~min}{ }^{-1}$, the critical flux for home made flat-sheet PVDF membranes with a pore size of $0.1 \mu \mathrm{m}$ was $52 \pm 3 \mathrm{~L} \mathrm{~m}^{-2} \mathrm{~h}^{-1}$, while the critical flux for irreversibility exceeded $100 \mathrm{~L} \mathrm{~m}^{-2} \mathrm{~h}^{-1}$.

The improved flux-step method has distinct advantages over the common flux-step method. Fouling history caused by reversible fouling is minimized, and fouling irreversibility can be estimated at each flux-step. The common flux-step method lacks these advantages.

\subsection{Acknowledgements}

This work was performed in the TTIW-cooperation framework of Wetsus, Centre of Excellence for Sustainable Water Technology (www.wetsus.nl). Wetsus is funded by the Dutch Ministry of Economic Affairs, the European Union Regional Development Fund, the Province of Fryslân, the City of Leeuwarden and the EZ/Kompas program of the 'Samenwerkingsverband Noord-Nederland". The authors like to thank the participants of the research theme 'Membrane Bioreactors' for the discussions and their financial support. 


\subsection{Used symbols and abbreviations}

\begin{tabular}{|c|c|c|}
\hline \multicolumn{2}{|c|}{ Symbol } & \multirow{2}{*}{$\frac{\text { Unit }}{\mathrm{m}^{-1} \mathrm{~s}^{-1}}$} \\
\hline$\overline{F_{\text {crit }}}$ & Critical fouling rate & \\
\hline$F_{\text {irr }}$ & Irreversible fouling rate & $m^{-1} s^{-1}$ \\
\hline$F_{\text {total }}$ & Total fouling rate & $\mathrm{m}^{-1} \mathrm{~s}^{-1}$ \\
\hline HRT & Hydraulic retention time & $\mathrm{h}$ \\
\hline$J_{C}$ & Critical flux & $\mathrm{L} \mathrm{m}^{-2} \mathrm{~h}^{-1}$ \\
\hline$J_{\mathrm{C} 20}$ & Temperature corrected critical flux & $\mathrm{L} \mathrm{m}^{-2} \mathrm{~h}^{-1}$ \\
\hline$J_{\mathrm{Ci}}$ & Critical flux for irreversibility & $\mathrm{L} \mathrm{m}^{-2} \mathrm{~h}^{-1}$ \\
\hline$J_{\mathrm{H}}$ & Larger flux in the improved flux-step method & $\mathrm{L} \mathrm{m}^{-2} \mathrm{~h}^{-1}$ \\
\hline$J_{\mathrm{L}}$ & Low reference flux used for relaxation & $\mathrm{L} \mathrm{m}^{-2} \mathrm{~h}^{-1}$ \\
\hline MBR & Membrane bioreactor & \\
\hline K & Permeability & $\mathrm{L} \mathrm{m}^{-2} \mathrm{~h}^{-1} \mathrm{Bar}^{-1}$ \\
\hline$K_{0}$ & Clean water permeability & $\mathrm{L} \mathrm{m}^{-2} \mathrm{~h}^{-1} \mathrm{Bar}^{-1}$ \\
\hline$P_{\text {end }}$ & End pressure of a flux-step $J_{H}$ & $\mathrm{~Pa}$ \\
\hline$P_{\text {initial }}$ & Initial pressure of a flux-step $J_{\mathrm{H}}$ & $\mathrm{Pa}$ \\
\hline PVC & Polyvinylchloride & \\
\hline PVDF & Polyvinylidenedifluoride & \\
\hline$R$ & Hydraulic resistance & $m^{-1}$ \\
\hline$R_{\text {initial }}$ & Initial resistance of a flux-step run & $m^{-1}$ \\
\hline SEM & Scanning electron microscope & \\
\hline SRT & Solid retention time & $\mathrm{h}$ \\
\hline$T$ & Temperature & ${ }^{\circ} \mathrm{C}$ \\
\hline TMP & Transmembrane pressure & $\mathrm{Pa}$ \\
\hline$\eta$ & Permeate viscosity, in this research corrected for $\mathrm{T}$ of $20^{\circ} \mathrm{C}$ & Pas \\
\hline
\end{tabular}

\subsection{References}

1. Cicek, N., et al., Effectiveness of the membrane bioreactor in the biodegradation of high molecular weight compounds. Water Research, 1998. 32: p. 1553-1563.

2. Judd, S.J., The MBR Book: Principles and Applications of Membrane Bioreactors in Water and Wastewater Treatment. 1st ed. 2006, Oxford: Elsevier.

3. Howell, J.A., Subcritical flux operation of microfiltration. Journal of Membrane Science, 1995. 107: p. 165-171.

4. Defrance, L. and M.Y. Jaffrin, Reversibility of fouling formed in activated sludge filtration. Journal of Membrane Science, 1999. 157: p. 73-84.

5. Le Clech, P., et al., Critical flux determination by the flux-step method in a submerged membrane bioreactor. Journal of Membrane Science, 2003. 227: p. 81-93.

6. Bacchin, P., P. Aimar, and R.W. Field, Critical and sustainable fluxes: Theory, experiments and applications. Journal of Membrane Science, 2006. 281: p. 42. 
7. Mulder, M., Basic principles of membrane technology. 2nd ed. 2003, Dordrecht: Kluwer Academic Publishers.

8. Espinasse, B., P. Bacchin, and P. Aimar, On an experimental method to measure critical flux in ultrafiltration. Desalination, 2002. 146: p. 91-96.

9. Metsamuuronen, S., J. Howell, and M. Nystrom, Critical flux in ultrafiltration of myoglobin and baker's yeast. Journal of Membrane Science, 2002. 196: p. 13-25.

10. Defrance, L. and M.Y. Jaffrin, Comparison between filtrations at fixed transmembrane pressure and fixed permeate flux: application to a membrane bioreactor used for wastewater treatment. Journal of Membrane Science, 1999. 152: p. 203-210.

11. Chen, V., et al., Particle deposition during membrane filtration of colloids: transition between concentration polarization and cake formation. Journal of Membrane Science, 1997. 125: p. 109-122.

12. Benkahla, Y.K., et al., Cake growth-mechanism in cross-flow microfiltration of mineral suspensions. Journal of Membrane Science, 1995. 98: p. 107-117.

13. Wang, Z., et al., Membrane fouling in a submerged membrane bioreactor (MBR) under sub-critical flux operation: Membrane foulant and gel layer characterization. Journal of Membrane Science, 2008. 325: p. 238-244.

14. Remy, M., et al., Low dose powdered activated carbon addition at high sludge retention times to reduce fouling in membrane bioreactors. Water Research, 2009. 43: p. 345-350.

15. Ould-Dris, A., et al., Analysis of cake build-up and removal in cross-flow microfiltration of $\mathrm{CaCO} 3$ suspensions under varying conditions. Journal of Membrane Science, 2000. 175: p. 267-283.

16. Cho, B.D. and A.G. Fane, Fouling transients in nominally sub-critical flux operation of a membrane bioreactor. Journal of Membrane Science, 2002. 209: p. 391-403.

17. Guglielmi, G., et al., Flux criticality and sustainability in a hollow fibre submerged membrane bioreactor for municipal wastewater treatment. Journal of Membrane Science, 2007. 289: p. 241-248.

18. Ognier, S., C. Wisniewski, and A. Grasmick, Membrane bioreactor fouling in subcritical filtration conditions: a local critical flux concept. Journal of Membrane Science, 2004. 229: p. 171-177.

19. Wu, Z., et al., Effects of various factors on critical flux in submerged membrane bioreactors for municipal wastewater treatment. Separation and Purification technology, 2008. 62: p. 56-63.

20. Le-Clech, P., V. Chen, and T.A.G. Fane, Fouling in membrane bioreactors used in wastewater treatment. Journal of Membrane Science, 2006. 284: p. 17-53.

21. Fan, F., H. Zhou, and H. Husain, Identification of wastewater sludge characteristics to predict critical flux for membrane bioreactor processes. Water Research, 2006. 40: p. 205-212. 


\section{Chapter 3}

Influence of membrane properties on membrane fouling in submerged membrane bioreactors

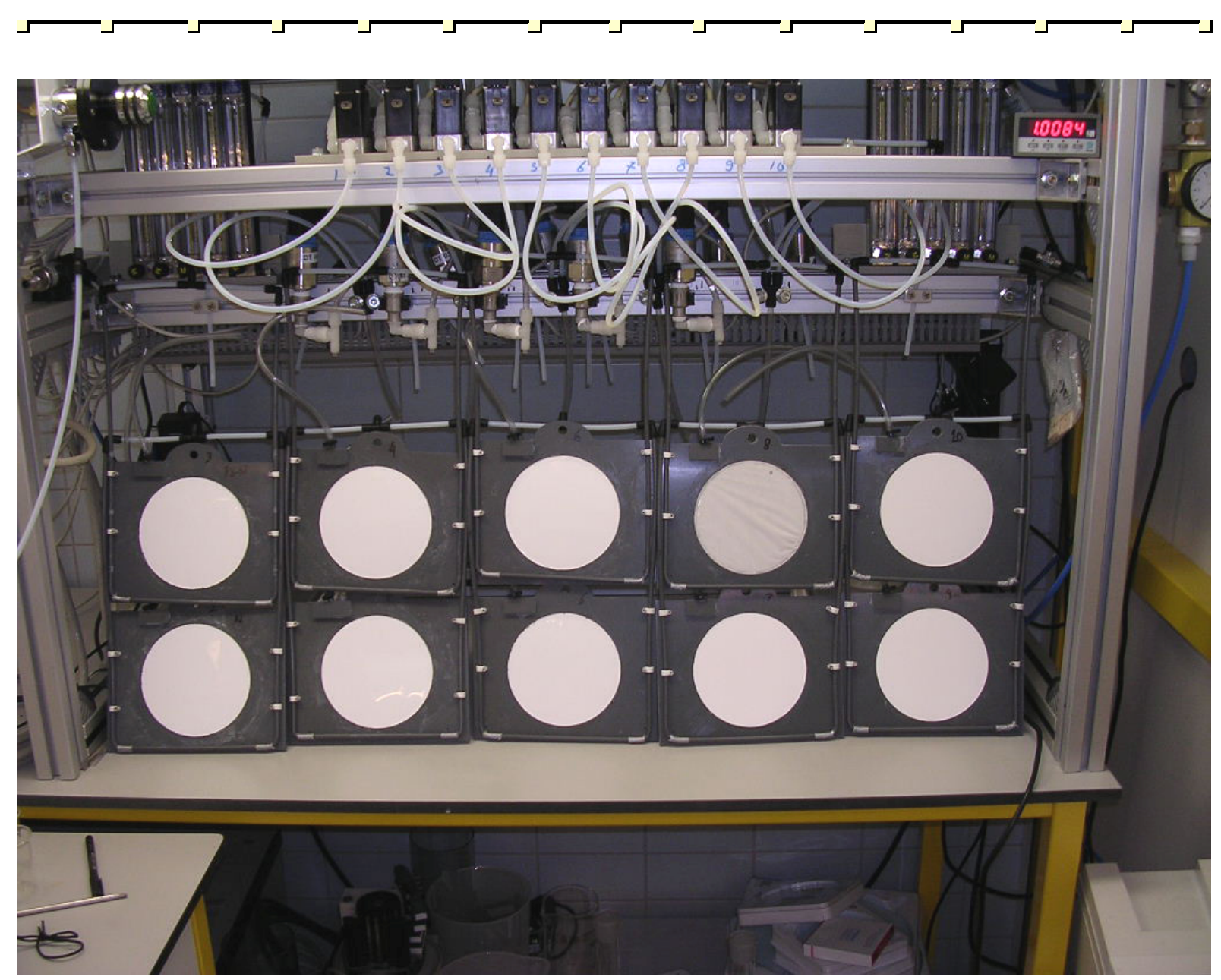




\section{Abstract}

Polymeric flat-sheet membranes with different properties are used in filtration experiments with activated sludge from a pilot-scale MBR to investigate the influence of membrane pore size, surface porosity, pore morphology, and hydrophobicity on membrane fouling. An improved flux-step method is used to measure both the critical flux and critical flux for irreversibility. Long-term experiments are performed to evaluate if influences of membrane properties on short-term can be translated to long-term fouling behavior.

The results show that a hydrophilic asymmetric membrane with an interconnected pore structure, a nominal pore size of $0.3 \mu \mathrm{m}$, and large surface porosity of $27 \%$, provides the best membrane performance with respect to critical flux and critical flux for irreversibility. The dominant fouling mechanism in long-term filtration experiments is gel layer formation, which for this membrane is the least severe, and therefore extends the sustainable filtration time.

This Chapter is submitted for publication as: van der Marel, P., Zwijnenburg, A., Kemperman, A.J.B., Wessling, M., Temmink, H., van der Meer, W.G.J. Influence of membrane properties on fouling in submerged membrane bioreactors. Journal of Membrane Science, 2009. 


\subsection{Introduction}

Membrane fouling of flat-sheet membranes in a submerged membrane bioreactor is caused by accumulation of feed water constituents on the surface of the membrane (cake and/or gel formation) or in the membrane matrix (pore blocking and/or adsorption). The nature and extent of the fouling is influenced by membrane properties [1], operational conditions (like aeration or the applied filtration protocol), and feed properties. The performance of different membranes in a submerged MBR can be examined using the critical flux $\left(J_{C}\right)$ concept [2], most commonly measured by flux-step methods [3-6]. Previous work on $J_{C}$-studies investigated the effect of membrane pore size and/or hydrophobicity. At the same time other membrane properties such as surface porosity, membrane material and pore morphology were varied (e.g. [7, 8]). This makes a correlation with membrane fouling extremely difficult [9] and may have contributed to inconclusive results. For example, in different studies a larger pore size was shown to have no effect, a positive effect, or a negative effect on $J_{C}$ $[6,10-13]$. Clearly, the influence of membrane pore size on $J_{C}$ should be investigated in close relation to membrane surface porosity and pore morphology. In general membranes with larger pores also have larger surface porosities, resulting in a lower local flux [14, 15] and lower transmembrane pressures (TMP), whereas pore morphology (pore structure and interconnectivity) affects the amount of internal fouling [16-18].

Intermediate physical cleaning (relaxation or backwashing) can help to remove some of the foulants, and in this manner restore the filtration resistance [11]. This type of fouling is called reversible fouling. Applying physical cleaning in flux-step methods therefore enables to discriminate between reversible and irreversible fouling. In addition, a critical flux for irreversibility $\left(J_{\mathrm{Ci}}\right)$ can be defined; i.e. the flux above which irreversible fouling occurs $[4,19]$. This $J_{\mathrm{Ci}}$ equals $J_{\mathrm{C}}$ if all fouling is irreversible, while it exceeds $J_{C}$ if fouling is (partially) reversible. The cleaning method that is applied should always be part of the definition of $J_{\mathrm{C} i}$. Cake layers generally can be removed by both relaxation and backwashing. On the other hand, internal fouling caused by pore blocking and adsorption, is hardly removed by these physical cleaning methods, and neither are gel layers (being more adhesive than a cake layer [20]) and compressed cake layers [21-23].

This Chapter aimed at elucidating the influence of several membrane properties on membrane fouling. The influence of the pore size on $J_{C}$ and $J_{C i}$ were determined, taking into account differences in membrane material, hydrophobicity, surface porosity, and pore morphology. Long-term experiments were performed to evaluate if influences of membrane properties on short-term could be extrapolated to long-term fouling behavior. 


\subsection{Material and methods}

\subsubsection{Membranes}

To obtain membranes with different pore sizes, surface porosities, and pore morphologies four different polymeric membrane materials were selected from commercially available hydrophilic flat-sheet membranes (Table 3.1). Mixed cellulose ester (MCE) and polycarbonate $(P C)$ membranes with four different pore sizes were obtained from filter discs $(\varnothing 0.142 \mathrm{~m}$ ) supplied by Millipore. Polyvinylidenedifluoride (PVDF) membranes from Toray were obtained from flat-sheets previously used in a MBR, and hydrophilised chlorinated polyethylene (PE) membranes from Kubota were obtained from commercially available A4 modules. Additionally, hydrophilic PVDF membranes with four different pore sizes were home made using a diffusion induced phase inversion method by casting a PVDF dope solution on a polyester non-woven material and immersing it in a nonsolvent bath. By heat treatment one of the hydrophilic PVDF membranes was made hydrophobic afterwards, without changing the other membrane properties.

\subsubsection{Experimental set-up}

A lab-scale filtration set-up was used similar to the one described in detail in Chapter 2 and in reference [4]. Five reactors were used in parallel, and each reactor contained two vertically flat-sheet plates (see Figure 2.1 in Chapter 2). An aerator was placed below all membranes, providing a $0.4 \mathrm{~m}^{3} \mathrm{~h}^{-1}$ air flow at approximately $0.25 \mathrm{~m} \mathrm{~s}^{-1}$ superficial velocity across the membrane surface. Activated sludge circulated over the filtration set-up provided by a pilotscale MBR of $85 \mathrm{~L}$ running at $50 \mathrm{~d}$ SRT, which was fed with municipal wastewater [24]. The reactor volume and the hydraulic retention time in the filtration set-up were kept constant at $5 \mathrm{~L}$ and $1 \mathrm{~h}$, respectively.

Permeate was extracted and recycled to the filtration set-up. Labview software (National Instruments) was used to control the experiments and to store data. The hydraulic resistance was calculated by Darcy's law (Equation 1.1, see Section 1.4.4 in Chapter 1). The TMP was calculated from absolute pressures measured with pressure sensors (Endress and Hauser, Cerabar M). The permeate flow was measured periodically to check the imposed flux. A temperature sensor measured the temperature of the activated sludge mixture, to allow correction of the dynamic viscosity of the permeate $(\eta)$ for temperature (Equation 1.2, see Section 1.4.4 in Chapter 1). 


\subsubsection{Experimental procedure}

\section{Membrane characterization}

The nominal pore sizes of the membranes were obtained in three different ways: from supplier's specifications, by Scanning Electron Microscopy (SEM, JEOL-6480LV), and by bubble point analysis. SEM pictures of the membrane surface were analyzed with image processing software to determine the nominal pore size and the surface porosity (ImageJ, NiH). SEM pictures of membrane cross-sections were analyzed visually to obtain pore morphology and membrane thickness. Bubble point analysis was performed by a Coulter porometer II (wetting fluid, trade name 'Porofil'). Hydrophobicity of the membranes was measured by a contact angle measurement with a CAM-200 (KSV). The contact angle of a droplet of Milli-Q ultrapure water $(3 \mu \mathrm{L})$ after $30 \mathrm{~s}$ was reported.

\section{Improved flux-step method}

For each membrane three experiments were carried out, each consisting of ten consecutive runs of an improved flux-step method (IFSM, see Chapter 2 and in reference [4]), to determine an average $J_{C}$ and $J_{C \text { i }}$. Each run in the IFSM consisted of incrementing flux-steps of $5 \mathrm{~L} \mathrm{~m}^{-2} \mathrm{~h}^{-1}$ from 5 to $100 \mathrm{~L} \mathrm{~m}^{-2} \mathrm{~h}^{-1}$ in steps, with an intermediate relaxation step at a low reference flux of $5 \mathrm{~L} \mathrm{~m}^{-2} \mathrm{~h}^{-1}$. Five $\mathrm{h}$ of relaxation were applied in between each distinct consecutive run, resulting in $15 \mathrm{~h}$ total time per run $(10 \mathrm{~h}$ for the IFSM run and $5 \mathrm{~h}$ for the relaxation period). The initial filtration resistance $\left(R_{\text {initial }}\right)$ was determined in each consecutive filtration run as the average for the first six flux-steps (i.e. below $J_{C}$ ). This value for the first run equaled the clean membrane resistance, and an increase with consecutive runs gave an indication for the occurrence of irreversible fouling.

\section{Long-term experiments}

Long-term experiments were performed at a fixed flux with or without intermediate relaxation. In the case of relaxation, two filtration protocols were applied to obtain two different net fluxes; i.e. the instantaneous flux corrected for the lack of permeate production during the intermediate relaxation. Filtration for 8 minutes at a flux of $32 \mathrm{~L} \mathrm{~m}^{-2} \mathrm{~h}^{-1}$ followed by 2 minutes relaxation resulted in a net flux of $25 \mathrm{~L} \mathrm{~m}^{-2} \mathrm{~h}^{-1}$, arbitrarily chosen as being a standard operating flux for full scale submerged flat-sheet MBRs. Furthermore filtration for 15 minutes at a flux of $100 \mathrm{~L} \mathrm{~m}^{-2} \mathrm{~h}^{-1}$ followed by 15 minutes relaxation resulted in a net flux of $50 \mathrm{~L} \mathrm{~m}^{-2} \mathrm{~h}^{-1}$. The end-resistance is given just before applying relaxation. An increase in end-resistance indicates the occurrence of irreversible fouling. 


\subsubsection{Membrane cleaning}

The membranes were physically and chemically cleaned only after experiments were finished. First, the flat-sheet membranes were removed from the membrane tank. Physical cleaning was applied with a water jet running at $0.5 \mathrm{~L} \mathrm{~min}^{-1}$ at $5 \times 10^{4} \mathrm{~Pa}$ (called a forward flush, FF), removing all accumulated feed water constituents from the surface of the membrane. Chemical cleaning was applied by soaking the membrane for $2 \mathrm{~h}$ in $2000 \mathrm{ppm}$ sodium hypochlorite $(\mathrm{NaOCl})$.

\subsubsection{Chemical oxygen demand}

The chemical oxygen demand (COD) of permeate of the membranes with different nominal pore sizes was measured with photometric test kits (Dr. Lange, Hach, Merck).

\subsection{Results}

\subsubsection{Membrane characterization}

Table 3.1 shows the membrane properties. For every series of membranes from the same supplier the surface porosity increased with increasing pore size. Additional bubble point analyses were performed since the MCE pore sizes provided by the supplier did not agree with those from the ImageJ analyses. For each membrane the pore size determined with the ImageJ analysis is used throughout this Chapter to refer to the membrane examined. For the larger pores Contact angle measurement revealed pore infiltration by the bubbles. Nevertheless, it was concluded that all membranes were hydrophilic, except for the hydrophobized PVDF membrane $\left(\mathrm{PVDF}_{\mathrm{H}}\right)$. 
Table 3.1 Membrane properties of five different membrane materials.

\begin{tabular}{|c|c|c|c|c|c|c|c|c|}
\hline $\begin{array}{l}\text { Membrane } \\
\text { Material }\end{array}$ & $\begin{array}{r}\text { No } \\
\text { Specs } \\
(\mu \mathrm{m}) \\
\end{array}$ & $\begin{array}{c}\text { minal p } \\
\text { Image J } \\
(\mu \mathrm{m}) \\
\end{array}$ & $\begin{array}{l}\text { ore size } \\
\text { Bubblepoint } \\
\quad(\mu \mathrm{m})\end{array}$ & $\begin{array}{c}\text { Contact } \\
\text { angle } \\
\left({ }^{\circ}\right)\end{array}$ & $\begin{array}{c}\text { Surface } \\
\text { porosity } \\
(\%)\end{array}$ & $\begin{array}{c}\text { Membrane } \\
\text { thickness } \\
(\mu \mathrm{m})\end{array}$ & $\begin{array}{c}\text { Pore } \\
\text { morphology } \\
(-) \\
\end{array}$ & $\begin{array}{c}R_{\text {initial }} \\
\left(10^{10} \mathrm{~m}^{-1}\right) \\
\end{array}$ \\
\hline \multirow{4}{*}{$\begin{array}{l}\text { Home made } \\
\text { PVDF }\end{array}$} & n.a. & 0.02 & $>0.05$ & 71 & 4 & 65 & \multirow{5}{*}{ Asymmetric } & 20.5 \\
\hline & n.a. & 0.03 & $>0.05$ & 69 & 6 & 110 & & 9.8 \\
\hline & n.a. & 0.1 & 0.1 & 77 & 15 & 165 & & 4.3 \\
\hline & n.a. & 0.3 & n.a. & n.a. & 27 & 190 & & 2.6 \\
\hline $\mathrm{PVDF}_{\mathrm{H}}$ & n.a. & 0.1 & n.a. & 101 & 15 & 165 & & 5.4 \\
\hline Toray, $\mathrm{PVDF}_{\mathrm{T}}$ & 0.08 & 0.07 & n.a. & 84 & 7 & 320 & Asymmetric & 4.1 \\
\hline \multirow{4}{*}{$\begin{array}{l}\text { Millipore } \\
\text { MCE }\end{array}$} & 0.1 & 0.1 & 0.1 & 71 & 23 & 100 & \multirow{4}{*}{ Symmetric } & 26.1 \\
\hline & 0.5 & 0.8 & 0.6 & * & 31 & 150 & & 0.8 \\
\hline & 3 & 1.8 & 1.7 & * & 37 & 150 & & 0.3 \\
\hline & 8 & 2.7 & 3.3 & * & 41 & 135 & & $<0.1$ \\
\hline Kubota, PE & 0.4 & 0.3 & 0.3 & * & 25 & 165 & Symmetric & 4.6 \\
\hline Millipore & 0.1 & 0.1 & 0.07 & n.a. & 3 & 20 & \multirow{4}{*}{$\begin{array}{l}\text { Straight } \\
\text { capillaries }\end{array}$} & 36.1 \\
\hline \multirow[t]{3}{*}{ PC } & 0.4 & 0.4 & 0.6 & 43 & 10 & 10 & & 0.8 \\
\hline & 1.2 & 0.9 & 1.3 & 52 & 11 & 20 & & 0.3 \\
\hline & 3 & 2.5 & n.a. & n.a. & 12 & 10 & & $<0.1$ \\
\hline
\end{tabular}

n.a.: not available.

*: the bubble changed significantly in time due to pore infiltration.

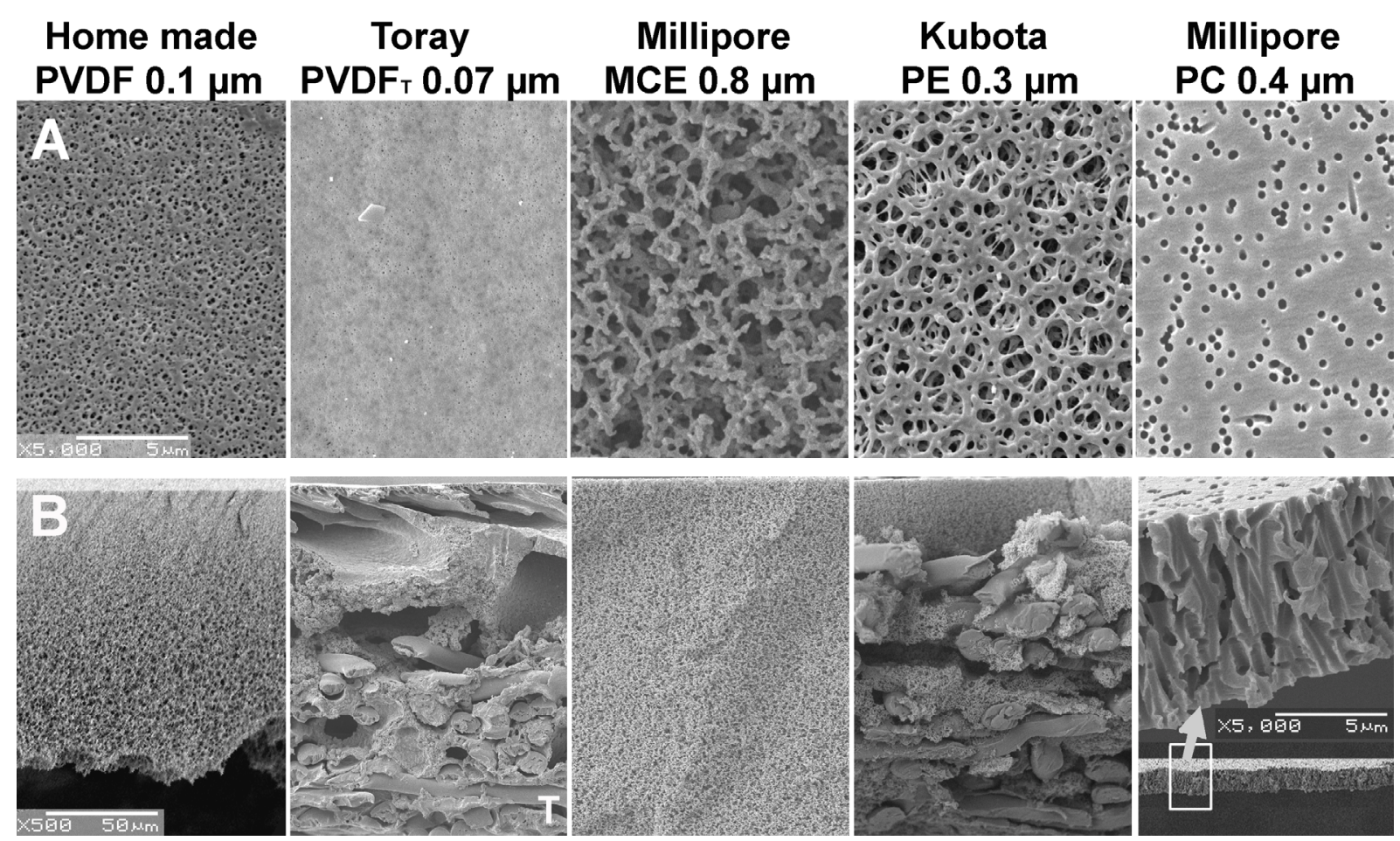

Figure 3.1 SEM images of the feed side of five different membrane materials $(A ; 5,000 x)$ and their cross-sections with filtration direction from top to bottom (B; 500x).

SEM images of the feed side surfaces (Fig. 3.1A) and cross-sections (Fig. 3.1B) revealed distinct differences in pore morphologies of the different membrane materials. The pore 
structure either showed an increasing pore size from the skin towards the permeate side (asymmetric structure or surface filter for PVDF membranes) or an uniform pore size over the cross-section (symmetric structure or depth filter for PE and MCE membranes). The home made PVDF, PE, and MCE membranes had an interconnected pore morphology. The PC membranes consisted of straight through pores without interconnectivity, whereas the Toray membrane $\left(\mathrm{PVDF}_{\mathrm{T}}\right)$ consisted of a thin dense skin $(<1 \mu \mathrm{m})$ on a substructure with large macro-voids. Table 3.1 also shows that the membrane resistance decreased with increasing pore size and/or surface porosity.

\subsubsection{Critical flux $\left(J_{C}\right)$ and critical flux for irreversibility $\left(J_{C i}\right)$}

Figure 3.2 shows $J_{C}$ and $J_{C i}$ for the different membranes (average value of three experiments; values taken from the first run of the ten consecutive IFSM runs). Membranes PC $0.1 \mu \mathrm{m}$ and PC $0.4 \mu \mathrm{m}$ were only measured once because of severe fouling during the experiments. The upwards arrow $(\uparrow)$ indicates when the critical fluxes exceeded the maximum flux of $100 \mathrm{~L} \mathrm{~m}^{-2} \mathrm{~h}^{-1}$ that was applied in the IFSM method. Clear differences were observed, which will be discussed below.

\section{Pore size and surface porosity}

$J_{C}$ increased with increasing pore size and/or surface porosity. This may be explained by a lower local flux through the pores and a lower retention of feed water constituents. The lower retention for membranes with larger pore sizes was verified from permeate COD values, which increased by $3 \%$ from PVDF $0.02 \mu \mathrm{m}$ to PVDF $0.3 \mu \mathrm{m}, 11 \%$ from MCE $0.1 \mu \mathrm{m}$ to MCE $2.7 \mu \mathrm{m}$, and $14 \%$ from PC 0.1 to PC $2.5 \mu \mathrm{m}$.

\section{Hydrophobicity and membrane material}

Hydrophobic membrane $\mathrm{PVDF}_{\mathrm{H}} 0.1 \mu \mathrm{m}$ showed approximately half $J_{\mathrm{C}}$ compared to the hydrophilic membrane PVDF $0.1 \mu \mathrm{m}$, although all the other membrane properties were the same. The lower $J_{C}$ is explained by a faster adsorption of or layer formation by feed water constituents on membrane $\mathrm{PVDF}_{\mathrm{H}} 0.1 \mu \mathrm{m}$. Consequently, the pores narrow or close for membrane $\mathrm{PVDF}_{\mathrm{H}} 0.1 \mu \mathrm{m}$, yielding a lower $J_{\mathrm{C}}$. This also explained the larger retention of feed constituents by $\mathrm{PVDF}_{\mathrm{H}} 0.1 \mu \mathrm{m}$, indicated by a $5 \%$ lower permeate COD despite a similar pore size compared to membrane PVDF $0.1 \mu \mathrm{m}$. Adsorption is irreversible by relaxation and therefore explained $J_{\mathrm{Ci}}$ being a fraction larger than $J_{\mathrm{C}}$. In the case of layer formation, the observation of a larger $J_{C i}$ indicated gel layer formation. 
The higher $J_{C}$ for membrane PVDF $0.03 \mu \mathrm{m}$ compared to membrane $\mathrm{PVDF}_{\mathrm{T}} 0.07 \mu \mathrm{m}$ was surprising since both are made of PVDF (additives undisclosed), and membrane PVDF $_{\mathrm{T}} 0.07 \mu \mathrm{m}$ had a larger pore size and similar surface porosity. Membrane PVDF $_{\mathrm{T}} 0.07 \mu \mathrm{m}$ therefore unexpectedly gave a lower $J_{\mathrm{C}}$ for which no explanation can be given at this time, but which will be further discussed in Section 3.4.

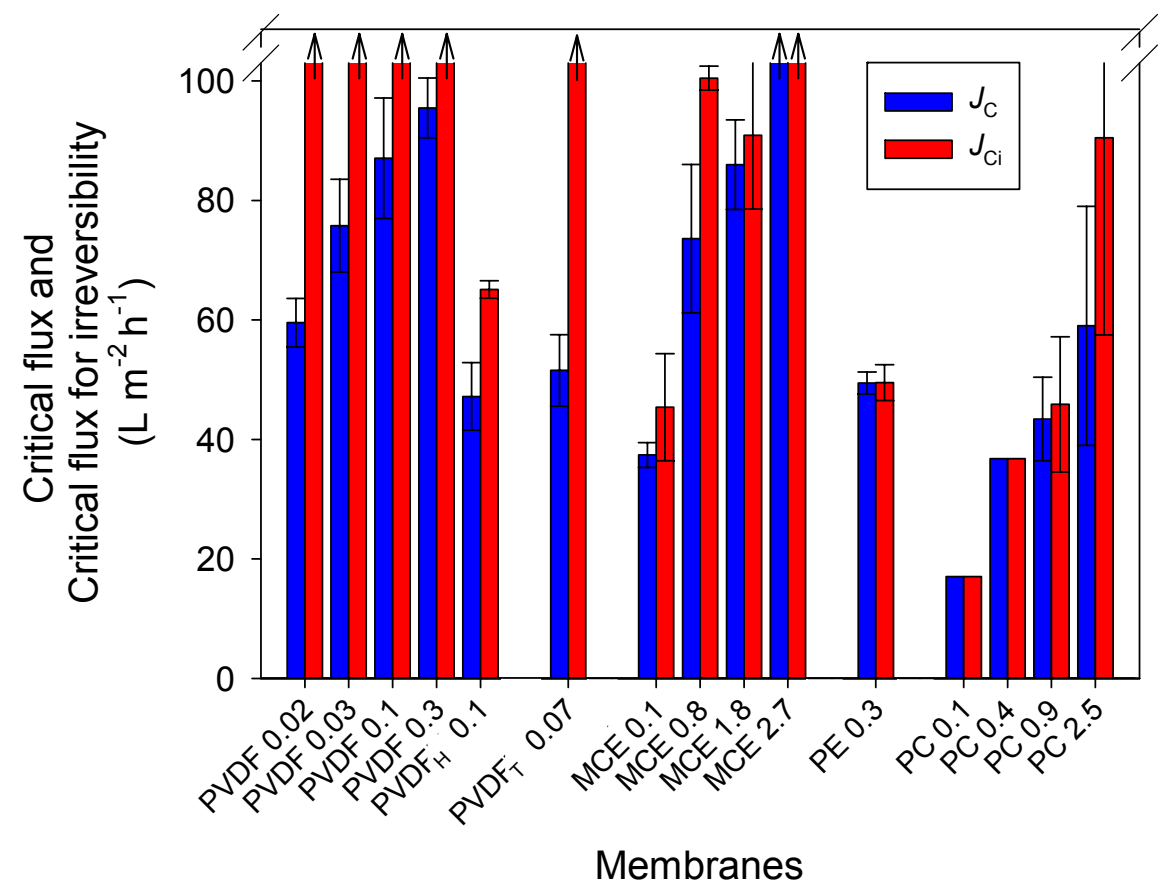

Figure 3.2 Critical flux $\left(J_{C}\right)$ and critical flux for irreversibility $\left(J_{C i}\right)$ for different membranes. These parameters are averaged for three experiments (standard deviation indicated) and for only the first out of ten consecutive runs of the improved flux-step method. The upwards arrow indicates a parameter value larger than the used maximum flux. The numbers on the $x$-axis are the membrane pore sizes in $\mu \mathrm{m}$.

\section{Pore morphology}

Differences in pore morphology may explain differences in $J_{\mathrm{Ci}}$ for the PVDF, MCE, and PC membranes. Pore morphology differences also may explain the lower $J_{C}$ and $J_{C i}$ of membrane PE $0.3 \mu \mathrm{m}$ compared to membrane PVDF $0.3 \mu \mathrm{m}$. The later two membranes showed a similar pore size and surface porosity.

The home made PVDF membranes exhibited a $J_{\mathrm{Ci}}$ which exceeded $J_{\mathrm{C}}$, indicating that the fouling was reversible during the relaxation step. From SEM observations no adsorption could be observed and it was assumed that all material entering the membrane could also flow out with the permeate, due to the asymmetric pore morphology of these membranes. $A$ similar observation was made for membrane $\mathrm{PVDF}_{\mathrm{T}} 0.07 \mu \mathrm{m}$. 
MCE membranes are depth filters and particle entrapment occurred along the tortuous path in the membrane matrix (SEM). This type of morphology may be responsible for the faster irreversible fouling and consequently lower values of $J_{C}$ and $J_{C i}$ of MCE membranes compared to home made PVDF membranes. The increase in $J_{C}$ with increasing pore size for the MCE membranes can be explained by the higher volume porosity which was $73 \%$ for MCE $0.1 \mu \mathrm{m}, 79 \%$ for MCE $0.8 \mu \mathrm{m}, 83 \%$ for MCE $1.8 \mu \mathrm{m}$, and $84 \%$ for MCE $2.7 \mu \mathrm{m}$ (data of the membrane supplier). Membrane PE $0.3 \mu \mathrm{m}$ exhibited a $J_{\mathrm{Ci}}$ which was similar to its $J_{\mathrm{C}}$. This can also be attributed to pore blocking of the symmetric pore morphology (depth filter). Its difference with the asymmetric membrane PVDF $0.3 \mu \mathrm{m}$ was remarkable in view of equal pore size and surface porosity. Pore filling did not occur for membrane PVDF $0.3 \mu \mathrm{m}$, explaining the larger $J_{C}$ and $J_{\mathrm{Ci}}$ compared to membrane PE $0.3 \mu \mathrm{m}$. Adsorption perhaps also occurred for MCE membranes and the PE membrane which however, was not elucidated as the dominant fouling mechanism.

The four PC membranes also incurred irreversible fouling, which could be explained by pore blocking elucidated by SEM investigation. The much lower critical fluxes compared to home made PVDF membranes can be explained by the differences in pore morphology. Ho and Zydney [17] showed that membranes with an interconnected pore structure like the home made PVDF membranes fouled more slowly compared to membranes with track-etched straight capillaries like the PC membranes. In an interconnected pore structure the permeate can by-pass blocked pores via the interconnections, which is not possible for straight-through track-etched pores. Consequently, membranes with straight-through pores have a lower $J_{C}$. Adsorption perhaps also occurred for PC membranes which however, also was not elucidated as the dominant fouling mechanism. A large standard deviation was measured for membranes PC $0.9 \mu \mathrm{m}$ and PC $2.5 \mu \mathrm{m}$. Sludge particles passed the membrane pores for these membranes, and were entrapped in between the non-woven and the membrane. These particles were supposed to flow through the non-woven having much larger pores. Its unexpected retention by the non-woven occurred randomly with increasing flux, affecting accurate fouling (reversibility) measurements.

\subsubsection{Irreversible fouling during consecutive filtration runs}

Figure 3.3 shows the development of initial membrane resistances $\left(R_{\text {initial }}\right)$ for 11 different membranes during ten consecutive IFSM runs, (please note the different scales on the $y$-axes). Fouling for the PC membranes was too severe to perform a second consecutive run and therefore are not included in Figure 3.3. An increase in initial membrane resistance during ten consecutive runs is an indication for the occurrence of irreversible fouling. 

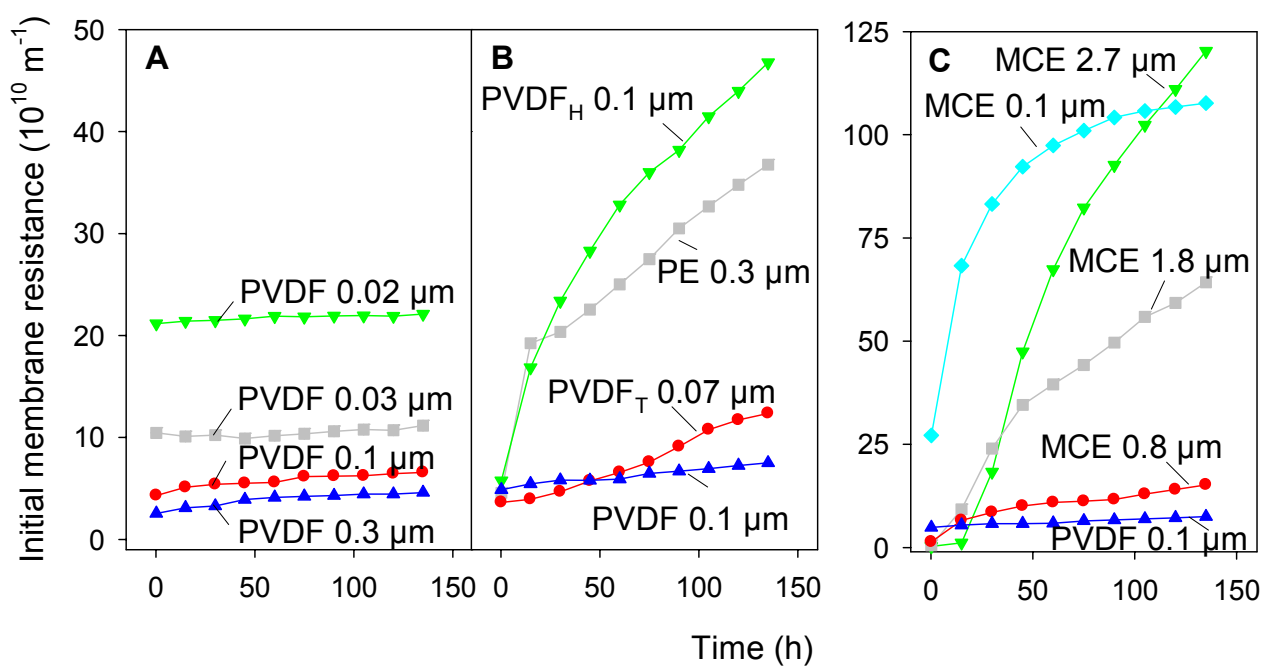

Figure 3.3 Initial membrane resistance during ten consecutive runs for 11 membranes; PVDF $0.1 \mu \mathrm{m}$ is shown in each graph for easy comparison (notice the identical $y$-axis scale for $(A)$ and $(B)$, and the larger $y$-axis scale for $(C)$ ).

The initial membrane resistance remained fairly stable during $150 \mathrm{~h}$ for the home made PVDF membranes (A). No significant irreversible fouling occurred during the ten runs. More severe irreversible fouling in each distinct run occurred for membranes PVDF $_{H} 0.1 \mu \mathrm{m}$, $\mathrm{PVDF}_{\mathrm{T}} 0.07 \mu \mathrm{m}$, and PE $0.3 \mu \mathrm{m}$ shown by the increase in initial filtration resistance (B). The continuous increase in initial resistance for hydrophobic membrane PVDF $_{H} 0.1 \mu \mathrm{m}$ contradicted with the nearly constant initial resistance for membrane PVDF $0.1 \mu \mathrm{m}$ having the same membrane properties but a more hydrophilic character. Such behavior clearly complies with the aforementioned larger irreversible fouling tendency of membrane PVDF $_{H} 0.1 \mu \mathrm{m}$ attributed to adsorption or layer formation. Membrane PE $0.3 \mu \mathrm{m}$ exhibited a fast increase in initial membrane resistance between run 1 and run 2, followed by a more moderate increase. A partially blocked pore matrix was the cause of this increase elucidated by SEM observations of membrane PE $0.3 \mu \mathrm{m}$ after ten consecutive runs (Figure 3.4). Membrane PVDF $_{\mathrm{T}} 0.07 \mu \mathrm{m}$ showed a very small but gradual increase in initial filtration resistance, which did not result in a $J_{\mathrm{Ci}}$ below $100 \mathrm{~L} \mathrm{~m}^{-2} \mathrm{~h}^{-1}$. Visual observation showed that membrane $\mathrm{PVDF}_{\mathrm{T}} 0.07 \mu \mathrm{m}$ had changed in color from white to brown after ten filtration runs. This was attributed to adsorption of feed water constituents, also explaining the increase in membrane resistance.

Severe particle entrapment for depth filter MCE membranes occurred when the value of $J_{C}$ was exceeded in each of the ten runs, shown by the drastic increase in initial membrane resistance (Figure 3.3C). This increase in resistance was more severe for the MCE membranes compared to membrane PE $0.3 \mu \mathrm{m}$, in spite of similar symmetric pore morphology, indicating larger volume porosity for the MCE membranes. Membrane MCE 2.7 $\mu \mathrm{m}$ showed the largest increase in resistance, which can be attributed to the largest volume porosity (Figure 3.4). Open depth filters apparently only initially have a good 
membrane performance, considering the superior critical fluxes as determined in the first run of the IFSM for membrane MCE $2.7 \mu \mathrm{m}$ (see Figure 3.2 in Section 3.3.2). For unknown reasons membrane MCE $0.8 \mu \mathrm{m}$ had a remarkable good membrane performance compared to the other three MCE membranes, as shown by the much lower increase in initial membrane resistance. A possible cause of this remarkable difference will be addressed in Chapter 4 of this thesis.

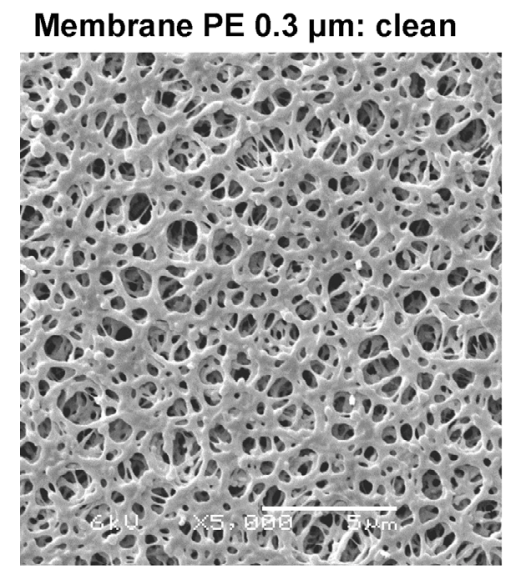

Membrane PE $0.3 \mu \mathrm{m}$ : fouled

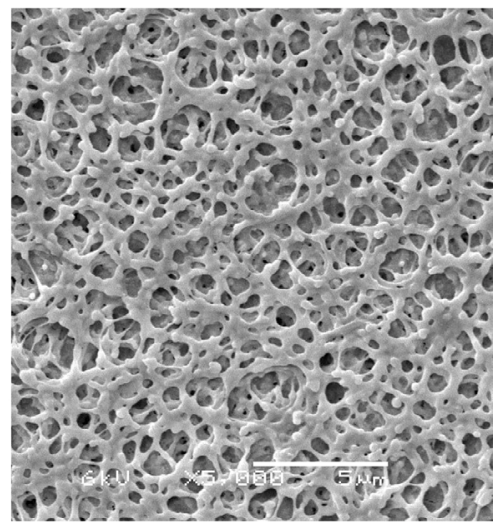

Membrane MCE $2.7 \mu \mathrm{m}$ : clean

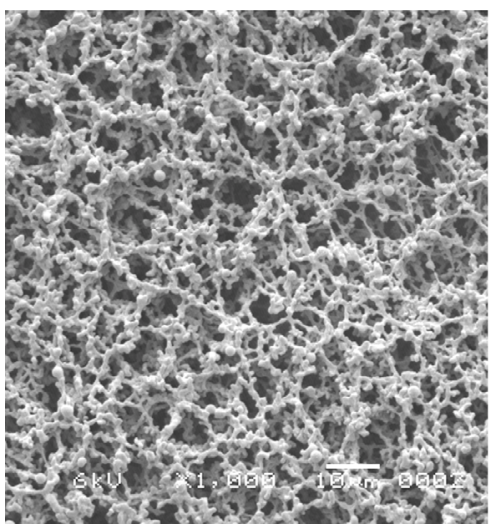

Membrane MCE $2.7 \mu \mathrm{m}$ : fouled

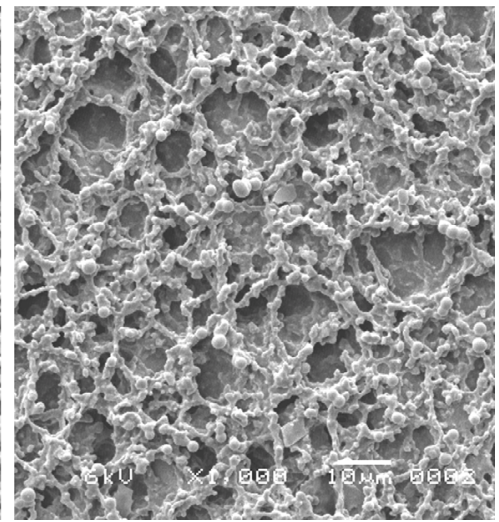

Figure 3.4 Membranes PE $0.3 \mu \mathrm{m}(5,000 \mathrm{x}$, top) and MCE $2.7 \mu \mathrm{m}(1,000 \mathrm{x}$, bottom) clean and fouled after ten consecutive runs. 


\subsubsection{Long-term experiments}

\section{Sub-critical filtration with home made PVDF membranes at fixed flux}

Sub-critical filtration at a fixed flux of $50 \mathrm{~L} \mathrm{~m}^{-2} \mathrm{~h}^{-1}$ was performed with the home made membranes PVDF $0.03 \mu \mathrm{m}$, PVDF $0.1 \mu \mathrm{m}$, and PVDF $0.3 \mu \mathrm{m}$ to investigate the influence of pore size and surface porosity $(6,15$, and $27 \%$, respectively) on long-term fouling behavior (Figure 3.5).

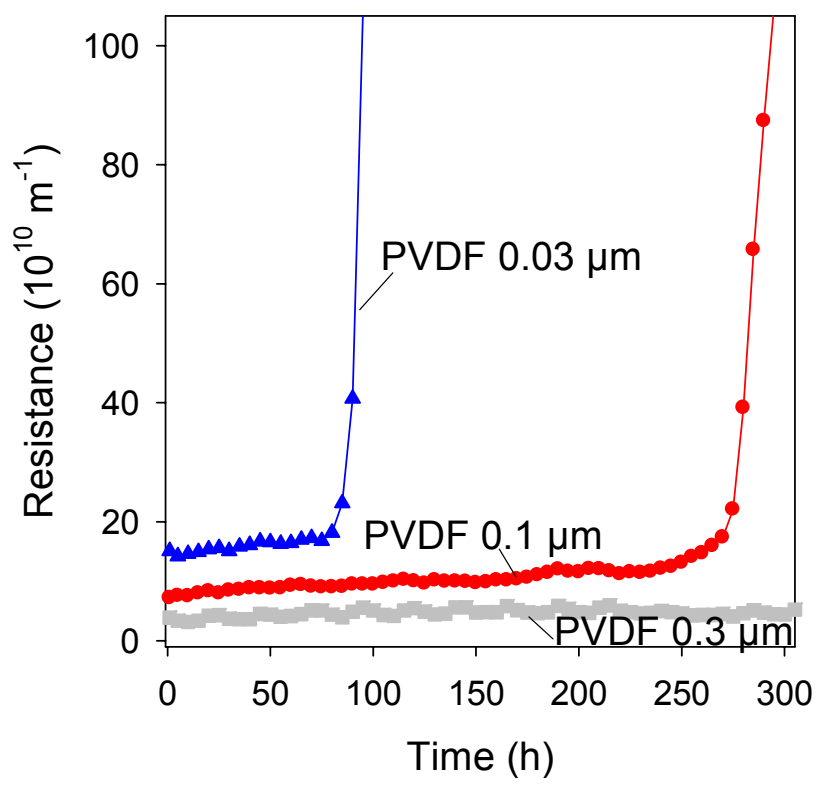

Figure 3.5 Filtration resistance of membranes PVDF $0.03 \mu \mathrm{m}$, PVDF $0.1 \mu \mathrm{m}$, and PVDF $0.3 \mu \mathrm{m}$ during fixed flux filtration at a flux of $50 \mathrm{~L} \mathrm{~m}^{-2} \mathrm{~h}^{-1}$.

Membrane PVDF $0.3 \mu \mathrm{m}$ showed a stable filtration resistance for more than $300 \mathrm{~h}$ of filtration. A characteristic two-stage resistance profile $[15,20,25,26]$ was observed for PVDF $0.03 \mu \mathrm{m}$ and PVDF $0.1 \mu \mathrm{m}$, although filtration was performed below $J_{\mathrm{C}}$. Fouling is not completely absent below $J_{C}$ in MBR. The gradual rise in resistance in the first stage can be explained by irreversible fouling: adsorption, pore blocking, and/or local deposition on the membrane of macromolecules, like extracellular polymeric substances (EPS [27]). These fouling mechanisms blocked part of the membrane, progressively increasing the local flux. The duration of the first stage is called the sustainable filtration time [25], which clearly increased with increasing pore size and/or surface porosity. The rapid increase for membranes PVDF $0.03 \mu \mathrm{m}$ and PVDF $0.1 \mu \mathrm{m}$ was caused by the gel layer formation detected on the fouled membranes (Figure 3.6). For visualization purposes, these membrane surfaces were partially forward flushed (FF). The FF removed the gel layer from the membrane surface yielding a whiter and cleaner membrane surface. This visualizes the gel layer as the darker left part of the membranes. 


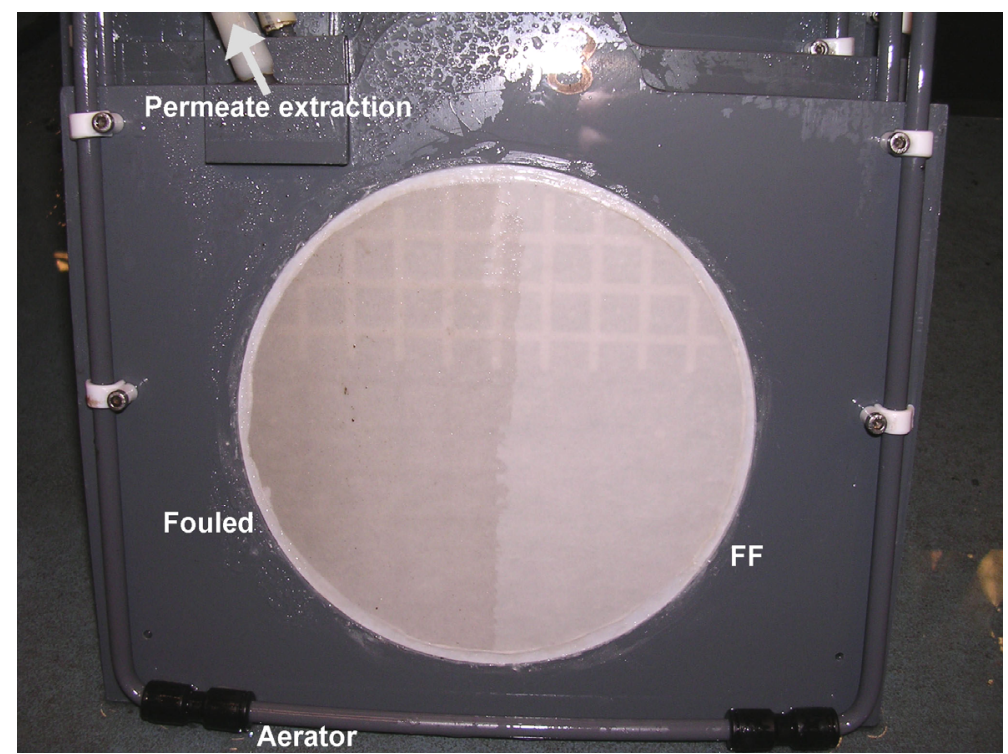

Figure 3.6 Membrane PVDF $0.1 \mu \mathrm{m}$ fouled by gel layer and partially forward flushed (FF) for gel layer visualization.

\section{Long-term filterability with commercial membranes}

The long-term fouling behavior of membrane PVDF $0.1 \mu \mathrm{m}$ was compared to commercial membranes PE $0.3 \mu \mathrm{m}$ (Kubota) and $\mathrm{PVDF}_{\mathrm{T}} 0.07 \mu \mathrm{m}$ (Toray). The latter two membranes where selected in this experiment for practical relevance. The results are shown in Figure 3.7. Filtration started at a fixed flux of $25 \mathrm{~L} \mathrm{~m}^{-2} \mathrm{~h}^{-1}$, and the flux was gradually step-wise increased after $140 \mathrm{~h}$ to speed up the fouling process.

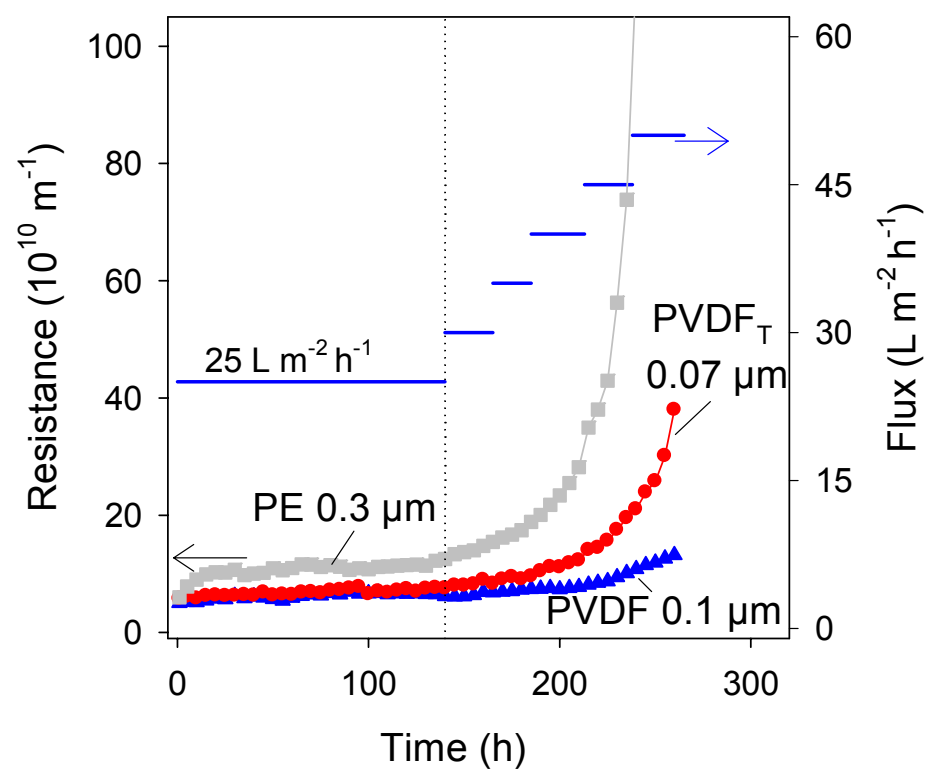

Figure 3.7 Filtration resistance of membranes PVDF $0.1 \mu \mathrm{m}, \mathrm{PE} \quad 0.3 \mu \mathrm{m}$, and $\mathrm{PVDF}_{\mathrm{T}} 0.07 \mu \mathrm{m}$ at incrementing fixed flux from 25 to $50 \mathrm{~L} \mathrm{~m}^{-2} \mathrm{~h}^{-1}$. 
The resistance initially increased faster for membrane PE $0.3 \mu \mathrm{m}$ compared to membranes PVDF $_{\mathrm{T}} 0.07 \mu \mathrm{m}$ and PVDF $0.1 \mu \mathrm{m}$, probably due to pore blocking, similar to the results shown in Figures 3.3 and 3.4. Incrementing the flux also showed a two-stage fouling process. Although membrane PE $0.3 \mu \mathrm{m}$ and membrane $\mathrm{PVDF}_{\mathrm{T}} 0.07 \mu \mathrm{m}$ approximately had the same $J_{C}$, with membrane PE $0.3 \mu \mathrm{m}$ a shorter sustainable time was achieved. Membrane PVDF $_{\mathrm{T}} 0.07 \mu \mathrm{m}$ discolored from white to brown similar as during the IFSM experiments, and attributed to adsorption of feed water constituents. The adsorption caused the resistance to gradually rise faster compared to the resistance increase observed for membrane PVDF $0.1 \mu \mathrm{m}$ which did not discolor. PVDF $_{\mathrm{T}} 0.07 \mu \mathrm{m}$ and PE $0.3 \mu \mathrm{m}$ both showed a gel layer on the membrane surface at the end of the experiment. Initially, pore blocking for membrane PE $0.3 \mu \mathrm{m}$ and adsorption for membrane PVDFT $0.07 \mu \mathrm{m}$ was the main fouling mechanism that switched to gel layer formation at the point were the rapid rise in resistance occurred. Membrane PVDF $0.1 \mu \mathrm{m}$ only showed a gradual increase in resistance upon increasing the flux, while gel formation did not occur.

\section{Fouling behavior with intermittent relaxation at two different net fluxes}

In full scale installations, submerged flat-sheet membranes are operated with intermittent relaxation, which might affect the fouling behavior of different membranes. For this reason, long-term filtration with intermittent relaxation at two different net fluxes was performed for membranes PVDF $0.02 \mu \mathrm{m}$, PVDF $0.1 \mu \mathrm{m}$, and PE $0.3 \mu \mathrm{m}$ (Figure 3.8). Initially, the net flux was $25 \mathrm{~L} \mathrm{~m}^{-2} \mathrm{~h}^{-1}$, by operating for 8 minutes at a flux of $32 \mathrm{~L} \mathrm{~m}^{-2} \mathrm{~h}^{-1}$ followed by 2 minutes relaxation. After chemical cleaning, a twice as high net flux was applied by 15 minutes of filtration at $100 \mathrm{~L} \mathrm{~m}^{-2} \mathrm{~h}^{-1}$ followed by 15 minutes of relaxation.

At a net flux of $25 \mathrm{~L} \mathrm{~m}^{-2} \mathrm{~h}^{-1}$ in Figure 3.8 no differences were observed in the development of the end-resistance for membranes PVDF $0.1 \mu \mathrm{m}$ and PE $0.3 \mu \mathrm{m}$ compared to the resistance development during fixed flux operation at the same flux value shown in Figure 3.7. Relaxation therefore did not affect the fouling behavior at these sub-critical conditions. Increasing the net flux to $50 \mathrm{~L} \mathrm{~m}^{-2} \mathrm{~h}^{-1}$ resulted in unsustainable membrane performance for membrane PE $0.3 \mu \mathrm{m}$. The instantaneous flux of $100 \mathrm{~L} \mathrm{~m}^{-2} \mathrm{~h}^{-1}$ was far above $J_{C}$ of $49 \mathrm{~L} \mathrm{~m}^{-2} \mathrm{~h}^{-1}$. The fast initial increase in end-resistance was explained by initial pore blocking, and shortly after start-up gel layer formation occurred. Cake layer formation clearly was absent when the membrane was examined visually, most likely because a cake layer has a higher reversibility by intermittent relaxation than a gel layer. The instantaneous flux also was above $J_{C}$ for membrane PVDF $0.02 \mu \mathrm{m}\left(75 \mathrm{~L} \mathrm{~m}^{-2} \mathrm{~h}^{-1}\right)$ but a sustainable filtration still was possible for $48 \mathrm{~h}$ at the net flux of $50 \mathrm{~L} \mathrm{~m}^{-2} \mathrm{~h}^{-1}$. With membrane PVDF $0.1 \mu \mathrm{m}$ only a gradual increase in resistance was detected, although sooner or later this probably also may have lead to a rapid increase in resistance. The differences in membrane behavior clearly demonstrate the importance of the membrane pore size and surface porosity when membranes PVDF $0.02 \mu \mathrm{m}$ and PVDF $0.1 \mu \mathrm{m}$ are compared, and pore morphology when membranes PVDF $0.1 \mu \mathrm{m}$ and PE $0.3 \mu \mathrm{m}$ are compared. 


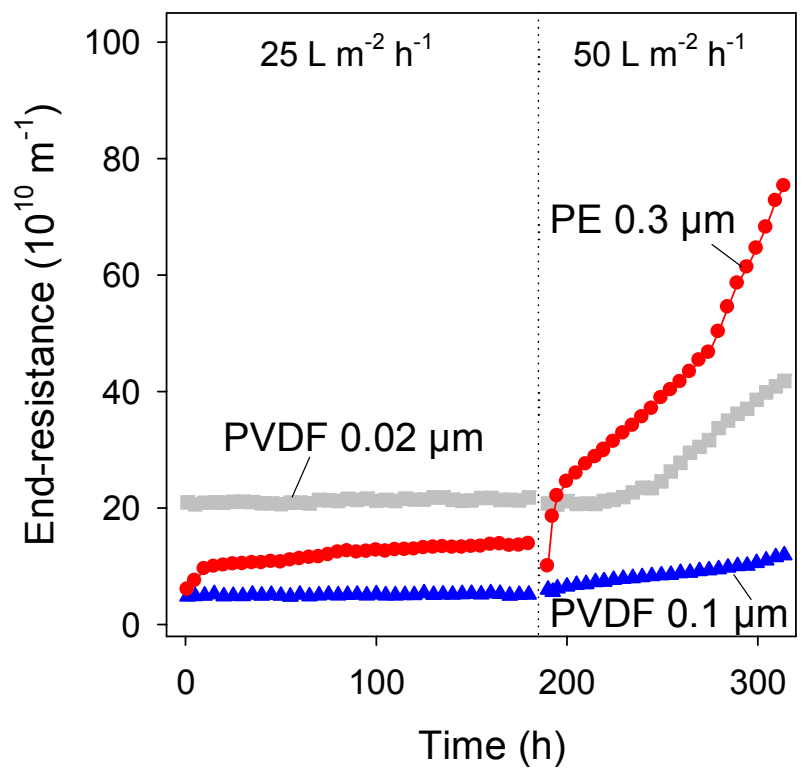

Figure 3.8 End-resistance of membranes PVDF $0.02 \mu \mathrm{m}$, PVDF $0.1 \mu \mathrm{m}$, and PE $0.3 \mu \mathrm{m}$ at two net fluxes, with intermittent relaxation (after $8 \mathrm{~min}$ filtration at $32 \mathrm{~L} \mathrm{~m}^{-2} \mathrm{~h}^{-1} 2$ min relaxation resulting in a net flux of $25 \mathrm{~L} \mathrm{~m}^{-2} \mathrm{~h}^{-1}$, or after 15 min at $100 \mathrm{~L} \mathrm{~m}^{-2} \mathrm{~h}^{-1}$ for $15 \mathrm{~min}$ relaxation resulting in a net flux of $50 \mathrm{~L} \mathrm{~m}^{-2} \mathrm{~h}^{-1}$ ).

\subsection{Discussion}

The experiments described in this Chapter focused on understanding the influence of membrane properties on membrane fouling in MBRs. The results clearly demonstrated that membrane material, pore size, surface porosity, pore morphology, and hydrophobicity all have a strong effect on membrane fouling.

Different polymeric materials cause different degrees of adsorption [28, 29]. Adsorption was also different for membranes PVDF $0.03 \mu \mathrm{m}$ and $\mathrm{PVDF}_{\mathrm{T}} 0.07 \mu \mathrm{m}$ which were both made of the organic polymer PVDF (additives undisclosed for membrane PVDF $0.07 \mu \mathrm{m}$ ). Membrane $\mathrm{PVDF}_{\mathrm{T}} 0.07 \mu \mathrm{m}$ discolored from initially white to brown during filtration caused by adsorption, whereas membrane PVDF $0.03 \mu \mathrm{m}$ did not change in color. This difference in adsorption seemed the most likely cause of the difference in $J_{C}$ between membrane PVDF $_{\mathrm{T}} 0.07 \mu \mathrm{m}$ and membrane PVDF $0.03 \mu \mathrm{m}$ as shown in Figure 3.2, despite the larger pore size of membrane $\mathrm{PVDF}_{\mathrm{T}} 0.07 \mu \mathrm{m}$. The different adsorption behavior can be caused by the more hydrophobic character of membrane $\mathrm{PVDF}_{\mathrm{T}} 0.07 \mu \mathrm{m}$ (Table 3.1). The surface charge or the different dope components also may have caused the difference in adsorption, which properties however were beyond the scope of this investigation. 
Membranes with larger pores often also have a larger surface porosity. Unfortunately, it is very difficult to obtain membranes with identical surface porosities but different pore sizes or vice versa, which makes it hard to uncouple the effects of pore size and surface porosity on fouling behavior. This study showed that increasing pore size and surface porosity reduces membrane fouling (larger $J_{\mathrm{C}}$ ) explained by a lower local flux through the pores and a smaller retention of feed water constituents. A higher surface porosity lowers the local flux to and through each pore, thus decreasing the drag force of material towards the membrane and increasing $J_{c}$. At similar fluxes a reduced retention reduces concentration polarization, allowing a higher flux before concentration polarization results in cake or gel formation [23]. Other studies suggested more internal fouling for larger pore membranes, as more material can pas the membrane skin and become entrapped in the membrane matrix [30, 31]. We showed this only applies for membranes with a symmetric pore morphology. Internal fouling is mitigated in asymmetric membranes; i.e. constituents smaller than the pore size entering the membrane matrix can leave with the permeate flow.

The MCE membranes showed a larger $J_{C}$ with increasing pore size, i.e. with increasing volume porosity. A larger volume porosity implies a larger dirt-loading capacity being able to entrap more material in the pore matrix which minimizes the extent of fouling on short term. On the longer term (consecutive filtration runs, Figure 3.3) however, the MCE membrane with the largest pore (MCE $2.7 \mu \mathrm{m}$ ) clearly was most severely fouled. A larger volume porosity for depth filters therefore is only beneficial on short term filtration.

The influence of membrane hydrophobicity on membrane fouling often is determined by comparing membranes not only different in their hydrophobic nature but also in other properties. In this study, it was possible to only vary hydrophobicity. From this it was demonstrated that $J_{C}$ for a hydrophobic membrane PVDF $_{H} 0.1 \mu \mathrm{m}$ only was half of that of a hydrophilic membrane PVDF $0.1 \mu \mathrm{m}$. The primarily hydrophobic nature of the biomass [32] was believed to cause a faster adsorption of feed water constituents and/or gel layer formation on the hydrophobic membrane $\mathrm{PVDF}_{\mathrm{H}} 0.1 \mu \mathrm{m}$.

A study by Choi et al. [33] indicated that hydrophobicity only affects fouling in the initial state by adsorption, where after these surface characteristics are masked by the adsorption layer. Our results however, showed that hydrophobicity results in progressive fouling during consecutive filtration runs, for which the mechanism was not clearly identified. Adsorption occurred by a multi-layer process and/or a transparent gel layer could have caused the progressive fouling, i.e. visual observation after the experiment did not show a deposit like that in Figure 3.6. A gel layer as the cause is supported by previous studies [14, 34-36] showing that hydrophobic membranes are less resistant to fouling by EPS.

Ognier et al. [15] and Cho et al. [26] explained the rapid increase in resistance, for example those in Figure 3.5, by the gradual increase in local flux eventually exceeding $J_{C}$, causing severe cake layer formation. Visual observation of the membranes in our study clearly did not show cake layer formation but gel layer formation as the source of the rapid increase in resistance, complying with findings in a recent study by Wang et al. [20]. It is hypothesized 
that the gradual increase in local flux also increases concentration polarization, and the transition to gel formation occurred when the gel concentration [37] of the macromolecular species present was reached. Subsequently, a gel was formed which became thicker or more compact due to the ongoing convection of material to the membrane, explaining the rapid rise in resistance. Chapter 6 will address gel layer formation more specifically.

The longer sustainable time for membrane PVDF $0.3 \mu \mathrm{m}$ compared to membrane PVDF $0.02 \mu \mathrm{m}$ and PVDF $0.1 \mu \mathrm{m}$ (Figure 3.5 ) can be explained by its lower local flux and lower retention; i.e. larger $J_{C}$, both avoiding gel layer formation in this experiment. The shorter sustainable time for membrane PE $0.3 \mu \mathrm{m}$ compared to membrane PVDF $0.1 \mu \mathrm{m}$ in Figure 3.7 can be explained by the more severe irreversible fouling for membrane PE $0.3 \mu \mathrm{m}$. This irreversible fouling caused a faster rise in local flux for membrane PE $0.3 \mu \mathrm{m}$ compared to membrane PVDF $0.1 \mu \mathrm{m}$. Consequently, causing gel layer formation to occur sooner on the partially blocked pore matrix despite the initial larger pore size and surface porosity.

It is gel layer formation that hampers sustainable filtration on the long-term (both at sub and supra-critical conditions). Future research therefore should focus on tackling gel layer formation by elucidating gel layer composition, and investigating the processes that contribute to the two-stage fouling process. Together with selection of appropriate membrane properties, this may lead to much higher sustainable fluxes. An increase in net flux for instance above fluxes conventionally applied in full scale installations would imply that a smaller membrane surface area can be installed. This also reduces energy consumption by air scouring, which is about $38 \%$ of the total energy consumption of the MBR Varsseveld in the Netherlands [38]. For instance, Figure 3.8 showed that the net flux for asymmetric membrane PVDF $0.1 \mu \mathrm{m}$ can be approximately twice as high as that for symmetric membrane PE $0.3 \mu \mathrm{m}$. The long-term experiments showed that membranes with a larger $J_{C}$ and $J_{\mathrm{Ci}}$ also can be operated at a larger net flux, and/or shows a longer sustainable time at similar instantaneous fluxes.

Finally, it cannot be ignored that the effect of membrane properties on membrane fouling also is determined by the feed properties. Chapter 4 therefore will compare membranes with similar properties, but using various sources of activated sludge. 


\subsection{Conclusions}

The results of the improved flux-step method and the long-term experiments showed a clear influence of the membrane properties on membrane fouling in a submerged membrane bioreactor. A hydrophilic membrane with a complete asymmetric, interconnected pore morphology, a relatively large pore size of $0.3 \mu \mathrm{m}$ and a surface porosity of $27 \%$, resulted in the best membrane performance.

By using the best performing membranes with reduced fouling characteristics, much larger fluxes can be applied in a sustainable manner, or at similar fluxes can result in a longer sustainable time. Long-term sustainable filtration eventually is hampered by gel layer formation which should be the topic of future research.

\subsection{Acknowledgements}

The company DSM is acknowledged for their contribution in the Contact angle measurements.

\subsection{Used symbols and abbreviations}

Symbol

Unit

\begin{tabular}{llc}
\hline COD & Chemical oxygen demand & $\mathrm{mg} \mathrm{L}^{-1}$ \\
EPS & Extracellular polymeric substances & \\
FF & Forward flush & \\
IFSM & Improved flux-step method & \\
$J_{C}$ & Critical flux & $\mathrm{L} \mathrm{m}^{-2} \mathrm{~h}^{-1}$ \\
$J_{\mathrm{Ci}}$ & Critical flux for irreversibility & $\mathrm{L} \mathrm{m}^{-2} \mathrm{~h}^{-1}$ \\
$R_{\text {initial }}$ & Initial resistance of a flux-step run & $\mathrm{m}^{-1}$ \\
SEM & Scanning electron microscope & \\
SMBR & Submerged membrane bioreactor & $\mathrm{h}$ \\
SRT & Solid retention time & $\mathrm{Pa}$ \\
TMP & Transmembrane pressure & \\
\hline
\end{tabular}




\subsection{References}

1. Chang, I.S., et al., Membrane fouling in membrane bioreactors for wastewater treatment. Journal of Environmental Engineering, 2002. 128: p. 1018-1029.

2. Field, R.W., et al., Critical flux concept for microfiltration fouling. Journal of Membrane Science, 1995. 100: p. 259-272.

3. Le Clech, P., et al., Critical flux determination by the flux-step method in a submerged membrane bioreactor. Journal of Membrane Science, 2003. 227: p. 81-93.

4. van der Marel, P., et al., An improved flux-step method to determine the critical flux and critical flux for irreversibility in a membrane bioreactor. Journal of Membrane Science, 2009. 332: p. 24-29.

5. Andreottola, G. and G. Guglielmi. Critical flux determination in two MBRs for municipal wastewater treatment. in: Proceedings of the IMSTEC, Sydney, Australia. 2003.

6. Madaeni, S.S., A.G. Fane, and D.E. Wiley, Factors influencing critical flux in membrane filtration of activated sludge. Journal of Chemical Technology and Biotechnology, 1999. 74: p. 539-543.

7. Metsamuuronen, S., J. Howell, and M. Nystrom, Critical flux in ultrafiltration of myoglobin and baker's yeast. Journal of Membrane Science, 2002. 196: p. 13-25.

8. Wu, Z., et al., Effects of various factors on critical flux in submerged membrane bioreactors for municipal wastewater treatment. Separation and Purification Technology, 2008. 62: p. 56-63.

9. Le-Clech, P., V. Chen, and T.A.G. Fane, Fouling in membrane bioreactors used in wastewater treatment. Journal of Membrane Science, 2006. 284: p. 17-53.

10. Kwon, D.Y., et al., Experimental determination of critical flux in cross-flow microfiltration. Separation and Purification Technology, 2000. 19: p. 169-181.

11. Judd, S.J., The MBR Book: Principles and Applications of Membrane Bioreactors in Water and Wastewater Treatment. 1st ed. 2006, Oxford: Elsevier.

12. Wu, D., J.A. Howell, and R.W. Field, Critical flux measurement for model colloids. Journal of Membrane Science, 1999. 152: p. 89-98.

13. Chen, V., Performance of partially permeable microfiltration membranes under low fouling conditions. Journal of Membrane Science, 1998. 147: p. 265-278.

14. Fane, A.G. and C.J.D. Fell, A review of fouling and fouling control in ultrafiltration. Desalination, 1987. 62: p. 117-136.

15. Ognier, S., C. Wisniewski, and A. Grasmick, Membrane bioreactor fouling in subcritical filtration conditions: a local critical flux concept. Journal of Membrane Science, 2004. 229: p. 171-177.

16. Wu, Q.L. and B.M. Wu, Study of membrane morphology by image-analysis of electron-micrographs. Journal of Membrane Science, 1995. 105: p. 113-120.

17. Ho, C.C. and A.L. Zydney, Effect of membrane morphology on the initial rate of protein fouling during microfiltration. Journal of Membrane Science, 1999. 155: p. 261-275.

18. Fang, H.H.P. and X. Shi, Pore fouling of microfiltration membranes by activated sludge. Journal of Membrane Science, 2005. 264: p. 161-166. 
19. Espinasse, B., P. Bacchin, and P. Aimar, On an experimental method to measure critical flux in ultrafiltration. Desalination, 2002. 146: p. 91-96.

20. Wang, Z., et al., Membrane fouling in a submerged membrane bioreactor (MBR) under sub-critical flux operation: Membrane foulant and gel layer characterization. Journal of Membrane Science, 2008. 325: p. 238-244.

21. Defrance, L. and M.Y. Jaffrin, Reversibility of fouling formed in activated sludge filtration. Journal of Membrane Science, 1999. 157: p. 73-84.

22. Benkahla, Y.K., et al., Cake growth-mechanism in cross-flow microfiltration of mineral suspensions. Journal of Membrane Science, 1995. 98: p. 107-117.

23. Chen, V., et al., Particle deposition during membrane filtration of colloids: transition between concentration polarization and cake formation. Journal of Membrane Science, 1997. 125: p. 109-122.

24. Remy, M., et al., Low dose powdered activated carbon addition at high sludge retention times to reduce fouling in membrane bioreactors. Water Research, 2009. 43: p. 345-350.

25. Guglielmi, G., et al., Sub-critical fouling in a membrane bioreactor for municipal wastewater treatment: Experimental investigation and mathematical modelling. Water Research, 2007. 41: p. 3903-3914.

26. Cho, B.D. and A.G. Fane, Fouling transients in nominally sub-critical flux operation of a membrane bioreactor. Journal of Membrane Science, 2002. 209: p. 391-403.

27. Drews, A., C.-H. Lee, and M. Kraume, Membrane fouling - a review on the role of EPS. Desalination, 2006. 200: p. 186-188.

28. Yamato, N., et al., Difference in membrane fouling in membrane bioreactors (MBRs) caused by membrane polymer materials. Journal of Membrane Science, 2006. 280: p. 911-919.

29. Zhang, G., et al., Adsorptive fouling of extracellular polymeric substances with polymeric ultrafiltration membranes. Journal of Membrane Science, 2008. 309: p. 2835.

30. Tarleton, E.S. and R.J. Wakeman, Understanding flux decline in cross-flow microfiltration.1. Effects of particle and pore-size. Chemical Engineering Research \& Design, 1993. 71: p. 399-410.

31. Gesan-Guiziou, G., R.J. Wakeman, and G. Daufin, Stability of latex crossflow filtration: cake properties and critical conditions of deposition. Chemical Engineering Journal, 2002. 85: p. 27-34.

32. Chang, I.S., S.O. Bag, and C.H. Lee, Effects of membrane fouling on solute rejection during membrane filtration of activated sludge. Process Biochemistry, 2001. 36: p. 855-860.

33. Choi, J.-H. and H.Y. Ng, Influence of membrane material on performance of a submerged membrane bioreactor. Vol. Proceedings IWA conference Harrogate 2007.

34. Marshall, A.D., P.A. Munro, and G. Tragardh, The effect of protein fouling in microfiltration and ultrafiltration on permeate flux, protein retention and selectivity - $A$ literature review. Desalination, 1993. 91: p. 65-108.

35. Till, S.W., S.J. Judd, and B. McLoughlin, Reduction of faecal coliform bacteria in sewage effluents using a microporous polymeric membrane. Water Research, 1998. 32: p. 1417-1422. 
36. Chang, I.-S. and C.-H. Lee, Membrane filtration characteristics in membrane-coupled activated sludge systems - the effect of physiological states of activated sludge on membrane fouling. Desalination, 1998. 120: p. 221-233.

37. Mulder, M., Basic principles of membrane technology. 2nd ed. 2003, Dordrecht: Kluwer Academic Publishers.

38. van Bentem, A., and $\mathrm{H}$. van der Roest, $M B R$ energiezuiniger in de toekomst. Afvalwaterwetenschap, 2007, jaargang 6, nr. 2, pp. 105-114. 


\section{Chapter 4}

Influence of membrane properties on membrane fouling in three different activated sludge mixtures

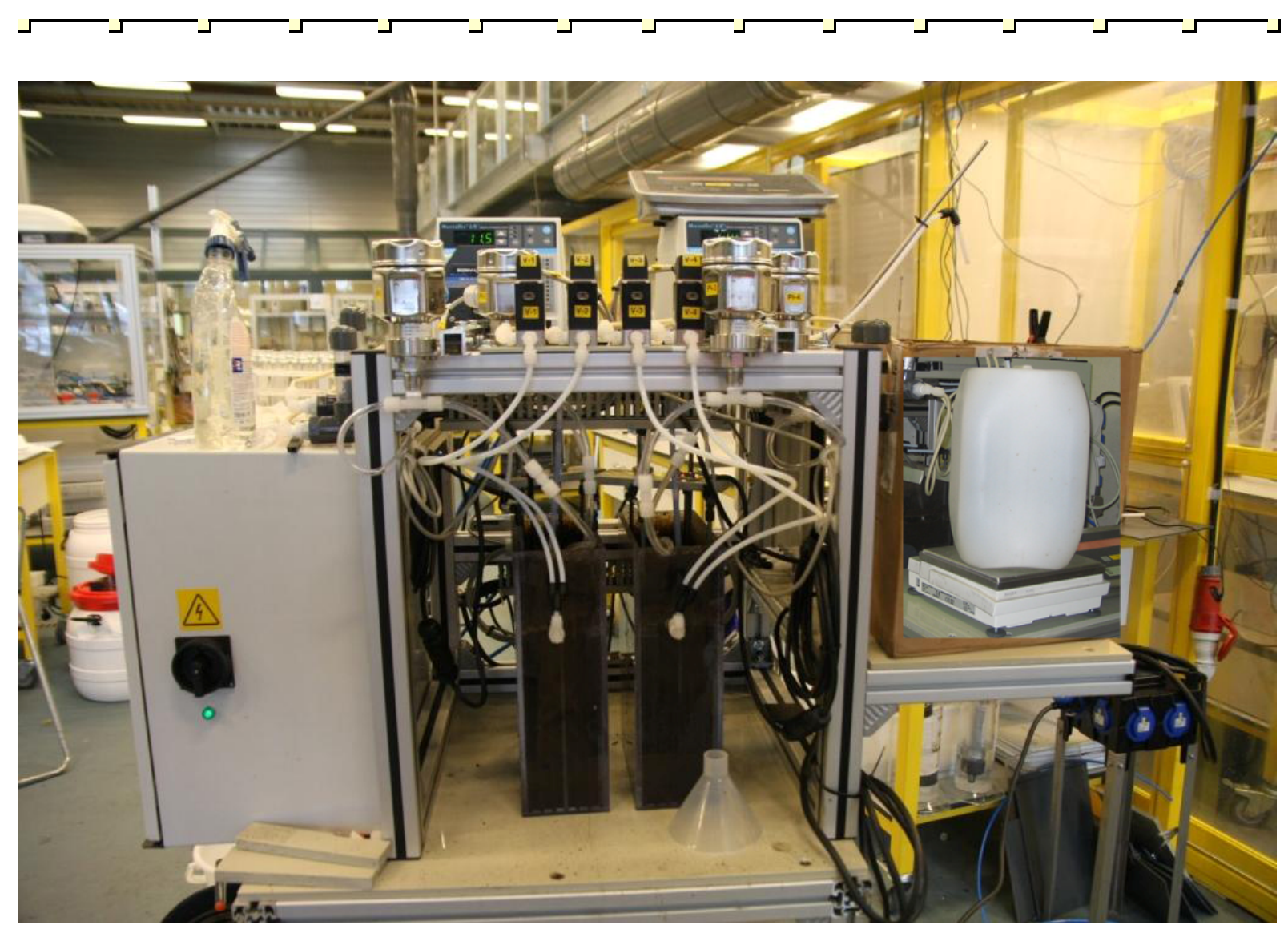




\begin{abstract}
This Chapter discusses membrane fouling for a number of membranes operated under equal operating conditions in three different activated sludge mixtures. Batches of sludge are taken from the conventional wastewater treatment plant of the city of Leeuwarden (NL). A mobile filtration set-up is placed for two months at a full scale MBR in Varsseveld (NL). The improved flux-step method and long-term experiments are performed to determine the filtration characteristics of the membranes in these two sludges. The results are compared with those previously found for sludge from the pilot-scale MBR (Chapter 3 of this thesis) to determine whether the fouling trends of different membranes are similar for different activated sludge mixtures. It is concluded that membranes with different membrane properties show the same tendency towards membrane fouling in all three sludge mixtures. The fouling is more severe for sludge from the conventional wastewater treatment plant and the MBR Varsseveld than for sludge from the pilot-scale MBR. A detailed physical and chemical analysis of the activated sludge mixtures will be necessary to explain these differences.
\end{abstract}

This Chapter will be submitted for publication as: van der Marel, P., Zwijnenburg, A., Kemperman, A.J.B., Wessling, M., Temmink, H., van der Meer, W.G.J. Influence of membrane properties on membrane fouling in three activated sludge mixtures. Water Research, 2009. 


\subsection{Introduction}

Membrane fouling is a process that increases the filtration resistance over time. It is the main bottleneck for a widespread introduction of MBR technology. Besides the membrane module configuration, three key parameters influence membrane fouling: membrane properties, membrane operational process conditions, and properties of the sludge mixture [1]. Research often focuses on one of these parameters only, without paying careful attention to the others. This contributes to contradictory findings in literature [2, 3]. For example, by fractionating activated sludge into three fractions, and subsequently measuring the resistance of each fraction, it was shown that the dominant fouling fraction was either the colloidal material [4], the particulate material [5], or the soluble material [6]. In these studies, the fractionation method, membrane properties (e.g. the membrane pore size), and feed properties (e.g. mixed liquor suspended solids (MLSS) concentration) all were different and this probably resulted in the different conclusions. Consequently, there is a need for general systematic tools to investigate membrane fouling and allow for a more adequate correlation between the results obtained in different studies [1].

The aim of the present study was to elucidate whether the fouling trends for different membranes, as determined with activated sludge of a pilot-scale MBR and described in Chapter 3 of this thesis, were also found for activated sludges of two other wastewater treatment plants (WWTPs). The same measuring principle and similar operating conditions were applied for each sludge type.

\subsection{Material and Methods}

\subsubsection{Activated sludge mixtures and membranes}

A series of flat-sheet membranes were investigated on fouling behavior using sludge from a conventional activated sludge system of the city of Leeuwarden (CAS-L), and sludge from a full scale MBR in Varsseveld (MBR-V). Both WWTPs were located in the Netherlands. Operating characteristics of the plants are given in Table 4.1. The results were compared to those obtained with the same membranes operated with sludge from a pilot-scale MBR (MBR-P), which already were extensively discussed in Chapter 3 of this thesis.

The CAS-L treats about $35,000 \mathrm{~m}^{3} \mathrm{~d}^{-1}$ of municipal wastewater, including a significant wastewater load contribution from local industry. The system consists of two parallel streets, equipped with an anaerobic compartment, denitrifying compartments, aerobic compartments, and secondary clarifiers to separate the treated water from the activated sludge. The CAS-L 
removes phosphorus biologically (Bio-P), followed by chemical phosphorus removal by iron precipitation (Chem-P). The MBR-V was started up in 2005 and treats about 3,000 $\mathrm{m}^{3} \mathrm{~d}^{-1}$ municipal wastewater. The system contains an anaerobic compartment, a denitrifying compartment, an aerobic compartment, and four parallel membrane streets for activated sludge separation. Analogous to CAS-L also Bio-P and Chem-P removal takes place in MBR-V. The membranes applied in the MBR-V are ZW500d PVDF hollow fiber membranes with a nominal pore size of $0.035 \mu \mathrm{m}$ (GE Zenon). All four membrane streets are operated simultaneously in case of a maximum hydraulic load during rain weather flow $\left(\approx 755 \mathrm{~m}^{3} \mathrm{~h}^{-1}\right)$, and only one street is operated in case of a dry weather flow of $<100 \mathrm{~m}^{3} \mathrm{~h}^{-1}$. This procedure results in a net flux of $9 \mathrm{~L} \mathrm{~m}^{-2} \mathrm{~h}^{-1}$ [7]. The MBR-P (total volume $85 \mathrm{~L}$ ) is described in detail by Remy et al. [8] and treats $0.2 \mathrm{~m}^{3} \mathrm{~d}^{-1}$ of municipal wastewater. The system is equipped with a denitrifying compartment, an aerobic compartment, and a membrane tank containing home made flat-sheet PVDF membranes with a nominal pore size of $0.1 \mu \mathrm{m}$. The net flux is $25 \mathrm{~L} \mathrm{~m}^{-2} \mathrm{~h}^{-1}$. The MBR-P was not designed for phosphorus removal.

Table 4.1 Operating conditions of the three selected WWTPs.

\begin{tabular}{|c|c|c|c|}
\hline Activated sludge & $\begin{array}{c}\text { Leeuwarden } \\
\text { CAS-L }\end{array}$ & $\begin{array}{c}\text { Varsseveld } \\
\text { MBR-V }\end{array}$ & $\begin{array}{l}\text { Wetsus } \\
\text { MBR-P }\end{array}$ \\
\hline Data averaged over & 2005 & 2008 & 2008 \\
\hline $\operatorname{MLSS}\left(\mathrm{g} \mathrm{L}^{-1}\right)^{1}$ & 4.9 & 9.2 & 10.2 \\
\hline $\operatorname{SRT}(d)$ & 25 & 25 & 50 \\
\hline Flow $\left(\mathrm{m}^{3} \mathrm{~d}^{-1}\right)$ & 34,723 & $2,937 \pm 729^{2}$ & 0.2 \\
\hline Wastewater type & Municipal + Industrial & Municipal & Municipal \\
\hline Nitrification/denitrification & Yes & yes & yes \\
\hline COD-wastewater $\left(\mathrm{mg} \mathrm{L}^{-1}\right)^{3}$ & 554 & 707 & 352 \\
\hline COD-permeate $\left(\mathrm{mg} \mathrm{L}^{-1}\right)^{3^{\prime}}$ & 34.3 & 27.4 & 33.3 \\
\hline Sludge load (gCOD g $\left.{ }^{-1} \mathrm{MLSS} \mathrm{d}^{-1}\right)$ & 0.095 & 0.062 & 0.081 \\
\hline Bio-P & yes & yes & no \\
\hline Chem-P & yes & yes & no \\
\hline
\end{tabular}

Properties of the sludge mixtures of the three WWTPs were assumed to be different as the wastewater strength and wastewater load were different and different operating conditions were applied (SRT, sludge load, Bio-P and Chem-P, and MLSS concentration). Furthermore, average chemical oxygen demands (COD) of permeates from MBR-V were lower compared to those of MBR-P over the experimental period. This may be attributed to different operating conditions and/or to differences in the membrane pore size. A membrane with a smaller pore size retains more soluble material, i.e. material smaller than $0.45 \mu \mathrm{m}[10,11]$.

The same membrane types were used for all three sludges (Table 4.2). For a detailed characterization of the membrane properties one is referred to Chapter 3 of this thesis. One hydrophilic PVDF membrane from Millipore $\left(\mathrm{PVDF}_{\mathrm{M}}\right)$ was only applied in experiments with 
the CAS-L sludge. This membrane had a symmetrical pore morphology, similar to MCE membranes.

Table 4.2 Membranes operated in three activated sludge mixtures.

\begin{tabular}{|c|c|c|c|c|c|c|c|}
\hline $\begin{array}{c}\text { Membrane } \\
\text { material }\end{array}$ & $\begin{array}{c}\text { Nominal } \\
\text { pore size } \\
(\mu \mathrm{m})\end{array}$ & $\begin{array}{c}\text { Surface } \\
\text { porosity } \\
(\%)\end{array}$ & Hydrophobicity & $\begin{array}{c}\text { Pore } \\
\text { morphology } \\
(-)\end{array}$ & CAS-L & MBR-V & MBR-P \\
\hline Home made & 0.02 & 4 & 71 & & $\bar{X}$ & $\mathrm{X}$ & $\bar{X}$ \\
\hline \multirow{3}{*}{ PVDF } & 0.03 & 6 & 69 & & $\mathrm{x}$ & & $\mathrm{X}$ \\
\hline & 0.1 & 15 & 77 & Asymmetric & $\mathrm{x}$ & $\mathrm{X}$ & $\mathrm{X}$ \\
\hline & 0.3 & 27 & n.a. & & & $x$ & $x$ \\
\hline $\mathrm{PVDF}_{\mathrm{H}}$ & 0.1 & 15 & 101 & & & $x$ & $x$ \\
\hline Millipore, $\mathrm{PVDF}_{\mathrm{M}}$ & 1.0 & 26 & n.a. & Symmetric & $x$ & & \\
\hline Toray, $\mathrm{PVDF}_{\mathrm{T}}$ & 0.07 & 7 & 84 & Asymmetric & & $x$ & $x$ \\
\hline Millipore & 0.3 & 23 & 71 & & $x$ & & $x$ \\
\hline \multirow[t]{3}{*}{ MCE } & 0.8 & 31 & * & Symmetric & $x$ & & $x$ \\
\hline & 1.8 & 37 & * & & $\mathrm{X}$ & & $\mathrm{X}$ \\
\hline & 2.7 & 41 & * & & $\mathrm{x}$ & & $\mathrm{X}$ \\
\hline Kubota, PE & 0.3 & 25 & * & Symmetric & & $x$ & $x$ \\
\hline Millipore & 0.1 & 3 & n.a. & Straight & $\mathrm{x}$ & & $\mathrm{X}$ \\
\hline \multirow[t]{2}{*}{ PC } & 0.4 & 10 & 43 & capillaries & $\mathrm{X}$ & & $x$ \\
\hline & 0.9 & 11 & 52 & & $x$ & & $x$ \\
\hline
\end{tabular}

n.a.: not available.

*: the bubble changed significantly in time due to pore infiltration.

\subsubsection{Experimental set-up}

CAS-L sludge was examined with the same experimental set-up used for MBR-P sludge. The experiments were started within $2 \mathrm{~h}$ after sludge collection from the aerobic tank of the WWTP in batches of $30 \mathrm{~L}$ per experiment, transport to the research facility and pre-sieving at $1 \mathrm{~mm}$ mesh size. The experimental set-up consisted of five filtration reactors of $5 \mathrm{~L}$ of sludge. These were operated in parallel and each reactor was equipped with two vertically placed flat-sheet membranes. Pressure transducers recorded the transmembrane pressure (TMP), a mass balance and regulating valves measured the permeate flux, and a temperature sensor determined the temperature of the activated sludge. Labview software was used to automate the set-up (permeate pumps and valves) and for data collection. The hydraulic resistance $(R)$ was calculated by Darcy's law in which the dynamic viscosity of the permeate $(\eta)$ was corrected for temperature (Equation 1.1 and 1.2, see Section 1.4.4 in Chapter 1). 


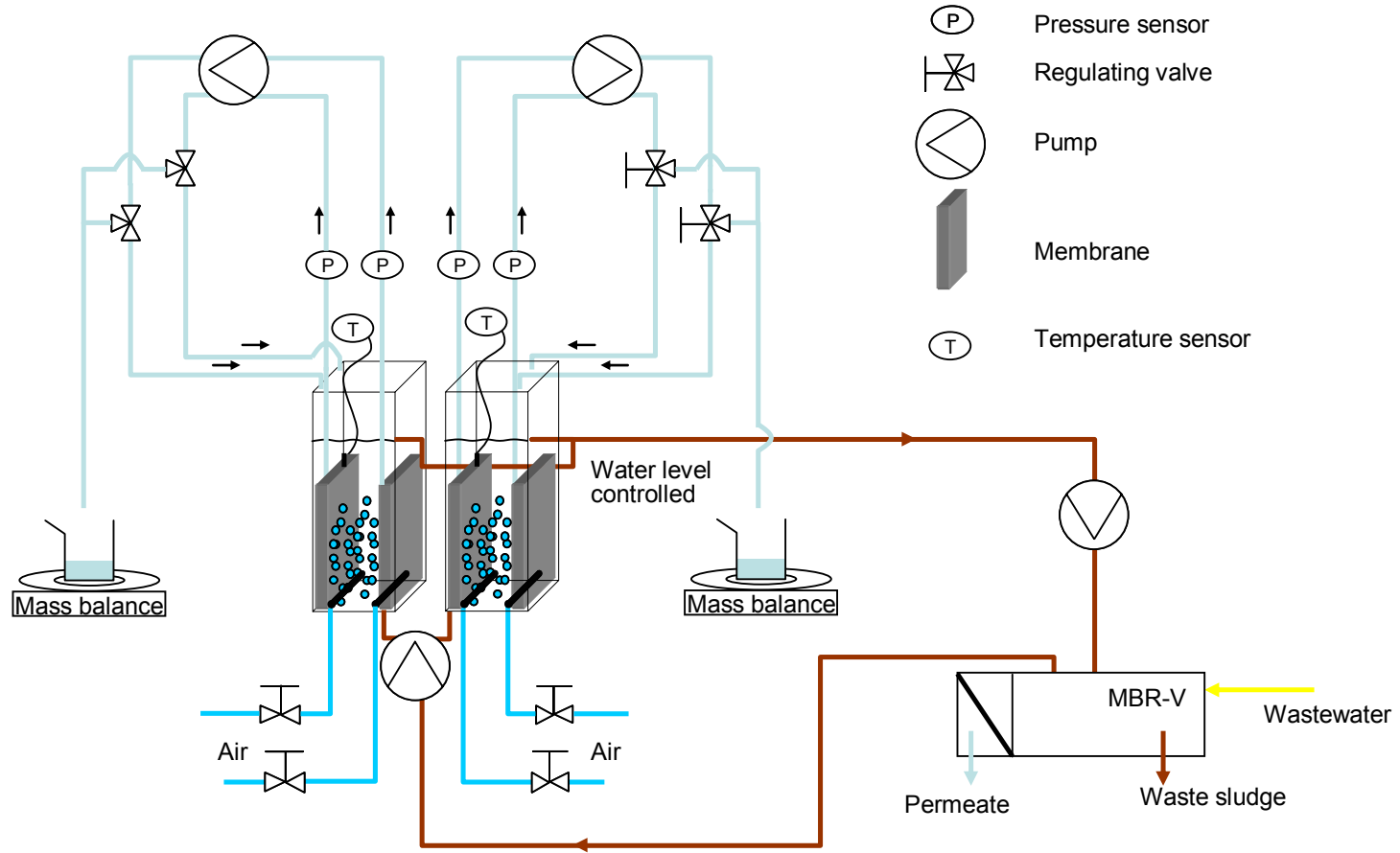

Figure 4.1 Mobile filtration unit.

Sludge from MBR-V was continuously circulated from the aerobic compartment to a mobile filtration unit. This unit was specially designed and built to perform stand-alone long-term fouling experiments at WWTPs, and was placed for two months at MBR-V. It contained the same equipment as the lab-scale filtration set-up that was used for MBR-P and CAS-L sludge, but only consisted of two filtration reactors (Figure 4.1).

\subsubsection{Experimental procedure}

Membrane fouling was examined by performing two different sets of experiments. MBR-V sludge was examined during long-term operation (100 h). A typical relaxation strategy for flat-sheet MBR's was applied [12]: in each 10 minutes of operation 8 minutes of filtration at an instantaneous flux of $31 \mathrm{~L} \mathrm{~m}^{-2} \mathrm{~h}^{-1}$ was followed by 2 minutes of relaxation. The resulting net flux, i.e. the instantaneous flux of $31 \mathrm{~L} \mathrm{~m}^{-2} \mathrm{~h}^{-1}$ corrected for the lack of permeate production during relaxation, was $25 \mathrm{~L} \mathrm{~m}^{-2} \mathrm{~h}^{-1}$. The filtration resistance just before a relaxation was applied was calculated and reported (end-resistance). The end-resistance after each $5 \mathrm{~h}$ of operation is plotted. An increase in end-resistance indicates the occurrence of irreversible fouling.

Membrane fouling also was examined with the improved flux-step method (IFSM) to determine the critical flux $\left(J_{C}\right)$ and the critical flux for irreversibility $\left(J_{C i}\right)$ for each membrane in both MBR-V and CAS-L sludge. The IFSM procedure was described in detail in Chapter 2 of this thesis and in reference [13]. Each single run of the IFSM consisted of incrementing 
flux-steps of $5 \mathrm{~L} \mathrm{~m}^{-2} \mathrm{~h}^{-1}$ from 5 to $100 \mathrm{~L} \mathrm{~m}^{-2} \mathrm{~h}^{-1}$, with an intermediate relaxation step at a low reference flux of $5 \mathrm{~L} \mathrm{~m}^{-2} \mathrm{~h}^{-1}$ in between each flux-step. The duration of each step was $0.25 \mathrm{~h}$ and one IFSM run lasted for $10 \mathrm{~h}$. When ten consecutive IFSM runs were performed, $5 \mathrm{~h}$ of relaxation were applied in between each run, resulting in $15 \mathrm{~h}$ total time per run.

Two experiments of ten consecutive runs were performed with different membranes in MBR-V sludge. Since feed properties may differ between the two experiments always one membrane PVDF $0.1 \mu \mathrm{m}$ was used as reference. Only one IFSM run was performed for each batch sample of CAS-L sludge, since circulation of sludge was not possible. Two experiments of ten consecutive runs of the IFSM method were performed with MBR-V sludge by continuous circulation of sludge from the WWTP to the filtration reactors. In each of the ten consecutive runs also the initial filtration resistances at the beginning of the runs were determined by averaging the hydraulic resistances for the first six flux-steps that where all below $J_{C}$. In this flux region there is still a linear relationship between the applied flux and obtained pressure (no fouling), resulting in the same value for the resistance at each flux-step. The initial filtration resistance for the first run was equal to the clean membrane resistance, and an increase with consecutive runs indicated the occurrence and extent of irreversible fouling.

The ISFM method results in a $J_{C}$ and a $J_{C \text { i }}$. Definitions of these flux concepts and an extensive discussion of their relation with membrane fouling mechanisms can be found in Chapter 2 of this thesis. Table 4.3 summarizes the most important aspects of this relation. When $J_{C}$ equals $J_{C i}$ for irreversibility this indicates that irreversible fouling caused by pore blocking, adsorption or gel layer formation is the dominant fouling mechanism. When $J_{\mathrm{Ci}}$ exceeds $J_{C}$ this implies the formation of a reversible cake layer at $J_{C}$, while at $J_{C i}$ cake layer compression, gel layer formation, pore blocking, or adsorption takes place.

It is important to realize that $J_{\mathrm{Ci}}$ is based on TMP differences of only $150 \mathrm{~Pa}$ and its value therefore is susceptible to experimental error. For this reason, $J_{\mathrm{Ci}}$ was considered to be approximately equal to $J_{C}$ when their difference was less than $20 \%$.

Table 4.3 Relation between the critical flux $\left(J_{C}\right)$ and the critical flux for irreversibility $\left(J_{C i}\right)$.

\begin{tabular}{ccc}
\hline Relation & Reversibility of fouling & Fouling mechanism \\
\hline$J_{\mathrm{C}}=J_{\mathrm{Ci}}{ }^{1}$ & Irreversible & $\begin{array}{c}\text { Pore blocking } \\
\text { Adsorption } \\
\text { Gel layer formation }\end{array}$ \\
\hdashline$J_{\mathrm{C}}<J_{\mathrm{Ci}}$ & $\begin{array}{c}\text { Reversible at } J_{\mathrm{C}} \\
\text { Irreversible at } J_{\mathrm{Ci}}\end{array}$ & $\begin{array}{c}\text { Cake layer formation } \\
\text { Compression of cake layer } \\
\text { Gel layer formation } \\
\text { Pore blocking or adsorption }\end{array}$ \\
\hline
\end{tabular}

${ }^{1}$ : considered to be equal when the difference is less than $20 \%$. 


\subsection{Results and discussion}

\subsubsection{Fouling trends in three activated sludge mixtures}

The results on the fouling behavior of the different membranes in CAS-L and MBR-V sludge were compared with the fouling behavior observed in MBR-P sludge (Chapter 3). Observations for MBR-P sludge are summarized in Table 4.4.

Figure 4.2 shows $J_{C}$ and $J_{C i}$ for the different membranes used in filtration of CAS-L and MBR-V sludge. The upwards arrow $(\uparrow)$ indicates critical fluxes that exceeded the maximum flux of $100 \mathrm{~L} \mathrm{~m}^{-2} \mathrm{~h}^{-1}$ that was applied in the IFSM method.

The critical fluxes for identical membranes generally were larger with MBR-P sludge, indicating that fouling was less severe than with CAS-L and MBR-V sludge. Since membrane properties and operating conditions were equal, the differences in feed properties must have caused the variation in critical fluxes. This will be briefly discussed in Section 4.3.4.

The fouling behavior of the different membranes with CAS-L and MBR-V sludge showed the same fouling trend as was found for MBR-P sludge, indicating that this tendency is not dependent on the sludge properties. For an extensive discussion explaining this trend one is referred to Chapter 3 of this thesis.

Table 4.4 Fouling behavior of different membranes in MBR-P sludge.

\begin{tabular}{llcccc}
\hline Parameter & \multicolumn{3}{l}{ Observation } \\
\hline Pore size \& surface porosity & $J_{\mathrm{C}}$ and $J_{\mathrm{Ci}}$ increased with increase in pore size and surface porosity \\
(home made PVDF, MCE, and PC membranes)
\end{tabular}

${ }^{1}:$ the number of tested membranes of this material with a different pore size and surface porosity. 
CAS-L

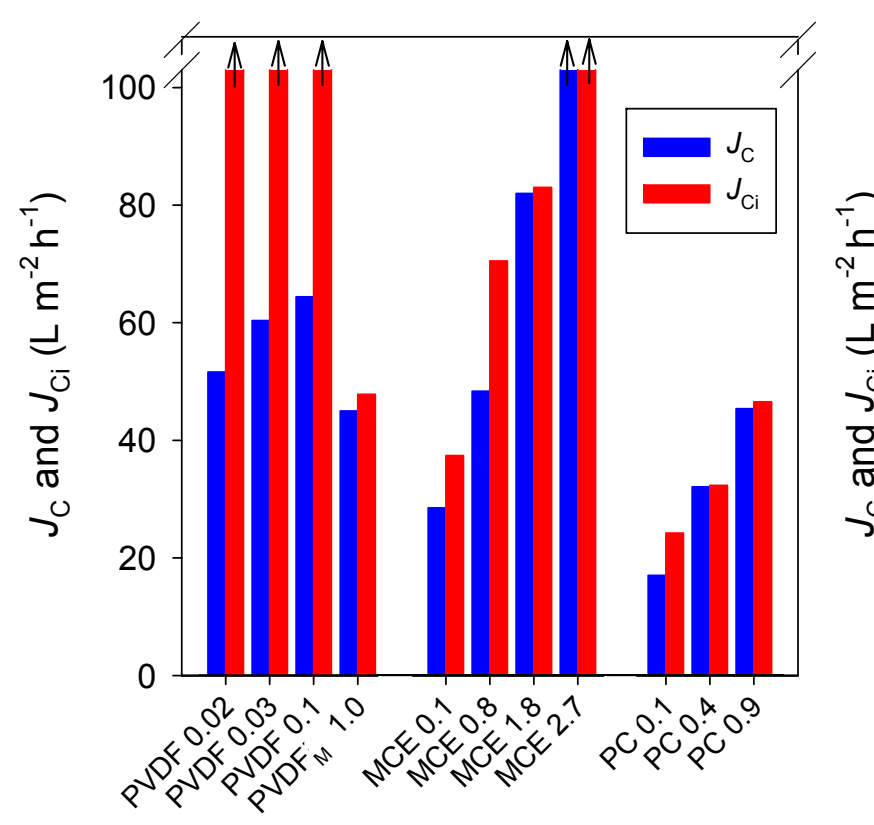

Membranes
MBR-V

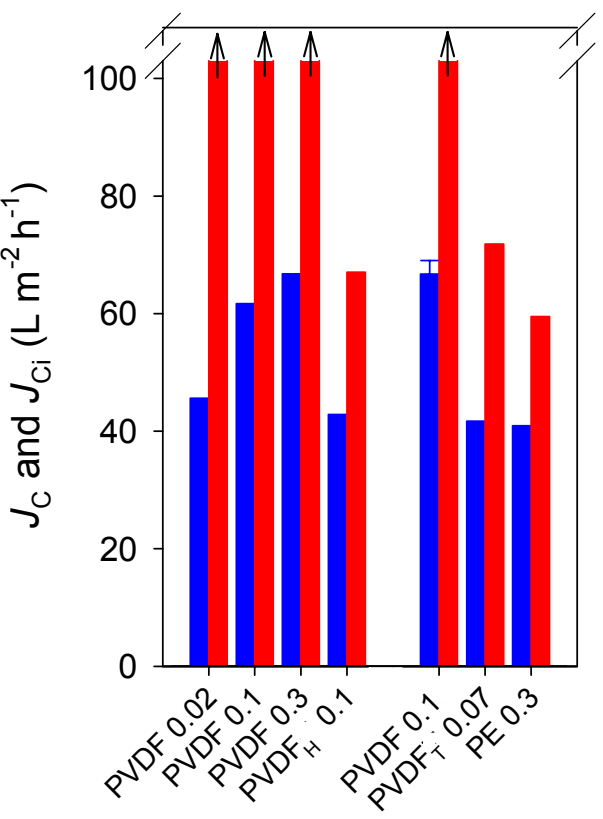

Membranes

Figure 4.2 Critical flux $\left(J_{C}\right)$ and critical flux for irreversibility $\left(J_{\mathrm{C} i}\right)$ for different membranes in filtration of activated sludge from the wastewater treatment plant of Leeuwarden (CAS-L) and from the full scale MBR in Varsseveld (MBR-V).

Comparing the fouling trends of the same membranes in different sludges revealed one remarkable difference. For membrane PE $0.3 \mu \mathrm{m} J_{\mathrm{Ci}}$ was equal to $J_{\mathrm{C}}$ in MBR-P sludge (Table 4.4) but was larger in MBR-V sludge (Figure 4.2). This difference remains to be further investigated, but could either be related to the difference in feed properties between the two activated sludges, or to the use of virgin membranes in the experiments with MBR-P sludge and the application of used membranes in MBR-V sludge. The used membrane PE $0.3 \mu \mathrm{m}$ always was extensively chemically cleaned after each experiment. This procedure however, may have altered the membrane properties such that less irreversible fouling occurred and, hence, a larger $J_{\mathrm{Ci}}$ was measured.

Membrane MCE $0.8 \mu \mathrm{m}$ showed a relatively large $J_{\mathrm{Ci}}$ compared to $J_{\mathrm{C}}$ in the CAS-L sludge, whereas membranes MCE $0.1 \mu \mathrm{m}$ and MCE $1.8 \mu \mathrm{m}$ gave approximately identical values for $J_{C}$ and $J_{\mathrm{Ci}}$. This remarkable difference between the MCE membranes also was found in MBR-P sludge (see Figure 3.2 in Chapter 3), but an explanation for this observation is not found yet. Particle size distributions (PSD) of CAS-L sludge and of activated sludge after $5 \mu \mathrm{m}$ paper-filtration (filtrate) were measured (see Appendix I). The filtrate was examined with photon cross-correlation, enabling PSD measurements in the range of $1 \mathrm{~nm}$ to $10 \mu \mathrm{m}$. The filtrate clearly showed the absence or only low amounts of material in the range of the nominal pore size of membrane MCE $0.8 \mu \mathrm{m}$, and significant amounts of material in the pore size range of membrane MCE $0.1 \mu \mathrm{m}$ and membrane MCE $1.8 \mu \mathrm{m}$. It was hypothesized that 
the smaller number of particles in the pore size range of membrane MCE $0.8 \mu \mathrm{m}$ decreased the degree of pore blocking by dirt loading. This caused its relatively large $J_{\mathrm{Ci}}$.

Membrane $\mathrm{PVDF}_{\mathrm{M}}$ was only examined in CAS-L sludge. It was clear that membrane PVDF $_{M}$ was more susceptible to fouling compared to home made PVDF membranes. $J_{C}$ was lower despite the larger pore size and surface porosity of $\mathrm{PVDF}_{\mathrm{M}}$, and the fouling was primarily irreversible since $J_{C}$ was approximately equal to $J_{C i}$. Analogous to MCE membranes and membrane PE $0.3 \mu \mathrm{m}$ (see Figure 3.4 in Chapter 3 ), the irreversible fouling was attributed to particles that became entrapped in the symmetric pore morphology (dirt-loading, Figure 4.3). The fouled $\mathrm{PVDF}_{\mathrm{M}}$ membrane reveals closed pores by activated sludge. The exterior part of the membrane also is visible in this image, which shows that the fouling occurred in the membrane matrix.

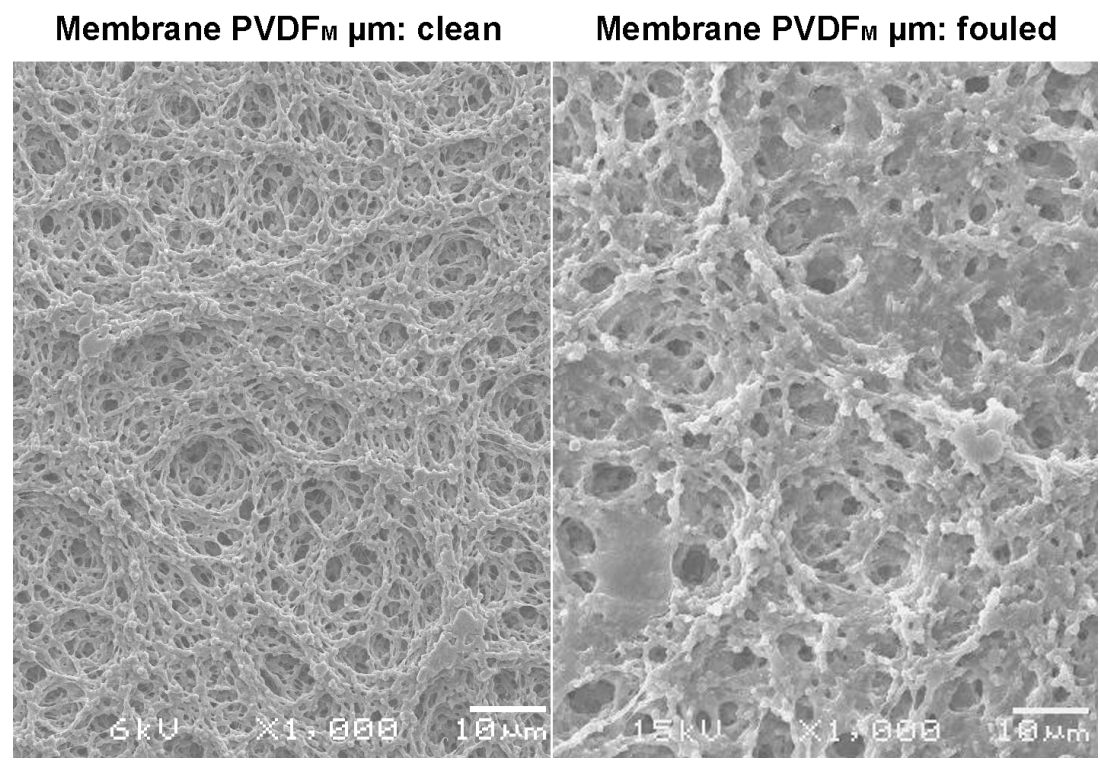

Figure 4.3 Clean and fouled surfaces of membrane $\mathrm{PVDF}_{\mathrm{M}}$ from Millipore after one run of the improved flux-step method at equal magnification (1,000x).

\subsubsection{Consecutive IFSMs using MBR-V activated sludge}

Figure 4.4 shows the development of the initial membrane resistance in time in two experiments of ten consecutive runs of the IFSM method using MBR-V sludge (Exp. 1 and Exp. 2). In Exp. 2 two PVDF $0.1 \mu \mathrm{m}$ membranes were used. The results of the two PVDF $0.1 \mu \mathrm{m}$ membranes were averaged and plotted with their standard deviation.

The increase in initial membrane resistance over time was more severe for MBR-V sludge compared to that for MBR-P sludge (see Figure 3.3 in Chapter 3). For the latter, no significant increase in initial resistance was observed in ten consecutive runs for the hydrophilic PVDF membranes, and a total increase of 42, 8 , and $28 \times 10^{10} \mathrm{~m}^{-1}$ for 
membranes $\mathrm{PVDF}_{\mathrm{H}} 0.1 \mu \mathrm{m}, \mathrm{PVDF}_{\mathrm{T}} 0.07 \mu \mathrm{m}$, and PE $0.3 \mu \mathrm{m}$, respectively. The trends and relative differences in initial membrane resistance increase for the various membranes in MBR-V sludge however, were similar to those observed for MBR-P sludge reported in Chapter 3. This again confirms that the fouling trend for a number of different membranes was independent of the sludge type used, at least for the three sludges investigated.

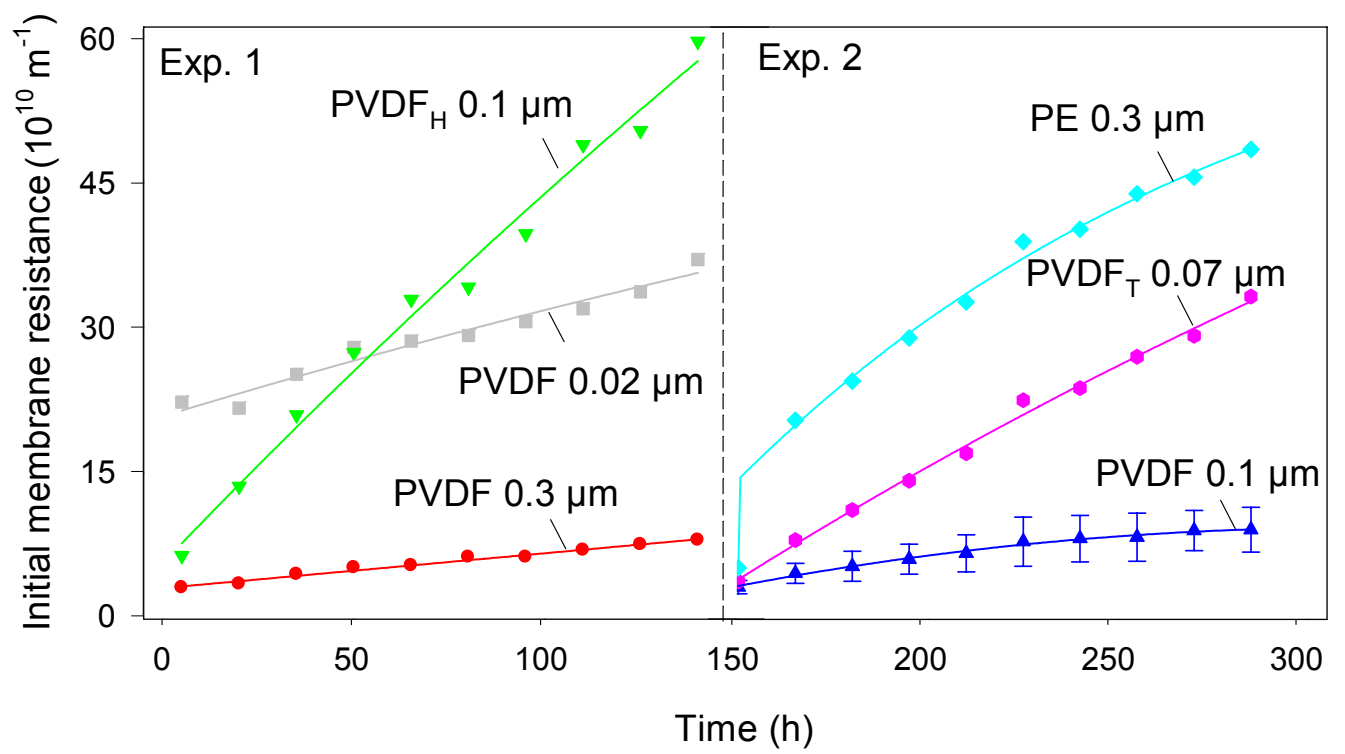

Figure 4.4 The development of the initial membrane resistance in two experiments consisting of ten consecutive runs using MBR-V sludge.

For each membrane, the increase in initial membrane resistance could partially be attributed to an unevenly distributed fouling deposition on the membrane surface, which could be observed visually (see Appendix II). The deposition was caused by sludge particles and by gel layer formation, and could be removed by intensive rinsing with a forward flush. Since on SEM images no internal fouling could be observed for the home made PVDF membranes, this surface deposition was considered to be the only cause of the increase in initial membrane resistance for membranes PVDF $0.02 \mu \mathrm{m}$ and PVDF $0.3 \mu \mathrm{m}$ in Exp. 1 and membrane PVDF $0.1 \mu \mathrm{m}$ in Exp. 2. During the ten consecutive runs, the aerator of membrane PVDF $0.1 \mu \mathrm{m}$ that also was used in Exp. 1 became clogged with sludge causing an insufficient cleaning by aeration. Therefore the results of this membrane are not shown in Figure 4.4 .

The increase in initial membrane resistance was most severe for the hydrophobic membrane $\mathrm{PVDF}_{\mathrm{H}} 0.1 \mu \mathrm{m}$, which was also the case in MBR-P sludge. This can be explained by its larger affinity for membrane foulants compared to hydrophilic membranes [1]. Although no significant difference in fouling deposition between membrane PE $0.3 \mu \mathrm{m}$ and membrane PVDF $0.1 \mu \mathrm{m}$ was observed visually (Appendix II), the increase in initial resistance of PE $0.3 \mu \mathrm{m}$ was much higher than that of PVDF $0.1 \mu \mathrm{m}$. This was attributed to fouling 
deposition and to pore blocking of the PE $0.3 \mu \mathrm{m}$ membrane, as also was elucidated by SEM on fouled membranes showing a blocked membrane matrix. Visual observation of the $\mathrm{PVDF}_{\mathrm{T}} 0.07 \mu \mathrm{m}$ membrane revealed that it discolored from white to brown, whereas the other PVDF membranes did not, or only to a much lesser extent. Colorization of $\mathrm{PVDF}_{\mathrm{T}} 0.07 \mu \mathrm{m}$ was also found with MBR-P sludge, and was attributed to irreversible adsorption of organic foulants (humic substances or EPS) on the membrane surface. Adsorption together with fouling deposition resulted in the more severe increase of the initial membrane resistance for membrane $\mathrm{PVDF}_{\mathrm{T}} 0.07 \mu \mathrm{m}$ compared to home made PVDF membranes.

\subsubsection{Long-term filtration at a fixed flux with MBR-V sludge}

Figure 4.5A shows the end-resistances during a long-term experiment at a net flux of $25 \mathrm{~L} \mathrm{~m}^{-2} \mathrm{~h}^{-1}$ performed with MBR-V sludge, and using home made PVDF membrane PVDF $0.1 \mu \mathrm{m}$ and two commercial flat-sheet membranes $\left(\mathrm{PVDF}_{\mathrm{T}} 0.07 \mu \mathrm{m}\right.$ and PE $\left.0.3 \mu \mathrm{m}\right)$. An increase of the end-resistance indicates the occurrence of irreversible fouling. Fig $4.5 \mathrm{~B}$ shows the results previously described in Chapter 3 , for the same membranes but with MBR-P sludge instead of MBR-V sludge. In the MBR-P sludge experiments a step-wise increase in flux and no relaxation was employed, and therefore the resistances and not end-resistances are shown.
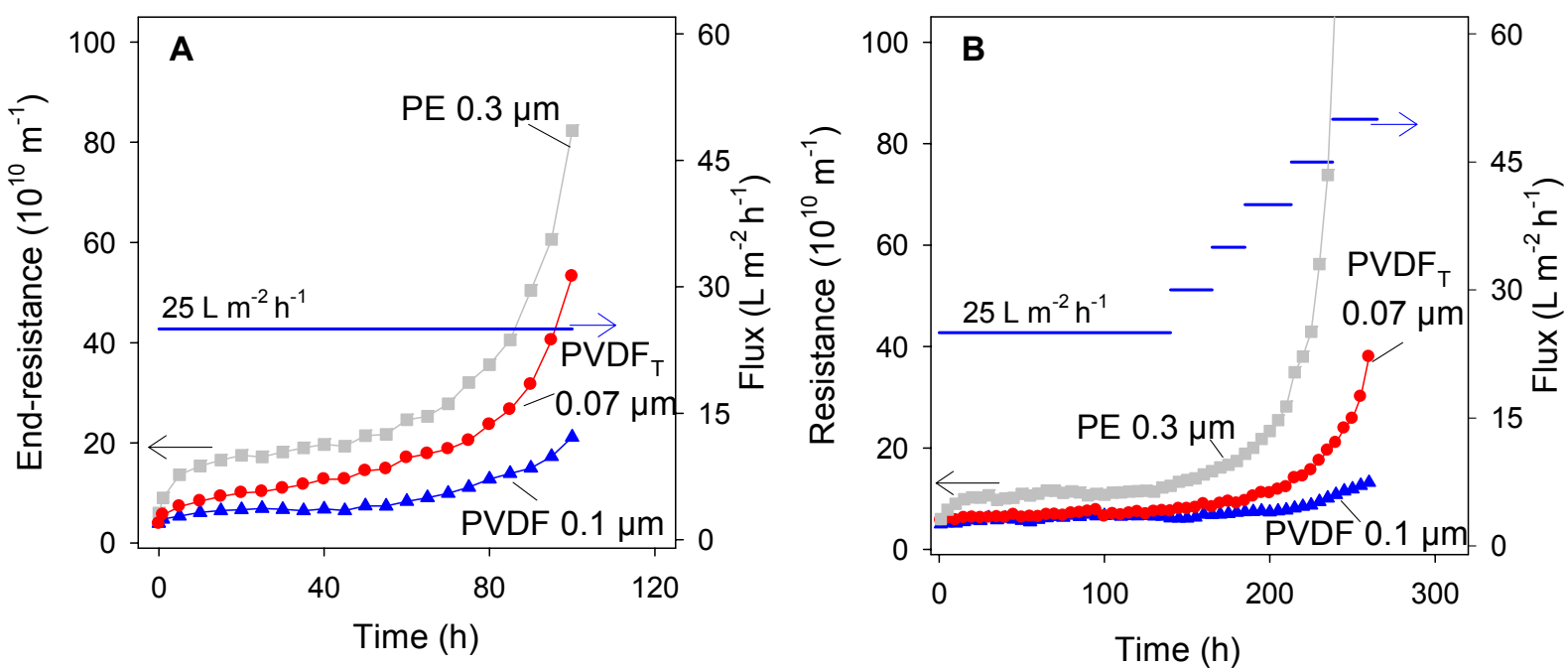

Figure 4.5 Filtration resistances in long-term filtration for $100 \mathrm{~h}$ at a net flux of $25 \mathrm{~L} \mathrm{~m}^{-2} \mathrm{~h}^{-1}$ in MBR-V sludge (A) and fixed flux filtration at various fluxes in MBR-P sludge (B, from Figure 3.7 in Chapter 3).

For all three membranes the net flux of $25 \mathrm{~L} \mathrm{~m}^{-2} \mathrm{~h}^{-1}$ as well as the instantaneous flux of $31 \mathrm{~L} \mathrm{~m}^{-2} \mathrm{~h}^{-1}$ were well below their critical fluxes (Figure 4.2). Despite this, they all exhibited irreversible fouling (A). The differences in fouling behavior between membranes 
PVDF $0.1 \mu \mathrm{m}, \mathrm{PE} 0.3 \mu \mathrm{m}$, and $\mathrm{PVDF}_{\mathrm{T}} 0.07 \mu \mathrm{m}$ in MBR-V sludge was similar to that observed when using MBR-P sludge (B), even though the operating conditions applied in both sludges were different which affected membrane fouling. Despite the application of intermediate relaxation steps with MBR-V sludge, at the net flux of $25 \mathrm{~L} \mathrm{~m}^{-2} \mathrm{~h}^{-1}$ more severe fouling occurred in time with this sludge compared to a fixed-flux operation at a flux of $25 \mathrm{~L} \mathrm{~m}^{-2} \mathrm{~h}^{-1}$ with MBR-P sludge (please notice the different time scale on the $x$ axis). The three different membranes clearly showed a similar fouling trend in both sludges. The two-stage fouling process was caused by gradual irreversible fouling (stage 1) followed by gel layer formation on the fouled membranes (stage 2) causing the rapid rise in resistance. Membranes PE $0.3 \mu \mathrm{m}$ and PVDF $_{\mathrm{T}} 0.07 \mu \mathrm{m}$ exhibited more irreversible fouling compared to membrane PVDF $0.1 \mu \mathrm{m}$, due to more severe pore blocking and adsorption, respectively. Membrane PVDF $0.1 \mu \mathrm{m}$ showed superior filterability with respect to the smallest increase of the end-resistance in time, indicating the least amount of irreversible fouling.

\subsubsection{Fouling behavior in different activated sludges}

Membrane fouling was more severe in CAS-L and MBR-V sludge compared to MBR-P sludge. The critical fluxes in sludges from these two full scale WWTPs were lower. The increase in membrane resistance during ten consecutive runs of the IFSM method and during long-term filtration was more severe in MBR-V sludge than in MBR-P sludge. Since membrane properties and operating conditions were the same, these differences must have been caused by the feed properties [2]. Based on the differences in operating conditions, such as the wastewater load MLSS, and SRT, it was concluded in section 4.2.1 that the feed properties of the three WWTPs must have been different. A detailed investigation of the different feed properties however was not carried out.

Lower critical fluxes for MBR-P sludge were expected when the MLSS concentrations of the sludges were considered. MLSS concentrations of CAS-L sludge and MBR-V sludge were lower compared to MBR-P sludge (4.9, 9.2 and $10.2 \mathrm{~g} \mathrm{~L}^{-1}$, respectively). The viscosity of activated sludge increases with increasing MLSS concentrations [12]. Consequently, the shear exerted by air scouring is expected to be larger in CAS-L sludge due to its low MLSS concentration, resulting in a higher $J_{C}$. The feed-membrane interaction obviously is much more complex and dominated by other feed properties than MLSS concentration alone [12]. Many papers have reported controversial findings with an increase, decrease or no effect on membrane fouling with varying MLSS concentration [5, 14-16].

The less severe fouling observed when using MBR-P sludge possibly could be attributed to the longer SRT applied in this system. The SRT is considered as one of the most important parameters in activated sludge processes affecting the biological treatment performance [11]. The SRT was 25 days for MBR-V and CAS-L whereas it was 50 days for MBR-P (Table 4.1 in section 4.2.1). Previous research showed a shorter SRT increased particularly 
the colloidal concentration [17, 18]. It is this fraction that is generally considered to be dominant in membrane fouling, and it could explain the less severe fouling observed in MBR-P sludge.

\subsection{Conclusions}

In this Chapter fouling of a number of different membranes was examined under equal operating conditions using three activated sludge mixtures from different WWTPs. It was found that membranes with different membrane properties showed similar fouling trends towards membrane fouling in each sludge type. Out of the 16 different membrane types examined the home made PVDF $0.1 \mu \mathrm{m}$ membrane remained superior in all three sludge mixtures. The extent of fouling however differed depending on the sludge used, and a more detailed investigation of the sludges and its relation to the degree of fouling should be a future topic of investigation.

\subsection{Acknowledgements}

Frank Niesink and Gert Doornink of the water board 'Rijn and IJssel' are acknowledged for their enthusiasm and support during the experimental trials at the full scale MBR Varsseveld. Without your help it was not yet possible to run the stand-alone mobile set-up continuously.

Philip Schijns of the water board 'Rijn and IJssel' is acknowledged for allowing us to perform the measurements at the MBR Varsseveld.

Andre van Benthem of DHV is acknowledged for supplying us a detailed overview of the analyses performed on the MBR Varsseveld during the last three years, and for the full scale permeability data of the MBR during the period of our research. 


\subsection{Used symbols and abbreviations}

Symbol

Unit

\begin{tabular}{llc}
\hline Bio-P & Biological phosphorus removal & \\
CAS-L & Conventional activated sludge system of Leeuwarden & \\
Chem-P & Chemical phosphorus removal & \\
COD & Chemical oxygen demand & $\mathrm{mg} \mathrm{L}^{-1}$ \\
EPS & Extracellular polymeric substances & \\
FF & Forward flush & \\
IFSM & Improved flux-step method & $\mathrm{L} \mathrm{m}^{-2} \mathrm{~h}^{-1}$ \\
$J_{C}$ & Critical flux & $\mathrm{L} \mathrm{m}^{-2} \mathrm{~h}^{-1}$ \\
$J_{C i}$ & Critical flux for irreversibility & \\
MBR & Membrane bioreactor & \\
MBR-P & Pilot-scale MBR operated in the research facility at Wetsus & \\
MBR-V & Full scale MBR in Varsseveld & \\
MLSS & Mixed liquor suspended solids & $\mathrm{g} \mathrm{L}^{-1}$ \\
PSD & Particle size distribution & \\
PVDF & Polyvinylidenedifluoride & \\
SEM & Scanning electron microscope & $\mathrm{d}$ \\
SRT & Solids retention time & $\mathrm{Pa}^{-1}$ \\
TMP & Transmembrane pressure & \\
WWTPs & Wastewater treatment plants &
\end{tabular}




\section{Appendix I: Particle size distributions (PSD)}

The activated sludge of the conventional activated sludge system of the wastewater treatment plant of Leeuwarden (CAS-L) was analyzed on its particle size distribution (PSD). Figure 4.6 shows on the left side the PSD of the total activated sludge mixture that was measured with laser diffraction using a particle size analyzer of Sympatec GmbH (HELOS $(\mathrm{H} 0169))$. The interaction of the laser light with the particles can be described mathematically, and its diffraction relates to the particle size. This method supplied no information on particle size in the range of pore sizes of the membranes tested.
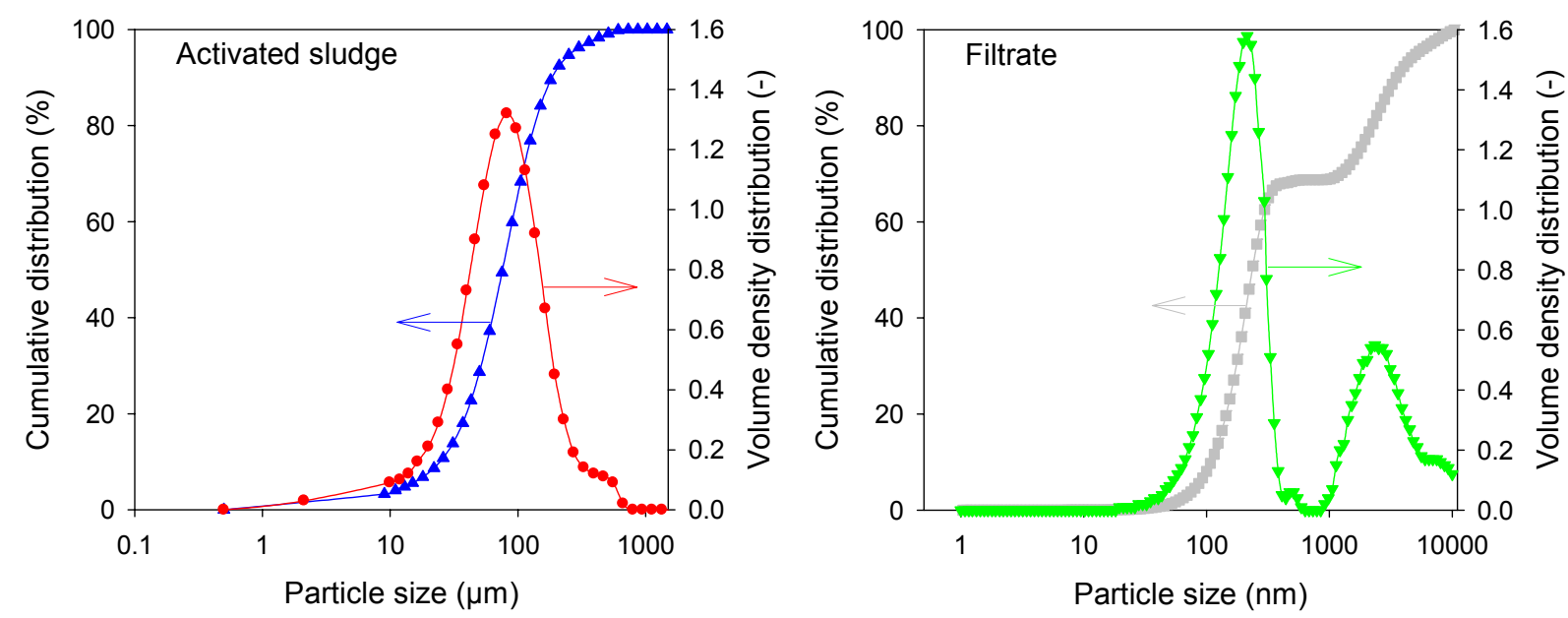

Figure 4.6 Particle size distributions (PSD) of CAS-L sludge (left) and paper filtrate (right).

A different PSD tool was used to analyze sludge filtrate, containing particles in the range of the membrane pore size. Photon cross correlation spectroscopy was performed to analyze the particle size range of $1 \mathrm{~nm}$ to several $\mu \mathrm{m}$ (Sympatec $\mathrm{GmbH}$ (NANOPHOX (0109P)). This technique is similar to dynamic light scattering (or photon correlation spectroscopy) that is applicable for diluted suspensions. For the photon cross correlation spectroscopy the larger sludge particles were removed from the liquid by $5 \mu \mathrm{m}$ paper filtration (yellow ribbon paper filter of Schleicher \& Schuell). Please note that the $x$-axis scale of the PSD of the filtrate in Figure 4.6 is given in $\mathrm{nm}$, whereas that of the PSD of the total activated sludge mixture is given in $\mu \mathrm{m}$. Clearly the PSD of the filtrate gives information on the particle size of material in the range of the membrane pore sizes. 


\section{Appendix II: Images of fouled membranes}

For visual analysis of the fouling on the membranes, digital images of fouled and physically cleaned membranes after ten consecutive runs and from two experiments of the IFSM method in the full scale MBR Varsseveld sludge (MBR-V) are given. Intensive rinsing by a forward flush is performed with a water jet of $0.5 \times 10^{4} \mathrm{~Pa}$ of $0.5 \mathrm{~L} \mathrm{~min}^{-1}$. This forward flush removes deposited material by cake and gel layer formation.

\section{Experiment 1}

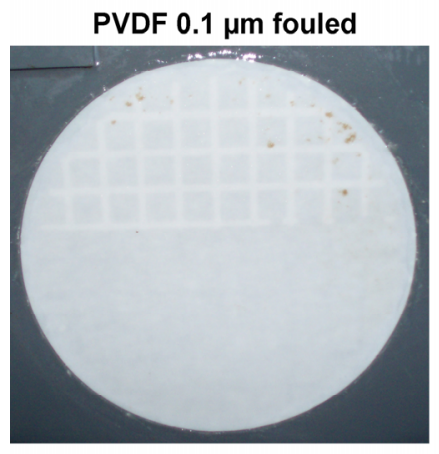

PVDF $0.1 \mu \mathrm{m}$ FF

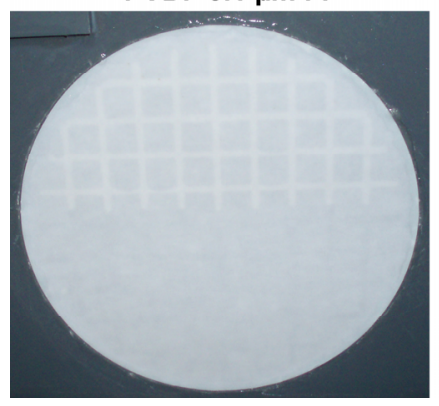

\section{Experiment 2}

PVDF $0.02 \mu \mathrm{m}$ fouled

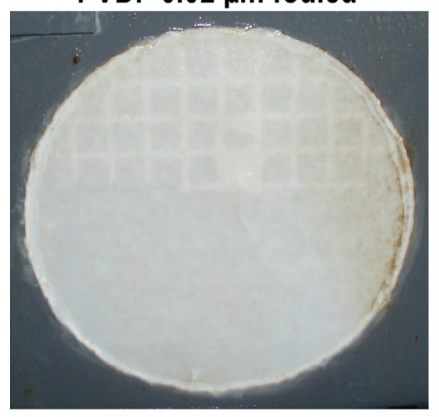

PVDF $0.02 \mu \mathrm{m}$ FF

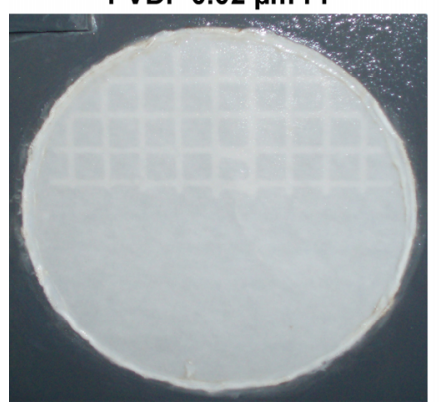

PVDFT $0.07 \mu \mathrm{m}$ fouled

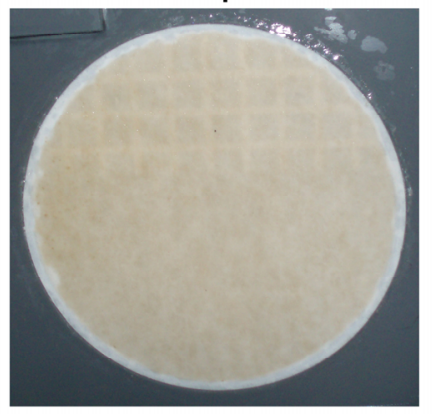

PVDFT $0.07 \mu \mathrm{m}$ FF

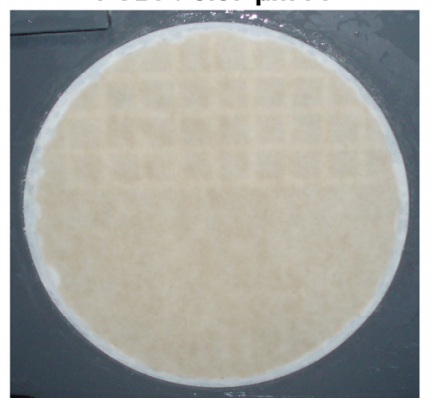

PVDF $0.3 \mu \mathrm{m}$ fouled

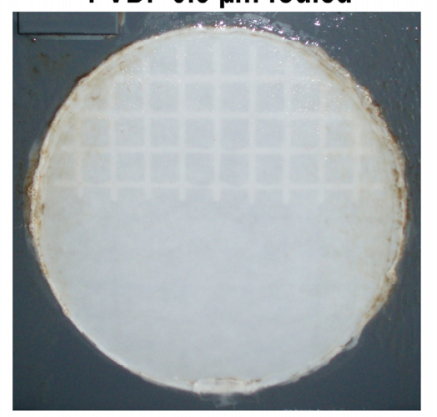

PVDF $0.3 \mu \mathrm{m}$ FF

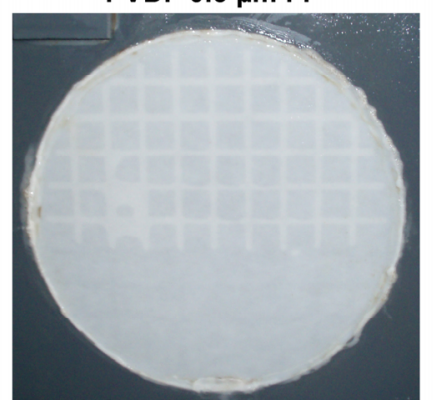

PE $0.3 \mu \mathrm{m}$ fouled

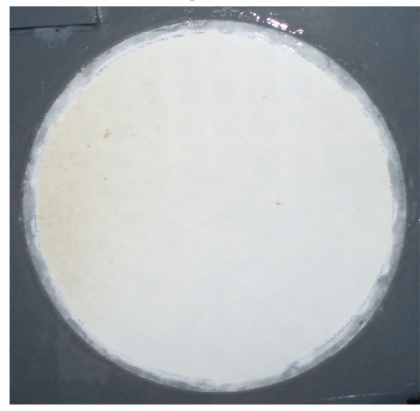

PE $0.3 \mu \mathrm{m}$ fouled

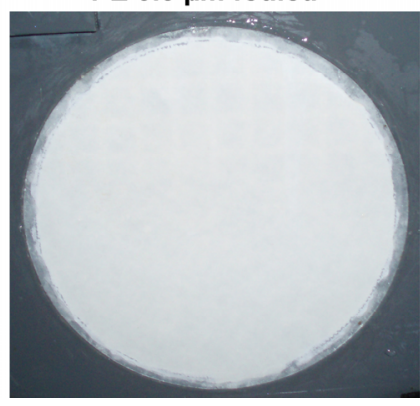

PVDFH $_{0.1 \mu \mathrm{m} \text { fouled }}$

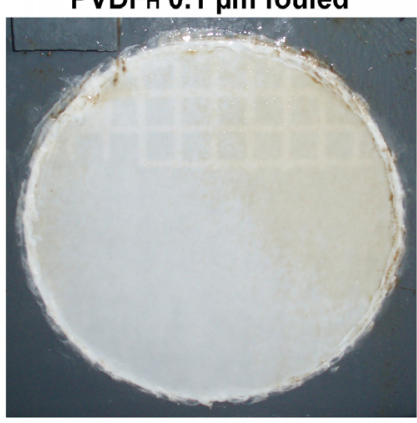

PVDFH $0.1 \mu \mathrm{m}$ FF

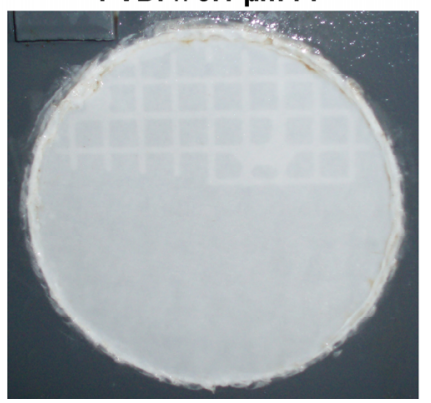




\subsection{References}

1. Le-Clech, P., V. Chen, and T.A.G. Fane, Fouling in membrane bioreactors used in wastewater treatment. Journal of Membrane Science, 2006. 284: p. 17-53.

2. Chang, I.S., et al., Membrane fouling in membrane bioreactors for wastewater treatment. Journal of Environmental Engineering, 2002. 128: p. 1018-1029.

3. Meng, F., et al., Recent advances in membrane bioreactors (MBRs): Membrane fouling and membrane material. Water Research, 2009. 43: p. 1489.

4. Bouhabila, E., R. Ben Aim, and H. Buisson, Fouling characterisation in membrane bioreactors. Separation and Purification Technology, 2001. 22-23: p. 123-132.

5. Defrance, L., et al., Contribution of various constituents of activated sludge to membrane bioreactor fouling. Bioresource Technology, 2000. 73: p. 105 - 112.

6. Wisniewski, C. and A. Grasmick, Floc size distribution in a membrane bioreactor and consequences for membrane fouling. Colloids and Surfaces A: Physicochemical and Engineering Aspects, 1998. 138: p. 403.

7. STOWA, Onderzoek MBR Varsseveld - Hoofdrapport. 1st ed. 2006, Utrecht: Kruyt grafisch advies bureau.

8. Remy, M., et al., Low dose powdered activated carbon addition at high sludge retention times to reduce fouling in membrane bioreactors. Water Research, 2009. 43: p. 345-350.

9. Clesceri, L., A. Greenberg, and A. Eaton, Standard methods for the examination of water and wastewater. 20th ed. 1998, Washington, DC: American Public Health Association, American Water Works Association, Water Environment Federation.

10. Gregory, J., Particles in Water. 1st ed. 2006, London: IWA publishing.

11. Metcalf\&Eddy, Wastewater engineering: treatment and reuse. 4th international ed. 2003, New York: McGraw-Hill.

12. Judd, S.J., The MBR Book: Principles and Applications of Membrane Bioreactors in Water and Wastewater Treatment. 1st ed. 2006, Oxford: Elsevier.

13. van der Marel, P., et al., An improved flux-step method to determine the critical flux and critical flux in a membrane bioreactor. Journal of Membrane Science, 2009. 332: p. 24-29.

14. Madaeni, S.S., A.G. Fane, and D.E. Wiley, Factors influencing critical flux in membrane filtration of activated sludge. Journal of Chemical Technology and Biotechnology, 1999. 74: p. 539-543.

15. Sato, T. and Y. Ishii, Effects of activated-sludge properties on water flux of ultrafiltration membrane used for human excrement treatment. Water Science and Technology, 1991. 23: p. 1601-1608.

16. Hong, S.P., et al., Fouling control in activated sludge submerged hollow fiber membrane bioreactors. Desalination, 2002. 143: p. 219-228.

17. Cho, J., et al., Quantitative analysis of biological effect on membrane fouling in submerged membrane bioreactor. Water Science and Technology, 2005. 51: p. 9-18.

18. Grelier, P., Rosenberger, S. and Tazi-Pain, A., Influence of sludge retention time on membrane bioreactor hydraulic performance. Desalination, 2006. 192: p. 10-17. 


\section{Chapter 5}

Backwashing versus relaxation of flat-sheet membranes in a membrane bioreactor

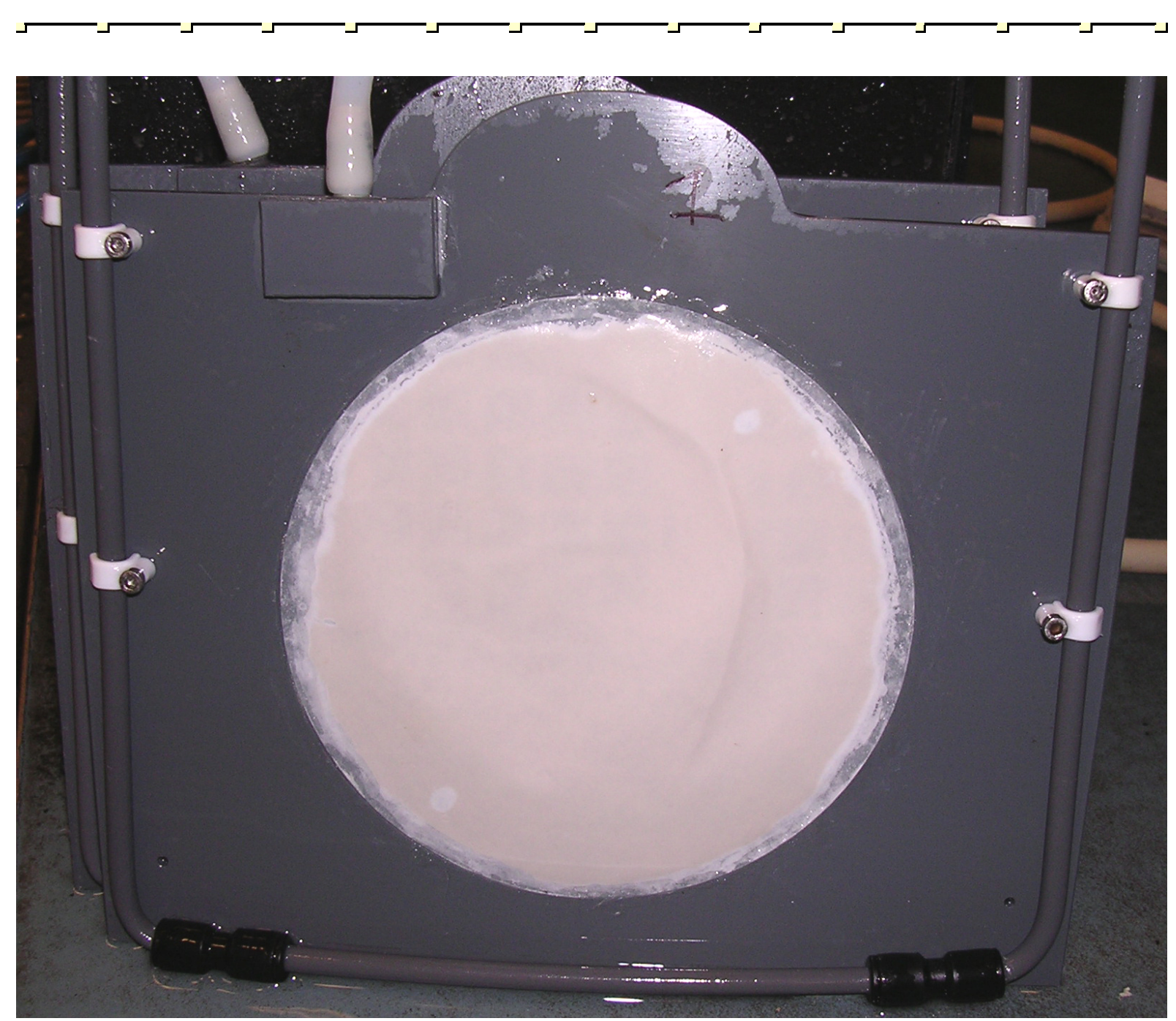




\section{Abstract}

The effectiveness of backwashing and relaxation on reducing fouling is compared for three different flat-sheet membranes in submerged membrane bioreactors. The membranes are operated at equal instantaneous and net fluxes, enabling a comparison of the effect of the two physical cleaning methods. Backwashing and relaxation are equally effective in removing membrane fouling, but both do not remove irreversible fouling caused by internal fouling and gel layer formation. A chemically enhanced backwash with sodium-hypochlorite could remove internal fouling.

P. van der Marel, A. Zwijnenburg, A.J.B. Kemperman, M. Wessling, H. Temmink, and W.G.J. van der Meer. 


\subsection{Introduction}

Membrane fouling in membrane bioreactors (MBRs) is one of the major bottlenecks hampering their widespread practical application. The filtration resistance increases due to accumulation of feed mixed liquor constituents on the surface of the membrane (cake or gel formation) or in the membrane matrix (pore blocking and/or adsorption). Intermediate physical cleaning can assist in removing these foulants and in restoring the initial filtration resistance. Fouling removed by physical cleaning is called reversible fouling, whereas fouling that is not removed by physical cleaning is defined as irreversible fouling. This classification depends on the applied physical cleaning procedure, since different cleaning methods remove different amounts of fouling. The most commonly applied physical cleaning methods in submerged MBRs are relaxation and backwashing [1, 2]. Backwashing may offer the advantage over relaxation that also internal fouling is (partly) removed. In case the fouling is irreversible, chemical cleaning is required with oxidants such as sodium-hypochlorite for organic foulants, or acids such as citric acid for removing inorganic foulants. A chemical cleaning can be performed using a cleaning-in-place (CIP) strategy by a chemically enhanced backwash (CEB) [2].

Submerged MBRs usually are equipped with polymeric hollow fiber or flat-sheet membranes. A major disadvantage of polymeric flat-sheet membranes is that they cannot be backwashed at high fluxes. This lead to the development of flat-sheet polymeric membranes and modules with a backwash capability $[3,4]$. In addition, ceramic flat-sheet membranes have become available which have a much higher mechanical strength compared to conventional polymeric flat-sheet membranes, and thus are mechanically strong enough for backwashing.

The type of fouling and its reversibility depend on the feed composition, membrane properties [5], and on operational process conditions like the physical cleaning method that is applied [6]. Due to the limited availability of backwashable flat-sheet membranes, most backwash studies in submerged MBRs were performed with hollow fiber modules [6-9]. Limited information is available on backwashing of flat-sheet membranes. The aim of this study was to compare the effect of relaxation and backwashing on fouling reversibility for three different types of flat-sheet membranes. For the fouling experiments, activated sludge from a pilot-scale MBR treating municipal wastewater was used. To allow for a good comparison between relaxation and backwashing, the MBRs were operated at identical instantaneous and net fluxes. A flux well above the critical flux $[10,11]$ was chosen to induce significant fouling. Additional cleaning by CEB also was investigated. 


\subsection{Material and Methods}

\subsubsection{Membranes}

Three different types of flat-sheet membranes were used. Polyvinylidenefluoride membranes (PVDF) were prepared using a diffusion induced phase inversion method by casting a PVDF dope solution on a polyester non-woven material and immersing it in a nonsolvent bath. This membrane was called 'PVDF $0.1 \mu \mathrm{m}$ ' in the previous Chapters. Hydrophilised, chlorinated polyethylene membranes (PE) were cut from commercial Kubota A4 modules, and was coded 'PE $0.4 \mu \mathrm{m}$ '. A ceramic flat-sheet membrane module with a pore size of $0.2 \mu \mathrm{m}$ ('CER $0.2 \mu \mathrm{m}$ '), was obtained from ItN Nanovation AG (Germany). The ceramic membrane was made of aluminum oxide $\left(\mathrm{Al}_{2} \mathrm{O}_{3}\right)$, had a multi-channel geometry, and was operated with outside-in filtration from both sides of the module. Table 5.1 shows the most relevant membrane parameters. The nominal pore sizes were taken from specifications provided by the membrane suppliers or measured after image analysis of images obtained by a JEOL-6480LV Scanning Electron Microscope (SEM) for the home made PVDF membrane. The membrane resistance $\left(R_{\mathrm{m}}\right)$ was calculated from clean-water flux experiments using demineralized water purified by a Milli-Q system from Millipore as feed. Additionally, SEM images also were made of clean cross-sections of each membrane type to elucidate differences in pore morphology. Furthermore, SEM images of the surfaces of both fouled and cleaned membranes were made to identify fouling mechanisms.

Table 5.1 Membrane parameters.

\begin{tabular}{cccc}
\hline Supplier & Material & $\begin{array}{c}\text { Nominal pore size } \\
(\boldsymbol{\mu m})\end{array}$ & $\begin{array}{c}\boldsymbol{R}_{\mathrm{m}} \\
\left(\mathbf{1 0}^{\mathbf{1 0}} \mathbf{~ m}^{-1}\right)\end{array}$ \\
\hline Home made & $\mathrm{PVDF}$ & 0.1 & $4.3 \pm 0.6$ \\
Kubota & $\mathrm{PE}$ & 0.4 & $4.6 \pm 0.7$ \\
ItN-Nanovation & $\mathrm{Al}_{2} \mathrm{O}_{3}$ & 0.2 & $9.0 \pm 0.7$ \\
\hline
\end{tabular}

The outer part of the circular polymeric membranes was glued on a PVC support plate, resulting in an effective surface area of $0.014 \mathrm{~m}^{2}$ (Figure 5.1A). A cyanoacrylate UV adhesive was used (Loctite, 4305) to prevent membrane detachment during backwashing. The ceramic membrane module was mounted vertically in a PVC plate (Figure 5.1B). Filtration for the ceramic membrane was carried out from both sides, resulting in a larger membrane surface area $\left(0.039 \mathrm{~m}^{2}\right)$ than that for the polymeric membranes. An aerator was placed underneath all membranes (one aerator at each side of the ceramic module), providing a $0.4 \mathrm{~m}^{3} \mathrm{~h}^{-1}$ tangential air flow across the membrane surface at approximately $0.25 \mathrm{~m} \mathrm{~s}^{-1}$ superficial velocity. 

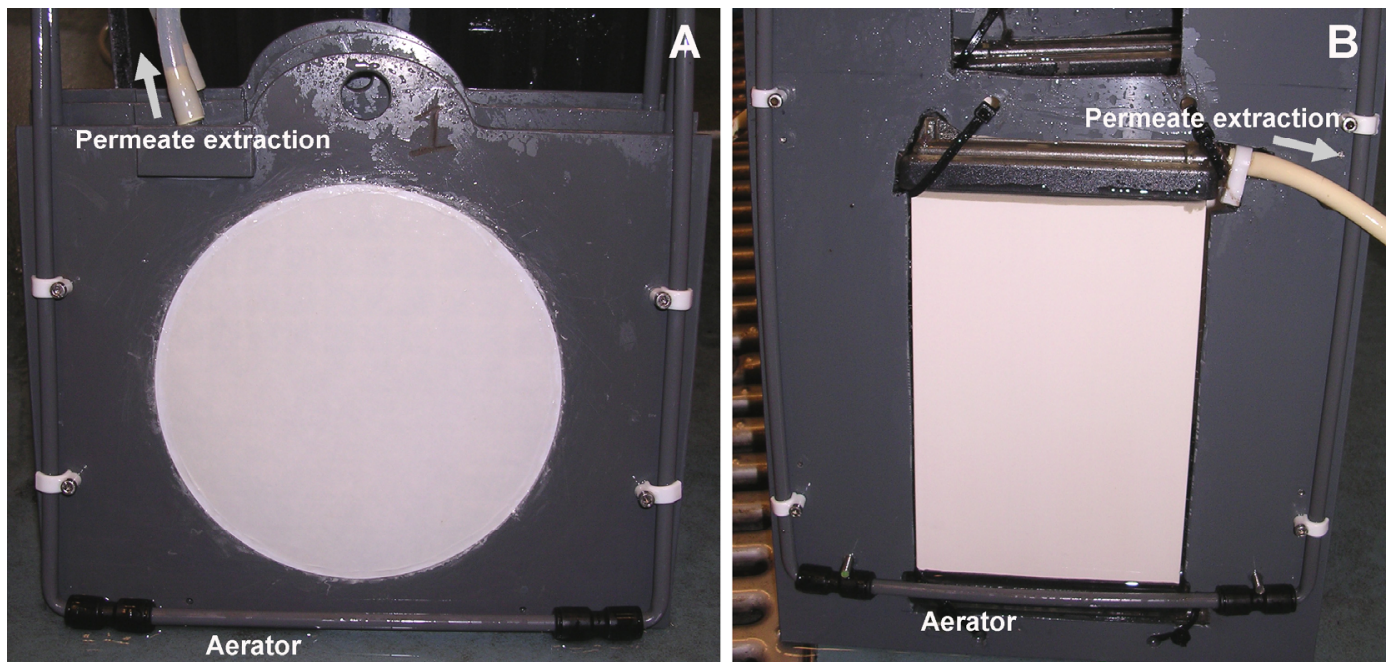

Figure 5.1 Plate and frame module for polymeric membranes $(A)$ and for the ceramic membrane (B).

\subsubsection{Experimental set-up}

A lab-scale filtration set-up was used for the experiments (Figure 5.2). Two flat-sheet polymeric membranes were placed vertically at each side in the reactor. One membrane was operated using intermediate backwash steps and the other with intermediate relaxation steps. For the ceramic membrane these cleaning methods were examined consecutively, since only one ceramic membrane module was available. Activated sludge from a $85 \mathrm{~L}$ pilot-scale MBR fed with municipal wastewater [12] circulated through the filtration set-up. The reactor volume and the hydraulic retention time in the filtration set-up were kept constant at $5 \mathrm{~L}$ and $1 \mathrm{~h}$, respectively.

Permeate was extracted and recycled to the filtration set-up in case of relaxation experiments, or to a permeate vessel in the case of backwashing. The pumps were controlled by Labview software (National Instruments). The transmembrane pressure was calculated from absolute pressures measured with pressure sensors (Endress and Hauser, Cerabar M). The imposed flux through the membrane was checked each $5 \mathrm{~h}$ by transferring the permeate flow for 2 minutes to a mass balance. A temperature sensor measured the temperature of the activated sludge mixture to allow correction of the dynamic viscosity of the permeate for temperature. The hydraulic resistance was calculated by Darcy's law (Equation 1.1 and 1.2, see Section 1.4.4 in Chapter 1). 


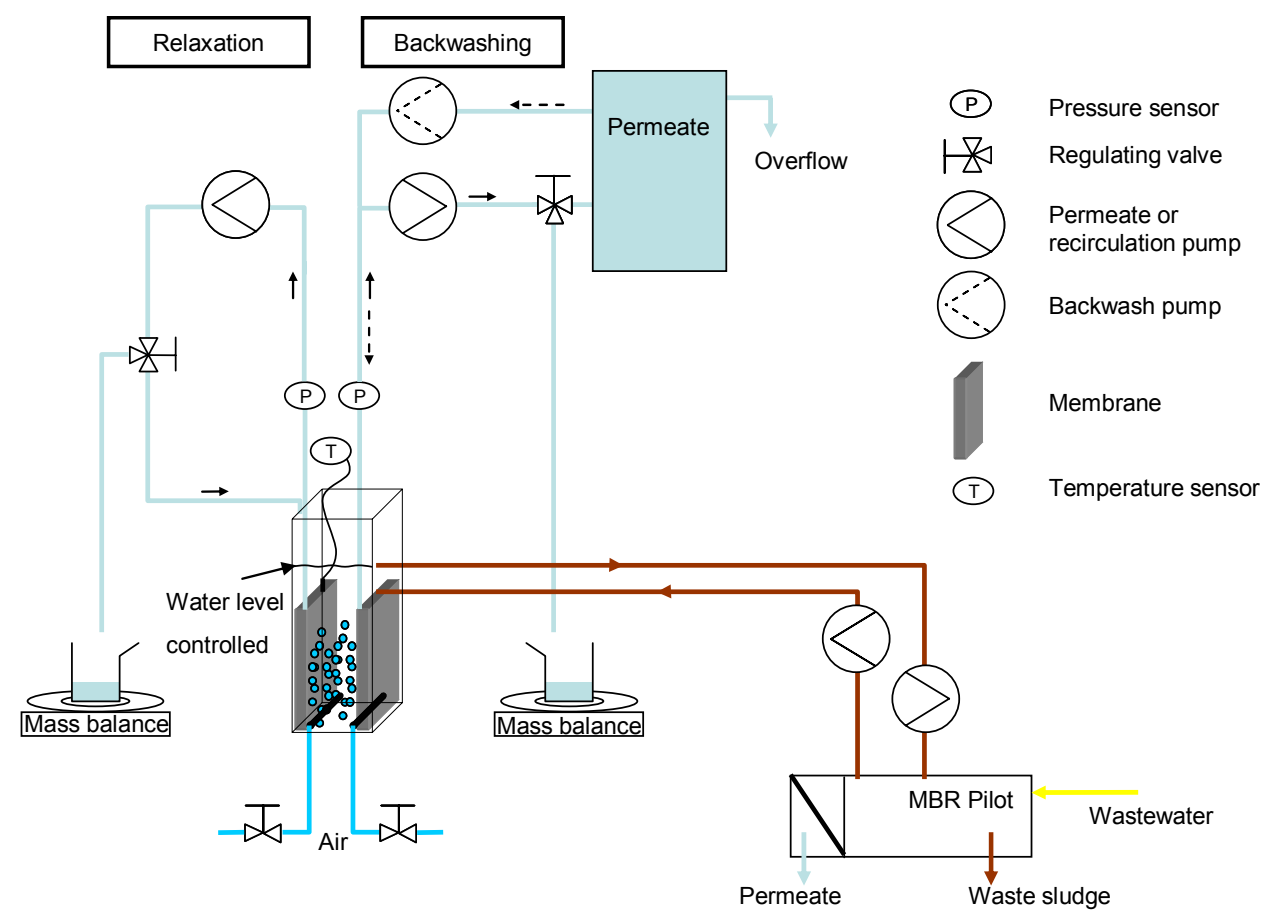

Figure 5.2 Schematic representation of the experimental filtration set-up.

\subsubsection{Experimental procedure}

Both the instantaneous and the net flux (i.e. the instantaneous flux corrected for the loss of permeate during the cleaning step) affect membrane fouling [6], and therefore these were chosen to be the same for both physical cleaning methods. Filtration above the critical flux ('supra-critical filtration') was applied to induce significant fouling. The improved flux-step method as described in Chapter 2 and in reference [13], was applied prior to the relaxation and backwash experiments. The results revealed a critical flux of 67 and $48 \mathrm{~L} \mathrm{~m}^{-2} \mathrm{~h}^{-1}$ for the PVDF $0.1 \mu \mathrm{m}$ and the PE $0.4 \mu \mathrm{m}$ membranes, respectively. The critical flux for the CER $0.2 \mu \mathrm{m}$ membrane was $35 \mathrm{~L} \mathrm{~m}^{-2} \mathrm{~h}^{-1}$. Therefore, the instantaneous flux for the three membrane types was fixed at $85 \mathrm{~L} \mathrm{~m}^{-2} \mathrm{~h}^{-1}$.

Each filtration step lasted for a total of $900 \mathrm{~s}$, including intermediate cleaning (Table 5.2). The backwash flux was set at $370 \mathrm{~L} \mathrm{~m}^{-2} \mathrm{~h}^{-1}$ during $60 \mathrm{~s}$, yielding a net flux of $55 \mathrm{~L} \mathrm{~m}^{-2} \mathrm{~h}^{-1}$ for the ceramic membrane. The polymeric flat-sheet membranes also were backwashed for $60 \mathrm{~s}$. For approximately the first $30 \mathrm{~s}$ however, the membranes exhibited bulging. It was assumed that the membranes were not really backwashed during bulging, and the effective backwash time therefore only was $30 \mathrm{~s}$. The membranes resumed their original shape upon filtration only after approximately $140 \mathrm{~s}$, thereby decreasing the effective filtration time. Nevertheless, at an instantaneous flux of $85 \mathrm{~L} \mathrm{~m}^{-2} \mathrm{~h}^{-1}$ the net flux of the polymeric membranes in the backwash experiment was comparable to that applied for the ceramic membrane. The relaxation time was chosen such that the same net flux was obtained as for the backwashing experiments (Table 5.2). 
Table 5.2 Filtration time, cleaning time, and net fluxes for the two physical cleaning strategies.

\begin{tabular}{lccccc}
\hline Cleaning action & $\begin{array}{c}\text { Effective } \\
\text { filtration time } \\
(\mathrm{s})\end{array}$ & $\begin{array}{c}\text { Effective } \\
\text { cleaning time } \\
(\mathrm{s})\end{array}$ & $\begin{array}{c}\text { Instantaneous } \\
\text { Flux } \\
\left(\mathrm{L} \mathrm{m}^{-2} \mathrm{~h}^{-1}\right)\end{array}$ & $\begin{array}{c}\text { Backwash } \\
\text { Flux } \\
\left(\mathrm{L} \mathrm{m}^{-2} \mathrm{~h}^{-1}\right)\end{array}$ & $\begin{array}{c}\text { Net } \\
\text { Flux } \\
\left(\mathrm{L} \mathrm{m}^{-2} \mathrm{~h}^{-1}\right)\end{array}$ \\
\hline Backwash ceramic & 840 & 60 & 85 & 370 & 55 \\
Backwash polymeric & 700 & 30 & 85 & 370 & 54 \\
Relaxation & 570 & 330 & 85 & 0 & 54 \\
\hline
\end{tabular}

Backwashing and relaxation do remove the reversible part of the membrane fouling, but it was the irreversible fouling that was of interest in this study. Removal of the reversible fouling will not be discussed in this Chapter for that reason. Usually the resistance immediately after the cleaning step is used as parameter to compare the irreversible fouling. However, due to the supra-critical filtration causing rapidly occurring fouling after backwashing or relaxation, and because of the bulging of the polymeric membranes, it was impossible to determine the resistance accurately immediately after cleaning. Therefore, the resistance just before a cleaning step (termed $R_{\text {end }}$ ) was used to compare the effect of backwashing and relaxation. An increase of this parameter in time reveals the build up of irreversible fouling on or in the membrane. Since also the reversible fouling is incorporated in this value which also could be variable, the $R_{\text {end }}$ only can be used indicatively as parameter for irreversible fouling.

\subsubsection{Chemical cleaning and forward flush}

The membranes were chemically cleaned prior to each experiment by taking them out of the reactor, rinsing them with tap water and soaking them for $2 \mathrm{~h}$ in $0.2 \mathrm{~g} \mathrm{~L}^{-1}$ sodium-hypochlorite and for $2 \mathrm{~h}$ in $1.25 \mathrm{~g} \mathrm{~L}^{-1}$ citric acid, successively. Chemical cleaning always restored the clean membrane resistance.

Two additional cleaning strategies besides relaxation and backwashing were investigated to examine fouling removal. Firstly, intensive rinsing with a water-jet produced by a pump and a nozzle $\left(5 \times 10^{4} \mathrm{~Pa}\right.$ at a flow of $\left.0.5 \mathrm{~L} \mathrm{~min}^{-1}\right)$ was occasionally applied, to which will be referred as a forward flush (FF). For this purpose the membranes were taken out of the reactor at the end of a filtration run. The membranes were forward flushed and placed back in the reactor, after which filtration and relaxation or backwashing were resumed. $R_{\text {end }}$ before and at the first filtration step directly after the forward flush are plotted. A decrease in $R_{\text {end }}$ indicated the removal of fouling. Please note that this rigorous type of physical cleaning removes fouling that in this research is defined as irreversible fouling (see also Section 1.4.4 in Chapter 1 of this thesis).

Secondly, a CIP by a chemically enhanced backwash (CEB) was occasionally applied instead of the normal physical backwash procedure for the PE $0.4 \mu \mathrm{m}$ membrane. For this purpose the permeate vessel in de experimental set-up was replaced by a beaker containing permeate in which the chemical was dissolved. Either $1.25 \mathrm{~g} \mathrm{~L}^{-1}$ citric acid ('CEB ${ }_{1}$ ') or 
$0.2 \mathrm{~g} \mathrm{~L}^{-1}$ sodium-hypochlorite (' $\mathrm{CEB}_{2}$ ') was used. Arbitrarily, four $\mathrm{CEB}_{1}$ steps and ten $\mathrm{CEB}_{2}$ steps were performed consecutively, and only for the PE $0.4 \mu \mathrm{m}$ membrane. Similar to the FF also $R_{\text {end }}$ before and at the first filtration step after the four $\mathrm{CEB}_{1}$ and after the ten $\mathrm{CEB}_{2}$ steps was plotted to determine the effect of the CEBs on the removal of fouling.

It must be emphasized that the focus in this study was on comparing backwashing and relaxation under equal conditions. The applied procedures for the additional cleaning steps are not comparable to those used in full scale MBR installations. A more systematic approach on cleaning procedures and mechanisms than presented here would be necessary when efficiency and optimization of the additional chemical cleanings and forward flushing is the research focus.

\subsection{Results}

\subsubsection{The effect of relaxation and backwashing on membrane fouling}

Figure 5.3 shows the end-resistances $R_{\text {end }}$ of two PVDF $0.1 \mu \mathrm{m}$ membranes operated in parallel for $185 \mathrm{~h}$ with either backwashing or relaxation as the intermediate physical cleaning method. For graphical reasons the $R_{\text {end }}$ per $5 \mathrm{~h}$ of operation is given. A FF was applied at the end of the experiments. Figure 5.3 also shows $R_{\text {end }}$ for membrane CER $0.2 \mu \mathrm{m}$ for two successive experiments, i.e. operated with backwashing for the first $90 \mathrm{~h}$ and after chemical cleaning operated with relaxation for the next $125 \mathrm{~h}$. An intermediate FF was applied for each cleaning method.

For each membrane type the increase in $R_{\text {end }}$ over time was similar for backwashing and relaxation, indicating a similar development in irreversible fouling for both physical cleaning methods. It therefore was concluded that physical cleaning by backwashing was as effective as physical cleaning by relaxation for both membrane types. Visual observation of the PVDF $0.1 \mu \mathrm{m}$ and CER $0.2 \mu \mathrm{m}$ membranes just before a FF revealed the presence of a gel layer on the membrane surface. SEM analysis of the membrane surfaces after FF showed this cleaning to be capable of removing the gel layer completely. Apparently FF is a more powerful physical cleaning method than relaxation or backwashing with respect to gel layer removal. The gel layer was fully responsible for the irreversible fouling of membrane PVDF $0.1 \mu \mathrm{m}$, since $R_{\text {end }}$ after application of a FF was equal to $R_{\text {end }}$ after the very first filtration step. For membrane CER $0.2 \mu \mathrm{m}$ on the other hand, it was not only gel layer formation that was responsible for irreversible fouling. This was concluded since the FF could reduce $R_{\text {end }}$ by $20 \times 10^{10} \mathrm{~m}^{-1}$ out of a total increase of $60 \times 10^{10} \mathrm{~m}^{-1}$ in the case of backwashing, and by $25 \times 10^{10} \mathrm{~m}^{-1}$ out of a total increase of $75 \times 10^{10} \mathrm{~m}^{-1}$ in the case of relaxation. Recalling the observation that the FF removed the gel layer on the membrane 
surface, this indicated that for the CER $0.2 \mu \mathrm{m}$ membrane besides gel layer formation also internal membrane fouling contributed to irreversible fouling, and that this internal fouling was not removed by backwashing or FF.

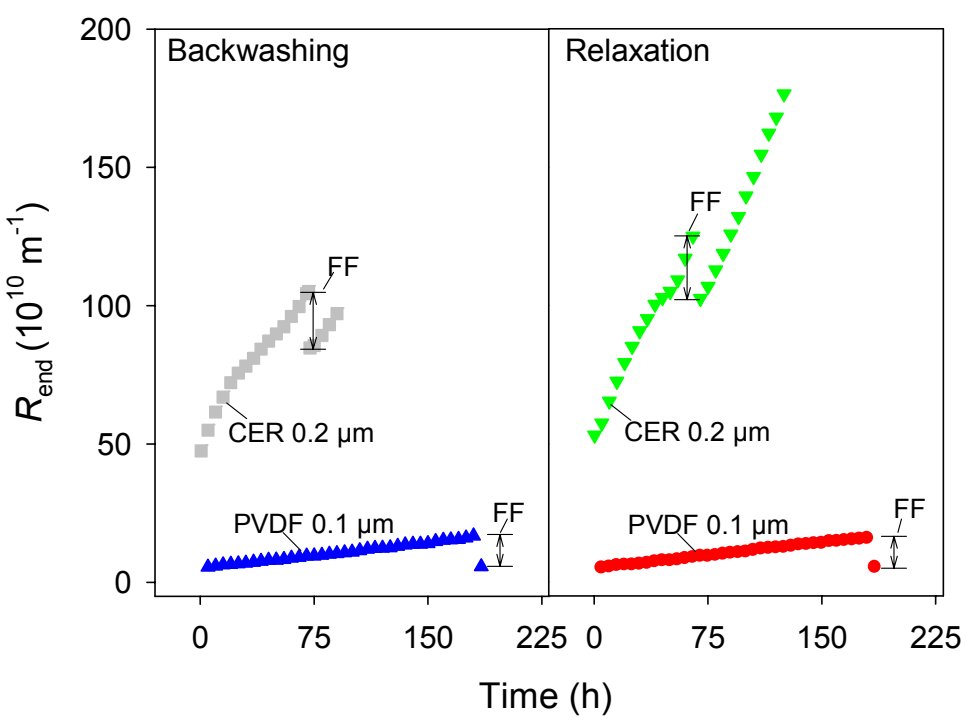

Figure 5.3 End-resistances $\left(R_{\text {end }}\right)$ of two polymeric membranes (PVDF $0.1 \mu \mathrm{m}$ ) operated in parallel with either backwashing or relaxation at equal net flux of $54 \mathrm{~L} \mathrm{~m}^{-2} \mathrm{~h}^{-1}$ and with a forward flush (FF) at the end of the experiments, and one ceramic membrane (CER $0.2 \mu \mathrm{m}$ ) first operated for $90 \mathrm{~h}$ with backwashing with one intermediate FF followed by $125 \mathrm{~h}$ operation with relaxation with one intermediate $F F$ at equal net flux of $55 \mathrm{~L} \mathrm{~m}^{-2} \mathrm{~h}^{-1}$.

\subsubsection{The effect of chemically enhanced backwash (CEB) on membrane fouling}

Two PE $0.4 \mu \mathrm{m}$ membranes were operated in parallel for $265 \mathrm{~h}$ with either backwashing or relaxation as physical cleaning step (Figure 5.4). Again, $R_{\text {end }}$ is given per $5 \mathrm{~h}$ of operation. Three intermediate forward flushes were applied to elucidate whether fouling mainly took place on the membrane surface or that internal fouling was also important. Additionally, two CEBs preceded the third FF in the backwashing experiment: a $\mathrm{CEB}_{1}$ with citric acid (four consecutive backwash steps, each for $60 \mathrm{~s}$ while maintaining filtration between the backwash steps) followed by a $\mathrm{CEB}_{2}$ using hypochlorite (ten consecutive backwash steps, each for $60 \mathrm{~s}$ while maintaining filtration between the backwash steps). The removal of fouling elucidated by the reduction in $R_{\text {end }}$ achieved by each additional cleaning, FF as well as CEB, was calculated. 


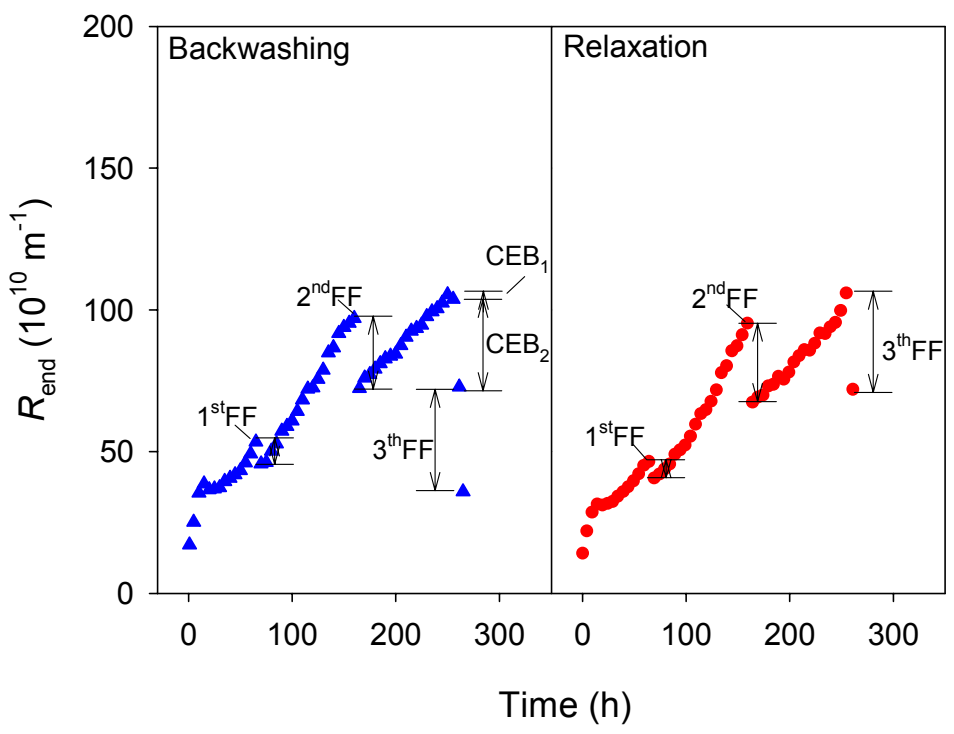

Figure 5.4 $R_{\text {end }}$ of two PE $0.4 \mu \mathrm{m}$ membranes operated in parallel with three intermediate forward flushes (FF). For the backwashing experiments also two incidental chemically enhanced backwashes with citric acid $\left(\mathrm{CEB}_{1}\right)$ and sodium-hypochlorite $\left(\mathrm{CEB}_{2}\right)$ were applied. Both experiments were carried out at an equal net flux of $54 \mathrm{~L} \mathrm{~m}^{-2} \mathrm{~h}^{-1}$.

Up to the application of the CEB, the development of $R_{\text {end }}$ was similar for both physical cleaning methods. It therefore was concluded that also for the PE $0.4 \mu \mathrm{m}$ membrane physical cleaning by backwashing was as effective as physical cleaning by relaxation. For the first $70 \mathrm{~h}$ of filtration, $R_{\text {end }}$ rose in total by 33 and $35 \times 10^{10} \mathrm{~m}^{-1}$ for backwashing and relaxation, respectively. The PE $0.4 \mu \mathrm{m}$ membranes also were fouled by a gel layer, which was visually observed just before the first FF was applied. The first FF only could reduce $R_{\text {end }}$ by $7 \times 10^{10} \mathrm{~m}^{-1}$ in the case of backwashing and by $6 \times 10^{10} \mathrm{~m}^{-1}$ in the case of relaxation, by removing the gel layer. This indicated that most of the irreversible fouling that occurred during this filtration period was caused by internal fouling. A second FF was applied after another $90 \mathrm{~h}$ of filtration (second filtration period). This FF reduced $R_{\text {end }}$ equally for both backwashing and relaxation by $23 \times 10^{10} \mathrm{~m}^{-1}$ out of a total increase of $50 \times 10^{10} \mathrm{~m}^{-1}$ in the second filtration period. About $46 \%$ of the fouling that occurred during this second filtration period therefore was caused by the gel layer and $54 \%$ by internal fouling. After the third filtration period of in total $100 \mathrm{~h}$, the $3^{\text {rd }} \mathrm{FF}$ (after the CEBs in the case of backwashing) decreased $R_{\text {end }}$ by $37 \times 10^{10} \mathrm{~m}^{-1}$ out of a total increase of $38 \times 10^{10} \mathrm{~m}^{-1}$ in the case of backwashing, which is comparable to the $34 \times 10^{10} \mathrm{~m}^{-1}$ reduction in $R_{\text {end }}$ out of a total increase of $38 \times 10^{10} \mathrm{~m}^{-1}$ in the case of relaxation. This almost $100 \%$ reduction in $R_{\text {end }}$ in both cleaning experiments showed that practically all fouling during the third filtration period could be attributed to gel layer formation. This was concluded since the FF only removed fouling on the membrane surface, which was a gel layer in this experiment. The involvement of gel layer formation in the fouling process clearly increased from filtration period 1 to filtration period 3. 
The four $\mathrm{CEB}_{1}$ steps with citric acid reduced $R_{\text {end }}$ in total only by $1.5 \times 10^{10} \mathrm{~m}^{-1}$, whereas the ten $\mathrm{CEB}_{2}$ steps with hypochlorite reduced $R_{\text {end }}$ in total by $31 \times 10^{10} \mathrm{~m}^{-1}$. Clearly, the hypochlorite was much more effective in removing irreversible fouling, which was attributed only to internal fouling. This was concluded because the $3^{\text {rd }} \mathrm{FF}$ after the CEBs reduced $R_{\text {end }}$ in an amount that was comparable to the increase in $R_{\text {end }}$ that occurred during the third filtration period. Additionally, the reduction in $R_{\text {end }}$ by the $3^{\text {rd }} \mathrm{FF}$ was approximately equal for backwashing and relaxation. Since no CEBs were applied in the case of relaxation, this also indicated that the CEBs only affected internal fouling. The final $R_{\text {end }}$ after the $3^{\text {rd }} \mathrm{FF}$ in the case of backwashing was located below the starting point that was situated after the $2^{\text {nd }} \mathrm{FF}$ due to the removal of both the gel layer and internal fouling.

\subsubsection{Comparison of filtration characteristics}

The filtration performance of the PVDF $0.1 \mu \mathrm{m}$ membranes concerning fouling susceptibility was superior compared to that of the PE $0.4 \mu \mathrm{m}$ and CER $0.2 \mu \mathrm{m}$ membranes: lower $R_{\text {end }}$ values and a smaller increase of $R_{\text {end }}$ in time. The differences in fouling behavior could be explained by pore morphology differences between the membranes. This is illustrated in Figure 5.5 and in agreement with findings reported and discussed in Chapter 3 of this thesis. The PVDF $0.1 \mu \mathrm{m}$ membrane had an asymmetric skin pore morphology, i.e. the pore size widens from the feed towards the permeate side. As a result, material entering the membrane matrix may easily flow out together with the permeate flow. The PVDF membrane therefore only suffered from fouling on the membrane surface. The PE $0.4 \mu \mathrm{m}$ membrane and the CER $0.2 \mu \mathrm{m}$ membrane on the other hand had symmetric skin pore morphologies, and consequently material can become trapped along the tortuous path [14].
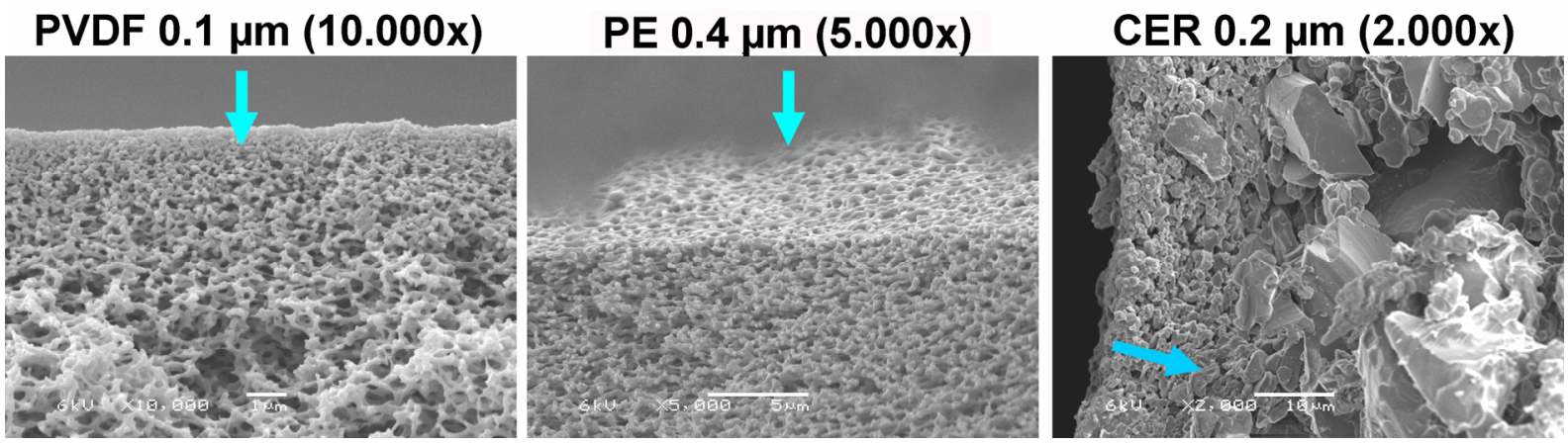

Figure 5.5 SEM images of the cross section of the top skin of the three membrane materials. The different magnifications are indicated between brackets. The blue arrow indicates the filtration direction. 


\subsection{Discussion}

This study compared relaxation and backwashing for three different types of flat-sheet membranes at equal instantaneous and net fluxes. Compared to practical MBR operation, in our experiments a relatively long relaxation time (330 s instead of a typical $120 \mathrm{~s}$ [1]) and high backwash flux / filtration flux ratio (4.4 compared to 1.3-1.5 for hollow fiber MBR configurations [1]) were used. This high backwash flux / flux ratio and the long relaxation time were chosen because it was expected that most reversible fouling that was caused by the supra-critical operating conditions could be removed.

It was demonstrated that physical cleaning by backwashing was as effective as physical cleaning by relaxation, because the increase in $R_{\text {end }}$ was similar for both cleaning methods. A recent study of Wu et al. [6] based on $24 \mathrm{~h}$ of filtration at an equal net flux, but at different instantaneous fluxes, concluded likewise. Both cleaning methods were unable to remove irreversible fouling caused by internal fouling and by gel layer formation.

In contrast with the expectations, physical backwashing was not able to remove internal fouling, since it resulted in the same increase in $R_{\text {end }}$ in time as in the relaxation experiments. Apparently, strong adsorption of foulants on the internal membrane matrix was the main internal fouling mechanism. Another explanation could be that the backwash water was forced to flow through the open non-fouled pores via the interconnected internal structures, instead of via the (partially) blocked pores. Consequently, the internal fouling will not be removed. A CEB with sodium-hypochlorite appeared to be more effective in removing internal fouling compared to a normal backwash, and compared to a CEB with citric acid. The latter is an indication that the internal fouling is of an organic nature. The oxidation process by sodium-hypochlorite reduced the adhesion of organic fouling constituents to the membrane [15], facilitating their removal by the hydraulic backwash.

The additional FF carried out was a more powerful cleaning method compared to relaxation or backwashing. Interestingly, the relative reduction in $R_{\text {end }}$ by the FF increased from the first filtration period to the third filtration period for the PE $0.4 \mu \mathrm{m}$ membranes (Figure 5.4). This observation indicated that internal fouling first was dominant, whereas gel layer formation on the membrane that was removable by the FF became dominant in the course of the experiment. This may be explained by entrapment of potential internal foulants in the structure of the gel layer, thereby reducing internal fouling.

The gel layer could not be removed by relaxation or backwashing only. The gel layer therefore was considered to be more adhesive than a cake layer, which also was concluded by Wang et al. [16]. The gel layer also was not affected by the CEBs with either sodium-hypochlorite or citric acid, where a CEB with citric acid was expected to have an effect. Salt bridges between divalent cations and extracellular polymeric substances (EPS) can be formed causing a denser gel layer, and citric acid could affect divalent cations by its chelating effect (comparable to EDTA) [17]. Perhaps divalent cations were not involved in the 
gel layer formation process, or the contact time between the gel layer and the citric acid was too short. In full scale systems a CEB with a low dose chemical normally is applied for 15 min in stead of the normal backwash time $[1,17]$

This study clearly showed that from a cleaning perspective backwashing is as effective compared to relaxation, and did not offer the advantage of removing more internal fouling. Other aspects might influence the choice for relaxation or backwashing. Relaxation is simple and only requires one valve in the permeate line, and is applicable for membranes that cannot be backwashed. On the other hand, relaxation relies on a good hydrodynamic environment in front of the membrane (for instance no preferential flow of air bubbles over the membrane surface and/or modules), and the duration of the cleaning is much longer than for a backwash which decreases productivity. For backwashing an additional (and larger) pump is required, it uses permeate with the chance of membrane clogging at the permeate side of the membrane, and it might deform the membrane which is not the case with relaxation.

Relaxation seems preferable from a membrane point of view since the chance of membrane damage is minimized. Backwashing might be preferred from an operator's point of view, because fouling control via air scouring during relaxation in submerged MBRs remains a challenge due to unevenly distribution of the air bubbles in the membrane modules. Also the possibility of applying an occasional CEB that removes internal fouling (hypochlorite) pleads for the use of backwashing compared to relaxation.

\subsection{Conclusions}

This study demonstrated that physical cleaning by backwashing was as effective as physical cleaning by relaxation at equal instantaneous and net fluxes, and for three different types of flat-sheet membranes. Both physical cleaning methods however could not avoid internal membrane fouling and gel layer formation.

Developing backwashable flat-sheet membranes is useful in case a chemically enhanced backwashing is necessary to tackle irreversible fouling. Enhancing backwashing with sodium-hypochlorite removes internal fouling, while the gel layer remained unaffected by chemical backwashing with sodium-hypochlorite or citric acid. 


\subsection{Used symbols and abbreviations}

\begin{tabular}{lll} 
Symbol & & Unit \\
\hline CER & Ceramic membrane & \\
CEB & Chemically enhanced backwash \\
CEB $_{1}$ & Chemically enhanced backwash with $0.2 \mathrm{~g} \mathrm{~L}^{-1}$ sodium-hypochlorite & \\
CEB $_{2}$ & Chemically enhanced backwash with $1.25 \mathrm{~g} \mathrm{~L}^{-1}$ citric acid & \\
FF & Forward flush & \\
MBR & Membrane bioreactor & \\
PVDF & Polyvinylidenedifluoride & $\mathrm{m}^{-1}$ \\
$R_{\text {end }}$ & End-resistance just before a cleaning was applied & $\mathrm{m}^{-1}$ \\
$R_{\mathrm{m}}$ & Membrane resistance & \\
SEM & Scanning electron microscope &
\end{tabular}

\subsection{References}

1. Judd, S.J., The MBR Book: Principles and Applications of Membrane Bioreactors in Water and Wastewater Treatment. 1st ed. 2006, Oxford: Elsevier.

2. Le-Clech, P., V. Chen, and T.A.G. Fane, Fouling in membrane bioreactors used in wastewater treatment. Journal of Membrane Science, 2006. 284: p. 17-53.

3. Lyko, M., Managing wastewater: Using membrane bioreactors for water supply. Filtration \& Separation, 2008. 1: p. 16-19.

4. Doyen, W., et al., Integrated permeate channel membrane. European Patent EP20050778312, 2005.

5. Chang, I.S., et al., Membrane fouling in membrane bioreactors for wastewater treatment. Journal of Environmental Engineering, 2002. 128: p. 1018-1029.

6. Wu, J., et al., Effects of relaxation and backwashing conditions on fouling in membrane bioreactor. Journal of Membrane Science, 2008. 324: p. 26-32.

7. Hong, S.P., et al., Fouling control in activated sludge submerged hollow fiber membrane bioreactors. Desalination, 2002. 143: p. 219-228.

8. Bouhabila, E., R. Ben Aim, and H. Buisson, Fouling characterisation in membrane bioreactors. Separation and Purification Technology, 2001. 22-23: p. 123-132.

9. Yigit, N.O., et al., Effects of various backwash scenarios on membrane fouling in a membrane bioreactor. Desalination, 2009. 237: p. 346.

10. Field, R.W., et al., Critical flux concept for microfiltration fouling. Journal of Membrane Science, 1995. 100: p. 259-272.

11. Le Clech, P., et al., Critical flux determination by the flux-step method in a submerged membrane bioreactor. Journal of Membrane Science, 2003. 227: p. 81-93. 
12. Remy, M., et al., Low dose powdered activated carbon addition at high sludge retention times to reduce fouling in membrane bioreactors. Water Research, 2009. 43: p. 345-350.

13. van der Marel, P., et al., An improved flux-step method to determine the critical flux and critical flux for irreversibility in a membrane bioreactor. Journal of Membrane Science, 2009. 332: p. 24-29.

14. Choi, J.H., S.K. Park, and H.Y. Ng, Membrane fouling in a submerged membrane bioreactor using track-etched and phase-inversed porous membranes. Separation and Purification Technology, 2008.17.

15. Pall Corporation (2006). Membrane chemical cleaning: From art to science. Available in: http://www.pall.com/pdf/mtcpaper.pdf, accessed Jan. 13, 2009.

16. Wang, Z., et al., Membrane fouling in a submerged membrane bioreactor (MBR) under sub-critical flux operation: Membrane foulant and gel layer characterization. Journal of Membrane Science, 2008. 325: p. 238-244.

17. Li, N.N., et al., Advanced membrane technology and applications, page 160. 1st ed. 2008, Hoboken, New Jersey: John Wiley \& Sons. 159-160. 



\section{Chapter 6}

Reducing fouling in membrane bioreactors by using corrugated membranes

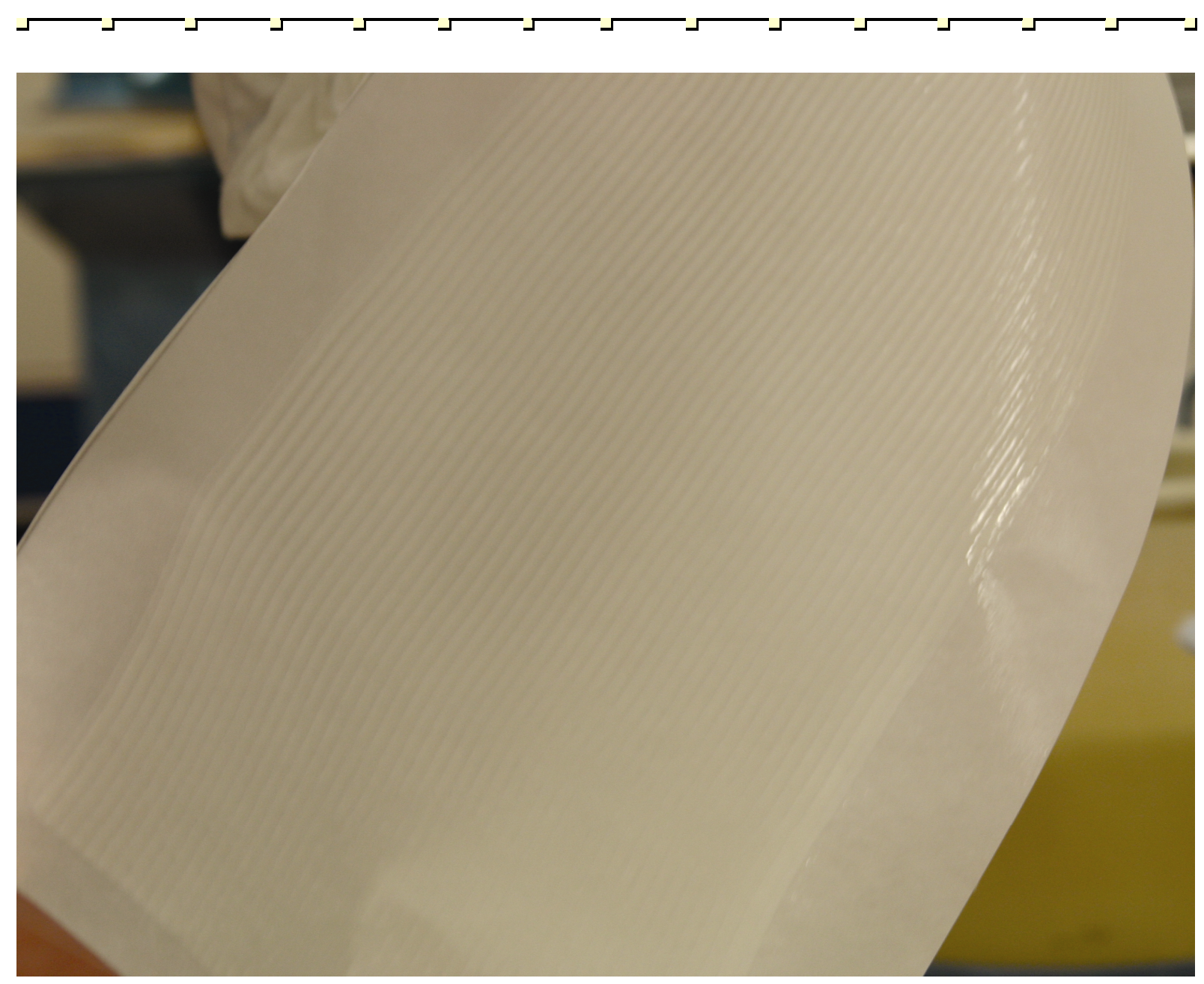




\section{Abstract}

Long-term filtration in submerged membrane bioreactors below the critical flux, as described in the previous Chapters of this thesis, reveal a two-stage fouling process. A gradual increase of filtration resistance - caused by a slowly developing irreversible fouling - is followed by a rapid increase attributed to severe layer formation by cake or gel layer formation. The time needed before this severe fouling occurs is defined as the sustainable time. This Chapter describes experiments with corrugated membrane surfaces in MBR in order to extend this sustainable time. Corrugation leads to a larger membrane surface area and therefore a lower local flux. Furthermore, the corrugates can be positioned vertically as well as horizontally with respect to the air flow in the reactor to enhance turbulence.

In this work, home made corrugated flat-sheet PVDF membranes are used. The corrugations increase the critical flux by $5 \%$ due to a $5 \%$ larger membrane surface area. An additional $2.5 \%$ increase in critical flux is obtained by positioning the corrugates horizontally, most likely since this configuration induces more turbulence at the membrane-liquid interface due to the vertical air flow. The critical flux primarily is related to fouling by layer formation, which is reduced by the enhanced turbulence.

Despite the higher critical flux for the horizontal corrugates, this configuration is less beneficial for long-term filtration, since sludge particles deposit in the valleys between the corrugates. On the long-term membranes with vertical corrugates result in the longest sustainable time, due to the larger membrane surface area enabling a lower local flux which suppressed layer formation.

P. van der Marel, A. Zwijnenburg, A.J.B. Kemperman, M. Wessling, H. Temmink, and W.G.J. van der Meer. 


\subsection{Introduction}

Submerged MBRs generally are operated below the critical flux at which cake layer formation takes place. Typically, fluxes between 10 and $25 \mathrm{~L} \mathrm{~m}^{-2} \mathrm{~h}^{-1}$ are applied in practice [1, 2]. This so called sub-critical filtration [3] however, does not prevent membrane fouling during long-term operation $[4,5]$. The fouling that occurs usually is observed as a two-stage fouling process (Figure 6.1). The gradual increase in resistance in stage 1 is caused by a slowly developing irreversible fouling process [5]. This is the result of the adsorption and initial pore blocking by organic substances [6], and of the random attachment of extracellular polymeric substances (EPS) or sludge fragments on the membrane surface [4]. These processes even occur at sub-critical conditions with high shear, and may be influenced by a preferential distribution of shear and/or flux over the membrane. This will result in an irregular distribution of fouling on the membrane surface [7]. The duration of stage 1 until the sharp increase in resistance is defined as the sustainable time [8].

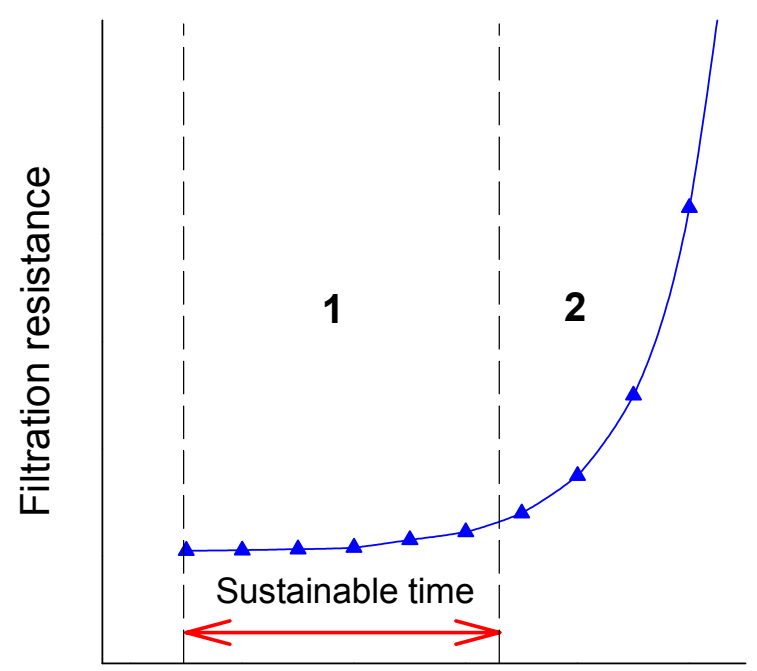

Time

Figure 6.1 Example of the two-stage fouling process.

Stage 2 shows a rapid increase in resistance, which often is explained using the so-called local critical flux concept [5]. The local flux decreases towards membrane areas that become irreversibly fouled during stage 1 . In case the overall flux is held constant this results in a higher local flux towards the more open or less fouled membrane areas. This locally higher flux eventually exceeds the critical flux causing severe fouling by cake formation in those areas $[4,5]$. At this point particle transport towards the membrane surface by the high local flux exceeds particle removal from the membrane surface by shear and back diffusion. This 
causes a transition in these areas from concentration polarization to cake formation [9], and leads to the rapid rise in the filtration resistance.

Literature also reports other explanations for the rapid rise in resistance. For instance, Hermanowicz [10] explained it by the so called percolation hypothesis, i.e. the morphology of the deposited fouling layer that was formed during stage 1 suddenly changes. The porous fouling layer looses its porosity and interconnectivity due to continuous filtration and deposition of material in and on this layer. The sudden increase in resistance is caused by further entrapment of material in this fouling layer or by fouling layer compression. Additionally, oxygen transfer limitations in the fouling layer may cause the dying of bacteria present in the inner fouling layer [11]. Such an event can also result in a sudden change in composition and resistance of the deposited fouling layer [12].

Previous Chapters in this thesis indicated in our system gel layer formation as reason for the sudden rapid rise in resistance. This process is believed to be different from cake layer formation which occurs when locally the critical flux is exceeded. A gel layer is a highly swollen three dimensional and possibly cross-linked network structure of macromolecules on the membrane surface $[13,14]$, e.g. in our case suspected membrane foulants such as EPS. The rise in (local) flux during stage 1 of the two-stage fouling process locally increases the concentration of EPS at the membrane wall. The EPS concentration in the liquid cannot exceed a maximum concentration called the gel concentration [15]. A phase transition from a liquid state towards a gelled phase [16] occurs in case the critical gel concentration is exceeded. Ongoing convection of EPS towards the membrane will make the local gel layer thicker [17]. This contributes to a further increase in local flux towards other, opener membrane areas where finally also a gel layer will be formed. This process accelerates itself and causes the rapid rise of resistance during stage 2 as less and less open membrane area is available. In the end the whole membrane surface will be covered with a gel layer.

Increasing the sustainable time in MBR limits the cleaning frequency and therefore saves operational costs. In practice it is difficult to prevent the slow gradual irreversible fouling in stage 1. It occurs even during sub-critical filtration, and even with membranes with optimal membrane properties (see Chapter 3). To extend the sustainable time during stage 1 therefore the eventual transition from concentration polarization to either cake or gel formation should be delayed. Hence, the increase in concentration polarization as a consequence of the increase in local flux should be minimized. Possibilities to reduce concentration polarization are lowering the imposed flux or an increase of the turbulence at the membrane-liquid interface $[17,18]$. This Chapter describes pioneering work on corrugating flat-sheet membrane surfaces in an attempt to increase the sustainable filtration time in MBRs. Corrugated membranes have a larger filtration area due to the corrugations, and therefore can operate at lower flux while providing the same permeate yield compared to regular smooth flat-sheet membranes. Both the lower flux as well as the promoted turbulence by the corrugates are expected to decrease concentration polarization and consequently extend the sustainable time. 


\subsection{Corrugated membranes, a short review}

Corrugated flat-sheet membranes can be manufactured for instance by using a hot pressing method [19]. Other methods use a mold to mirror the corrugates on support material. These methods are (1) cold pressing of a casted polymeric membrane on a corrugated surface [20], (2) hot embossing by pressing a mold structure in a semi-finished polymer at a temperature above its glass temperature [21], (3) phase separation micromolding by casting films on corrugated molds [22], and (4) pouring the polymer-dope solution on corrugated surfaces and curing the material in an oven at elevated temperatures afterwards [23].

Corrugated membranes were used in filtration of emulsions [19, 24], water with ceramic particles [25], or saline waters [20, 26], but are not yet applied for activated sludge filtration in MBR. Furthermore, the main work is performed on tubular membranes (or flat-sheet membranes in a small channel) and not on flat-sheet submerged membranes. The most relevant conclusion out of the work performed on corrugated membranes is the fact that corrugated membranes allows for a higher flux due to the increased shear which repeatedly mixes the boundary layer, and hence disrupts concentration polarization and limits cake layer formation. The flux increases further in case the corrugates are placed at a $90^{\circ}$ angle opposite the feed flow. Additionally, a higher flux can be applied due to the increased membrane surface area.

\subsection{Materials and methods}

\subsubsection{Smooth and corrugated membranes}

Smooth polyvinylidenedifluoride (PVDF) microfiltration membranes with a pore size of $0.1 \mu \mathrm{m}$ were produced from a highly viscous polymer dope solution (PVDF/NMP/PVP base composition) using a non-solvent induced phase inversion method. A thin film of the dope solution was casted on an A4 sized polyester non-woven material (FO 2416, Freudenberg) using a casting knife with a slit height of $150 \mu \mathrm{m}$ (Figure 6.2A). The casted film was immersed in a non-solvent bath (water). After the phase separation process excess PVP was removed by immersing the membranes for $24 \mathrm{~h}$ in a water bath containing 2500 ppm sodium-hypochlorite. 


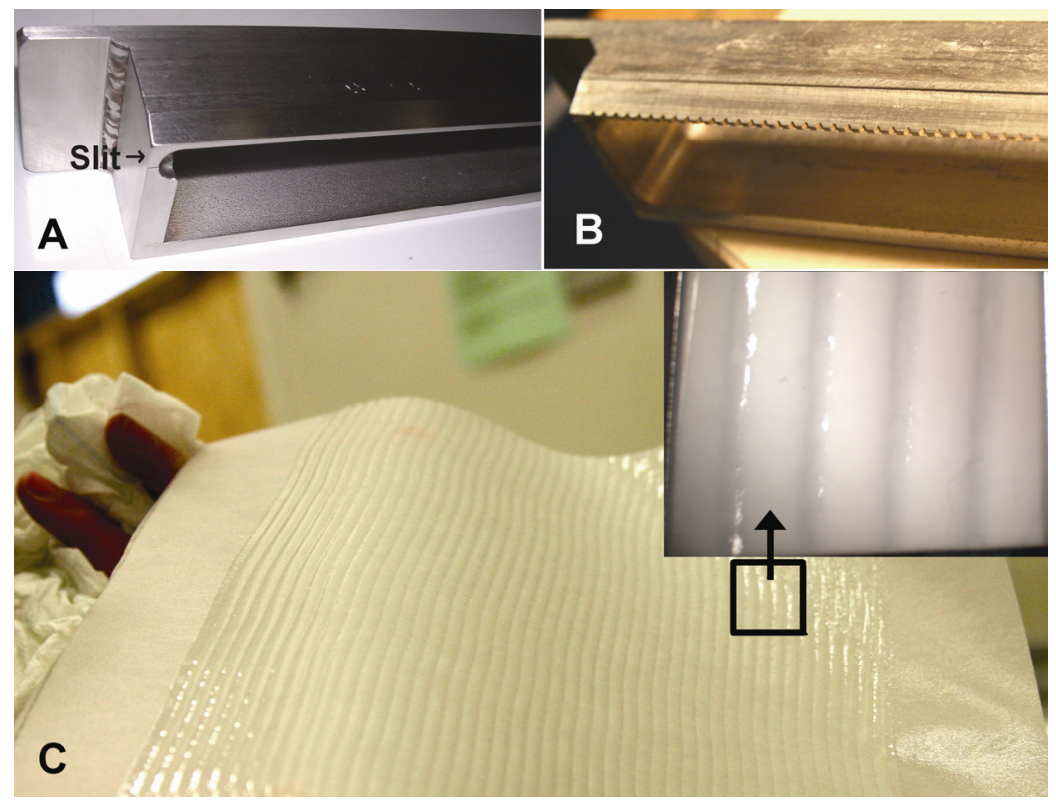

Figure 6.2 Normal casting knife (A), modified casting knife for corrugated membranes (B), and the corrugated A4 PVDF $0.1 \mu \mathrm{m}$ membrane (C).

For preparing corrugated membranes a different approach was used that is quite similar to spinning hollow fibers with geometrical corrugates on the outer (or inner) perimeter by using micro-corrugated spinnerets [27]. The corrugates in our work were prepared using a simple modification to the casting knife (Figure 6.2B). Triangular notches with dimensions of $2 \mathrm{~mm}$ and $1 \mathrm{~mm}$ for base and depth, respectively, were milled every $4 \mathrm{~mm}$ over the total length of the casting knife. These dimensions were also used in a study of Hu et al.[19], and believed to facilitate air scouring of $5 \mathrm{~mm}$ air bubbles in between the corrugates in the final membrane. The rest of the procedure was similar to the production of smooth flat-sheet membranes. Our procedure allows formation of corrugated membranes that mimic the form of the corrugates that were produced in the work of $\mathrm{Hu}$ et al. which are schematically shown in Figure 6.3.

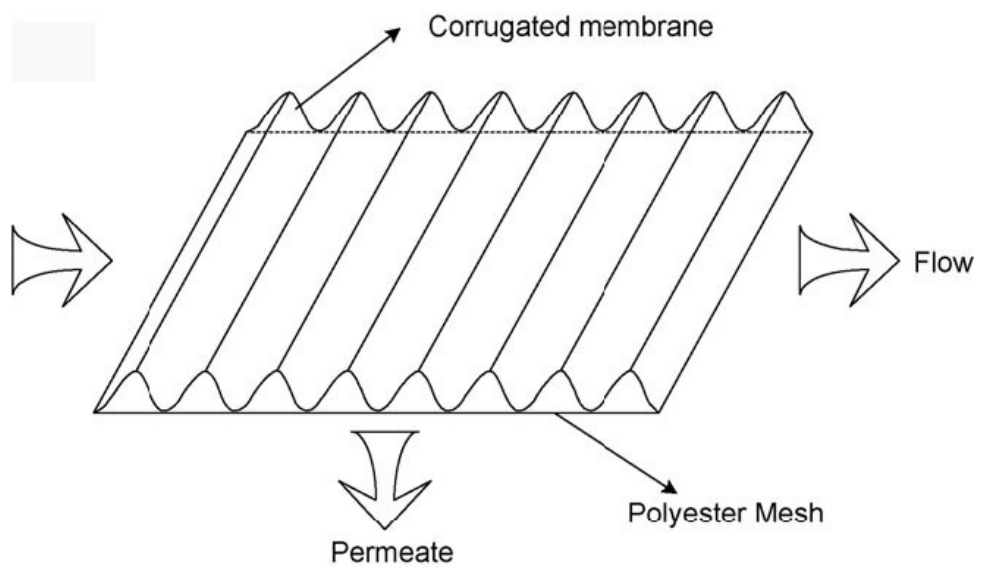

Figure 6.3 Schematic diagram of corrugated membranes with angle of corrugation $90^{\circ}$ to the tangential flow across the membrane surface (from [19]). 
The surfaces and cross-sections of the smooth and corrugated membranes were examined by SEM using a JEOL-6480LV Scanning Electron Microscope. The SEM pictures of the membrane surfaces were analyzed with image processing software (ImageJ, $\mathrm{NiH}$ ) to obtain the nominal pore size and the surface porosity.

\subsubsection{Experimental set-up}

The same lab-scale filtration set-up as described in detail in Chapter 2 of this thesis was used. Two filtration reactors were operated in parallel, each reactor containing two vertically placed flat-sheet plates (Figure 6.4, left). An aerator was placed beneath each membrane producing an air flow rate of $0.4 \mathrm{~m}^{3} \mathrm{~h}^{-1}$ per membrane producing approximately a $0.25 \mathrm{~m} \mathrm{~s}^{-1}$ superficial velocity across the membrane surface. Figure 6.4 shows the three membrane configurations that were tested. Circular membranes were cut from the A4 membrane sheets and glued on four separate PVC plates, yielding two smooth membranes and two corrugated membranes with a diameter of $0.14 \mathrm{~m}$ each. One smooth membrane is shown in Figure 6.4 with permeate connection and aerator $(\mathrm{C} 1)$. The corrugated membranes were glued on the plates either with vertical orientation (C2), or with a horizontal orientation of the corrugates with a $90^{\circ}$ angle opposite the vertical air flow. Each reactor contained configuration $\mathrm{C} 1$ as a reference membrane and either corrugated membrane configuration C2 or C3. The two reactors always were operated at the same time.
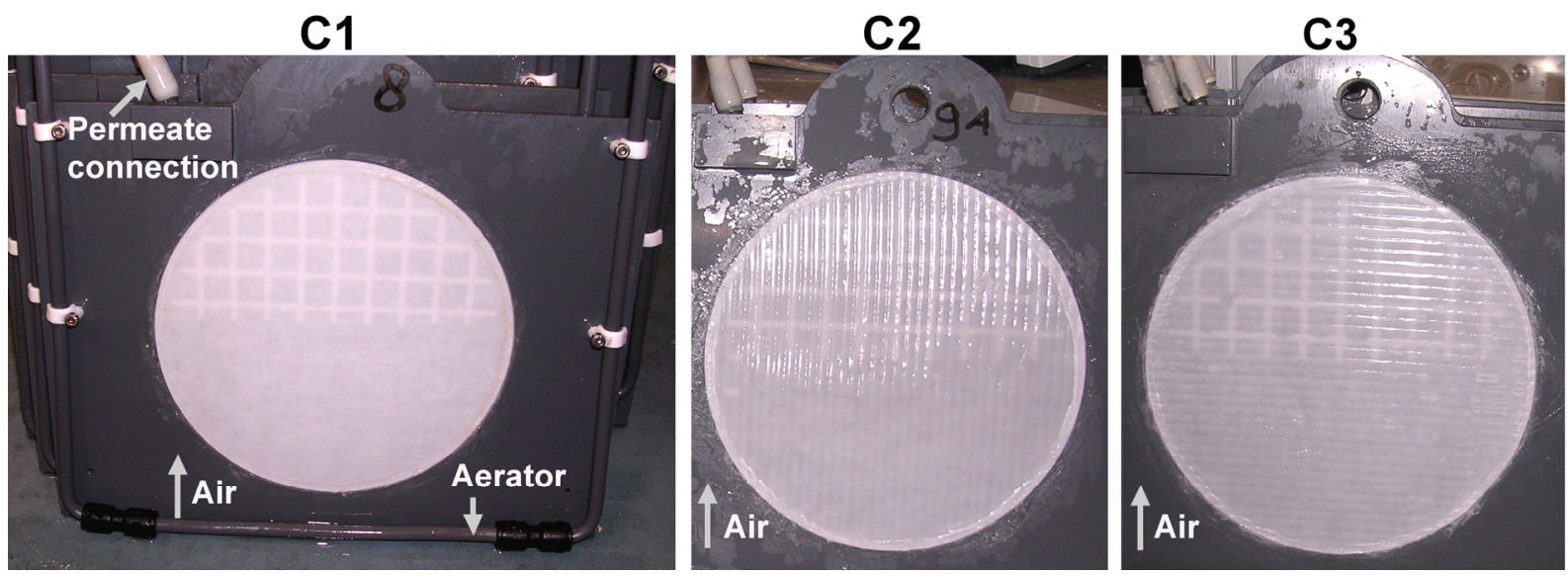

Figure 6.4 Membrane plates with smooth flat-sheet membrane (C1), and corrugated flatsheet membranes with vertical (C2) and horizontal orientation of the corrugates (C3) opposite the vertical air flow.

Activated sludge provided by a pilot-scale MBR of $85 \mathrm{~L}$ fed with municipal wastewater [28] was circulated over the filtration set-up. The reactor volume and the hydraulic retention time in the filtration set-up were kept constant at $5 \mathrm{~L}$ and $1 \mathrm{~h}$, respectively. Permeate was extracted and recycled to the filtration set-up. Pressure transducers recorded the transmembrane pressure (TMP), a mass balance and regulating valves measured the 
permeate flux, and a temperature sensor determined the temperature of the activated sludge. Labview software was used to automate the set-up (permeate pumps and valves) and for data collection. The hydraulic resistance $(R)$ was calculated by Darcy's law in which the dynamic viscosity of the permeate was corrected for temperature (Equation 1.1 and 1.2 respectively, see Section 1.4.4 in Chapter 1).

\subsubsection{Experimental procedure}

Firstly, the membrane resistance of each membrane was determined by clean-water flux measurements. For this purpose, the flat-sheet membranes were placed in the filtration reactors which were filled with demineralized water produced by a Milli-Q system from Millipore.

Short-term flux-step measurements were carried out using one run of the improved flux-step method (IFSM), described in detail in Chapter 2. The IFSM consists of increasing the flux from 5 to $100 \mathrm{~L} \mathrm{~m}^{-2} \mathrm{~h}^{-1}$ with incrementing flux-steps of $5 \mathrm{~L} \mathrm{~m}^{-2} \mathrm{~h}^{-1}$, and using intermediate relaxation steps at a low reference flux of $5 \mathrm{~L} \mathrm{~m}^{-2} \mathrm{~h}^{-1}$ in between each flux increase. The duration of each step was $15 \mathrm{~min}$ and one complete run lasted for $10 \mathrm{~h}$. The critical flux $\left(J_{C}\right)$ and critical flux for irreversibility $\left(J_{C i}\right)$ were determined as described in detail in Chapter 2.

Two long-term experiments of $100 \mathrm{~h}$ duration time were performed. The first experiment was performed at a continuous fixed flux of $50 \mathrm{~L} \mathrm{~m}^{-2} \mathrm{~h}^{-1}$. The second experiment was performed using $8 \mathrm{~min}$ filtration at a flux of $50 \mathrm{~L} \mathrm{~m}^{-2} \mathrm{~h}^{-1}$ followed by 2 min relaxation, yielding a net flux of $40 \mathrm{~L} \mathrm{~m}^{-2} \mathrm{~h}^{-1}$.

\subsection{Results and discussion}

\subsubsection{Corrugate form, membrane pore size, and surface porosity}

It was intended to mirror the triangular corrugates of the modified casting knife on the casted film. The produced corrugates however, did not have the same structure as the triangular notches of the casting knife (Figure 6.2C, inset: picture by light-microscopy). The polymer solution spread out during casting despite the high viscosity of the PVDF dope solution and the immediate immersion of the film into the non-solvent bath after casting. The final structure obtained was a ridged sheet with approximately $0.5 \mathrm{~mm}$ height difference between the hills and valleys of the ridges, instead of the $1 \mathrm{~mm}$ difference intended. This change in ridged shape was also observed for corrugated hollow fibers, when the residence time in air 
between the spinneret and the non-solvent bath was too long, inducing relaxation of the geometric corrugates [27, 29].

SEM investigation of the membrane surfaces (Figure 6.5) and subsequent image analysis of the pictures showed that the nominal pore size $(0.1 \pm 0.02 \mu \mathrm{m})$ and surface porosity $(15 \pm 2 \%)$ were equal at different positions on the corrugated membranes, i.e. on hill, valley, and slopes of the corrugates. These values were identical to those for the smooth membranes. The fact that the pore sizes in the skin at all positions on the corrugated membrane were the same indicated that the coagulation process initially was the same at each position on the membrane. The spreading of the polymer dope solution during casting contributed to this appearance, due to the absence of sharp corners and relatively high height differences which otherwise would have influenced the coagulation process.

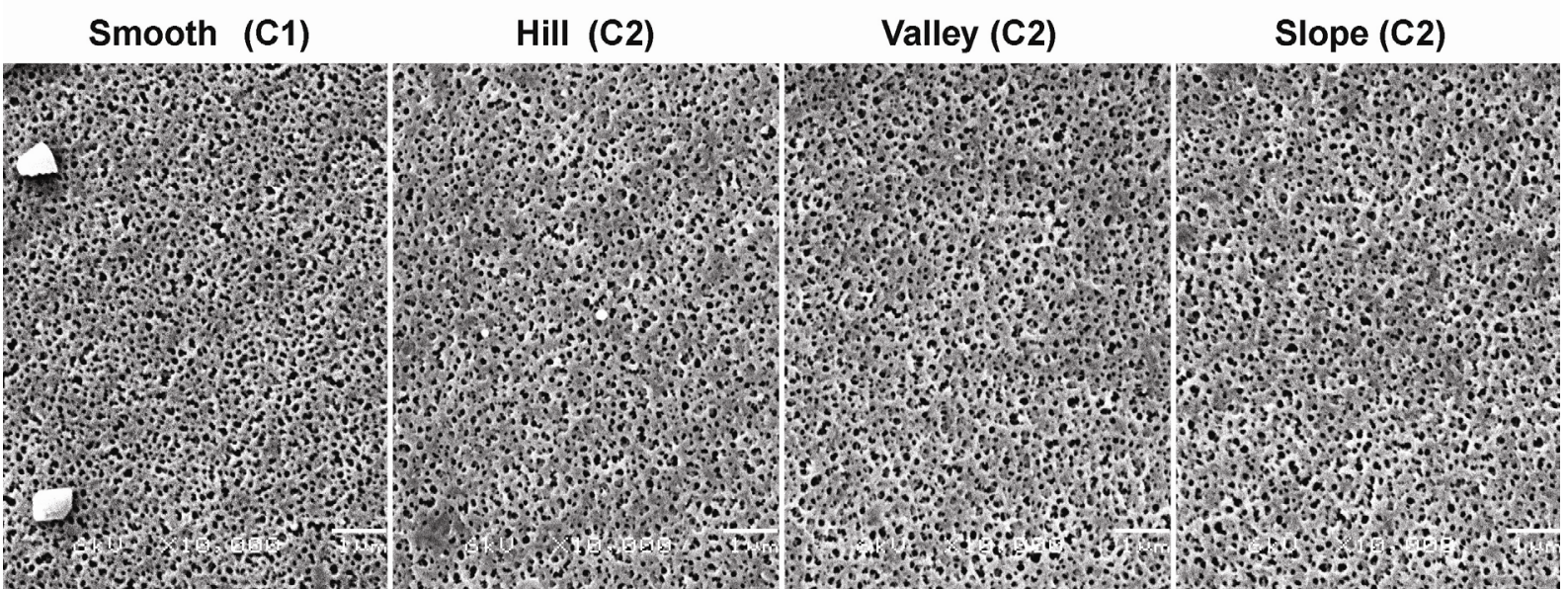

Figure 6.5 SEM pictures of the smooth membrane surface (C1) and that for the hill, valley, and slope of the corrugated membrane with vertically oriented corrugates $(\mathrm{C} 2)$, all at the same magnification $(10,000 \mathrm{x})$.

SEM analysis of the cross-sections of the smooth and corrugated membranes were carried out. The results are shown in Figure 6.6. Compared to the thickness of the smooth membranes, the corrugated membranes were much thicker at the hill-sections of the membrane, while in the valley-sections the thickness was approximately equal (left images in Figure 6.6). The cross-section morphologies of smooth and corrugated membranes also were different (center images). The smooth membranes showed an asymmetric structure with a gradual increase in porosity from feed to permeate side (from top till bottom in Figure 6.6), whereas the corrugated membranes contained large macro-voids underneath a dense skin with a thickness of approximately $10 \mu \mathrm{m}$. However, the membrane skins determining the filtration properties of the smooth and corrugated membranes visually were similar for the first $10 \mu \mathrm{m}$ (right hand side images). 
C1 total

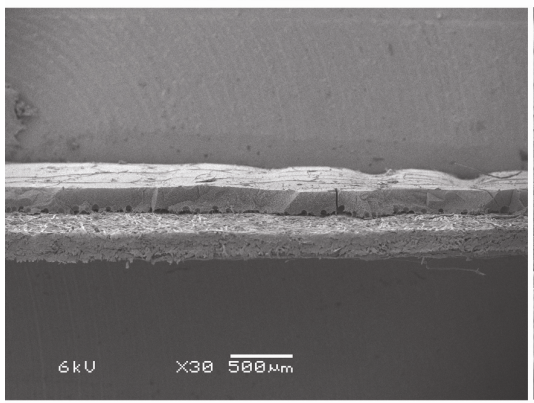

C2 total

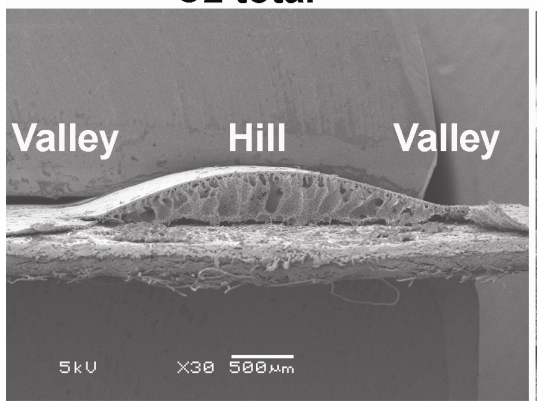

C1

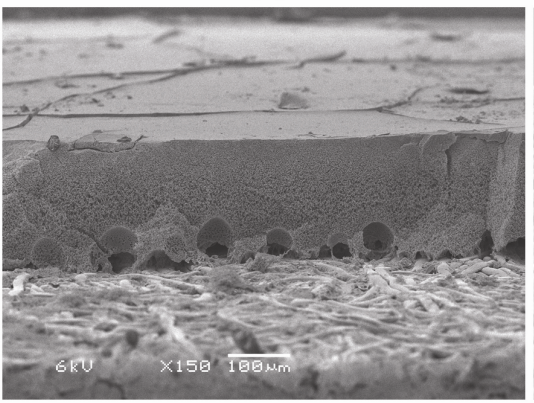

C2 hill

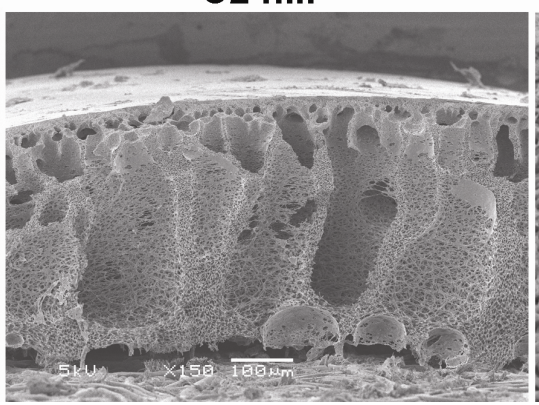

C1 skin

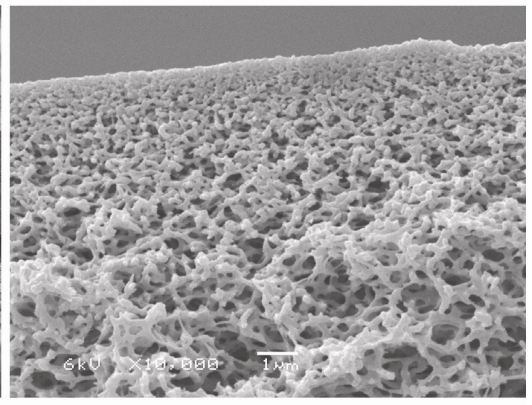

C2 skin

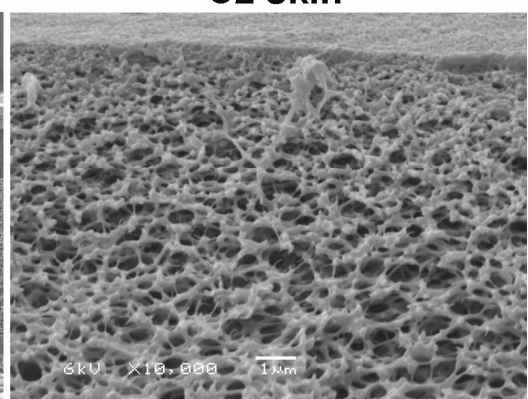

Figure 6.6 Membrane cross sections of a smooth membrane (Top, C1) and a corrugated membrane (bottom, C2 (or C3)). For each membrane a total cross-section (left, 30x), cross-section of the membrane (middle, 150x), and of the membrane skin (right, 10,000x) are given.

\subsubsection{Membrane resistance}

Four clean-water flux measurements were performed for each membrane at the same imposed permeate flow. The average membrane resistances are given in Table 6.1. The membrane resistance of the corrugated membranes was $40 \%$ lower compared to that of the smooth membranes. This was unexpected since pore size and surface porosity were equal and the corrugated membrane was thicker at the hills. Corrugated membranes had a $5 \%$ larger membrane surface area compared to smooth membranes, as estimated from the perimeters of the cross-sections in SEM pictures. At equal imposed permeate flow, the flux per square meter of support material was similar for smooth and corrugated membranes. Per membrane surface area however, the flux across the corrugated surface was $5 \%$ lower for the corrugated membranes. This lower flux only partially can explain the $40 \%$ lower membrane resistance for the corrugated membranes. Additional causes remain to be determined at this point. The macro-voids in the cross-section of the corrugated membrane may also partially contribute to the lower membrane resistance of the corrugated membranes. 
Table 6.1 Membrane resistance, critical flux $\left(J_{C}\right)$, and critical flux for irreversibility $\left(J_{C i}\right)$.

\begin{tabular}{cccc}
\hline Membrane & $\begin{array}{c}\text { Resistance } \\
\left(10^{10} \mathrm{~m}^{-1}\right)\end{array}$ & $\begin{array}{c}J_{\mathrm{C}} \\
\left(\mathrm{L} \mathrm{m}^{-2} \mathrm{~h}^{-1}\right)\end{array}$ & $\begin{array}{c}J_{\mathrm{Ci}} \\
\left(\mathrm{L} \mathrm{m}^{-2} \mathrm{~h}^{-1}\right)\end{array}$ \\
\hline $\mathrm{C} 1$ & $4.6 \pm 0.2$ & $74 \pm 2$ & $>100$ \\
$\mathrm{C} 2$ & $2.9 \pm 0.2$ & $78 \pm 4$ & $>100$ \\
$\mathrm{C} 3$ & $2.8 \pm 0.2$ & $80 \pm 2$ & $>100$ \\
\hline
\end{tabular}

C1, smooth membrane surface

$\mathrm{C} 2$, vertically oriented corrugates

$\mathrm{C} 3$, horizontally oriented corrugates

\subsubsection{Critical flux measurements}

Two runs of the IFSM were performed for membranes C1, C2 and C3. In between the runs the membranes were rinsed and chemically cleaned by soaking them for two $\mathrm{h}$ in $0.2 \mathrm{~g} \mathrm{~L}^{-1}$ sodium-hypochlorite and $1.25 \mathrm{~g} \mathrm{~L}^{-1}$ in citric acid, successively. Clean water test after cleaning showed that the clean membrane resistance was restored. Table 6.1 gives the average $J_{C}$ and $J_{C i}$ for the three different membrane configurations.

A marginally larger $J_{C}$ was measured for the corrugated membranes compared to the smooth membranes. $J_{C}$ is generally regarded as the flux where a transition from concentration polarization to cake formation occurs $[3,9,18]$. At this flux convection of particles towards the membrane by the permeate drag flow exceeds their back transport from the membrane induced by shear and Brownian diffusion. At equal permeate flow, $J_{C}$ of the smooth membrane was $5 \%$ lower than $J_{C}$ of the membrane with vertical oriented corrugates $(C 2)$. This could be attributed to the $5 \%$ larger membrane surface area. $J_{C}$ of the membrane with horizontal oriented corrugates (C3) was an additional $2.5 \%$ larger than $J_{C}$ of the membrane with vertical oriented corrugates (C2). This can be explained by the tangential air-flow inducing more turbulence over the horizontal corrugates with an angle of $90^{\circ}$ opposite to the air flow, compared to the vertical oriented corrugates [19, 31].

All three PVDF membranes did not show any irreversible fouling during $10 \mathrm{~h}$ of filtration, since $J_{\mathrm{Ci}}$ was larger than $100 \mathrm{~L} \mathrm{~m}^{-2} \mathrm{~h}^{-1}$. A gel layer is more adhesive than a cake layer [30] and therefore less or perhaps not reversible during relaxation. Operation at the low reference flux of $5 \mathrm{~L} \mathrm{~m}^{-2} \mathrm{~h}^{-1}$ in between each flux step in the IFSM method completely restored the resistance indicating a full reversibility of the fouling, suggesting that $J_{C}$ was determined by cake layer formation.

\subsubsection{Long-term experiments}

The results in Chapter 3 of this thesis revealed that larger critical fluxes generally were an indication for longer sustainable times. Two long-term experiments were performed to verify that the corrugated membranes also show a longer sustainable time compared to smooth membranes during sub-critical filtration. The results of the long-term experiments are shown 
in Figure 6.7. The membranes were chemically cleaned in between the two long-term experiments by rinsing and soaking them for two $\mathrm{h}$ in $0.2 \mathrm{~g} \mathrm{~L}^{-1}$ sodium-hypochlorite and for two $\mathrm{h}$ in $1.25 \mathrm{~g} \mathrm{~L}^{-1}$ citric acid, successively. Also in this case the chemical cleaning restored the clean membrane resistance. Furthermore there was a time span of two weeks between both long-term experiments.

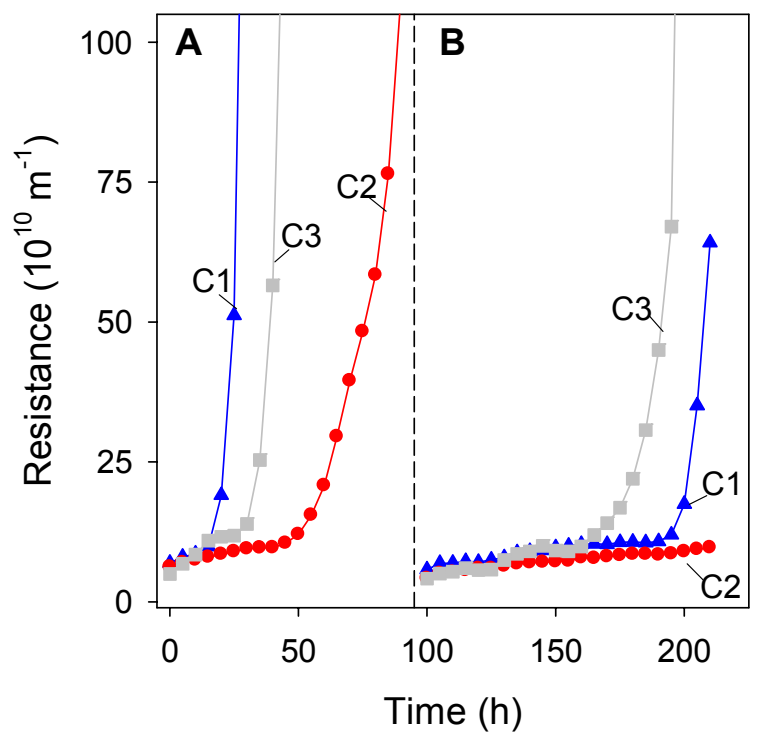

Figure 6.7 Two long-term filtration runs at a fixed flux of $50 \mathrm{~L} \mathrm{~m}^{-2} \mathrm{~h}^{-1}(A)$, and with relaxation steps at a net flux of $40 \mathrm{~L} \mathrm{~m}^{-2} \mathrm{~h}^{-1}(\mathrm{~B})$, with a smooth membrane (C1), and membranes with vertical (C2) and horizontal oriented corrugates (C3).

Sub-critical filtration at a fixed flux of $50 \mathrm{~L} \mathrm{~m}^{-2} \mathrm{~h}^{-1}$ showed the characteristic two-stage resistance profile for all three membrane configurations (Figure 6.7A). Please notice that filtration with each configuration was carried out for $100 \mathrm{~h}$, but that the filtration resistance is only shown up to a value of $100 \times 10^{10} \mathrm{~m}^{-1}$. The smooth membrane (C1) showed a sustainable time of approximately $20 \mathrm{~h}$ while this was longer for the corrugated membranes: $40 \mathrm{~h}$ for horizontal oriented corrugates (C3) and $60 \mathrm{~h}$ for vertical oriented corrugates (C2). The membrane surface for all three configurations was covered with a gel layer after the experiment was finished (Figure 6.8). For visualization purposes, these membrane surfaces were partially forward flushed (FF). The FF removed the gel layer from the membrane surface yielding a whiter and cleaner membrane surface. This visualizes the gel layer as the darker right part of the membranes. It is assumed that more gel is present on the membrane in case the membrane reveals a darker surface. With this assumption the gel layer visually seemed less thick for the corrugated membrane with vertical oriented corrugates when compared to the other two configurations. This is in agreement with the observation that the corrugated membrane with vertical oriented corrugates had been in stage 2 of the fouling process for a shorter time period than the other two configurations, i.e. $40 \mathrm{~h}$ for the vertical oriented corrugates, $60 \mathrm{~h}$ for the horizontal oriented corrugates, and $80 \mathrm{~h}$ for the smooth membrane. 

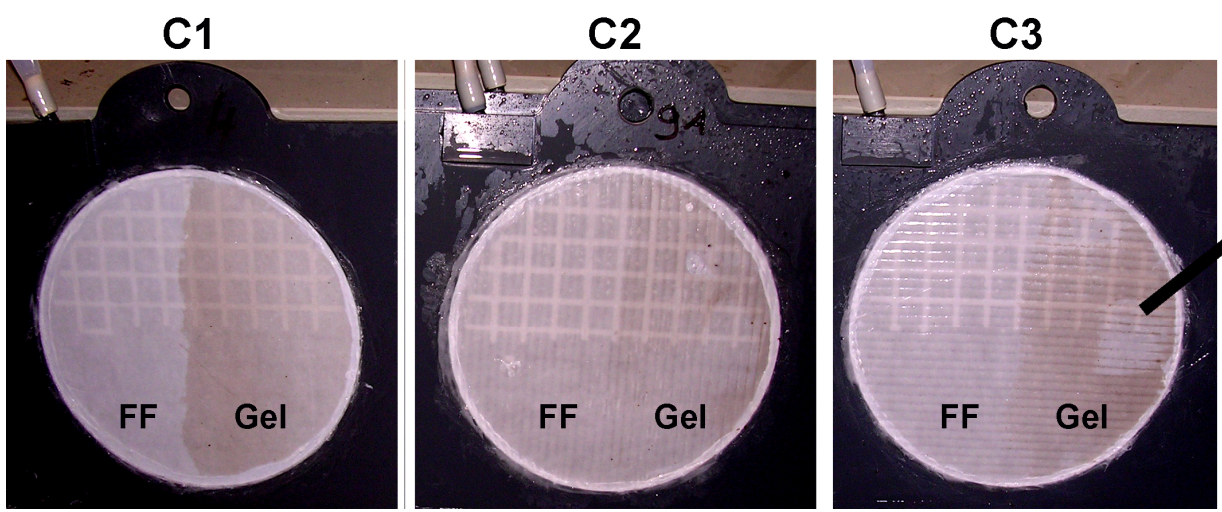

C3 enlarged

Figure 6.8 Gel layer formation after $100 \mathrm{~h}$ of filtration at a fixed flux of $50 \mathrm{~L} \mathrm{~m}^{-2} \mathrm{~h}^{-1}$ on a smooth membrane (C1), and on corrugated membranes with vertical oriented corrugates (C2) and horizontal oriented corrugates (C3). The membrane surfaces were partially forward flushed to see the gel layer on the part of the membrane that is not forward flushed (FF). The image most to the right shows an enlargement of the right hand part of the corrugated membrane with perpendicular positioned corrugates.

The longer sustainable time of the corrugated membrane with vertical oriented corrugates compared the corrugated membrane with horizontal oriented corrugates did not correspond with previous observations in Chapter 3 that membranes with the largest $J_{C}$ also revealed the longest sustainable time. Deposition of sludge particles in the valleys of the corrugates (most right image in Figure 6.8) was observed visually, which did not occur for the corrugated membrane with vertical oriented corrugates. As a result, the local flux on the hills of the corrugates increased faster in the case of horizontal oriented corrugates, finally resulting in a shorter sustainable time compared to the vertical oriented corrugates. This might explain the different relation between sustainable time and $J_{C}$ as observed in Chapter 3 .

Sub-critical filtration at a net flux of $40 \mathrm{~L} \mathrm{~m}^{-2} \mathrm{~h}^{-1}$ (Figure 6.7B) also revealed the characteristic two-stage fouling pattern for the smooth membrane and the corrugated membrane with horizontally oriented corrugates. For the corrugated membrane with vertically oriented corrugates however, this was not observed. The sustainable times were much longer than those measured at a fixed flux of $50 \mathrm{~L} \mathrm{~m}^{-2} \mathrm{~h}^{-1}$, even though an equal instantaneous flux was applied. Apparently, intermittent relaxation minimized the formation of the gel layer resulting in a longer sustainable time. Relaxation intermittently disrupted concentration polarization, preventing that the gel concentration was reached. Furthermore a gel layer is assumed to be more adhesive than a cake layer [30], but this does not mean that the gel layer present on the membrane can not be removed partly by air scouring during relaxation.

In contrast with the first experiment, the second experiment showed a shorter sustainable time for the corrugated membrane with horizontally oriented corrugates compared to the smooth membrane. It was assumed that an intermediate relaxation while maintaining air-scouring, could not remove the local deposition of material in the valleys of the horizontal 
oriented corrugates. The work of van der Waal and Racz [26] showed that in case the corrugates are placed too close to each other and are positioned with a $90^{\circ}$ angle to the air flow, that the main flow over the surface does not reach the membrane surface in between the corrugates. Hence, air bubbles are unable to scour off the membrane surface in the areas between the corrugates. In this case relaxation had more effect for the smooth membrane resulting in its longer sustainable time. The valleys of the vertical oriented corrugates surprisingly did not reveal more deposition in the valleys compared to the rest of the membrane surface.

\subsubsection{Optimization of corrugated membranes for MBR}

The method used to prepare the corrugated membranes in this study was a new approach and is not yet optimized. The procedure used approximately four times more casting solution compared to smooth membrane fabrication. Obviously, for commercial membrane fabrication this is undesirable from a cost perspective view. The use of other microfabrication techniques mentioned earlier, like embossing or phase inversion micromolding, could solve this drawback.

Also the corrugate shape was not yet optimized. The intended triangular corrugates would have increased the membrane surface area by $20 \%$, instead of the $5 \%$ increase found in this study for the ridged corrugates. In a future study the polymer dope solution should be solidified faster directly after casting to prevent flowing of the corrugates, in order to obtain more distinct corrugates with corresponding larger membrane surface area. With PVDF as polymer, a faster fixation of corrugates is difficult to realize with the equipment available. By using faster coagulating polymers such as poly(ether)sulphone this might be easier realizable. In this perspective, squared corrugates might also be feasible to further increase the membrane surface area, and in this way the sustainable time. A squared gap between two corrugates however, also reduces air scouring in between the corrugates and especially in the corners. Additionally, in case the corrugates are vertically oriented the distance between corrugates may be decreased depending on the form of the corrugate. This would increase the membrane surface area even more and so further increase the sustainable time. A smaller distance between corrugates however, may also lead to more severe fouling due to air scouring inability in between the vertically oriented corrugates. 


\subsection{Conclusions}

This study shows results of the first experiments to produce corrugated flat-sheet membrane surfaces to extend the sustainable filtration time at sub-critical filtration in MBRs. Previous Chapters showed that an increase in critical flux indicates a longer sustainable filtration time. The corrugated membranes had a $5 \%$ larger membrane surface area increasing the critical flux by $5 \%$. An additional $2.5 \%$ enhancement in critical flux was established by orienting the corrugates horizontally at a $90^{\circ}$ angle opposite the vertical air flow. This configuration induced more turbulence at the membrane-liquid interface compared to vertical oriented corrugates that limited cake layer formation.

On the long term gel layer formation was the dominant fouling mechanism. Corrugated membranes with vertical oriented corrugates always showed the longest sustainable time attributed to the larger membrane surface area. The horizontal oriented corrugates were less beneficial on long-term, since sludge particles deposited in the valleys between the corrugates.

\subsection{Used symbols and abbreviations}

Symbol

Unit

\begin{tabular}{lll}
\hline C1 & PVDF membrane with a smooth surface & \\
C2 & PVDF membrane with vertical oriented corrugates & \\
C3 & PVDF membrane with horizontal oriented corrugates & \\
EPS & Extracellular polymeric substances & \\
FF & Forward flush & \\
IFSM & Improved flux-step method & $\mathrm{L} \mathrm{m}^{-2} \mathrm{~h}^{-1}$ \\
$J_{C}$ & Critical flux & $\mathrm{L} \mathrm{m}^{-2} \mathrm{~h}^{-1}$ \\
$J_{\mathrm{Ci}}$ & Critical flux for irreversibility & \\
MBR & Membrane bioreactor & \\
PVDF & Polyvinylidenedifluoride & $\mathrm{m}^{-1}$ \\
$R$ & Hydraulic resistance & \\
SEM & Scanning electron microscope & $\mathrm{Pa}$ \\
TMP & Transmembrane pressure \\
\hline
\end{tabular}




\subsection{References}

1. Judd, S.J., The MBR Book: Principles and Applications of Membrane Bioreactors in Water and Wastewater Treatment. 1st ed. 2006, Oxford: Elsevier.

2. Stephenson, T., Judd, S., Jefferson, B., and Brindle, K., Membrane bioreactors for wastewater treatment. 2000, London: IWA Publishing.

3. Howell, J.A., Subcritical flux operation of microfiltration. Journal of Membrane Science, 1995. 107: p. 165-171.

4. Cho, B.D. and A.G. Fane, Fouling transients in nominally sub-critical flux operation of a membrane bioreactor. Journal of Membrane Science, 2002. 209: p. 391-403.

5. Ognier, S., C. Wisniewski, and A. Grasmick, Membrane bioreactor fouling in subcritical filtration conditions: a local critical flux concept. Journal of Membrane Science, 2004. 229: p. 171-177.

6. Jiang, T., et al., Optimising the operation of an MBR pilot plant by quantitative analysis of the membrane fouling mechanism. Water Science and Technology, 2005. 51: p. 19-25.

7. Le-Clech, P., V. Chen, and T.A.G. Fane, Fouling in membrane bioreactors used in wastewater treatment. Journal of Membrane Science, 2006. 284: p. 17-53.

8. Guglielmi, G., et al., Sub-critical fouling in a membrane bioreactor for municipal wastewater treatment: Experimental investigation and mathematical modelling. Water Research, 2007. 41: p. 3903-3914.

9. Chen, V., et al., Particle deposition during membrane filtration of colloids: transition between concentration polarization and cake formation. Journal of Membrane Science, 1997. 125: p. 109-122.

10. Hermanowicz, S.W., Membrane filtration of biological solids: a unified framework and its application to MBR. in: Proceedings of the Water Environment-Membrane Technology Conference, Seoul, Korea, 2004.

11. Zhang, J., et al., Factors affecting the membrane performance in submerged membrane bioreactors. Journal of Membrane Science, 2006. 284: p. 54-66.

12. Hwang, B.K., Lee, W. N., Yeon, K. M., Park, P. K., Lee, C. H., Chang, I. S., Drews, A. and Kraume, M., Correlating TMP increases with microbial characteristics in the biocake on the membrane surface in a membrane bioreactor. Environmental Science and Technology, 2008. 42: p. 3963-3968.

13. Koros, W.J., Y.H. Ma, and T. Shimidzu, Terminology for membranes and membrane processes. Journal of Membrane Science, 1996. 120: p. 149-159.

14. Koops, G.H., Nomenclature and symbols in membrane science and technology. 1995, European Society of Membrane Science and Technology, the Netherlands.

15. Michaels, A.S., New seperation technique for the CPI. Chemical Engineering and Progress, 1968. 64: p. 31-43.

16. Bacchin, P., et al., A unifying model for concentration polarization, gel-layer formation and particle deposition in cross-flow membrane filtration of colloidal suspensions. Chemical Engineering Science, 2002. 57(1): p. 77-91.

17. Mulder, M., Basic principles of membrane technology. 2nd ed. 2003, Dordrecht: Kluwer Academic Publishers. 
18. Judd, S. and B. Jefferson, Membranes for industrial wastewater recovery and reuse. 1st ed. 2003, Oxford: Elsevier science Itd.

19. $\mathrm{Hu}, \mathrm{B}$. and K. Scott, Influence of membrane material and corrugation and process conditions on emulsion microfiltration. Journal of Membrane Science, 2007. 294: p. 30-39.

20. Racz, I.G., J. Groot Wassink, and R. Klaassen, Mass transfer, fluid flow and membrane properties in flat and corrugated plate hyperfiltration modules. Desalination, 1986. 60: p. 213-222.

21. Heckele, M., W. Bacher, and K.D. Müller, Hot embossing-the molding technique for plastic microstructures. Microsystem Technologies, 1998. 4: p. 122-124.

22. Vogelaar, L., et al., Phase Separation Micromolding-PS $\mu M$. Advanced Materials, 2003. 15: p. 1385-1389.

23. Gronda, A.M., S. Buechel, and E.L. Cussler, Mass transfer in corrugated membranes. Journal of Membrane Science, 2000. 165(2): p. 177-187.

24. Scott, K., R.J. Jachuck, and D. Hall, Crossflow microfiltration of water-in-oil emulsions using corrugated membranes. Separation and Purification Technology, 2001. 22: p. 431-441.

25. Garcia, F.J.G. and T.Y. Chiu, Economic aspects of critical flux operability in star shaped microfiltration membranes: Influence of some operating conditions. Journal of Membrane Science, 2008. 325: p. 641-646.

26. Van der Waal, M.J. and I.G. Racz, Mass transfer in corrugated-plate membrane modules. I. Hyperfiltration experiments. Journal of Membrane Science, 1989. 40: p. 243-260.

27. Nijdam, W., et al., High performance micro-engineered hollow fiber membranes by smart spinneret design. Journal of Membrane Science, 2005. 256: p. 209-215.

28. Remy, M., et al., Low dose powdered activated carbon addition at high sludge retention times to reduce fouling in membrane bioreactors. Water Research, 2009. 43: p. 345-350.

29. Ven, W.v.d., Towards optimal saving in membrane operation, the development of process inspection and feedwater characterization tools. PhD Thesis, University of Twente, Enschede, the Netherlands, 2008.

30. Wang, Z., et al., Membrane fouling in a submerged membrane bioreactor (MBR) under sub-critical flux operation: Membrane foulant and gel layer characterization. Journal of Membrane Science, 2008. 325: p. 238-244. 



\section{Chapter 7}

Conclusions \& Outlook

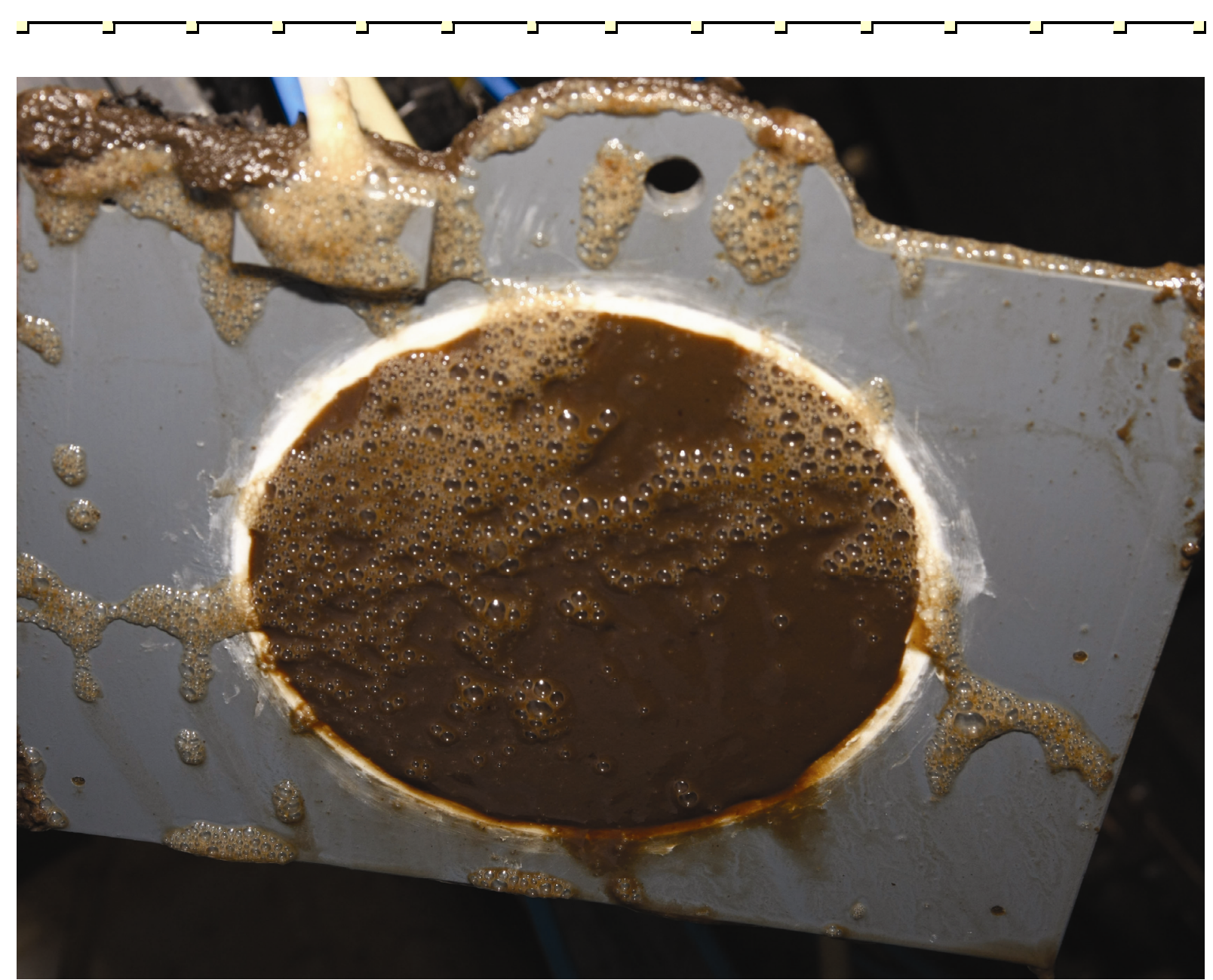


P. van der Marel, A. Zwijnenburg, A.J.B. Kemperman, M. Wessling, H Temmink, and W.G.J. van der Meer. 


\subsection{Improved flux-step method}

This study was initiated to identify those membrane properties for submerged MBR which reduce membrane fouling problems as much as possible. For this purpose a distinction is required between reversible and irreversible fouling, because a membrane that suffers from much reversible fouling for instance can be operated in practical MBR installations without any problems compared to a membrane suffering from minor irreversible fouling. The flux-step method was selected for fouling elucidation by determining the critical flux. A disadvantage of commonly applied flux-step methods however, is they cannot distinguish between reversible and irreversible fouling. For this purpose an improved flux-step method (IFSM, see Chapter 2) was developed which incorporated a physical cleaning step by relaxation between flux-stepping, in order to determine the critical flux for irreversibility. The IFSM therefore has distinct advantages over common flux-step methods, and allows for the identification of optimal membrane properties (see Section 7.2). Theoretically, fouling occurs during filtration above the critical flux, and irreversible fouling starts to develop above the critical flux for irreversibility. On the long-term, filtration above the critical flux might be applied in case the critical flux for irreversibility is much larger than the critical flux.

The type of physical cleaning used in the IFSM method determines the degree of reversible fouling, and therefore may affect the experimental values of critical flux and critical flux for irreversibility. In full scale MBRs different filtration times are applied, and various relaxation times and/or backwash fluxes are used to recover from reversible fouling. It is suggested for future studies with the IFSM to apply different cleaning conditions to investigate their effect on the critical flux and critical flux for irreversibility. This might result in better cleaning strategies for MBRs.

\subsection{Optimal membrane properties}

The objective of this study was to identify optimal membrane properties, i.e. those properties that give the largest critical flux and critical flux for irreversibility. Furthermore, the objective was to see whether the results are valid for different activated sludge mixtures, and if results from short-term flux-step methods can be extrapolated to long-term operation.

Optimal membrane properties were identified by comparing 15 different flat-sheet membranes. The best performing membrane in our study was a hydrophilic, home made PVDF membrane with an asymmetric interconnected pore morphology, with a pore size of $0.3 \mu \mathrm{m}$, and with a surface porosity of $27 \%$. Initially, the IFSM was performed for 15 different membranes in activated sludge of a pilot scale MBR (see Chapter 3). The filtration behavior 
of the same membranes also was examined in sludge from a conventional activated sludge (CAS) system and from a full scale MBR (see Chapter 4). The relative fouling trends measured using the IFSM for the different membranes was the same for all three sludge mixtures. Besides flux-step measurements, long-term filtration experiments at fluxes below the critical flux were performed. The results showed that membranes with optimal properties as determined in short-term IFSM also gave the longest sustainable filtration time, i.e. the time before the transmembrane pressure (TMP) rapidly started to increase. Typical operating fluxes in submerged MBR are $25 \mathrm{~L} \mathrm{~m}^{-2} \mathrm{~h}^{-1}$, and with optimal membrane properties a fixed flux twice as high could be applied without or with marginal fouling problems. The dominant long-term fouling could be related to gel layer formation.

Three items for further research are proposed with respect to find optimal membrane properties. Firstly, membranes with larger pores often also have a larger surface porosity. It is unknown which of these two properties is most important in the fouling process in an MBR. Unfortunately, it is very difficult to obtain membranes with identical surface porosities but with different pore sizes and vice versa, which makes it hard to uncouple the effects of these two parameters on fouling behavior. The use of polymeric micro-sieves [1] is proposed to investigate the influence of the surface porosity and pore size on fouling solely. The method to produce these micro-sieves in principle allows for independent variation of pore size and surface porosity.

Secondly, the research in this thesis focused on membrane properties, while the feed properties only were marginally investigated. For future studies it is therefore proposed to investigate the relation between feed properties of different activated sludge mixtures and optimal membrane properties on the membrane fouling process. A mobile filtration unit as described in Chapter 4 could be used for this purpose (see Section 7.5). Together with a detailed analysis of the sludge properties and the information on membrane properties shown in this thesis, this may lead to a further understanding of the fouling process and site specific solutions for the fouling problems. The particle size distribution (PSD) of sludge from a CAS system for instance showed almost no material in the particle size range around $0.8 \mu \mathrm{m}$ (appendix I in Chapter 4). In addition, out of four mixed cellulose ester (MCE) membranes ranging in pore size from 0.1 to $2.7 \mu \mathrm{m}$, a membrane with a pore size of $0.8 \mu \mathrm{m}$ showed a remarkable better fouling behavior in activated sludge mixtures from the CAS system. The absence of a certain particle size in activated sludge could possibly lead to an optimal membrane pore size for that MBR installation. When optimizing membrane pore size also the permeate quality should also be investigated, since a reduction in fouling with increasing pore size is useless when the permeate quality becomes unacceptable. The chemical oxygen demand (COD) of the permeates in this work for pore sizes ranging from 0.02 to $8 \mu \mathrm{m}$ increased with increasing pore size. Each permeate however, revealed a COD concentration below the discharge standard of $125 \mathrm{mg} \mathrm{L}^{-1}$. In case of reusing the effluent obviously different standards apply, necessitating a certain maximum pore size.

At last, the research in this thesis focused on the flat-sheet membrane configuration, because a whole range of different membrane materials with varying pore sizes was easily 
available as flat-sheet. Other membrane configurations used in MBRs are hollow fiber and tubular systems. Although a variety in membrane properties for these configurations might be less easily available, it is proposed to investigate optimal membrane properties for these configurations with the IFSM method, with different activated sludge mixtures, and during long-term experiments under equal operating conditions.

\subsection{Fouling reversibility by relaxation and (chemical) backwashing}

Membranes may have a symmetric or an asymmetric pore morphology. A symmetric pore morphology could result in severe particle entrapment (or pore blocking) which cannot be removed by relaxation (Chapters 3 and 4 ). Chapter 5 showed that internal fouling also could not be removed by physical backwashing. This kind of fouling only could be removed by chemically enhanced backwashing. Our observations question the effort currently put in producing backwashable flat-sheet membranes for MBR [2, 3].

A lot of information about the use of cleaning chemicals in MBRs is available from operators, membrane manufacturers, and suppliers of chemical agents. In scientific literature however, not much is published about how fouling can be removed in an effective way using chemicals in order to restore membrane permeability. A scientifically based investigation of the use of chemical cleaning in MBR therefore is desirable. Research topics are for instance to what extent chemically enhanced backwashing is applicable (concentration and frequency), without affecting the biological treatment performance. Furthermore, a subject of interest is which cleaning agents or compositions of them can best be used to restore the filtration performance in case pore blocking or gel layer formation are the fouling mechanisms.

\subsection{Corrugated membranes}

During long-term sub-critical filtration at a certain moment a rapid rise in resistance (the TMP jump) is observed due to gel layer formation (Chapter 3 ). This needs to be tackled to increase the sustainable filtration time and to limit the cleaning frequency, and so to decrease operational cost of MBR. Initial results of the use of flat-sheet membranes with corrugated surfaces, placed vertically to the tangential air flow in an MBR, revealed up to a three times longer sustainable filtration time compared to smooth membrane surfaces (Chapter 6). This was explained by a lower superficial flux related to the increased membrane area of $5 \%$, and by enhanced turbulences in the vicinity of the corrugations. Both effects were believed to reduce gel layer formation. 
The production of the corrugated membranes had a trial-and-error character. The use of microfabrication techniques like embossing or phase inversion micromolding therefore are proposed for obtaining membranes with more distinct corrugated surfaces. Optimization with respect to size, position, and form of the corrugates is required to further increase the sustainable filtration time in MBR.

\subsection{Mobile filtration unit}

Collection and transportation of activated sludge to a research facility - and subsequently performing fouling experiments - will alter the composition and herewith the filterability of the sludge. This influences fouling results compared to fresh sludge operation [4]. Furthermore, only short-term experiments can be performed since the batches of sludge are not fed with fresh wastewater during the experiments. The use of a mobile filtration unit at MBR sites reduces these problems (Chapter 4 ) by applying a circulation flow of sludge between this unit and the aerobic or membrane compartment of the full scale MBR.

With the mobile filtration unit the sludge filterability of only one full scale MBR was investigated in this thesis, where the focus was put on the influence of membrane properties. For future studies it is suggested to use the mobile filtration unit on more MBR-sites. This will enable a full factorial design in investigating the three key parameters affecting membrane fouling: membrane properties, feed properties, and operational conditions. Activated sludge mixtures of different MBRs generally differ in feed properties, while all membrane operational conditions (aeration, flux, channel width, relaxation, backwashing, etc) can be controlled and varied in the mobile filtration unit. Furthermore, by means of the mobile unit it is very easy to test different flat-sheet filters on the activated sludge mixture of interest, since the mobile unit can contain 4 flat-sheet membranes at the same time. A similar approach was developed by Evenblij et al. to compare the filterability of different sludge mixtures with the same (tubular) membrane [5]. This system however was not developed for investigating membrane properties.

A second topic for further research is the use of the mobile filtration unit in combination with the improved flux-step method on a full scale MBR as a fast indicator for the filterability of the sludge. Variations in the critical flux will occur in case the filterability of the sludge changes, for instance due to temperature changes, day-night sequences, or in case of rain weather flow. This offers possibilities to create a response-strategy for the full scale installation in case changes in sludge filterability in the mobile unit are observed. 


\subsection{References}

1. Girones, M., et al., Polymeric microsieves produced by phase separation micromolding. Journal of Membrane Science, 2006. 283: p. 411-424.

2. Doyen, W., et al., Integrated permeate channel membrane. European Patent EP20050778312, 2005.

3. Lyko, M., Managing wastewater: Using membrane bioreactors for water supply. Filtration \& Separation, 2008. 1: p. 16-19.

4. Kraume, M., et al., Fouling in MBR: What use are lab investigations for full scale operation? Desalination, 2009. 236: p. 94-103.

5. Evenblij, H., et al., Filtration characterisation for assessing MBR performance: three cases compared. Desalination, 2005. 178: p. 115-124. 



\section{Summary}

Influence of membrane properties on fouling in MBRs

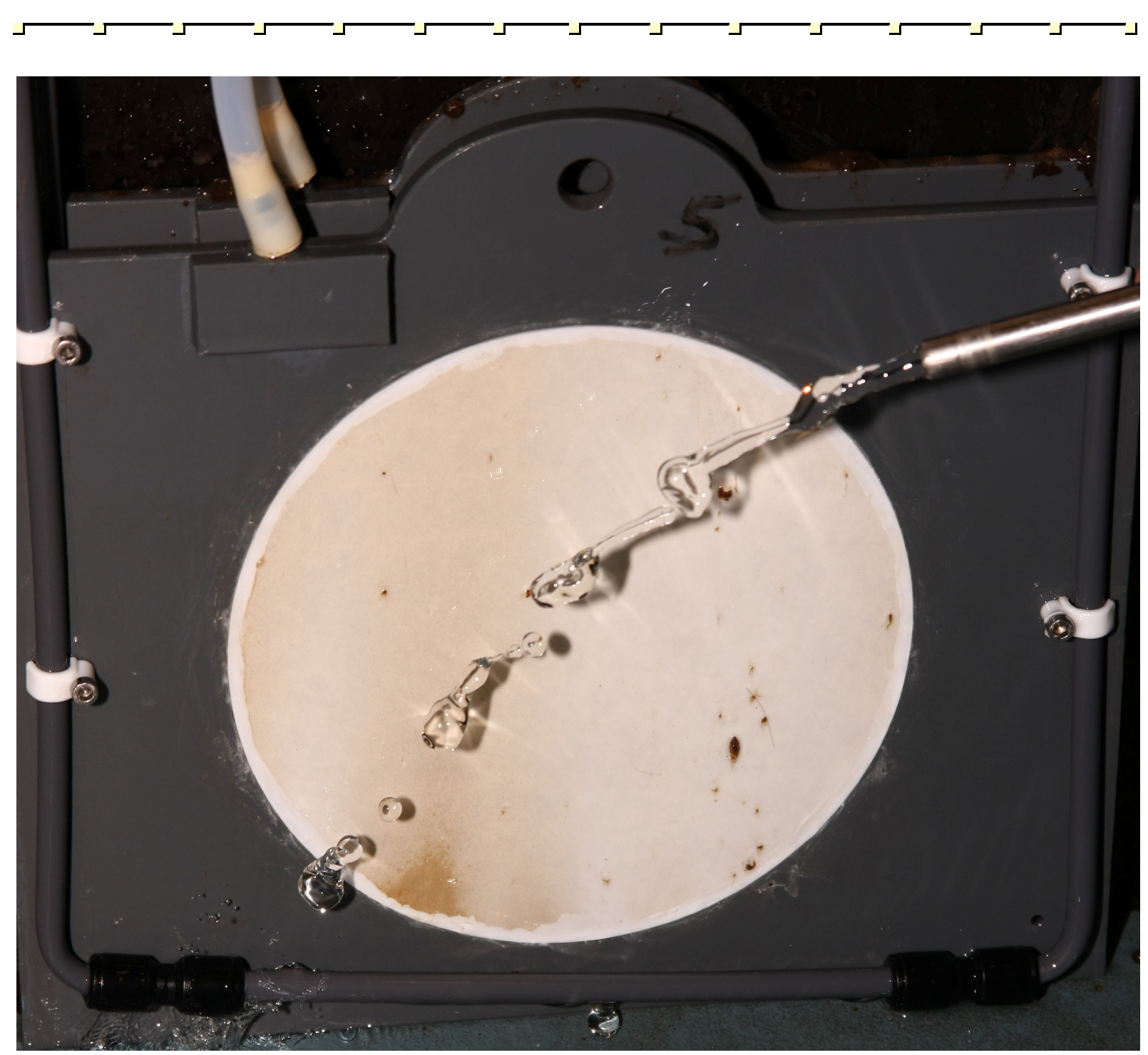




\section{Summary}

Nearly all wastewater treatment plants (WWTPs) apply an activated sludge process. In conventional activated sludge (CAS) systems the activated sludge is separated from the purified water before discharge using large clarifiers. The membrane bioreactor (MBR) applies membranes for separating the sludge and water. The use of membranes results in a smaller foot print and better effluent quality compared to CAS systems. Operational costs of MBRs, however, are higher due to measures necessary to reduce membrane fouling like coarse bubble aeration creating shear on the membrane surface, and membrane cleaning. Membrane fouling occurs by activated sludge material depositing on the membrane surface or inside the membrane pores. This raises the transmembrane pressure or lowers the membrane flux. The higher operational costs implies MBRs are only useful in situations where a high quality product is necessary (for example in the case of water reuse), or when a small footprint is required. Reducing operational costs by minimizing fouling is required for an MBR in order for it to become cost competitive with CAS systems, and to become a more standard wastewater treatment technology.

The subject of this thesis is to elucidate the role of the membrane properties on membrane fouling in MBRs, with the aim to identify optimal membrane properties which reduce membrane fouling. The use of optimal membrane properties in MBR will decrease the operational costs.

Chapter 2 introduces the improved flux-step method (IFSM): a new experimental protocol which is able to compare the influence of many different membrane properties on fouling and fouling reversibility. Reversible fouling easily can be removed via relaxation or backwashing. Irreversible fouling is a larger problem and can only be removed by more rigorous cleaning via for instance chemical cleaning. The distinction between reversible and irreversible fouling is required to identify the optimal membrane properties. A membrane that suffers from much reversible fouling at a certain flux for instance can be operated without any problems compared to a membrane which at the same flux only suffers from minor irreversible fouling. A disadvantage of current flux-step methods is that they cannot distinguish whether fouling is reversible or irreversible. In the IFSM a cleaning step by relaxation is applied which enables determination of both the critical flux and the critical flux for irreversibility. Membranes with optimal properties will lead to a high critical flux (low fouling) and a much higher critical flux for irreversibility.

The results show a similar critical flux for a home made polyvinylidenefluoride (PVDF) flat-sheet membrane in the IFSM compared to a common flux-step method. The IFSM also shows that the critical flux for irreversibility is much higher than the critical flux for this membrane. The fouling therefore is reversible, at least up to a flux of $100 \mathrm{~L} \mathrm{~m}^{-2} \mathrm{~h}^{-1}$. This result indicates the possibility of applying a flux above the critical flux during long-term filtration in MBR in case relaxation is applied. Usually sub-critical filtration is applied in an MBR, but the reversible nature of the fouling shows the applicability of a much larger flux for 
the PVDF membrane. A higher flux considerably lowers the investment costs, because less membrane surface area is required. Moreover, a smaller membrane surface area needs to be scoured off by the shear, which reduces the energy consumption for coarse bubble aeration.

Chapter 3 describes the use of the IFSM for five different polymeric membrane materials with varying membrane properties. The objective is to elucidate the influence of different membrane properties on fouling in order to find the optimal membrane that suffers the least from membrane fouling. The operational conditions for each membrane type are kept constant, and one type of activated sludge is used to maintain approximately equal feed properties.

The results show that the fouling behavior is different for the five membrane materials, and furthermore is different for membranes of the same membrane material differing in pore size, surface porosity, and hydrophobicity. The experiments with 15 different membranes show the best membrane performance for a hydrophilic asymmetric membrane with an interconnected pore structure, a nominal pore size of $0.3 \mu \mathrm{m}$, and large surface porosity of $27 \%$. In addition, long-term experiments are performed. The dominant fouling mechanism in long-term filtration experiments is gel layer formation. Gel layer formation is the least severe for the optimal membrane, showing the longest time before a dramatic increase in resistance occurs (sustainable filtration time).

In Chapter 4 the IFSM is applied for the same membranes as in Chapter 3, but now in two other activated sludge mixtures. The objective is to determine whether the different feed properties influence the optimal membrane properties. In Chapter 3 activated sludge from a pilot-scale MBR is used which is operated at the Wetsus research facility. In Chapter 4 activated sludge from the CAS system of the city of Leeuwarden and activated sludge from the full scale MBR in Varsseveld are used. The CAS-sludge is transported to the research facility of Wetsus, whereas a mobile filtration unit is placed for two months at the MBR Varsseveld. Both the IFSM as well as long-term experiments are performed.

The results show that membranes with different membrane properties have the same tendency towards membrane fouling in all three activated sludge mixtures. The fouling is more severe for sludge from the conventional wastewater treatment plant and the MBR Varsseveld compared to the activated sludge from the Wetsus pilot-scale MBR.

In MBRs with flat-sheet membranes usually relaxation is applied as cleaning method to remove the reversible membrane fouling deposited on the membrane surface. Backwashing however, may offer the advantage over relaxation that also internal fouling is (partly) removed: during backwashing the permeate is forced to flow from the permeate side to feed side of the membrane at a higher flux than the operating flux. Chapter $\mathbf{5}$ describes relaxation and backwashing experiments to elucidate which cleaning method is more effective for flat-sheet membranes. The amount of irreversible fouling which is not removed by the cleaning methods is determined at an equal net flux for both cleaning methods, and for three 
different membrane materials. A ceramic membrane is used which has a much higher mechanical strength compared to conventional polymeric flat-sheet membranes, and thus is mechanically strong enough for backwashing. Additionally, a home made PVDF membrane and a commercial polyethylene (PE) membrane are used.

The results show that cleaning by backwashing and relaxation are equally efficient in removing membrane fouling, but both do not remove irreversible fouling caused by internal fouling and gel layer formation. From the three membrane materials investigated the PVDF membrane fouled the least, which could be attributed to its asymmetric pore morphology. The ceramic membrane and the PE membrane both have a symmetric pore morphology in the membrane top layer. Particles become trapped in this top layer and are not removed by relaxation, and also not by backwashing. A chemically enhanced backwash (CEB) with sodium hypochlorite is able to remove the internal fouling partially.

The responsible deposition mechanism on the long run in this research is gel layer formation. This process seems inevitable since also during sub-critical filtration eventually an exponential increase in resistance occurs. Chapter 6 describes a pioneering study with corrugated membranes to extend the period until gel layer formation occurs: i.e. to extend the sustainable filtration time. The corrugated membranes are placed with their corrugates either with a vertical orientation or with a horizontal orientation of the corrugates to the vertical air flow. The critical flux and the sustainable filtration time of these two configurations are compared to a smooth flat-sheet membrane configuration.

The results show that the corrugations increase the critical flux by $5 \%$ due to a $5 \%$ larger membrane surface area. An additional $2.5 \%$ increase in critical flux is obtained by positioning the corrugates horizontally to the air flow, most likely since this configuration induces more turbulence at the membrane-liquid interface. Despite the higher critical flux for the horizontal oriented corrugates, this configuration is less favorable for long-term filtration, because sludge particles deposit in the valleys between the corrugates. On the long-term, membranes with vertical oriented corrugates result in the longest sustainable filtration time, because no sludge deposited in between the corrugates in this configuration. This corrugated membrane shows the potential of extending the sustainable filtration time in an MBR without increasing its operational costs.

Chapter 7 presents the main conclusions of the work in this thesis, together with the outlook for each addressed fouling topic. The main conclusion is that optimal membrane properties can reduce the operational costs of the MBR since fouling is reduced and higher fluxes can be applied. For future research it is proposed to also incorporate backwashing in the IFSM as cleaning method. Furthermore, investigation of optimal membrane properties for other membrane configurations (hollow fibre and tubular membranes) with the IFSM is recommended. In addition, a more detailed investigation of the application of CEBs in MBR is proposed to optimize the removal of the internal fouling. Additionally, research aiming at proper solutions to minimize the dominant fouling by gel layer formation is necessary. The application of different corrugated structures on flat-sheet membranes can be a start. Finally, 
the mobile filtration unit that is designed in this study should be used to investigate the influence of membrane properties on fouling in relation to feed properties in different MBRs. Moreover, the mobile filtration unit also can be used as a fast indicator for the filterability of the sludge when running parallel to a full scale MBR. This offers possibilities to create a response-strategy for the full scale installation in case changes in the filterability in the mobile unit are observed. 



\section{Samenvatting}

Invloed van membraaneigenschappen op vervuiling in MBRs

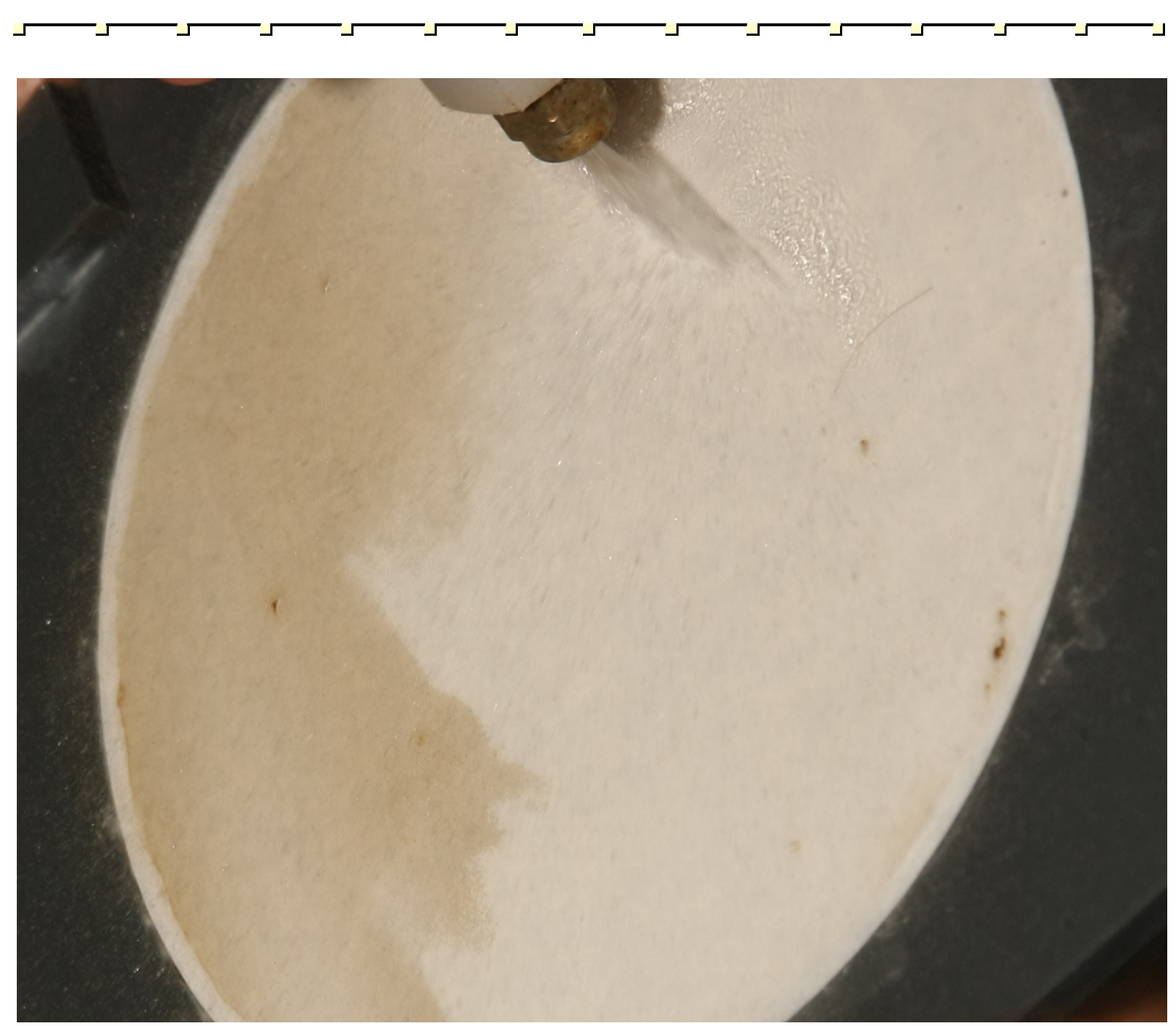




\section{Samenvatting}

De membraanbioreactor (MBR) is een afvalwaterzuiveringinstallatie (AWZI) die het actief slibproces combineert met membraanfiltratie. De membranen scheiden het gezuiverde water (permeaat) van het actief slib (retentaat). Voordelen ten opzichte van conventionele AWZl's - die gebruik maken van grote bezinktanken voor de slib-water scheiding - zijn een kleiner grondoppervlak en een betere kwaliteit van het gezuiverde water. Een groot nadeel van een MBR is membraanvervuiling door het actief slib. Vervuiling wordt veroorzaakt doordat slibmateriaal zich afzet op het membraanoppervlak of in de membraanporiën. Hierdoor gaat de transmembraandruk omhoog of de membraanflux van de MBR omlaag. Vervuiling leidt tot hogere operationele kosten voor een MBR vergeleken met conventionele AWZI's door maatregelen die enerzijds vervuiling minimaliseren (bijvoorbeeld grove bellenbeluchting over het membraanoppervlak, en afschuiving) en anderzijds vervuiling verwijderen (fysische en chemische reinigingen). Het gebruik van MBRs lijkt daardoor alleen interessant wanneer een hoogwaardige kwaliteit van het gezuiverde water is gewenst (zoals wanneer er sprake is van waterhergebruik) of wanneer ruimtegebrek voor de zuiveringsinstallatie een rol speelt. De operationele kosten van een MBR installatie moeten omlaag, ofwel vervuiling moet worden gereduceerd, om een MBR ook in elke andere situatie als AWZI toe te passen.

Het onderwerp van deze dissertatie is het bepalen van de invloed van verschillende membraaneigenschappen op de vervuiling, met als doel de optimale membraaneigenschappen te bepalen die vervuiling reduceren en daardoor de operationele kosten van MBR verlagen.

Hoofdstuk 2 introduceert de verbeterde flux-stap methode ('improved flux-step method', IFSM): een nieuwe experimentele methode die de invloed bepaalt van verschillende membraaneigenschappen op vervuiling en haar reversibiliteit. Reversibele vervuiling in een MBR is de fractie die kan worden verwijderd door relatief simpel te reinigen middels relaxatie of terugspoelen. Irreversibele vervuiling is een groter probleem en moet worden verwijderd met rigoureuzere reinigingsmethodieken, zoals het gebruik van chemicaliën. Het is van belang om onderscheid te maken tussen reversibele en irreversibele vervuiling wanneer optimale membraaneigenschappen worden bepaald, omdat een membraan dat bij een bepaalde flux veel reversibele vervuiling ervaart beter kan zijn dan een membraan dat bij dezelfde flux alleen weinig irreversibele vervuiling ervaart. Huidige flux-stap methoden voor MBRs maken geen onderscheid tussen reversibele vervuiling en irreversibele vervuiling. Door het toepassen van een reinigingsstap middels relaxatie in de IFSM kan deze methode zowel de kritische flux als de kritische flux voor irreversibiliteit bepalen. Membranen met optimale eigenschappen leiden tot een hoge kritische flux (laag vervuilend) en een veel hogere kritische flux voor irreversibiliteit.

De resultaten tonen aan dat de IFSM eenzelfde kritische fluxwaarde geeft als een standaard flux-stap methode. De IFSM toont tevens aan dat de kritische flux voor irreversibiliteit veel hoger is dan de kritische flux voor een zelfgemaakt polyvinylideenfluoride (PVDF) 
membraan. De vervuiling voor dit membraan is boven de kritische flux vrijwel geheel reversibel, in ieder geval tot een flux van $100 \mathrm{~L} \mathrm{~m}^{-2} \mathrm{~h}^{-1}$. Dit resultaat geeft aan dat wanneer relaxatie wordt toegepast, een flux boven de kritische flux kan worden toegepast tijdens lange duur filtratie in een MBR. Normaliter wordt subkritisch gefiltreerd, maar gezien de reversibele eigenschappen van de vervuiling kan voor dit PVDF membraan een hogere flux worden toegepast. Een hogere flux vermindert het benodigde membraanoppervlak en dus de investeringkosten. Tevens reduceert dit de energieconsumptie voor de beluchting, omdat voor een kleiner membraanoppervlak minder beluchting nodig is.

Hoofdstuk 3 beschrijft het gebruik van de IFSM voor vijf verschillende membraanmaterialen met variërende membraaneigenschappen. Het doel is te bepalen welke eigenschappen vervuiling verminderen om zo de membraaneigenschappen te vinden waarbij de vervuiling het minst is. De voedingseigenschappen en de operationele omstandigheden zijn hierbij gelijk gehouden.

De resultaten tonen aan dat het vervuilingsgedrag verschillend is voor de vijf membraanmaterialen. Ook de poriegrootte en oppervlakteporositeit blijken een grote invloed te hebben alsmede de hydrofobiciteit van het membraanmateriaal. Van de 15 geteste membranen worden de beste resultaten bereikt met een hydrofiel PVDF membraan met een asymmetrische poriemorfologie, met onderling verbonden poriën in het membraan, en met een relatief grote poriegroote en oppervlakte porositeit van respectievelijk $0.3 \mu \mathrm{m}$ en $27 \%$.

Ook zijn filtraties gedurende langere periodes uitgevoerd. Uit deze onderzoeken komt naar voren dat membranen met een hoge kritische flux en een nog hogere kritische flux voor irreversibiliteit langer gefiltreerd kunnen worden zonder de noodzaak tot reiniging (de zogenaamde duurzame filtratietijd). De noodzaak tot reinigen wordt duidelijk wanneer een exponentiële toename in filtratieweerstand optreedt, welke in dit onderzoek wordt veroorzaakt door gellaagvorming op het membraanoppervlak.

Het onderzoek in hoofdstuk 4 test dezelfde membranen als in hoofdstuk 3, maar nu in twee andere actief slib mengsels. In hoofdstuk 3 is actief slib uit een pilot MBR gebruikt die wordt bedreven in de experimenteerhal van Wetsus. In hoofdstuk 4 zijn actief slibmengsels van de conventionele AWZI van Leeuwarden en van de full scale MBR in Varsseveld gebruikt. Het actief slib van de AWZI van Leeuwarden is daartoe vervoerd naar Wetsus en een mobiele filtratie unit is voor twee maanden bij de full scale MBR in Varsseveld geplaatst. Zowel de IFSM als lange duur filtratietesten zijn uitgevoerd.

De resultaten laten zien dat de verschillen in vervuilingsgedrag tussen de membranen onderling hetzelfde zijn in het actief slib van de pilot MBR vergeleken met de twee andere actief slibmengsels. De optimale membraaneigenschappen zijn dus gelijk wanneer actief slib met verschillende voedingseigenschappen wordt gebruikt. Wel is de vervuiling als geheel ernstiger gebleken voor het slib van de AWZI van Leeuwarden en de full scale MBR dan dat van de pilot MBR. 
In MBRs met vlakke plaat membranen wordt normaliter gebruik gemaakt van relaxatie als reinigingsmethode om de reversibele vervuiling te verwijderen. Terugspoelen van de membranen heeft als mogelijk voordeel dat ook interne vervuiling wordt verwijderd, omdat het permeaat met een hogere stroomsnelheid dan de toegepaste flux van de permeaat- naar de voedingszijde van het membraan wordt gedrukt. In hoofdstuk 5 zijn relaxatie en terugspoelen met elkaar vergeleken om te bepalen welke reinigingsmethode effectiever is. De mate van irreversibele vervuiling welke niet wordt verwijderd door de reinigingstechniek is bepaald voor drie verschillende membraanmaterialen bij een identieke netto flux. Een keramisch membraan is gebruikt welke een hoge mechanische belasting kan weerstaan en daardoor rigoureus kan worden teruggespoeld. Daarnaast zijn een eigengemaakt PVDF membraan en een commercieel polyethyleen (PE) membraan gebruikt.

De resultaten tonen aan dat reiniging door middel van terugspoelen even efficiënt is als reiniging middels relaxatie, omdat de mate van irreversibele vervuiling even groot is voor beide bedrijfsvoeringen. Van de drie membraanmaterialen vervuilt het PVDF membraan het minst vanwege haar asymmetrische membraanstructuur. Het keramische membraan en het PE membraan hebben beiden een symmetrische membraanstructuur in de toplaag. Hierin worden deeltjes gevangen die niet verwijderd kunnen worden met relaxatie, en ook niet door middel van terugspoelen. Een chemisch versterkte terugspoeling ('chemically enhanced backwash', CEB) met natriumhypochloriet kan wel een deel van deze interne vervuiling verwijderen.

Gedurende lange termijn filtratie is de vorming van een gellaag op het membraan uiteindelijk de reden waarom gereinigd moet worden. Dit proces lijkt onvermijdelijk, omdat het zelfs plaatsvindt tijdens subkritische filtratie. In hoofdstuk 6 wordt getracht de duurzame filtratietijd te verlengen met behulp van gecorrugeerde membraanoppervlakken. De gecorrugeerde structuur kan zowel verticaal als horizontaal ten opzichte van de verticaal langsstromende bellen worden geplaatst. De kritische flux en de duurzame filtratietijd van deze twee configuraties is vergeleken met die van een normaal vlakke plaat membraan.

De gecorrugeerde membranen hebben een hogere kritische flux dan het vlakke membraan als gevolg van een groter membraanoppervlak. De hoogste kritische flux is gemeten wanneer het gecorrugeerde oppervlak horizontaal op langsstromende bellen is geplaatst. Dit wordt verklaard door additionele turbulentie aan het membraanoppervlak bij deze configuratie. De duurzame filtratietijd is echter het langst wanneer het gecorrugeerde membraanoppervlak verticaal op de langsstromende bellen wordt geplaatst, omdat er dan geen depositie van materiaal ontstaat tussen de structuren zoals bij de horizontaal geplaaste configuratie. Gecorrugeerde membranen hebben de potentie om de duurzame filtratietijd in MBR te verlengen zonder daarbij de operationele kosten te verhogen.

Hoofdstuk 7 besluit deze dissertatie met de conclusies uit dit onderzoek en suggesties voor vervolgonderzoek. De hoofdconclusie is dat optimale membraaneigenschappen de operationele kosten in MBR kunnen verlagen omdat vervuiling wordt verminderd en hogere fluxen kunnen worden toegepast. In vervolgonderzoek kan de IFSM procedure worden 
aangepast om ook terugspoelen als reinigingstechniek te onderzoeken. Verder moet er met de IFSM gekeken worden naar de optimale membraaneigenschappen voor andere membraanconfiguraties (tubulaire en holle vezel membranen). Het gedetailleerder kijken naar het toepassen van CEBs voor de verwijdering van de interne vervuiling kan de operationele kosten voor een MBR verder verlagen. Additioneel moet onderzoek verricht worden naar geschikte manieren om vervuiling door gellaagvorming te minimaliseren. Er kan onder andere gekeken worden naar verschillende gecorrugeerde membraanstructuren. Tot slot kan gebruik gemaakt worden van de in dit onderzoek ontwikkelde mobiele filtratie unit om de invloed van membraaneigenschappen op vervuiling in verschillende MBRs te onderzoeken. De mobiele filtratie unit kan tevens gebruikt worden als snelle indicator voor variaties in filtratie-eigenschappen van het actief slib om hiermee de procesvoering van de full scale MBR optimaal te kunnen sturen. 


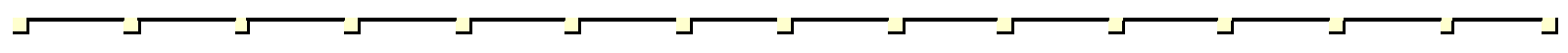

\section{Curriculum Vitae}

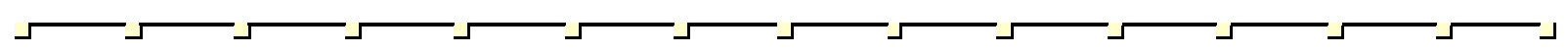

Perry van der Marel was born on August 21, 1981 in Delft, the Netherlands. After finishing secondary school (HAVO) at Aquamarijn college in Vlaardingen in 1998, he studied Environmental Science at the Hogere Agrarische School (HAS) in Delft. This Bachelor Degree in 2002 was followed by a Master Degree in Environmental Science at the Wageningen University in 2004. In both degrees he became specialized in Environmental Technology, and in both educations the membrane bioreactor (MBR) played a role. At HAS he built with a group of students a pilot scale MBR for teaching possibilities. The graduation project at the sub-department Environmental Technology at Wageningen University was on the topic pre-treatment of wastewater to reduce membrane fouling in MBR. After these activities the choice for a PhD study on MBR was logical. The PhD research was performed at Wetsus, Center of Excellence for Sustainable Water Technology in Leeuwarden, but this time under the supervision of the Membrane Technology Group of the University of Twente. The results are presented in this dissertation and will be defended in Leeuwarden, the Netherlands, on November 18, 2009. In April 2009 Perry started a new career as watertechnologist at Water Laboratorium Noord (WLN) in Glimmen, the Netherlands. 


\section{List of publications}

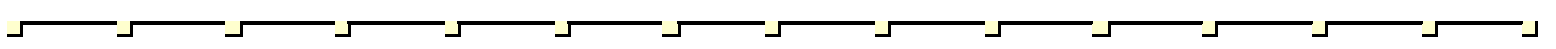

van der Marel, P., Zwijnenburg, A., Kemperman, A., Wessling, M., Temmink, H., van der Meer, W. An improved flux-step method to determine the critical flux and critical flux for irreversibility in a membrane bioreactor. Journal of Membrane Science, 2009. 332: p. 24-29.

Remy, M., van der Marel, P., Zwijnenburg, A., Rulkens, W., Temmink, H. Low dose powdered activated carbon addition at high sludge retention times to reduce fouling in membrane bioreactors. Water Research, 2009. 43: p. 345-350.

van der Marel, P., Zwijnenburg, A., Kemperman, A., Wessling, M., Temmink, H., van der Meer, W. Influence of membrane properties on fouling in submerged membrane bioreactors. Journal of Membrane Science, 2009. Submitted.

van der Marel, P., Zwijnenburg, A., Kemperman, A., Wessling, M., Temmink, H., van der Meer, W. Influence of membrane properties on membrane fouling in three different activated sludge mixtures. Water Research, 2009. In progress. 


\section{Dankwoord}

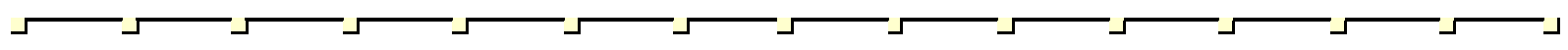

Een jaar geleden waren de Olympische zomerspelen in China en volgend jaar zijn de Olympische winterspelen in Vancouver. Olympische sporters werken 4 jaar lang hard voor die ene topprestatie. Alles valt of staat met het presteren op dat ene moment. Een prachtig vergelijk met een promovendus die zich ook 4 jaar hard moet inzetten om die ene topprestatie te leveren, het verdedigen van het proefschrift. Zowel sporters als promovendi worden in de vier jaar getest op vormbehoud. Zo heb je NK's, EK's en WK's voor sporters en het publiceren van artikels, presentaties op internationale congressen en themateam vergaderingen voor promovendi. Gelukkig word je op deze weg geholpen door veel mensen die ik daar voor wil bedanken.

Allereerst bedank ik mijn familie en in het bijzonder mijn ouders. Elf jaar geleden gingen we op zoek naar een hoveniersopleiding op HBO niveau. Die bestond niet en na enige omzwerving langs verschillende opleidingen zei ene Meivogel dat milieukunde bijna hetzelfde was. Het komt niet eens in de buurt kan ik je vertellen. Bedankt voor jullie zorg, het vertrouwen en de interesse. Ook bedankt voor het ter beschikking stellen van een stoomcleaner. Daar kun je heel mooie membranen mee maken!

Ik bedank mijn schoonfamilie voor de interesse in het onderzoek en voor de vele hulp die we hebben gehad in ons nieuwe huis. Zo kon het onderzoek en de vervaardiging van het proefschrift mooi doorgaan.

Ik wil mijn MBR collega's bedanken. Allereerst mijn begeleiders. Hardy, bedankt voor de afstudeer- én promotiebegeleiding die dit onderzoek hebben mogelijk gemaakt. Ik kan veilig stellen dat de basis voor dit proefschrift is gelegd bij jou in Bennekom. Antoine, later erbij gekomen toen de leukere werkzaamheden zo goed als gedaan waren, maar ik had je niet willen missen. Bedankt voor je onvoorstelbare vermogen om keer op keer kritisch te zijn op grotendeels dezelfde lappen tekst. Mede door jouw inzet is dit proefschrift stukken beter geworden. Arie, bedankt voor je scherpe kritiek en dat je me wegwijs maakte in de wondere wereld van membranen. Je toverde de meest prachtige exemplaren tevoorschijn. Het is niet voor niets dat het meeste optimale membraan voor MBR van jouw hand komt.

Ook dank aan mijn mede MBR onderzoekers. Tim, die ik altijd tegenkwam als mijn blik weer eens afdwaalde door het 'raam' en mij bij de les hield. Hellen, die slibreductie samen met Tim tot een cult heeft verheven met wormen. Maxime, my eguivalent from the biological perspective. Suitable experiments during my graduation project and during this $\mathrm{PhD}$ research could not be carried out without your careful attention for the activated sludge. Ook moet ik Anne Renze niet vergeten. De enige stagiair die ik heb gehad. Bedankt voor het plakken van membranen en de vele fluxen die je met de hand hebt moeten meten. Na jouw arbeid was het duidelijk dat dit laatste moest worden geautomatiseerd. Tot slot Paula, bedankt voor de 
discussies over de resultaten en vooral over gellagen. Ik vind het onvoorstelbaar hoe je in zeer korte tijd de skills hebt verworven om zowel een complexe MBR-pilot als twee membraanfiltratiesystemen in bedrijf te houden. Ik ben zeer blij dat jij mijn paranimf wilt zijn en vast bedankt voor het nodige geregel voor mijn verdediging en feest.

Een bijzonder woord van dank aan mijn promotor Walter van der Meer, en aan Matthias Wessling, Greet Kamminga en al de andere collega's van de Universiteit Twente. Bedankt voor de ondersteuning en het vertrouwen in mij. Ook bedankt voor de leuke spaarzame etentjes, het warme gezelschap gedurende een maand van interne aanwezigheid, en de enerverende fietstrip.

Ik wil iedereen bij Wetsus bedanken. Onvoorstelbaar hoe snel Wetsus is gegroeid en wat een successen het al heeft gekend in haar korte bestaan. Het is onmogelijk iedereen bij naam te bedanken zonder iemand te vergeten, en dat doe ik dan ook niet. Een speciaal woord van dank aan mijn oud-kamergenoten en pioniers bij Wetsus. Het scepticisme, het lesgeven, en de sportfeitjes hebben mij altijd geboeid. Mijn twee opvolgsters bedankt voor het overnemen van de Cartesius lessen. De technische handen bedankt voor de drijvende kracht achter goed lopende set-ups. De eerste PV bedankt voor het leggen van de basis voor nog meer leuke Wetsus trips, sinterklaasfeesten en borrels. Het lab bedankt voor de accurate kwaliteitsbewaking van veel experimenten. De squashers bedankt voor de geloste zweetdruppels. De quizzers bedankt voor het op vele avonden beantwoorden van de meest onmogelijke vragen. De allereerste vraag die we kregen was: wat was het gevangenisnummer van N. Mandela? Graag beantwoorden zonder google! Het management en secretariaat bedankt voor de goede organisatie van deze dynamisch groeiende wetenschappelijke grootmacht. En tot slot de AIO's en andere uitvoerders van al het onderzoek bedankt voor al de leuke momenten. Allen veel voorspoed in de afronding van het proefschrift en met de duizelingwekkende ambities van Wetsus.

Dank ook aan het Cartesius instituut voor de samenwerking en de mogelijkheid om mij te kunnen verdiepen in het doceren. De participanten van het MBR thema bedankt voor de inbreng en de discussies in het onderzoek naar de oplossing voor membraanvervuiling in MBR. Mijn nieuwe collega's bij WLN bedankt. Jullie zijn een bijzonder leuke groep mensen en ik ben blij dat ik mijn energie kan blijven steken in de wondere wereld van de watertechnologie.

Een woord van dank aan mijn vrienden. Van de vele dingen die ik geleerd heb tijdens mijn AlO-schap is tennis misschien wel het leukste. Goed om te kunnen ontspannen tussen het experimenteren door. Mijn tennismaten bedankt en hopelijk gaan we nog vele sets spelen. Mijn goede vrienden uit het pittoreske Maasland bedankt voor de weekendjes Peer en de vele jaren gezelligheid. Fijn dat jullie bij mijn promotie aanwezig zijn. 
Bijzonder dank aan Tjerk ter Veen. De vele e-mails over sport, klussen en andere belangrijke zaken was een welkome afwisseling in de wondere wereld van de details in de wetenschap. Ik kan maar met één iemand 65 poolframes op een avond spelen en het 32-33 laten worden. Ik ben bijzonder vereerd dat jij mijn paranimf wilt zijn.

Tot slot Janneke bedankt. Je bent je er niet van bewust hoeveel je hebt bijgedragen aan dit proefschrift. Niet alleen de vele analyses die je hebt uitgevoerd, maar vooral de morele steun en het vertrouwen. De laatste maanden zijn erg druk geweest met de verhuizing en met onze allergrootste trots Sam. Dat ik tussendoor ook nog dit proefschrift heb kunnen schrijven is aan jouw inzet te danken. Jij en Sam maken mij bijzonder gelukkig en ik hou zielsveel van jullie. Nu gaan we nog meer genieten!

Leeuwarden, 17 oktober 2009

Perry van der Marel 


\section{Stellingen behorende bij het proefschrift getiteld: \\ "Influence of membrane properties on fouling in MBRs" door Perry van der Marel.}

De improved flux-step method is de ideale methode om snel verschillende variabelen in membraanvervuiling in membraanbioreactoren te onderzoeken, te vergelijken, en een gegeven set aan condities te optimaliseren (dit proefschrift).

Global warming is gunstig voor de afzet van MBRs, omdat bij een hogere temperatuur de kritische flux toeneemt (dit proefschrift).

Het membraanvervuilingsproces is niet complex, omdat de voedingseigenschappen de optimale membraaneigenschappen niet beïnvloeden (dit proefschrift).

De ontwikkeling van terugspoelbare vlakke plaat membranen is zinloos vanuit een reinigingsperspectief, omdat simpel relaxeren evenveel vervuiling verwijdert (dit proefschrift).

De aanwezigheid van stoffen uit gezuiverd afvalwater in bronnen voor het produceren van drinkwater maakt gezuiverd afvalwater ook direct geschikt als bron voor drinkwaterproductie.

ledereen snapt het kaartspel solitaire, en daarom ook het periodiek systeem der elementen. Geinspireerd door Dmitri Mendelejev, schepper van het periodiek systeem.

Het voorkomen van MACHO's in de astronomie maakt het een stoere wetenschap.

Een AIO die het liefst experimenteert zal een baan zoeken in het bedrijfsleven en een AIO die het liefst publiceert zal een baan zoeken bij een universiteit.

Het vooruitzicht op een makkelijk examen maakt het mentaal moeilijker. Dit zie je ook in het voetbal terug aangezien de grotere clubs het doorgaans moeilijk hebben tegen de underdogs. 